\title{
A INFLUÊNCIA DE FÓSFORO, ENXOFRE E ESTRÔNCIO NA MINERALOGIA DO CLÍNQUER PORTLAND
}

\author{
Marcelo Pecchio \\ Orientador: Prof. Dr. Fábio Ramos Dias de Andrade

$$
\text { DISSERTAÇÃO DE MESTRADO }
$$ \\ Programa de Pós Graduação em Mineralogia e Petrologia
}

São Paulo 
Para Vania e Thomaz 


\section{Agradecimentos}

Meus agradecimentos Instituto de Geociências, ao qual, de um modo ou de outro, estou ligado por todos esses anos, por ter acolhido esta pesquisa.

À Associação Brasileira de Cimento Portland, nas pessoas do Dr. Yushiro Kihara e Arnaldo Forti Battagin, que contribuíram para meu desenvolvimento profissional em meio a um corpo técnico de alto nível e por terem disponibilizado o tempo e os recursos necessários para o desenvolvimento desse trabalho.

Às irmãs, Patrícia e a Janaina Candian, pelo incondicional apoio e incentivo pessoal, bem como pelo zelo e profissionalismo com que trataram os ensaios dessa pesquisa.

Ao Dr. Luciano Gobbo/PANalytical, pela disponibilidade em realizar ensaios de difratometria de raios $\mathrm{X}$ de reflexão e transmissão e ceder cópias do programa HighScore para o tratamento dos dados.

À minha querida esposa Vania, por ter feito a revisão de todo o texto e me auxiliado com a bibliografia.

Ao meu orientador Prof. Dr. Fábio Ramos Dias de Andrade, pelo incansável apoio e estímulo pessoal, imprescindível para a conclusão desse trabalho, e pelo profundo envolvimento com suas diversas etapas de elaboração.

Finalmente gostaria de agradecer aos amigos, família e colegas que de algum modo participaram com seu estímulo e torcida para a finalização dessa dissertação. 


\section{Índice}

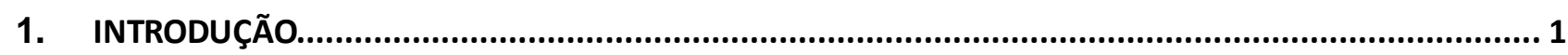

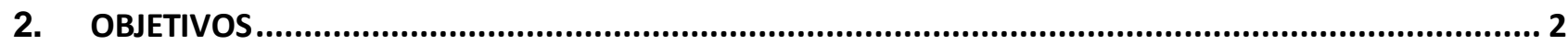

3. CIMENTO E CLINQUER PORTLAND: REVISÃO BIBLIOGRÁFICA............................................... 2

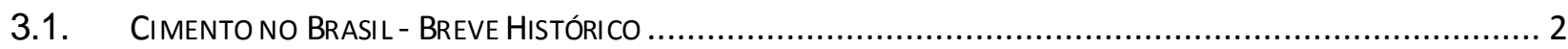

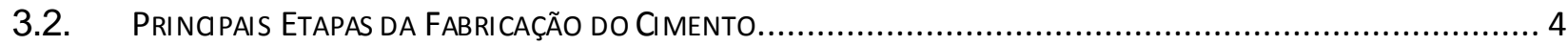

3.2.1. Matérias-primas - Extração, dosagem e preparação ................................................... 4

3.2.2. Forno de clínquer: calcinação e clinquerização............................................................ 7

3.2.3. Moagem: tipos de cimento e adições ativas ...............................................................10

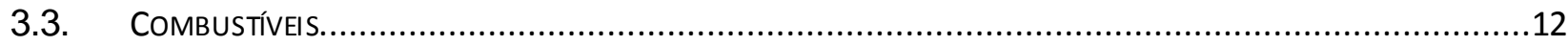

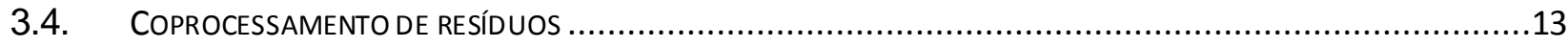

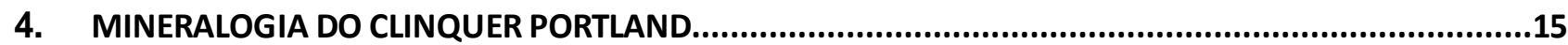

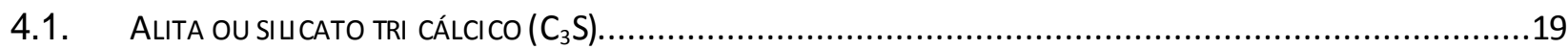

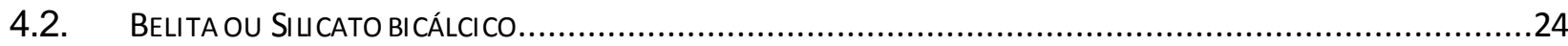

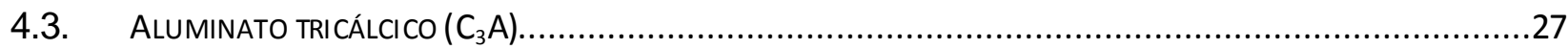

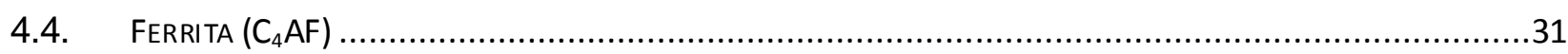

4.5. OUTROS CONSTITUINTES - CAL UVRE, PERI CLÁSI O E SULFATOS ALCALINOS ............................................32

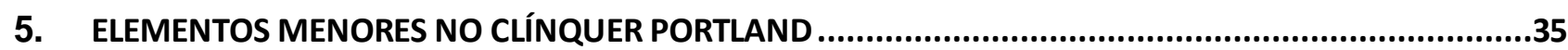

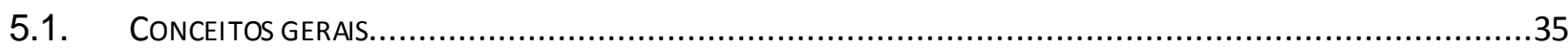

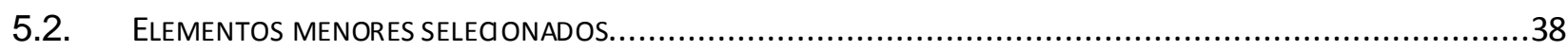

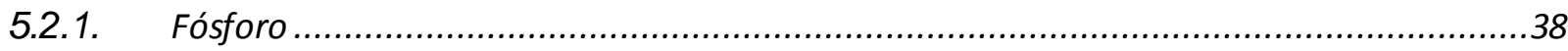

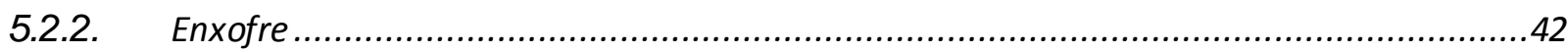

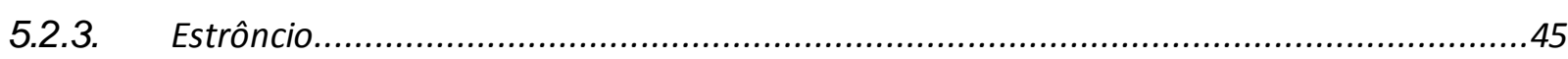

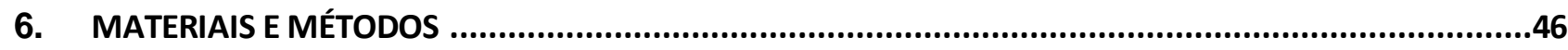

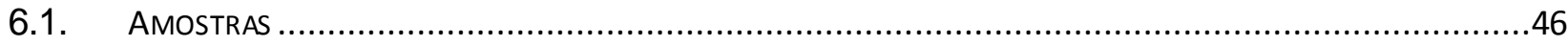

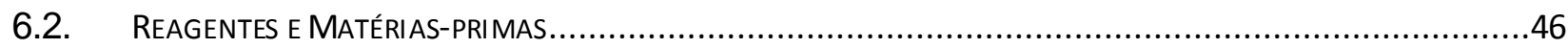

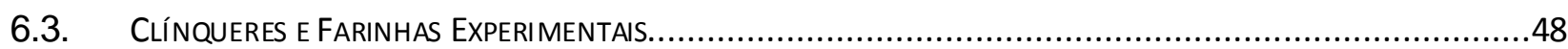

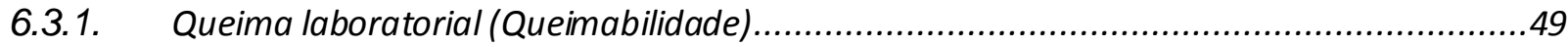

6.3.2. Determinação do teor de cal livre residual..................................................................49

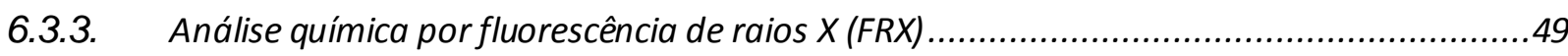

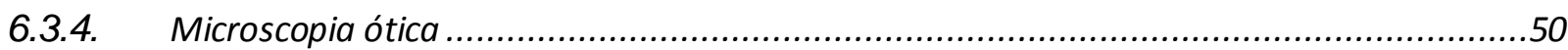

6.3.5. Difratometria de raios $X$ e Método de Rietveld .............................................................51

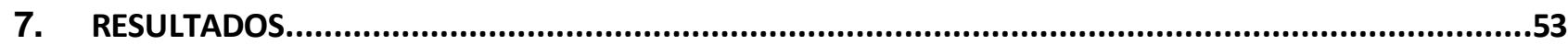

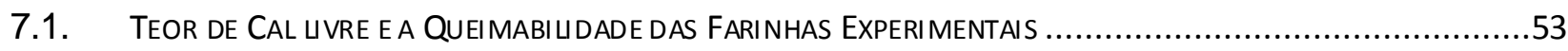

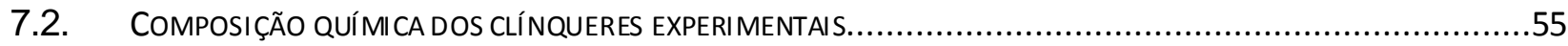

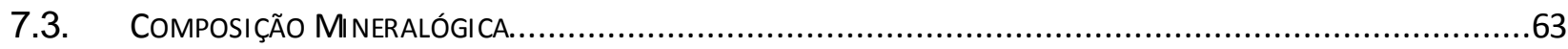

7.3.1. Composição mineralógica Microscopia ótica X Método de Rietveld...................................67

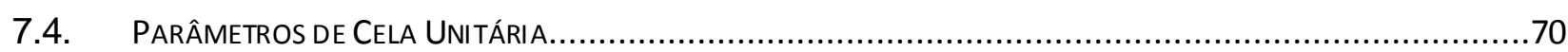




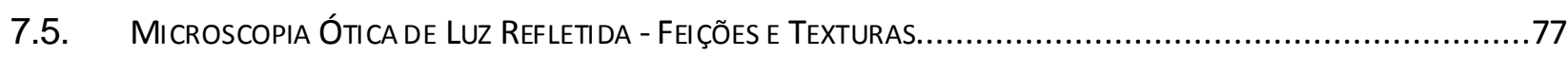

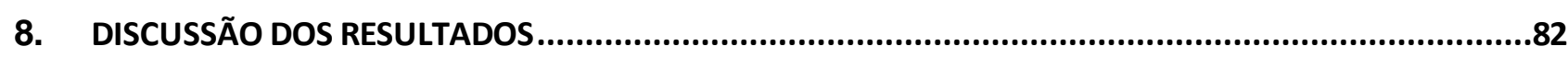

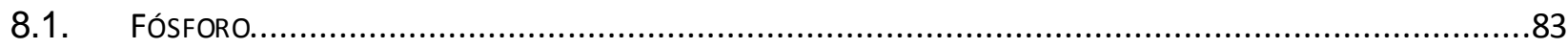

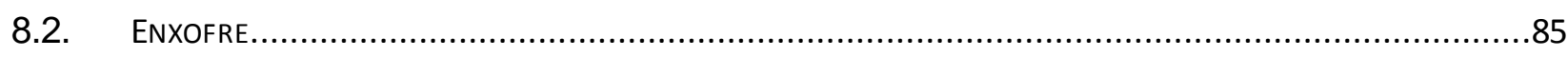

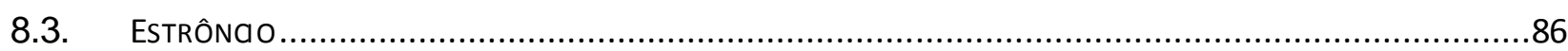

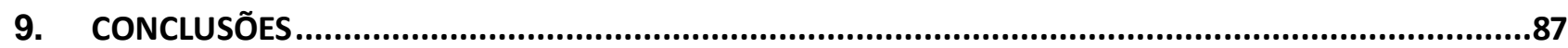

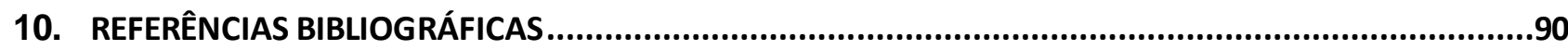

11. ANEXO A -ANÁLISE QUÍMICA SEMIQUANTITATIVA DOS REAGENTES .........................................96

12. ANEXO B - GRÁFICOS DE DIFRATOMETRIA DE RAIOS X DAS MATÉRIAS-PRIMASE REAGENTES

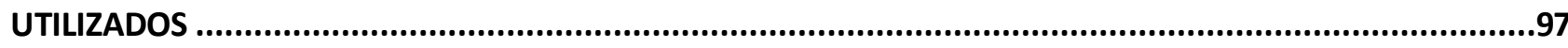

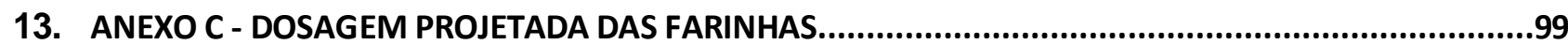




\section{Índice de Figuras}

Figura 1 - Evolução da produção de cimento no Brasil nos últimos quarenta anos

(http://www.snic.org.br/pdf/snic-relatorio2011-12_web.pdf).

Figura 2 - Pré-homogeneizadores tipo Chevron circular (a) e linear (b) (http://www.flsmidth.com/en-

US/Products/Cement/Raw+Materials+and+Raw+Coal+Handling/Storage)

Figura 3 - Moinhos de farinha: a) vertical de rolos e b) moinho de bolas ((http://www.flsmidth.com/ en-

US/Products/Cement/Raw+Materials+and+Raw+Coal+Handling/Grinding))....

Figura 4 - Silo de homogeneização. Notar formação dos cones de homogeneização provocados pela

extração diferenciada (http://www.flsmidth.com/en-

US/Products/Cement/Raw+Meal+Production/Feeding/Controlled+Flow+Raw+Meal+Silo/Controlled+FI

ow+Raw+Meal+Silo).

Figura 5 - Movimentação descendente da farinha em contracorrente com os gases quentes do forno (http://en.wikipedia.org/wiki/Cement_kiln)

Figura 6 - Torres de pré-aquecimento da farinha (torre de ciclones) com pré calcinador (à esquerda) e sempre calcinador. (http://www.flsmidth.com/en-

US/Products/Cement/Clinker+Production/Cement+Preheating).

Figura 7 - Fornos de cimento com apoio em duas ou três bases. Os primeiro normalmente equipam fornos mais modernos (http://www.flsmidth.com/en-

US/Products/Cement/Clinker+Production/Cement+Buming)

Figura 8-Resfriador tipo satélite ou planetário -O material calcinado deixa o forno por meio de dutos

laterais pelos quais entra o ar frio externo sugado pelos exautores do forno

(http://www.foundry.vesuvius.com/index.php?id=365)

Figura 9 - Resfriador de grelhas - O material calcinado que deixa o forno sofre resfriamento por meio do insuflamento de ar frio produzido pelos ventiladores laterais (http://www.flsmidth.com/en -

US/Products/Product+Index/All+Products/Cement+Clinker+Cooling/FLSmidth+Cross-Bar+Cooler) ....10

Figura 10- Matriz Energética da Indústria de Cimento - Balanço Energético Nacional 2010 - MME .............13

Figura 11-Reações que ocorrem durante a fabricação do clínquer (Wolter, 1985) .................................16

Figura 12 - Diagrama do sistema $\mathrm{CaO}-\mathrm{SiO}_{2}-\mathrm{Al}_{2} \mathrm{O}_{3}$ - Muan \& Osborn (1965 in Taylor, 1997).........................17

Figura 13 - Detal he do diagrama do sistema $\mathrm{CaO}-\mathrm{SiO}_{2}-\mathrm{Al}_{2} \mathrm{O}_{3}$ (Taylor, 1997) ........................................18

Figura 14 - Diagrama do sistema CaO-SiO 2 - Welch e Gutt (1959, in Taylor, 1997) .................................18

Figura 15-Aspecto do clínquer ao microscópio destacando-se os cristais idiomórficos de alita (A)...........19

Figura 16 - Cristais idiomórficos de alita (A) exibindo bordas corroíd as e formação de belita secundária (B)20

Figura 17 - Temperaturas das transições polimórficas do silicato tricálcico puro. T=triclínico, M=monoclínico

e $\mathrm{R}=$ romboédrico.

Figura 18 - Forma polimórfica do $\mathrm{C}_{3} \mathrm{~S}$ em função da relação $\mathrm{MgO}$ e $\mathrm{SO}_{3}$ (Taylor, 1997).

.22

Figura 19 - Intervalos angulares de difração de raios X (tubo Cu K alfa) propostas por Courtial el al. (2004)

para identificação dos polimorfos as alita:M1, M2 e M3

Figura 20 - Cristais arredondados de belita ou $C_{2} S$ (B). $A=A$ lita F=fase intersticial. 
Figura 21 - Cristais de belita agrupados em uma zona regular ou $\mathrm{C}_{2} \mathrm{~S}$ (B). P=poro.

Figura 22- Cristal de belita ao microscópio el etrônico de varredura exibindo variados conjuntos de estrias paralelas (Tipo I).

Figura 23 - Temperaturas das transições polimórficas do silicato bicálcico puro, onde: $\alpha=$ hexagonal, $\alpha^{\prime}{ }_{H}, \alpha_{L}^{\prime}$ e $\gamma=$ ortorrômbico e $\beta=$ monoclínico. .26

Figura 24 - Cela unitária da fase cúbica segundo Mondal e Jeferry, 1975 (in Taylor, 1997). 28

Figura 25 - Detal he da fase intersticial do clínquer mostrando cristais ortorrômbicos de $\mathrm{C}_{3} \mathrm{~A}$ (C) bem

formados. $E=C_{4} A F$ e $A=$ alita.

Figura 26 - Detal he da fase intersticial do clínquer mostrando cristais mal desenvolvidos $\operatorname{de~}_{3} A$ (seta) resultantes de um resfriamento classificado como normal. $A=a$ lita.

Figura 27 - Cinética de hidratação típica de pastas de fases puras do clínquer a temperatura ambiente. 0

$C_{3} A$ é representado com e sem gesso. (Odler, 1998 in Lea, 1998).

Figura 28 - Zona de cristais de cal livre (K) indicativa da presença de um grão grosso de cal cário não absorvido. $\mathrm{P}=$ Cristais de peridásio .

Figura 29 - Cristais de periclásio (tons róseos) dispersos no clínquer.

Figura 30 - Fotomicrografia do clínquer contendo 0,25\% $\mathrm{P}_{2} \mathrm{O}_{5}$ (Staněk e Sulovský2009). Na imagem as fases indicadas são C3S -alita,C2S-belita e C-cal livre

Figura 31 - Fotomicrografia do clínquer contendo $3 \% \mathrm{P}_{2} \mathrm{O}_{5}$ (Staněk e Sulovský 2009). Na imagem as fases indicadas são C3S -alita, C2S-belita, C3A, ferrita-aluminato e ferro aluminato associados e C-cal livre

Figura 32 - Diagrama do sistema $2 \mathrm{CaO} . \mathrm{SiO}_{2}-3 \mathrm{CaO} \mathrm{P}_{2} \mathrm{O}_{5}$ de FIX et al. (1969 in Mueller et al., 2003)

Figura 33 - Teores de cal livre em farinhas cal cinadas a 1450드 dopadas com diversas formas iônicas de enxofre e fósforo Kolovos et al. (2004)

Figura 34 - Influência do $\mathrm{P}_{2} \mathrm{O}_{5}$ e álcalis no desenvolvimento de resistências Coleman (in Moir e Glasser, 1992)

Figura 35 - Evolução do teor de cal livre dos clínqueres experimentais em função do teor dos elementos dopantes.

Figura 36 - Desvios relativos dos módulos químicos (FSC, MS e MA) das amostras de farinha elaboradas. ..60 Figura 37 - Desvios relativos dos módulos químicos (FSC, MS e MA) das amostras de clínquer experimentais.

Figura 38 - Comparação entre os teores de elementos dopantes $\left(\mathrm{P}_{2} \mathrm{O}_{5}\right.$ e SrO$)$ das farinhas e dos clínqueres experimentais.

Figura 39 - Comparação entre os teores de enxofre das farinhas dos clínqueres experimentais. ...............62

Figura 40 - Variação dos teores de alita com o incremento dos elementos dopantes ...............................65

Figura 41 - Variação dos teores de belita com o incremento dos elementos dopantes .............................65

Figura 42 - Variação do conteúdo de silicatos $\left(C_{3} S+C_{2} S\right)$ e fase intersticial $\left(C_{3} A+C_{4} A F\right)$ presentes nos clínqueres experimentais.

Figura 43 - Relação entre os teores de alita determinados por microscopia e Método de Rietveld.............68

Figura 44-Relação entre os teores de belita determinados por microscopia e Método de Rietveld. ...........68

Figura 45-Variação do Rwp dos refinamentos pelo teor de elementos dopantes - Método de Rietveld.....70 
Figura 46 - Variação do volume de cela unitária do $C_{3}$ S em função do teor de adição de elementos dopantes

Figura 47 - Variação do volume de cela unitária do $\mathrm{C}_{2} \mathrm{~S}$ em função do teor de adição de elementos dopantes

Figura 48 - Valores do ângulo $\beta$ da cela unitária monoclínica dos cristais de $C_{3} S$ e $C_{2} S$ em função do teor de adição de elementos dopantes. .74

Figura 49 - Valores de $R_{B}$ das fases cristalinas $C_{3} S_{\text {e }} C_{2} S$ das séries anualidades função do teor de adição de

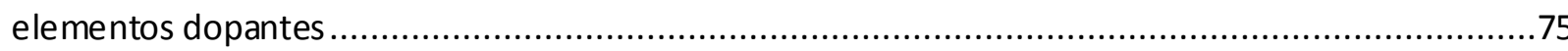

Figura 50 - Diagrama de Rietveld da amostra MPCL-Ref2 (Rwp=14,2) - difratograma experimental é observado em vermel ho e o calculado em azul, na parte inferior a linha da diferença em vermelho. ..76 Figura 51 - Diagrama de Rietveld da amostra MPCL-OS200 ( $R w p=20,9)$ - difratograma experimental é observado em vermelho e o calculado em azul, na parte inferior a linha da diferença em vermelho...77 Figura 52 - Aspecto geral da textura do clínquer MPCL-SX25 no qual se observam cristais de alita (A) de formas alongadas dispersos. Ataque de $\mathrm{HNO}_{3} 1 \%$ em álcool $+\mathrm{H}_{2} \mathrm{O}$ - Microscópio ótico de luz refletida Ampliação 100x

Figura 53 - Aspecto de detal he dos cristais de alita (A). Notar os cristais alongad os pequenos e cristais maiores melhor desenvolvidos. As bordas são retilíneas e não apresentam belita secundária. Clínquer MPCL-AP50 - B=belita Ataque de $\mathrm{HNO}_{3} 1 \%$ em álcool $+\mathrm{H}_{2} \mathrm{O}$ - Microscópio ótico de luz refletida Ampliação 400x

Figura 54 - Cristais desenvolvidos de alita (A) do clínquer MPCL-SX200. Notar as bordas retilíneas e as inclusões de cal livre (K). Ataque de $\mathrm{HNO}_{3} 1 \%$ em álcool $+\mathrm{H}_{2} \mathrm{O}$ - Microscópio ótico de luz refletida Ampliação 400x

Figura 55 - Cristais de belita em zonas regulares (B) do clínquer MPCL-AP200. Notar as bordas retilínease as inclusões de cal livre (K). Ataque de $\mathrm{HNO}_{3} 1 \%$ em álcool $+\mathrm{H}_{2} \mathrm{O}$ - Microscópio ótico de luz refletida Ampliação 100x

Figura 56 - Detalhe de uma zona de belita na qual se observam as três formas de belita identificadas. Ao centro cristais dendríticos (B1), na porção externa cristais individualizados (B3) e na porção intermediária massas de cristais indistintas (B2). Clínquer MPCL-SX50-Ataque de $\mathrm{HNO}_{3} 1 \%$ em álcool $+\mathrm{H}_{2} \mathrm{O}$ - Microscópio ótico de luz refletida - Ampliação 200x

Figura 57 - Cristais de belita dendríticos (b) desenvolvendo-se em meio à porção de vidro (V) MPCL-SX100.

Microscópio ótico de luz refletida - Ataque de $\mathrm{HNO}_{3} 1 \%$ em álcool $+\mathrm{H}_{2} \mathrm{O}-$ Ampliação $600 \mathrm{x}$......

Figura 58 - Aspecto da fase intersticial no qual se notam cristais melhor desenvolvidos de $C_{3} A$ (D) associados a uma textura rendilhada de cristais menores. Ataque com $\mathrm{KOH}+$ sacarose $5 \%$ em $\mathrm{H}_{2} \mathrm{O}$ Microscópio ótico de luz refletida - Ampliação 600x.

Figura 59 - Pequenos cristais de cal livre (K) individualizados de formas arredondadas. Sem ataque -

Microscópio ótico de luz refletida - Ampliação 100x.

Figura 60 - Gráfico de difratometria de raios $X$ dos três tipos de fosfatos utilizados sobrepostos ................84

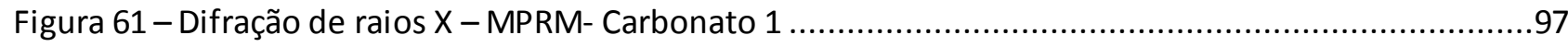

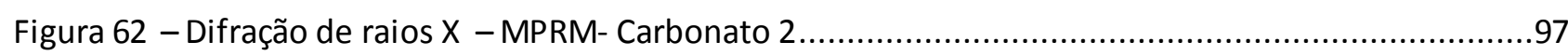

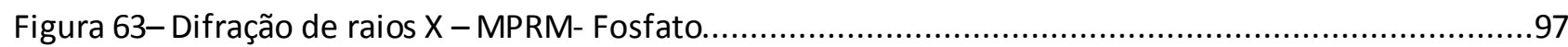




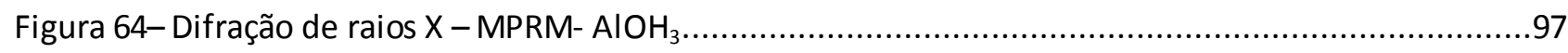

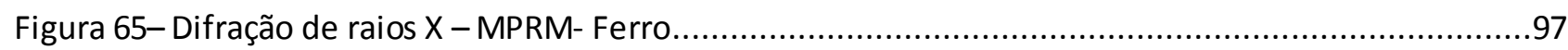

Figura 66 - Difração de raios X - MPRM- Quartzo......................................................................98

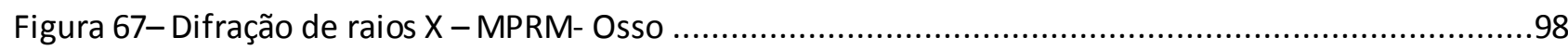

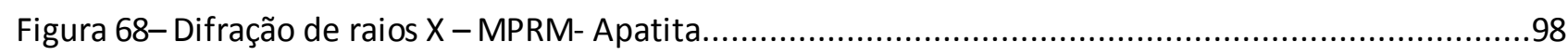

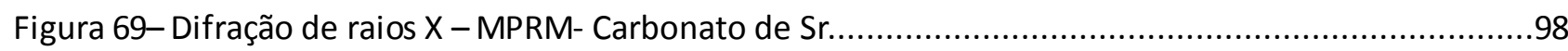

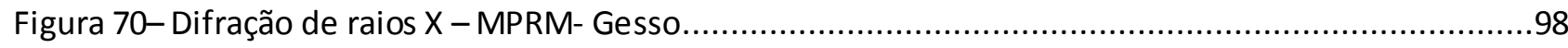




\section{Índice de Tabelas}

Tabela 1 - Módulos químicos para dosagem de farinha (Duda, 1975) …........................................... 6

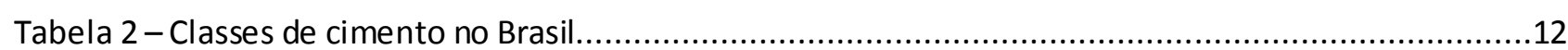

Tabela 3 - Resíduos industriais utilizados no coprocessamento (ABCP inédito) .....................................14

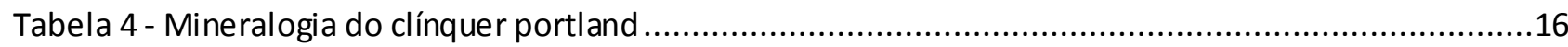

Tabela 5 - Polimorfos de $C_{3} S$ - Informações cristalográficas (modificada de Taylor 1997) .........................21

Tabela 6 - Polimorfos de $C_{2} S$ - Informações cristalográficas (modificado de Taylor 1997 e Taylor 1999) ......27

Tabela 7 - Modificações da estrutura do $\mathrm{C}_{3} \mathrm{~A}$ para a fórmula geral de $\mathrm{Na}_{2 x} \mathrm{Ca}_{3-x} \mathrm{Al}_{2} \mathrm{O}_{6}$ (modificada Taylor,

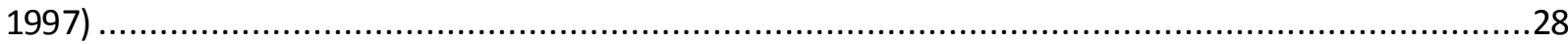

Tabela 8 - Modificações da estrutura da ferrita $(\mathrm{C} A \mathrm{AF})$ - fórmula geral de $\mathrm{Ca}_{2}\left(\mathrm{Al}_{x} \mathrm{Fe}_{1-\mathrm{x}}\right)_{2} \mathrm{O}_{5} \ldots \ldots \ldots \ldots \ldots \ldots \ldots \ldots . . . . . . . . . .31$

Tabela 9- Concentração média dos elementos menores e traços típicos encontrados no clínquer (Moire

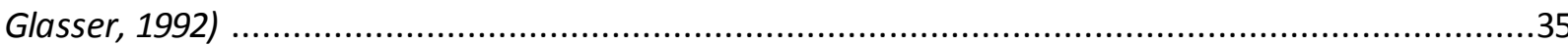

Tabela 10 - Concentração média de elementos menores em calcários e argilas (Sprung, 1598 in Bhatty, 1995)

Tabela 11 - Concentração média de elementos menores e traços em combustíveis (modificada de (Sprung,

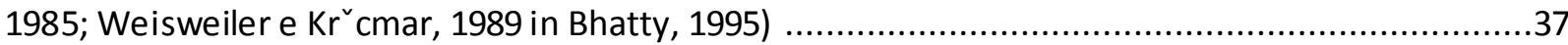

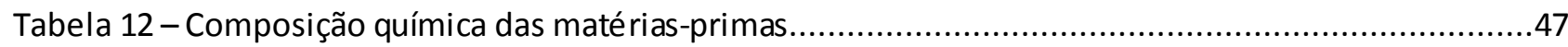

Tabela 13 - Caracterização mineralógica por difratometria de raios $X$ das matérias-primas .......................48

Tabela 14 - Reagentes utilizados na identificação de fases e feições ao microscópio ótico..........................50

Tabela $15-$ Teor de cal livre após queima $1450^{\circ} \mathrm{C}$ (\% em peso) * ........................................................54

Tabela 16 - Análise química por espectrometria de raios $X$ das farinhas dopadas com estrôncio.................56

Tabela 17 - Análise química por espectrometria de raios $X$ das farinhas dopadas com enxofre ..................56

Tabela 18 - Análise química por espectrometria de raios $X$ das farinhas dopadas com fósforo ...................57

Tabela 19- Análise química por espectrometria de raios $X$ dos clínqueres dopados com estrôncio..............58

Tabela 20- Análise química por espectrometria de raios $X$ dos clínqueres dopados com enxofre ...............58

Tabela 21 - Análise química por espectrometria de raios $X$ dos clínqueres dopados com fósforo ................59

Tabela 22 - Avaliação da variação dos teores de elementos dopantes por volatilização...........................61

Tabela 23 - Análise mineralógica dos clínqueres experimentais dopados com estrôncio..........................63

Tabela 24 - Análise mineralógica dos clínqueres experimentais dopados com enxofre ..........................63

Tabela 25 - Análise mineralógica dos clínqueres experimentais dopados com fósforo .............................64

Tabela 26 - Anál ise mineralógica dos clínqueres experimentais dopados com fósforo.............................64

Tabela 27 - Regressão linear dos teores de alita e belita com a adição de elementos dopantes..................66

Tabela 28 - Parâmetros de cela de $C_{3} S$ dos clínqueres experimentais ....................................................71

Tabela 29 - Parâmetros de cela de $\mathrm{C}_{2} \mathrm{~S}$ de amostras de clínquer sintetizadas em laboratório .....................72

Tabela 30 - Número de coordenação e raio iônico (Shannon, 1976) ....................................................82

Tabela 31 - Reações possíveis de substituição de elementos dopantes no clínquer .................................83 


\section{Resumo}

Em função de aspectos de sustentabilidade, a indústria de cimento tem utilizado, cada vez mais, combustíveis e matérias-primas não convencionais, que têm aportado ao clínquer portland uma maior variabilidade de elementos químicos. O presente estudo tem por objetivo analisar o efeito de elementos menores selecionados ( $\mathrm{S}, \mathrm{P}$ e $\mathrm{Sr}$ ) sobre a mineralogia do clínquer portland. Esses elementos passaram a fazer parte da composição de clínqueres industriais de modo mais expressivo na última década. O enxofre está relacionado ao uso intensivo de coque de petróleo (75 a 80\% da matriz energética da indústria de cimento nacional), o fósforo é resultante das ações de coprocessamento de farinha animal, resíduos de curtume entre outros; enquanto o estrôncio está presente em teores expressivos em carbonatitos e fosforitos que podem ser usados como matéria-prima para a fabricação de cimento. Foram analisadas amostras de clínqueres experimentais, sintetizados em laboratório a partir de matérias-primas puras com teores crescentes e controlados dos elementos químicos dopantes: 0,25; 0,50; 1,00; 1,50 e 2,00\% em peso dos seus respectivos óxidos $\left(\mathrm{SO}_{3}, \mathrm{P}_{2} \mathrm{O}_{5}\right.$ e $\left.\mathrm{SrO}\right)$. Todos os materiais (matérias-primas, farinhas e clínqueres) tiveram sua composição química determinada para controle dos processos de dosagem, mistura e queima. Os clínqueres foram observados ao microscópio ótico para a avaliação da mineralogia e texturas formadas e por difratometria de raios $X$ - Método de Rietveld para análise qualitativa e quantitativa das fases e determinação dos parâmetros de cela unitária. $A$ adição de $\mathrm{P}_{2} \mathrm{O}_{5}$ prejudica a queimabilidade e potencializa a formação de $\mathrm{C}_{2} \mathrm{~S}$, nas três formas de fosfato adicionadas (fosfato sintético, apatita e osso). O enxofre na forma de sulfato melhora a queimabilidade da farinha, porém conduz a um incremento do teor de $\mathrm{C}_{2} \mathrm{~S}$; observou-se uma significativa diminuição do volume da cela unitária do $\mathrm{C}_{3} \mathrm{~S}$ e do $\mathrm{C}_{2} \mathrm{~S}$. O estudo confirmou o caráter volátil do enxofre no processo de calcinação, sendo que o grau de perda é inversamente proporcional ao teor de adição do elemento. $\mathrm{O}$ íon $\mathrm{Sr}^{2+}$, estrôncio, devido a sua similaridade química com o $\mathrm{Ca}^{2+}$ é incorporado às fases cristalinas do clínquer nos sítios estruturais ocupados pelo cálcio, prejudicando a queimabilidade da farinha com aumento da cal livre e favorecendo a formação de $\mathrm{C}_{2} \mathrm{~S}$ em detrimento da alita. 


\section{Abstract}

Due to issues of sustainability, the cement industry has increasing the use of alternative fuel and raw materials, which have contributed to portland clinker greater variability of chemical elements. The present study aims to examine the effect of minor elements (S, P and Sr) on the mineralogy of portland cement clinker. These elements became part of the industrial composition of clinkers in a more expressive in the last decade. The sulfur is related to the intensive use of petroleum coke (75 to $80 \%$ of national cement industry energy matrix), phosphorus is the result of the co-processing of animal meal, waste tannery among others, while strontium is present in significant levels in carbonatites and phosphorites that can be used as raw material for cement manufacturing. Experimental clinkers were synthesized in the laboratory from pure raw materials with increasing levels of chemicals and controlled doping: 0.25, 0.50, 1.00, 1.50 and 2.00\% by weight of their respective oxides $\left(\mathrm{SO}_{3}, \mathrm{P}_{2} \mathrm{O}_{5}\right.$ and $\mathrm{SrO}$ ). All materials (raw materials, raw meal and clinkers) had determined its chemical composition for process control dosage, mixing and burning. The clinkers were observed under optical microscope to assess the mineralogy and textures formed and by $X$ ray diffraction - Rietveld method for qualitative and quantitative analysis of the phases and determining the unit cell parameters. The addition of $\mathrm{P}_{2} \mathrm{O}_{5}$ affects the burnability and enhances the formation of $\mathrm{C}_{2} \mathrm{~S}$ in the three forms of added phosphate (synthetic phosphate. bone and apatite). The sulphur, in the form of sulphate, improves the raw meal burnability, but leads to an increase in the content of $C_{2} S$; observed a significant decrease in the volume of the $C_{3} S$ and $C_{2} S$ unit cell. The study confirmed the volatile nature of the sulphur in the calcination process, once the degree of loss is inversely proportional to the amount of the element addition. The ion $\mathrm{Sr}^{2+}$, strontium, due to their chemical similarity with $\mathrm{Ca}^{2+}$ is incorporated into the crystal phases of the clinker in the structural sites occupied by calcium, impairing raw meal burnability with increased free lime and favoring the formation of $\mathrm{C}_{2} \mathrm{~S}$ at the expense of alite. 


\section{INTRODUÇÃO}

O clínquer portland é o produto intermediário da fabricação do cimento portland obtido por meio da calcinação de uma mistura devidamente dosada e finamente moída de calcário, argila e eventualmente materiais corretivos. O clínquer é o componente mais ativo do cimento e no Brasil está presente em teores médios de $65 \%$ em peso. A reologia e o desempenho final do cimento estão fortemente relacionados, entre outros parâmetros, à composição químico-mineralógica do clínquer. Esta, por sua vez, é resultado da composição química da farinha, de suas características granulométricas, da eventual presença de elementos menores e da interação desses parâmetros com as condições de queima e resfriamento no interior do forno rotativo.

O presente estudo procura verificar a influência dos elementos "menores" enxofre, fósforo e estrôncio sobre a mineralogia do clínquer. Os elementos menores presentes no clínquer são advindos das matérias-primas ou são aportados pelas cinzas dos combustíveis utilizados nos processos de calcinação.

O enxofre, que é advindo majoritariamente da queima do coque de petróleo como combustível, está presente no clínquer em teores próximos a 1,5\% em peso, possui grande afinidade principalmente com os álcalis (sódio e potássio) normalmente presentes nas matérias-primas. No entanto, na ausência desses elementos, ele pode ser absorvido pelas fases silicáticas do clínquer (alita e belita) podendo levar a alterações em sua estrutura e à estabilização de polimorfos de mais alta temperatura. Um aspecto relevante no estudo do comportamento do enxofre é o controle de sua volatilidade, uma vez que, ao entrar no forno de cimento na forma de sulfetos presentes nas matérias-primas, parte deste sofre uma oxidação e é incorporado ao clínquer, parte se volatiliza e é eliminado pelos sistemas de exaustão do forno. Por outro lado, quando advindo do combustível, o enxofre é rapidamente oxidado e quase sua totalidade passa a ser incorporada ao clínquer, seja como solução sólida nos silicatos cálcicos, seja na forma de sulfatos alcalinos.

O fósforo e o estrôncio são normalmente provenientes do tipo de calcário utilizado e estão presentes no clínquer em teores inferiores a $0,5 \%$ em peso. Podem ter como fonte carbonatos contaminados com fosforitos ou aqueles provenientes do beneficiamento de minério de apatita em carbonatitos, tais como descritos por Ruberti et al. (2000), nos quais esses elementos estão presentes em teores próximos a $1 \%$ em peso. Outra fonte possível de fosfato está relacionada ao coprocessamento de farinha animal, resíduos de esgoto, resíduos de abatedouros e à destruição de carcaças de animais contaminados (febre da vaca louca na Europa e na gripe aviária na Ásia). Na Comunidade Européia, a proibição do uso de farinha animal para alimentação do rebanho provocou uma enorme disponibilidade de material fosfático, que tem sido coprocessado em fornos de cimento. 


\section{OBJETIVOS}

Este trabalho tem por objetivo estudar os efeitos da presença dos elementos fósforo, enxofre e estrôncio na mineralogia do clínquer Portland. Esses elementos foram introduzidos de forma gradual na composição de clínqueres experimentais, sintetizados a partir de compostos puros.

Este estudo pretende determinar o efeito da introdução desses elementos sobre a abundância relativa entre as principais fases cristalinas dos clínqueres experimentais obtidos, como também avaliar as possíveis variações polimórficas de seus principais constituintes cristalinos em especial da alita $\left(C_{3} S\right)$ e a belita $\left(C_{2} S\right)$. Esses compostos estão entre os principais controladores do desempenho físico-mecânico do cimento.

\section{CIMENTO E CLINQUER PORTLAND: REVISÃO BIBLIOGRÁFICA}

O concreto é um dos principais materiais da construção civil, sendo composto por uma mistura de cimento portland, areia, pedra britada e água, além de outros eventuais aditivos de origem orgânica, modificadores de sua reologia. O concreto é a substância produzida pelo homem mais utilizada no mundo (www.cement.org/tech). Segundo o Sumário de Commodities Minerais da USGS (2012), a produção mundial de cimento em 2011 foi de 3,4 bilhões de toneladas. Supondo que o conteúdo médio de cimento no concreto fosse de 12\% em 2011 teriam sido consumidos aproximadamente 28,1 bilhões de toneladas de concreto.

\subsection{Cimento no Brasil - Breve Histórico}

O cimento portland tal qual conhecido hoje, ou algo muito próximo a isso, foi patenteado pelo construtor inglês Joseph Aspdin em 1824, depois de uma série de outras tentativas levadas a cabo por diversos pesquisadores e que tiveram como marco inicial os estudos do inglês John Smeaton em 1786, que criou uma mistura resistente por meio da calcinação de calcários argilosos para os trabalhos de reconstrução do Farol de Eddystone, na costa da Inglaterra. Apesar dos princípios do método de produção não ter se alterado ao longo dos anos, a indústria de cimento experimentou uma série de modernizações que possibilitaram o aumento da produção e uma melhor qualidade e uniformidade do produto, de tal sorte a tornar o cimento portland um importante e largamente utilizado insumo da moderna construção civil.

Desde as primeiras iniciativas de fabricar cimentos no país, creditadas ao Comendador Rodovalho, que em 1897 concluiu a instalação da Usina Rodovalho, a produção de cimento sofreu altos e baixos. A instalação definitiva de uma unidade industrial ocorreu somente no final da década de 1920, com a entrada em operação de uma fábrica da Companhia Brasileira de Cimento Portland (CBCP), em Perus, com capacidade de produção de 60 mil toneladas (Santos, 2011). Somente entre as décadas de 1930 e 1940 é que ocorreu sua consolidação e, em 1936, a Fábrica Votorantim S.A. inaugurou sua primeira unidade de cimento, com capacidade de produção de 175 mil toneladas/ano, no Distrito de Votorantim, Município de Sorocaba.

O fortalecimento da indústria de cimento brasileira a partir dos anos 1930 pode ser analisado a 
partir de quatro pontos principais: 1) urbanização e crescimento do mercado interno; 2) entrada de capital e tecnologia estrangeiros; 3) investimentos carreados de outros ramos econômicos presentes no país; 4) apoio incondicional do Estado (Santos , 2005 in Santos, 2011)

A partir do início dos anos 1960, a produção nacional alcançou os níveis necessários para abastecer o mercado interno e minimizar as importações. Nesse período se observou uma elevação da produção e consumo de cimento de 9,3 para $24,8 \mathrm{Mt}$ devido, sobretudo, às políticas habitacionais sob a tutela do Estado - por meio do Banco Nacional da Habitação (BNH) e aos grandes projetos de infraestrutura, entre eles a construção de hidrelétricas, rodovias e pontes (SNIC, 2011)

Nos anos 1980, em função da crise econômica decorrente do alto endividamento do país e das dificuldades de rolar a dívida externa, o consumo de cimento ficou estagnado por toda a década. Nos anos 1990, com o Plano Real e a estabilidade econômica, ocorreu um processo de reestruturação, com o fortalecimento e o crescimento dos maiores produtores, a aquisição dos pequenos grupos e a ampliação do capital internacional. A produção brasileira atingiu o patamar de 40Mt. No entanto, a partir de 1990 as seguidas crises econômicas no mundo e o término da paridade cambial fizeram com que o real se desvalorizasse frente ao dólar, afetando o consumo. Em 1999, o consumo de cimento chegou ao patamar recorde de 40 milhões, caindo em 2001 para 38,4 milhões para em seguida, no ano de 2003, descer até 33,8 Mt. (SNIC). Desde meados de 2003, passou a ocorrer um crescimento contínuo e significativo do consumo de cimento, com exceção da estagnação do ano de 2009, por causa da crise financeira internacional e da pequena contração da economia brasileira.

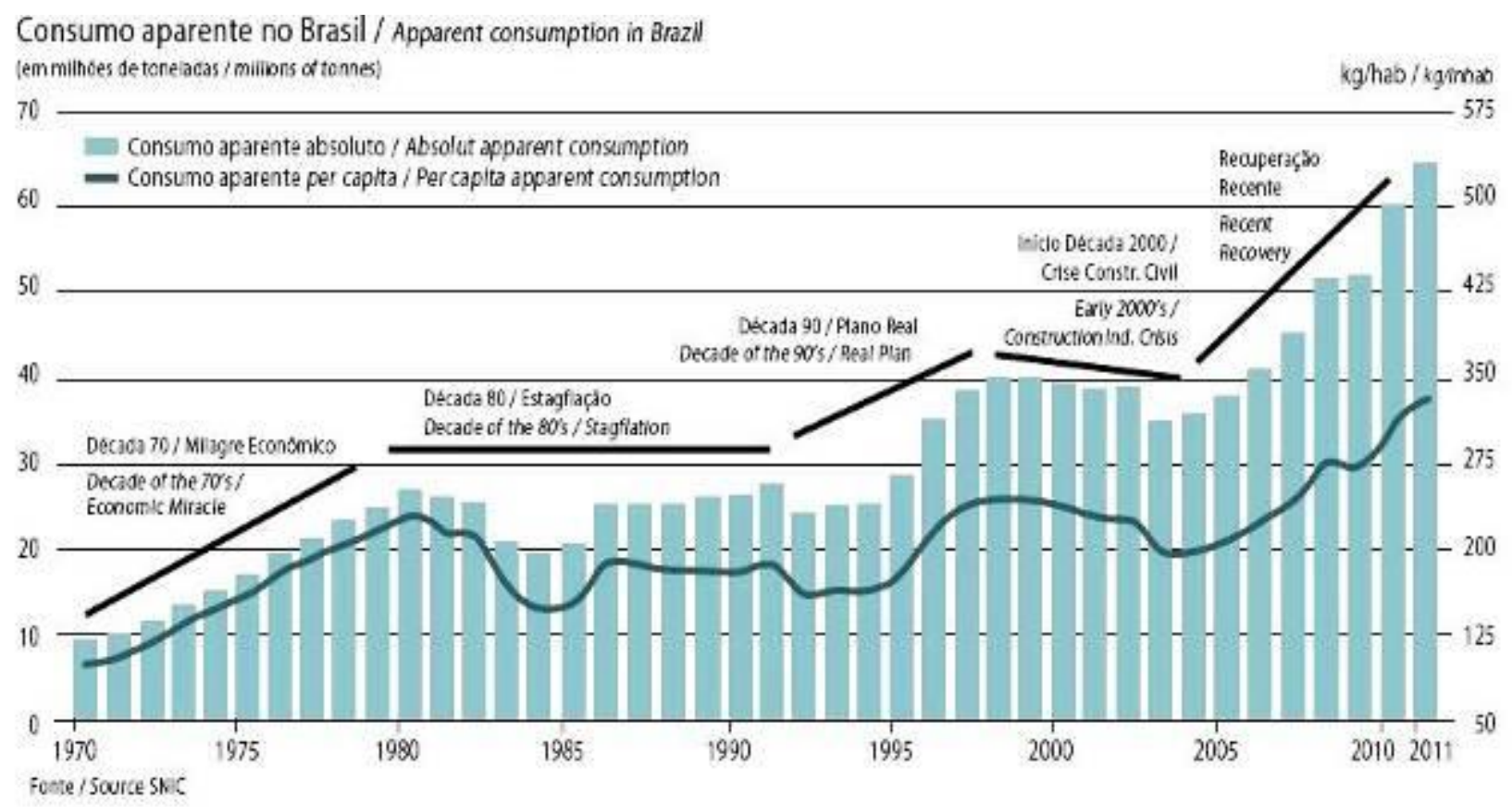

Figura 1 - Evolução da produção de cimento no Brasil nos últimos quarenta anos (http://www.snic.org.br/pdf/snic-relatorio2011-12_web.pdf) 
A retomada dos grandes projetos de infraestrutura, os fartos créditos destinados às moradias (programa habitacional Minha Casa, Minha Vida) e as perspectivas de manutenção das taxas de aumento do consumo graças ao ritmo de crescimento econômico do país tem alavancado a produção de cimento, que em 2011 alcançou 64 Mt (SNIC, 2011), com perspectivas de aumento para os próximos anos. A Figura 1 mostra a evolução da produção de cimento nos últimos 40 anos.

\subsection{Principais Etapas da Fabricação do Cimento}

A indústria do cimento pode ser classificada como uma indústria de base que processa grandes quantidades de materiais. Uma planta de dimensões médias produz aproximadamente 1Mt por ano, o que pressupõe a produção de 2000 t/dia de clínquer, um consumo 200 t/dia de combustível e 2700 t/dia de matéria-prima. Como uma indústria de transformação mineral, a produção do clínquer portland se inicia com a extração das matérias-primas, principalmente calcário e argila. Os aditivos eventualmente utilizados são adicionados em pequenas quantidades e não necessariamente vêm de jazidas próximas. O minério de ferro, o mais comumente utilizado, pode ser transportando por centenas de quilômetros até as plantas.

O processo de fabricação do cimento pode ser dividido nas seguintes etapas principais:
a. Extração e preparação das matérias-primas
b. Processo de queima e resfriamento do clínquer
c. Moagem de cimento.

\subsubsection{Matérias-primas - Extração, dosagem e preparação}

As matérias-primas para a fabricação do clínquer portland são principalmente calcários, argilas e eventuais corretivos, dos quais o mais utilizado é o minério de ferro. Esses materiais são misturados e moídos até darem origem a um pó fino homogêneo, de nome farinha ou cru

Os calcários utilizados na fabricação do clínquer portland perfazem normalmente $80 \%$ da farinha crua e são sua principal fonte de $\mathrm{CaO}$. Por esse motivo, dá-se preferência à utilização de calcários calcíticos com elevados conteúdos de $\mathrm{CaO}$, da ordem de 45 a 50\% em peso, e com baixos conteúdos de $\mathrm{MgO}$. O óxido de magnésio é mundialmente limitado no cimento, em 6,0 ou 6,5\% em peso, devido à possibilidade de reações expansivas relacionadas à hidratação do periclásio (MgO), além de seu efeito diluidor das fases hidraulicamente ativas do clínquer.

De fato, observa-se que uma grande variedade de litotipos de rochas carbonáticas é utilizada como matéria-prima para a fabricação de clínquer. No Brasil, como no mundo, utilizam-se mármores e metacalcários calcíticos, assim como margas e outras rochas cálcio silicáticas.

No Brasil há um caso, talvez único no mundo, de uso de um carbonatito como fonte ígnea de carbonato para a fabricação de clínquer Trata-se do carbonatito de Jacupiranga, localizado no Município de Cajati, extremo sul do Estado de São Paulo (Ruberti et al. 2000). O minério de apatita 
é extraído por flotação, sendo destinado à produção de ácido fosfórico e suplemento de ração animal. O carbonato de cálcio, sub-produto dessa extração, é encaminhado à planta de cimento localizada nas imediações e compõe a farinha para a produção de clínquer.

A extração do calcário é feita em minas normalmente a céu aberto e utiliza as técnicas tradicionais de desmonte de rocha por explosivos. Depois de extraído, o calcário é britado e, dependendo da heterogeneidade do minério, pode ser conduzido às pilhas de pré-homogeneização. Nas pilhas de pré-homogeneização, que normalmente são do tipo Chevron linear ou circular (Figura 2), o calcário é depositado em camadas em quantidades de aproximadamente de 10 mil toneladas e depois é retomado de modo perpendicular à sua deposição, provocando sua homogeneização e uma redução da variabilidade da composição química do minério, que será posteriormente transferido aos moinhos por correias transportadoras.
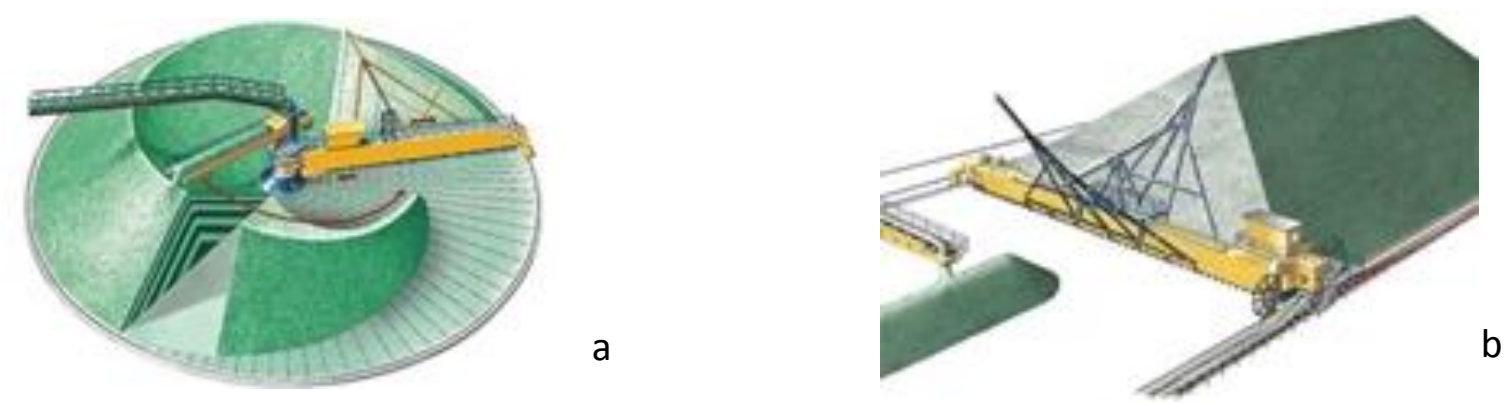

Figura 2 - Pré-homogeneizadores tipo Chevron circular (a) e linear (b) (http://www.flsmidth.com/en-US/Products/Cement/Raw+Materials+and+Raw+Coal+Handling/Storage)

As argilas utilizadas para a fabricação de clínquer possuem as mais variadas composições e origens. Esses materiais são normalmente utilizados em quantidades ao redor de $20 \%$ em peso e deveriam constituir a principal fonte de $\mathrm{Al}_{2} \mathrm{O}_{3}$ e $\mathrm{SiO}_{2}$. No entanto, sua seleção está condicionada não só à sua composição química, que se relaciona com a composição dos calcários por meio dos módulos químicos, como à sua disponibilidade nas proximidades das unidades fabris.

Os tipos e proporções dos materiais corretivos utilizados na fabricação de clínquer portland estão condicionados à deficiência de certos compostos químicos na farinha detectada por meio dos módulos químicos (Tabela 1), normalmente óxidos de ferro, sílica ou alumina. Esses corretivos são adicionados à farinha em teores normalmente inferiores a $5 \%$ em peso. Desse modo, se utiliza o minério de ferro quando a farinha necessita do elemento ferro, areia no caso de deficiência de sílica e, em casos mais especiais, minério de bauxita quando o problema é o alumínio.

A dosagem da farinha ou sua composição química devem respeitar estreitas relações entre os quatro componentes principais, $\mathrm{CaO}, \mathrm{SiO}_{2}, \mathrm{Al}_{2} \mathrm{O}_{3}$ e $\mathrm{Fe}_{2} \mathrm{O}_{3}$, de maneira a permitir a formação dos minerais de clínquer. Essas relações e seus valores mais usuais são descritos na Tabela 1. 
Tabela 1-Módulos químicos para dosagem de farinha (Duda, 1975)

\begin{tabular}{l|lc}
\hline \multicolumn{1}{c|}{ Módulos Químicos } & \multicolumn{1}{c}{ Equações } & Valores usuais \\
\hline Fator de Saturação em Cal & $F S C=\frac{100 \mathrm{CaO}}{2,8 \mathrm{SiO}_{2}+1,2 \mathrm{Al}_{2} \mathrm{O}_{3}+0,65 \mathrm{Fe}_{2} \mathrm{O}_{3}}$ & $92 \%$ a $120 \%$ \\
Módulo de Sílica & $M S=\frac{\mathrm{SiO}}{\mathrm{Al}_{2} \mathrm{O}_{3}+\mathrm{Fe}_{2} \mathrm{O}_{3}}$ & 2,2 a 3,0 \\
Módulo de Alumina & $M A=\frac{\mathrm{Al}_{2} \mathrm{O}_{3}}{\mathrm{Fe}_{2} \mathrm{O}_{3}}$ & 1,2 a 2,5 \\
\hline
\end{tabular}

Uma vez determinada a dosagem da farinha, que leva em consideração, além dos parâmetros químicos, a disponibilidade das matérias-primas, o tipo de combustível empregado, os tipos de cimento a serem fabricados e particularidades dos equipamentos disponíveis na planta, as matérias-primas são cominuídas em conjunto para garantir sua homogeneização. Normalmente, utiliza-se para essa tarefa moinhos que podem ser os tradicionais moinhos de bolas, ou moinhos verticais de rolos (Figura 3). Esses equipamentos transformam o material em um pó fino e homogêneo, cujas dimensões das partículas são 85 a 90\% inferiores $88 \mu \mathrm{m}$. A finura da farinha é de vital importância para o processo de fabricação, uma vez que grande parte das reações de formação do clínquer ocorre em estado sólido em fusão parcial de seus constituintes. Os sistemas de moagem são dotados de separadores de alta eficiência que atuam como classificadores de partículas, de maneira a separar o material fino e, portanto acabado, do material grosso que retorna para continuar sendo moído. Esse efeito se dá fundamentalmente pela ação de um fluxo de ar que atravessa todo o sistema e que arrasta as partículas finas. No caminho do fluxo de ar existe um sistema rotativo de palhetas (separador) cujo ângulo de abertura e velocidade de rotação podem ser ajustados permitindo melhorar a eficiência de separação. O moinho tem como função adicional secar as matérias-primas e, para isso, é alimentado com gases quentes provenientes do forno.
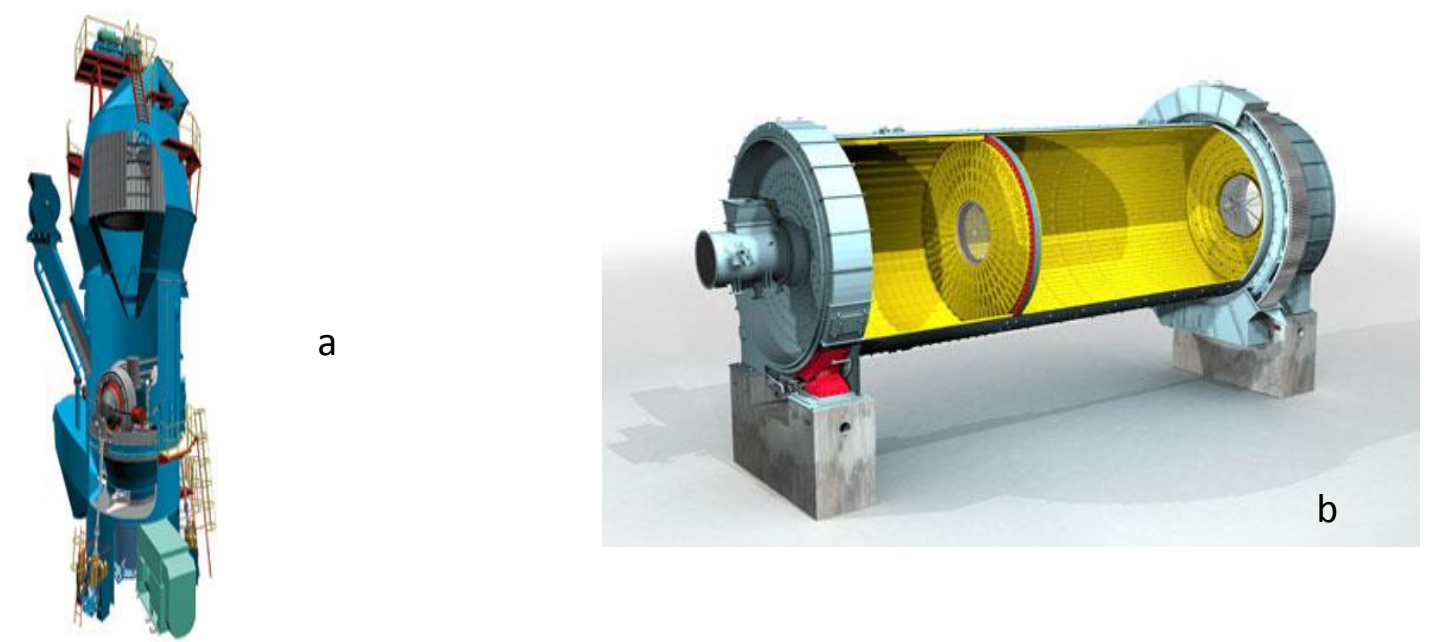

Figura 3 - Moinhos de farinha: a) vertical de rolos e b) moinho de bolas ((http://www.flsmidth.com/en-US/Products/Cement/Raw+Materials+and+Raw+Coal+Handling/Grinding)) 
O conjunto das matérias-primas, depois de dosado e moído, passa a ser denominado farinha ou cru, que é transportado para silos de armazenagem e homogeneização. A homogeneização é conseguida pela formação e evolução de cones de escoamento (Figura 4), formados pela extração diferencial da farinha por meio de bicos extratores posicionados no fundo dos silos de homogeneização. Outro método possível seria por meio do insuflamento de ar a alta pressão, de tal modo a provocar um turbilhonamento do material. No entanto, esse método possui como desvantagem a necessidade de grandes compressores e grande quantidade de energia elétrica, e por isso está em desuso.

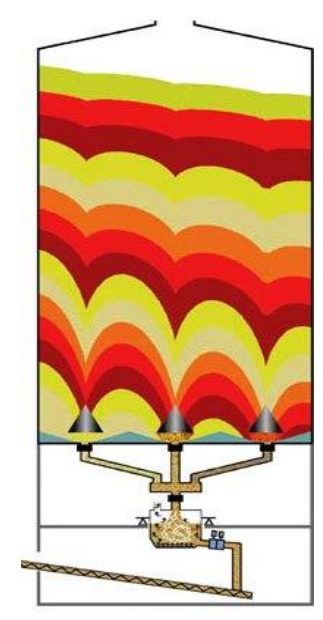

Figura 4 - Silo de homogeneização. Notar formação dos cones de homogeneização provocados pela extração diferenciada (http://www.flsmidth.com/enUS/Products/Cement/Raw+Meal+Production/Fee ding/Controlled+Flow+Raw+Meal+Silo/Controlled +Flow+Raw+Meal+Silo).

\subsubsection{Forno de clínquer: calcinação e clinquerização}

Após a conclusão do processo de preparação das matérias-primas, a farinha ou cru resultante é transportado ao forno de clínquer por meio de correias transportadoras e elevadores de canecas.

O forno de clínquer pode ser dividido em duas partes principais: a torre de ciclones trocadores de calor e o forno rotativo.

A torre de ciclones é dotada de uma série de equipamentos de formato cônico dispostos em sequência, que promovem o pré-aquecimento da farinha alimentada no alto da torre (Figura 5). Devido à geometria dos ciclones e ao fluxo de gases quentes advindos do forno rotativo, que sobem em contracorrente à descida das partículas de farinha, essas vão progressivamente se aquecendo até atingir temperaturas de até 800 a $1000^{\circ} \mathrm{C}$ na base da torre (caixa de fumaça). 


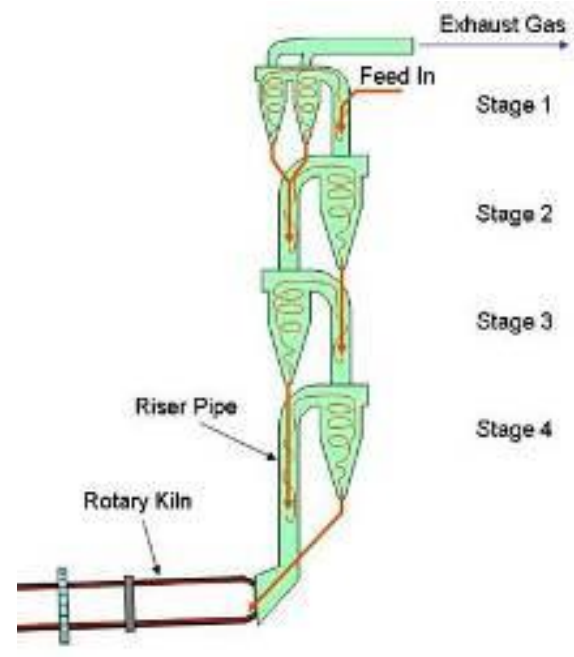

Figura 5 - Movimentação descendente da farinha em contracorrente com os gases quentes do forno (http://en.wikipedia.org/wiki/Cement_kiln)

O gradual aquecimento da farinha até temperaturas elevadas faz com que algumas reações do processo de sinterização ocorram na torre de ciclones, principalmente aquelas relacionadas à perda da água estrutural dos argilominerais e ao inicio da decomposição dos carbonatos (descarbonatação). Em torres de ciclones simples, ou seja, dotadas somente de 3 a 4 estágios de trocadores de calor, a farinha chega ao forno de cimento com níveis de descarbonatação entre 10 a $20 \%$ (Figura 6).
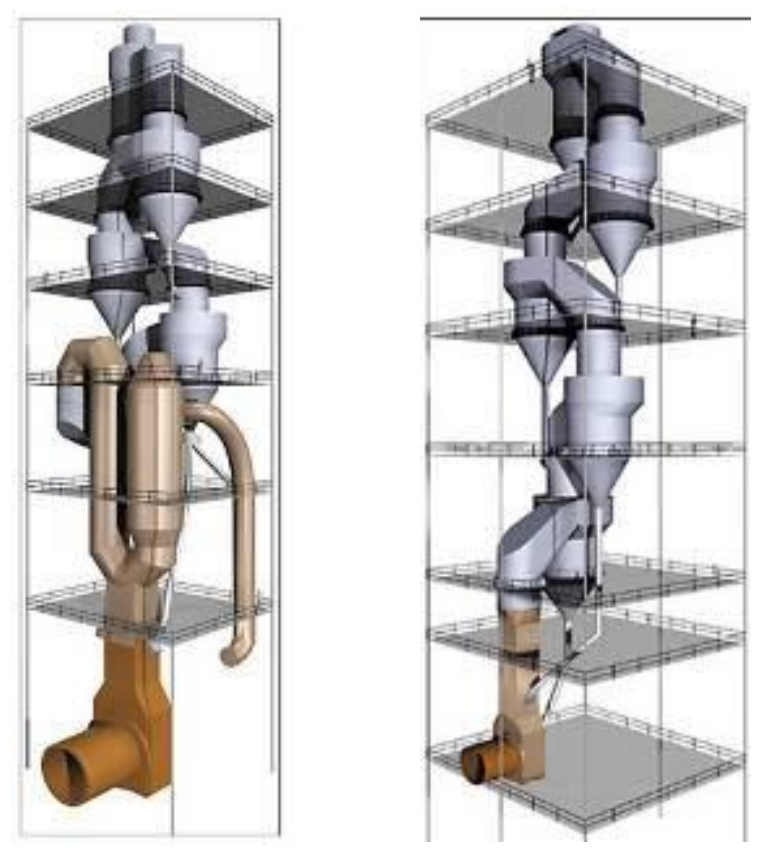

Figura 6 - Torres de pré-aquecimento da farinha (torre de ciclones) com pré calcinador (à esquerda) e sempre calcinador.

(http://www.flsmidth.com/en-

US/Products/Cement/Clinker+Production/Cement +Preheating).

A incorporação à torre de ciclones de um gerador de gases quentes, denominado pré-calcinador (Figura 6), modifica o perfil térmico da torre, aumentando a temperatura de saída do material. Esse fato melhora seu desempenho e a farinha pode a atingir níveis de descarbonatação de $95 \%$. O pré-calcinador é dotado de um maçarico secundário que, utilizando parte do ar de resfriamento 
do clínquer (ar terciário), pode utilizar combustíveis menos nobres (baixo poder calorifico) e é um dos locais preferenciais para o coprocessamento de resíduos. Normalmente, esses equipamentos têm equipado os fornos mais modernos.

O forno de cimento se liga à torre de pré aquecimento por meio de uma junção conhecida como caixa de fumaça (porção de coloração marrom na Figura 6). Na caixa de fumaça as temperaturas da farinha podem atingir $1000^{\circ} \mathrm{C}$ e já podem estar ocorrendo algumas das reações de formação dos minerais de clínquer.

O forno de clínquer está intimamente relacionado à torre de ciclones e suas operações e eficiência são interdependentes. O forno rotativo é constituído por um tubo metálico (virola), cujo comprimento pode variar de 50 a $150 \mathrm{~m}$ e o diâmetro pode ser de 2,5 a $6 \mathrm{~m}$. Ele é revestido por uma camada de refratários cujas características químicas e mineralógicas variam em função de cada região do forno. Por meio de um acionador mecânico, o forno, que possui um inclinação aproximada de $2^{\circ}$ a $6^{\circ}$, gira a baixa velocidade ( 2 a $3 \mathrm{rpm}$ ) fazendo com que o material a ser calcinado entre pela extremidade alta do cilindro e caminhe, pelos efeitos da rotação e da gravidade em direção à porção baixa passando pelo pico térmico do forno. Dependendo do modelo e dimensões do forno, bem como do tipo de tecnologia utilizada, a virola pode estar apoiada sobre duas ou três bases (Figura 7).
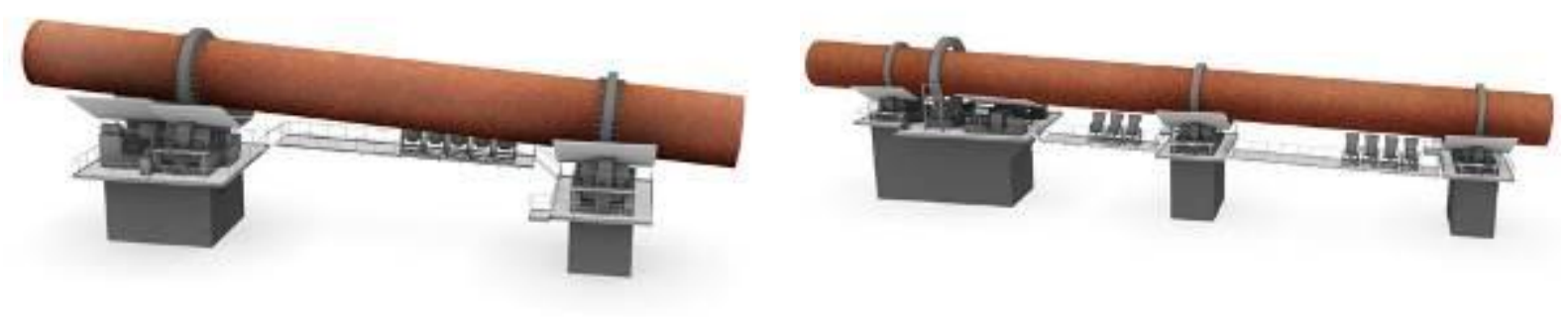

Figura 7 - Fornos de cimento com apoio em duas ou três bases. Os primeiro normalmente equipam fornos mais modernos (http://www.flsmidth.com/en-US/Products/Cement/Clinker+Production/Cement+Burning)

No interior do forno rotativo, mais precisamente em seu terço final, um maçarico produz uma chama, que pode atingir temperaturas de $2000^{\circ} \mathrm{C}$ e fornece a energia suficiente para que as transformações químico-mineralógicas ocorram. A chama pode ser alimentada por uma grande variedade de combustíveis conforme será discutido no item 3.3-Combustíveis.

Após a calcinação, o clínquer deve ser resfriado rapidamente de maneira a preservar a mineralogia e os compostos formados a altas temperaturas. Depois de atravessar a região mais quente do forno, denominada "zona de queima", o clínquer começa seu processo de resfriamento ainda dentro do forno rotativo, quando as temperaturas baixam de $1450^{\circ} \mathrm{C}$ para aproximadamente $1250^{\circ} \mathrm{C}$. Dentro dessa faixa de temperatura espera-se que ocorra a estabilização dos silicatos 
cálcicos (alita e belita).

Em seguida, o clínquer deixa o interior do forno para passar ao resfriador industrial, que pode ser do tipo satélite ou planetário (Figura 8) ou de grelhas (Figura 9). Nesta etapa as temperaturas se reduzem de mais de $1200^{\circ} \mathrm{C}$ para aproximadamente $200^{\circ} \mathrm{C}$, consolidando a fase líquida e, portanto, cristalizando os aluminatos e ferro aluminatos.

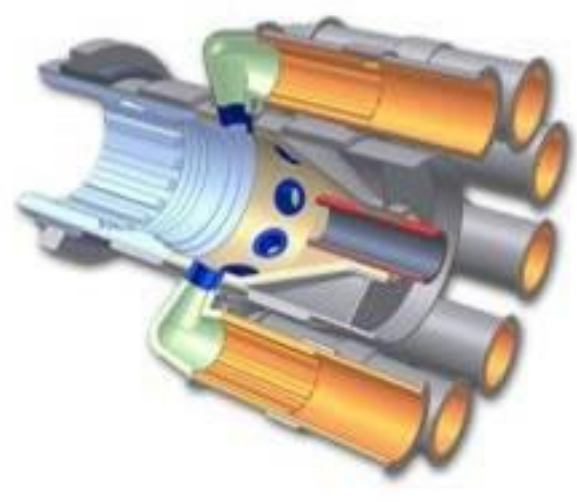

Figura 8 - Resfriador tipo satélite ou planetário - O material calcinado deixa o forno por meio de dutos laterais pelos quais entra o ar frio externo sugado pelos exautores do forno (http://www.foundry.vesuvius.com/index.php?i $d=365$ )

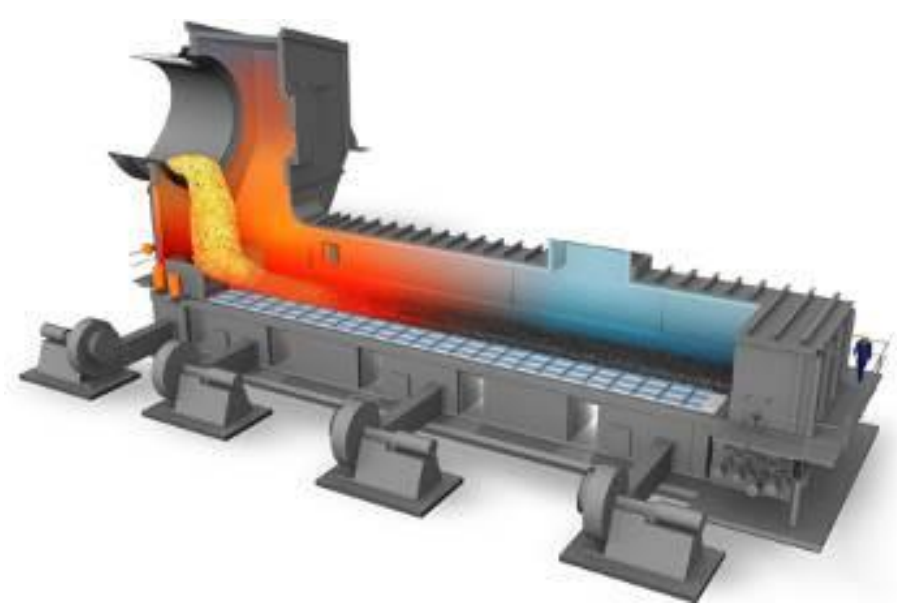

Figura 9 - Resfriador de grelhas - O material calcinado que deixa o forno sofre resfriamento por meio do insuflamento de ar frio produzido pelos ventiladores laterais (http://www.flsmidth.com/enUS/Products/Product+Index/All+Products/Cement+Clin ker+Cooling/FLSmidth+Cross-Bar+Cooler)

\subsubsection{Moagem: tipos de cimento e adições ativas}

Uma vez produzido, o clínquer portland é encaminhado a silos de armazenamento para posteriormente ser finamente moído e se transformar no produto final que é comercializado. A moagem do cimento é tradicionalmente feita em moinhos de bolas similares aos utilizados para a preparação da farinha (Figura 3), sendo que atualmente já estão sendo disponibilizados modernos sistemas de moagem vertical dotados de sofisticados separadores de alta eficiência, que possuem como vantagem o menor consumo de energia elétrica. O cimento moderno é um material bastante fino, $95 \%$ das partículas possuem dimensão inferior a $45 \mu \mathrm{m}$ e dimensão média ao redor de $10 \mu \mathrm{m}$. Em termos de área específica, medida largamente utilizada no controle da finura, o cimento atinge valores entre 3500 e $5000 \mathrm{~cm}^{2} / \mathrm{g}$.

O cimento portland mais simples é constituído por uma mistura de clínquer e gesso, esse último adicionado a todos os cimentos para controle da pega (endurecimento inicial). No entanto, as conjunturas econômicas e a necessidade de tornar o cimento um produto mais ambientalmente sustentável favoreceram o desenvolvimento de outros tipos de cimento portland que, no Brasil, possuem em sua composição adições ativas como escórias e pozolanas, além de filler calcário. 
A adição de calcário, que pode variar de 5 a 10\% em peso, tem como principal função ser um complementador da curva granulométrica do cimento, também possui um papel importante nos mecanismos de hidratação. Com relação às adições ativas, dependendo do tipo utilizado e de seu teor, as normas brasileiras estabelecem oito tipos de cimento Portland e onze variantes conforme a Tabela 2. De um modo geral, todos os tipos de cimento podem ser utilizados para as aplicações mais comuns com desempenhos similares. No entanto, em aplicações específicas alguns tipos de cimento apresentam desempenho mais favorável, como é o caso de barragens e fundações, nas quais se recomenda o uso de um cimento com alto teor de adição devido ao baixo calor de hidratação e resistência química, ou no caso da fabricação de peças pré-moldadas para a qual se recomenda cimentos de alta resistência inicial (CP V ARI) com a finalidade de diminuir o tempo de desforma.

As escórias siderúrgicas de alto forno, subproduto da produção do ferro gusa, encontradas principalmente na região sudeste, podem ser utilizadas em teores de 10 a 35\% ou de 35 a $70 \%$ em peso, dando origem aos cimentos CP II-E e CP III, respectivamente.

As pozolanas são materiais sílico-aluminosos amorfos ou desestruturados que reagem com o hidróxido de cálcio e a água para a formação de silicatos hidratados de cálcio (C-S-H). Esses materiais podem ser artificiais e naturais. As primeiras são representadas pelas cinzas volantes, sílica ativa e as pozolanas de argilas calcinadas (metacaulim). As cinzas volantes são o resíduo das termoelétricas a carvão comuns na região sul. Já pozolanas de argilas calcinadas são resultantes da queima de argilas cauliníticas e estão concentradas nas regiões nordeste e centro oeste. Entre as pozolanas naturais encontram-se tufos e cinzas vulcânicas ou mesmo de argilas ricas em carapaças diatomáceas, materiais menos utilizados no Brasil devido à sua ocorrência restrita. As normas brasileiras (NBR 11578 e NBR 5736) estabelecem que para teores de pozolanas 5 e 15\% em peso o cimento é classificado como um CP II Z, e para teores na faixa de 15 a 50\% em peso o cimento é denominado CP IV.

Existem ainda os tipos de cimento que se distinguem dos demais por apresentarem uma característica peculiar: é o caso do CP V ARI, que apresenta um rápido desenvolvimento de resistência mecânica, do cimento com baixo calor de hidratação e do cimento portland branco, elaborado com clínquer com baixo conteúdo de ferro.

O CP V ARI é composto por uma mistura de clínquer com elevado conteúdo de alita e gesso, podendo conter pequenas quantidades de filler calcário, esse tipo de cimento se caracteriza por possuir uma finura mais elevada e desenvolver elevadas resistências a pequenas idades.

O cimento branco é elaborado com um clínquer "branco". O clínquer branco, que possui coloração levemente esverdeada, possui como característica principal os baixos conteúdos de elementos corantes (ferro, cromo e manganês) e um resfriamento rápido que tem a função de manter incorporados esses elementos na estrutura dos silicatos cálcicos. 
Tabela 2 - Classes de cimento no Brasil

\begin{tabular}{l|cc}
\hline \multicolumn{1}{c|}{ Classe de cimento } & Teor de adição (\%) & Normas \\
\hline Cimento Portland Comum - CP I & Sem adição & ABNT - NBR 5732 \\
Cimento Portland Comum - CP I-S & $1-5 \%$ adições & ABNT - NBR 5732 \\
\hline Cimento Portland Composto - CP II-E & $6-34 \%$ escória & ABNT - NBR 11578 \\
Cimento Portland Composto - CP II-Z & $6-14 \%$ pozolana & ABNT - NBR 11578 \\
Cimento Portland Composto - CP II-F & $6-10 \%$ calcário & ABNT - NBR 11578 \\
\hline Cimento Portland de Alto Forno - CP III & $35-70 \%$ escória & ABNT - NBR 5735 \\
\hline Cimento Portland Pozolânico - CP IV & $15-50 \%$ pozolana & ABNT - NBR 5736 \\
\hline Cimento Portland de Alta Resistência Inicial CP V-ARI & Sem adições & ABNT - NBR 5733 \\
\hline Cimento Portland Resistente a Sulfatos - RS & - & ABNT - NBR 5737 \\
\hline Cimento Portland de Baixo Calor de Hidratação - BC & - & ABNT - NBR 13116 \\
\hline Cimento Portland Branco CPB & - & ABNT - NBR 12989 \\
\hline
\end{tabular}

O uso de variados tipo de adições em teores tão elevados, em até $50 \%$ em peso para pozolanas e $70 \%$ em peso para escórias de alto forno, só foi possível por conta da melhoria da qualidade do clínquer produzido. Herfort et al. (2010) apontam para a tendência dos clínqueres modernos possuírem altos conteúdos de alita como resultado da melhoria das condições de moagem e homogeneização das matérias-primas.

\subsection{Combustíveis}

A indústria de cimento apresenta uma grande versatilidade quanto ao tipo de combustível que pode ser utilizado para gerar as grandes quantidades de calor requeridas para a fabricação do clínquer portland. De um modo geral, e considerando o atual nível de tecnologia da indústria brasileira, pode-se estimar que para cada tonelada de clínquer produzido são consumidos aproximadamente $100 \mathrm{~kg}$ de combustível.

Ao longo dos últimos trinta anos, a indústria brasileira teve que se adaptar a importantes alterações de sua matriz energética (Balanço Energético Nacional-BEN 2010). Tradicionalmente a indústria fazia uso do óleo combustível pesado fornecido pela Petrobrás, os chamados óleos BPF. No princípio da década de 1980, a revolução islâmica no Irã e o conflito Irã/Iraque desestabilizaram o comércio internacional de petróleo, desencadeando a chamada quinta fase da crise do petróleo que mais que triplicou os preços internacionais, fazendo com que a indústria de cimento substituísse o óleo combustível pelo carvão mineral e vegetal; o óleo combustível só voltou a ser utilizado no início da década de 1990 com a queda do preço do barril de petróleo. A última alteração se deu de modo mais abrupto no final dos anos 1990, com a quebra do monopólio da Petrobrás sobre os combustíveis e a criação da Agência Nacional de Petróleo (lei 9478 de agosto de 1997). Esse fato permitiu à indústria de cimento ter acesso ao coque de petróleo (petcoke), um combustível sólido de elevado poder calorífico e de preços competitivos. A 
partir desse momento, o coque rapidamente ganhou espaço e se tornou o principal combustível da indústria de cimento no Brasil e em vários outros países do mundo, alcançando uma participação em nossa matriz energética de aproximadamente $75 \%$ (Figura 10).

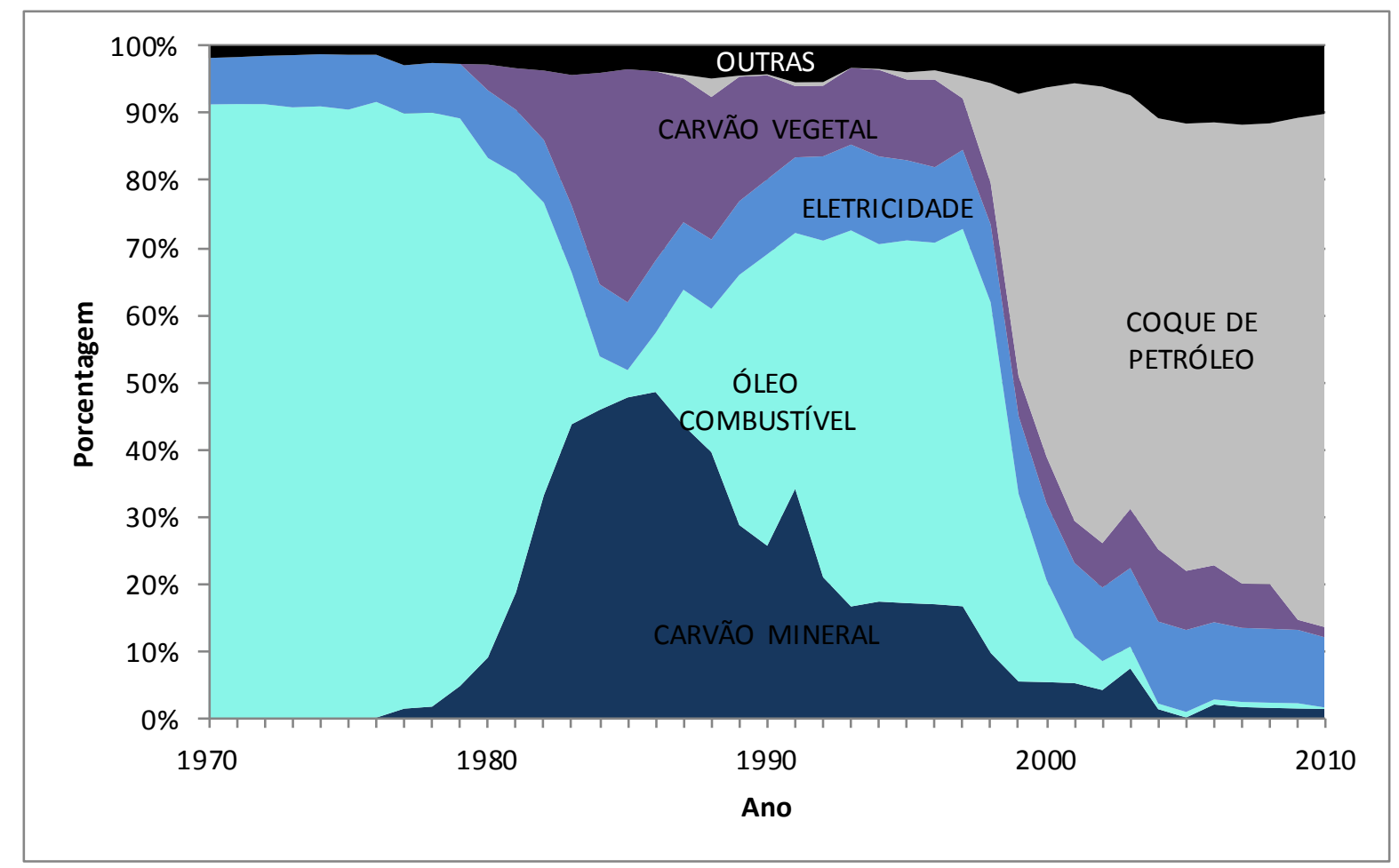

Figura 10- Matriz Energética da Indústria de Cimento - Balanço Energético Nacional 2010 - MME

O coque de petróleo é um sólido de coloração negra, normalmente granulado, pouco friável e com ligeiro odor de asfalto ( $A B C P, 2002)$. Trata-se do último subproduto do refino do petróleo, sendo produzido em unidade de craqueamento catalítico a partir do óleo pesado (ABCP, 2002). Desse modo, sua composição química e suas características físicas estão intimamente ligadas aos tipos de petróleo que the deram origem.

O coque de petróleo mais utilizado pela indústria de cimento vem do Golfo do México, e é produzido pelas refinarias americanas e venezuelanas. Esse possui como principal característica grande quantidade de asfaltenos, o que the confere um aspecto de esferas, e elevados teores de enxofre, que expresso na forma de $\mathrm{SO}_{3}$ podem variar de $4 \%$ a $6 \%$ em peso.

O coque de petróleo nacional é produzido pela Petrobrás e se caracteriza pelos conteúdos de enxofre inferior a $1 \%$ em peso.

\subsection{Coprocessamento de resíduos}

O coprocessamento é definido como uma operação combinada na qual se destrói um resíduo advindo de outros setores industriais enquanto se produz um clínquer de qualidade inalterada. Rocha et al. (2011) comenta que o coprocessamento é uma alternativa de eliminação de resíduos 
que poderiam ter uma disposição de maior impacto ambiental como, por exemplo, serem destinados em aterros. Além da destruição do resíduo, essa atividade tem como vantagem a redução do uso de combustíveis fosseis não renováveis e a diminuição da emissão total de $\mathrm{CO}_{2}$.

O Brasil atingiu em 2010 o patamar de 1Mt/ano de resíduos destruídos em fábricas de cimento (SNIC 2010) e essa já é uma atividade consagrada no Brasil e no mundo. Uma grande variedade de tipos de resíduos vem sendo destruídos em fornos de cimento (Tabela 3).

O coprocessamento de resíduos em fornos de cimento tem sido objeto de inúmeros trabalhos e pesquisas científicas, que procuram determinar a viabilidade e as limitações do uso de um determinado resíduo como substituto de combustível ou de matéria-prima.

Richards et al (2008) apontam os fornos de cimento como o meio mais eficiente para destruição de pneus. Os fornos de cimento possuem características operacionais que os tornam seguros e eficientes para o uso de pneus como combustível alternativo. Isso se deve ao fato do forno operar com temperatura de gases superiores a $1650^{\circ} \mathrm{C}$ e a temperatura do material acima de $1480^{\circ} \mathrm{C}$. Essas temperaturas são superiores às das caldeiras e incineradores municipais. Além disso, os gases em fornos de cimento permanecem em altas temperaturas acima de $1200^{\circ} \mathrm{C}$ por mais de $3 \mathrm{~s}$ e acima de $1000^{\circ} \mathrm{C}$ por $6 \mathrm{~s}$, tempo superior aos $2 \mathrm{~s}$ em altas temperaturas (acima de $1200^{\circ} \mathrm{C}$ ) obtidos em incineradores tradicionais. Oliveira (2011) relata a experiência de sucesso na queima de pneus inservíveis picados e inteiros em várias plantas de cimento brasileiras com vantagens econômicas, tecnológicas e ambientais.

Tabela 3 - Resíduos industriais utilizados no coprocessamento (ABCP inédito)

\begin{tabular}{|c|c|}
\hline \multicolumn{2}{|c|}{ Substitutos de Combustível } \\
\hline $\begin{array}{l}\text { Resíduos com poder calorífico superior a } 2600 \mathrm{Kcal} / \mathbf{k g} \text { : } \\
\text { Solventes } \\
\text { Graxas e resíduos oleosos } \\
\text { Óleos usados (de carro e fábricas) } \\
\text { Lama de processos químicos } \\
\text { Fundos de destilação } \\
\text { Resíduos de empacotamento } \\
\text { Resíduos de fábricas de borracha } \\
\text { Pneus usados } \\
\text { Resíduos de picagem de veículos } \\
\text { Resíduos têxteis e plásticos } \\
\text { Serragem } \\
\text { Resíduos de fábricas de papel } \\
\text { Lama de esgoto municipal } \\
\text { Farinha eossos de animais } \\
\text { Grãos e sementes de validade vencida }\end{array}$ & $\begin{array}{l}\text { Resíduos poder calorífico inferior a } 2600 \mathrm{kcal} / \mathbf{k g} \\
\text { Resíduos aquosos } \\
\text { Água poluída com solventes } \\
\text { Água de processos químicos } \\
\text { Água de plantas de pintura } \\
\text { Lama derivada de esgoto industrial }\end{array}$ \\
\hline \multicolumn{2}{|c|}{ Matérias-primas Alternativas } \\
\hline $\begin{array}{l}\text { Lama com alumina (alumínio) } \\
\text { Lamas siderúrgicas (ferro) } \\
\text { Areia de fundição (sílica) } \\
\text { Terras de filtragem (sílica) } \\
\text { Refratários usados (alumínio) }\end{array}$ & $\begin{array}{l}\text { Resíduos da fabricação de vidros (flúor) } \\
\text { Gesso } \\
\text { Cinzas } \\
\text { Escórias }\end{array}$ \\
\hline
\end{tabular}


Ariyaratne et al. (2010) mostra resultados positivos da substituição, em até $40 \%$ em peso, do carvão mineral por farinha de carne e osso em fornos de cimento, sem impactos significantes na qualidade do produto e na operação e marcha do forno. Com relação às emissões, comenta-se a possibilidade de redução de aproximadamente $10 \%$ em peso da emissão de $\mathrm{CO}_{2}$ anual.

A temperatura elevada, o tempo de residência e o ambiente oxidante garantem a destruição das moléculas orgânicas. Por outro lado, a maioria dos elementos químicos que compõe a porção inorgânica, as cinzas, é incorporada pelos minerais que compõe o clínquer na forma de solução sólida. Maringolo (2001) mostra como clínqueres coprocessados apresentam-se enriquecidos em elementos traços, aventando a hipótese inclusive da fixação parcial de elementos voláteis (Cd,Hg e $\mathrm{Pb})$.

\section{MINERALOGIA DO CLINQUER PORTLAND}

O clínquer portland é composto principalmente pelos óxidos $\mathrm{CaO}, \mathrm{SiO}_{2}, \mathrm{Al}_{2} \mathrm{O}_{3}$ e $\mathrm{Fe}_{2} \mathrm{O}_{3}$ que perfazem $90-97 \%$ em peso do clínquer. Os demais 3-10\% em peso são normalmente constituídos por óxidos de magnésio, álcalis ( $\mathrm{K}$ e $\mathrm{Na}$ ), enxofre e uma grande variedade de elementos menores. A literatura técnica especializada utiliza a seguinte notação para denominar os óxidos principais: $\mathrm{C}=\mathrm{CaO} ; \mathrm{S}=\mathrm{SiO}_{2} ; \mathrm{A}=\mathrm{Al}_{2} \mathrm{O}_{3} ; \mathrm{F}=\mathrm{Fe}_{2} \mathrm{O}_{3}$. Essas abreviações são empregadas de modo a respeitar as proporções estequiométricas de cada composto, por exemplo: $\mathrm{C}_{3} \mathrm{~S}=3 \mathrm{CaO} \cdot \mathrm{SiO}_{2}$ ou $\mathrm{Ca}_{3} \mathrm{SiO}_{5}$.

Esses óxidos são advindos principalmente das matérias-primas, normalmente calcário, argila e minério de ferro, e das cinzas dos combustíveis utilizados no processo de calcinação. Para a formação dos compostos cristalinos na variedade e teores requeridos para obtenção de clínqueres de boa qualidade, as matérias-primas devem ser misturadas respeitando estreitas relações entre os quatro componentes principais, $\mathrm{CaO}, \mathrm{SiO}_{2}, \mathrm{Al}_{2} \mathrm{O}_{3}$ e $\mathrm{Fe}_{2} \mathrm{O}_{3}$. Essas relações e seus valores mais usuais são descritos na Tabela 1 (Duda, 1975).

Esses elementos combinados dão origem às principais fases cristalinas do clínquer portland:

- Alita ou $\mathrm{C}_{3} \mathrm{~S}$, silicato tricálcico - principal composto do clínquer portland presente em teores de 50 a 70\% em peso. Responsável pelo desenvolvimento das resistências mecânicas dos cimentos às primeiras idades;

- Belita ou $\mathrm{C}_{2} \mathrm{~S}$, silicato dicálcico - ocorre em teores que podem variar de 0,5 a $20 \%$ em peso. É responsável pelo desenvolvimento de resistências às idades mais avançadas;

- $C_{3} \mathrm{~A}$ (aluminato cálcico) e $\mathrm{C}_{4} \mathrm{AF}$ (ferroaluminato cálcico) - ocorrem preenchendo os espaços (interstícios) entre as fases silicáticas em teores médios de 10 a $18 \%$ em peso. $\mathrm{O}_{3} \mathrm{~A}$ é um dos responsáveis pelo endurecimento inicial do cimento (pega). 


\begin{tabular}{l|lc}
\hline \multicolumn{3}{c}{ Tabela 4 - Mineralogia do clínquer portland } \\
\hline Minerais & \multicolumn{1}{c}{ Composição Química } & Sistemas cristalinos predominantes \\
\hline Alita $\left(\mathrm{C}_{3} \mathrm{~S}\right)$ & $\mathrm{Ca}_{3} \mathrm{SiO}_{5}$ & Monoclínico \\
Belita $\left(\mathrm{C}_{2} \mathrm{~S}\right)$ & $\mathrm{Ca}_{2} \mathrm{SiO}_{4}$ & Monoclínico \\
Aluminato $\left(\mathrm{C}_{3} \mathrm{~A}\right)$ & $\mathrm{Ca}_{3} \mathrm{Al}_{2} \mathrm{O}_{6}$ & Cubico e ortorrômbico \\
Ferrita $\left(\mathrm{C}_{4} \mathrm{AF}\right)$ & $\mathrm{Ca}_{2}\left(\mathrm{Al}_{x} \mathrm{Fe}_{\mathrm{x}-1}\right)_{2} \mathrm{O}_{5}$ & Ortorrômbico \\
Cal livre & $\mathrm{CaO}$ & Cúbico \\
Periclásio & $\mathrm{MgO}$ & Cubico \\
Anidrita & $\mathrm{CaSO}_{4}$ & Ortorrômbico \\
Arcanita & $\mathrm{K}_{2} \mathrm{SO}_{4}$ & Ortorrômbico \\
Thernardita & $\mathrm{Na}_{2} \mathrm{SO}_{4}$ & Ortorrômbico \\
Cálcio Langbeinita & $\mathrm{K}_{2} \mathrm{Ca}_{2}\left(\mathrm{SO}_{4}\right)_{3}$ & Cúbica \\
Aphthitalita & $\left(\mathrm{K}, \mathrm{Na}_{3} \mathrm{Na}_{\left(\mathrm{SO}_{4}\right)_{2}}\right.$ & Trigonal \\
\hline
\end{tabular}

Em menores proporções e dependendo da temperatura de queima, da taxa de resfriamento e da composição química da farinha, poderão se formar as fases cristalinas: cal livre, periclásio e vários sulfatos alcalinos. Esses minerais, assim como sua composição química aproximada, são apresentados na Tabela 4.

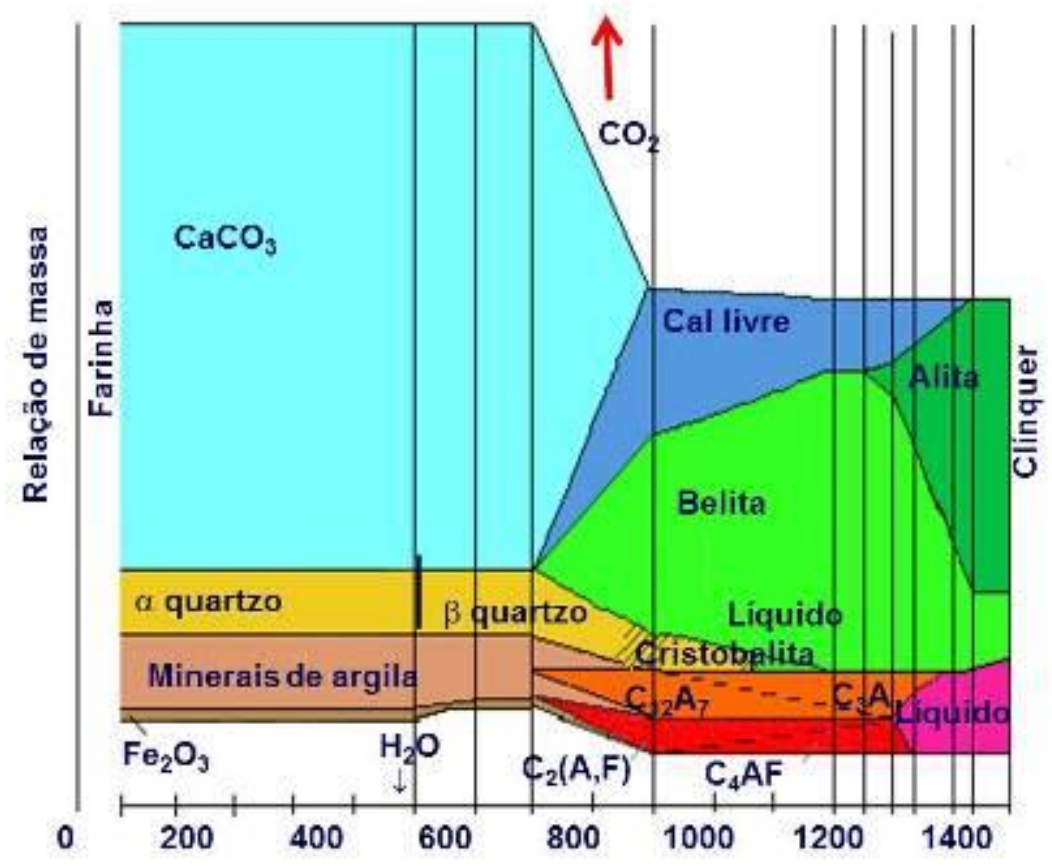

Figura 11 - Reações que ocorrem durante a fabricação do clínquer (Wolter, 1985)

A formação dos minerais do clínquer é resultado de uma série de transformações químicomineralógicas das matérias-primas durante o processo de calcinação. A Figura 11, adaptada de Wolter (1985), traz a evolução da mineralogia do clínquer com o aumento da temperatura.

Ressalta-se da Figura 11 a transformação de calcário em cal livre a temperaturas de $700^{\circ} \mathrm{C}$ a $800^{\circ} \mathrm{C}$, 
que posterirormente reage com a sílica liberada pela decomposição dos argilominerais e das transformações do quartzo para dar origem a belita ou $\mathrm{C}_{2} \mathrm{~S}$. Concomitantemente, observa-se a formação dos $C_{12} A_{7}$ e $C_{2}(A F)$, formados pela reação da cal com o alumínio e o ferro das argilas. Em temperatura superior a $1250^{\circ} \mathrm{C}$ esses aluminatos e ferroaluminatos cálcicos se fundem e dão origem a uma fase líquida, cujo aparecimento facilita e torna possível a reação entre a belita e a cal livre, promovendo a formação do silicato tricálcico, a alita. Ao final do aquecimento, na temperatura de $1450^{\circ} \mathrm{C}$, a composição do clínquer seria aproximadamente alita, belita e uma fase fundida que somente após o resfriamento dará origem ao $\mathrm{C}_{3} \mathrm{~A}$ e o $\mathrm{C}_{4} \mathrm{AF}$.

A formação dos minerais de clínquer é resultado de uma série de reações em estado sólido, uma vez que a fase líquida corresponde apenas a cerca de $20 \%$ da massa total do clínquer, o que torna necessário a utilização de elevadas temperaturas para promover sua homogeneidade e a obtenção de um equilíbrio entre as fases.

Os minerais de clínquer são metaestáveis a temperatura ambiente e estão presentes graças a um resfriamento rápido. $\mathrm{O}$ diagrama triangular da Figura 12 se refere ao sistema $\mathrm{CaO}-\mathrm{SiO}_{2}-\mathrm{Al}_{2} \mathrm{O}_{3}$ e traz uma primeira aproximação da evolução mineralógica das principais fases do clínquer com exceção dos compostos de ferro.

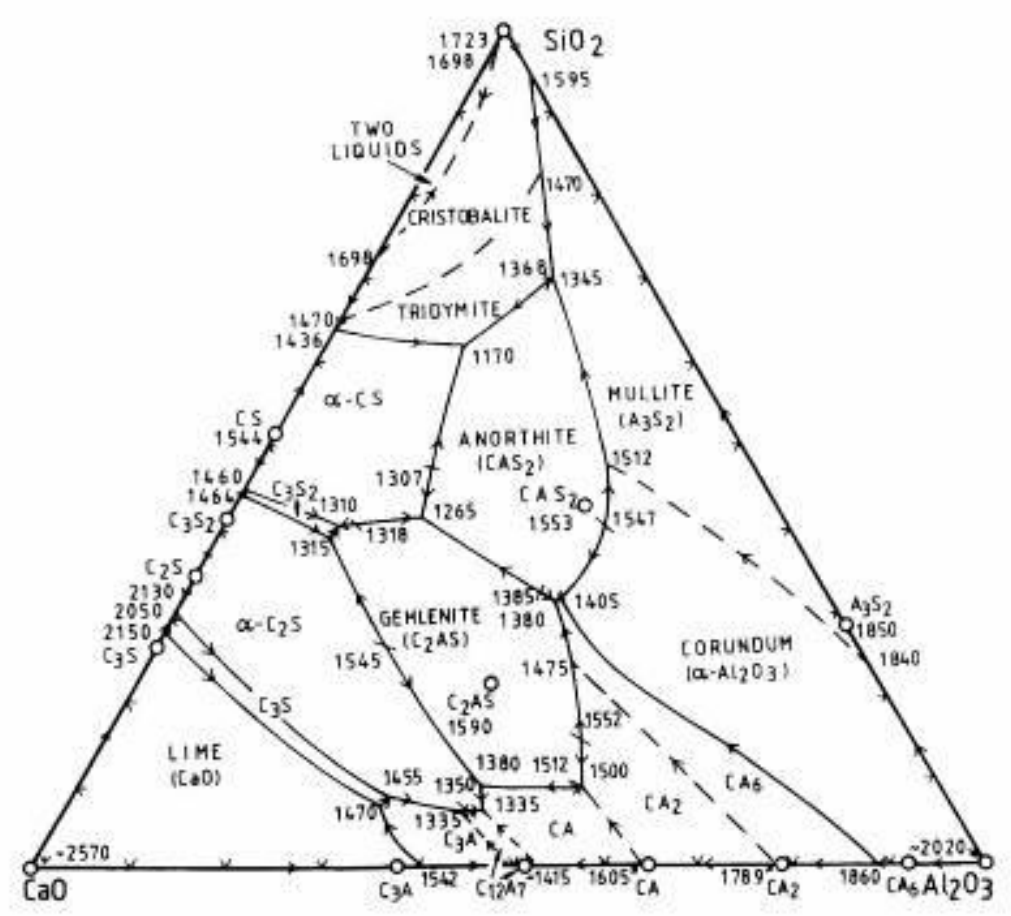

Figura 12 - Diagrama do sistema CaO-SiO ${ }_{2}-\mathrm{Al}_{2} \mathrm{O}_{3}$ - Muan \& Osborn (1965 in Taylor, 1997)

No detalhe do diagrama triangular $\mathrm{CaO}-\mathrm{SiO}_{2}-\mathrm{Al}_{2} \mathrm{O}_{3}$ (Figura 13), a região circundada pela linha tracejada, e que contém o ponto $\mathrm{P}$, representa a composição aproximada do clínquer portland $\mathrm{e}$ em particular do clínquer de cimento branco pela ausência de ferro. De fato, para qualquer composição dentro do triângulo formado pelos vértices $C_{3} S, C_{2} S$ e X em condições de equilíbrio a $1500^{\circ} \mathrm{C}$, teremos a cristalização desses silicatos e de um líquido de composição $X$. 


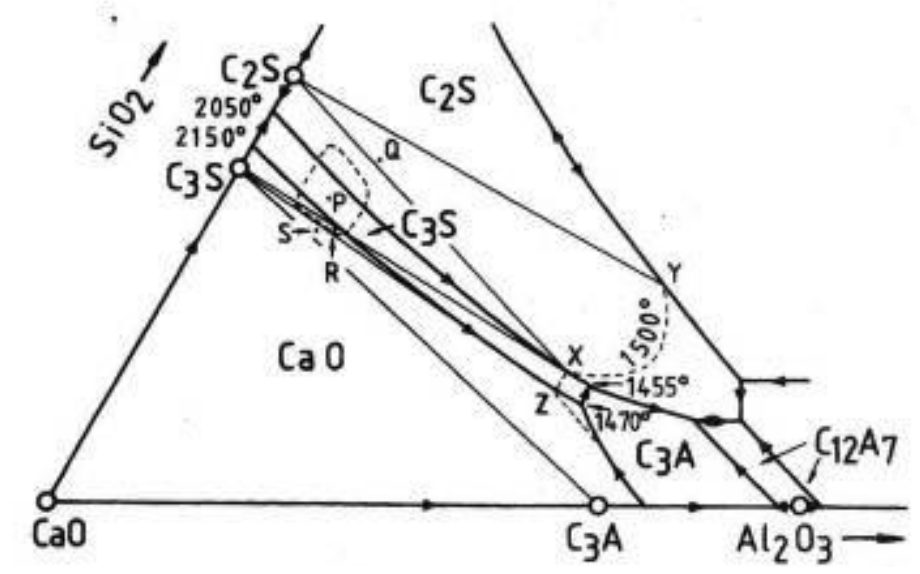

Figura 13 - Detalhe do diagrama do sistema $\mathrm{CaO}-\mathrm{SiO}_{2}-\mathrm{Al}_{2} \mathrm{O}_{3}$ (Taylor, 1997)

Do gráfico pode-se depreender que pequenas alterações na composição do material calcinado poderão levar a resultados bastante distintos. Para líquidos de composição $Q$, o resultado em condições de equilíbrio, isoterma de $1500^{\circ} \mathrm{C}$, será a cristalização de $\mathrm{C}_{2} \mathrm{~S}$ e um líquido de composição $X$, enquanto as composições em $R$, nas mesmas condições de equilíbrio, cristalizam-se o $\mathrm{C}_{3} \mathrm{~S}$ e um líquido de composição variando entre $\mathrm{Z}$ e $\mathrm{X}$. Na composição $\mathrm{S}$ o excesso de $\mathrm{CaO}$ dá origem a $\mathrm{C}_{3} \mathrm{~S}$ e $\mathrm{CaO}$ livre.

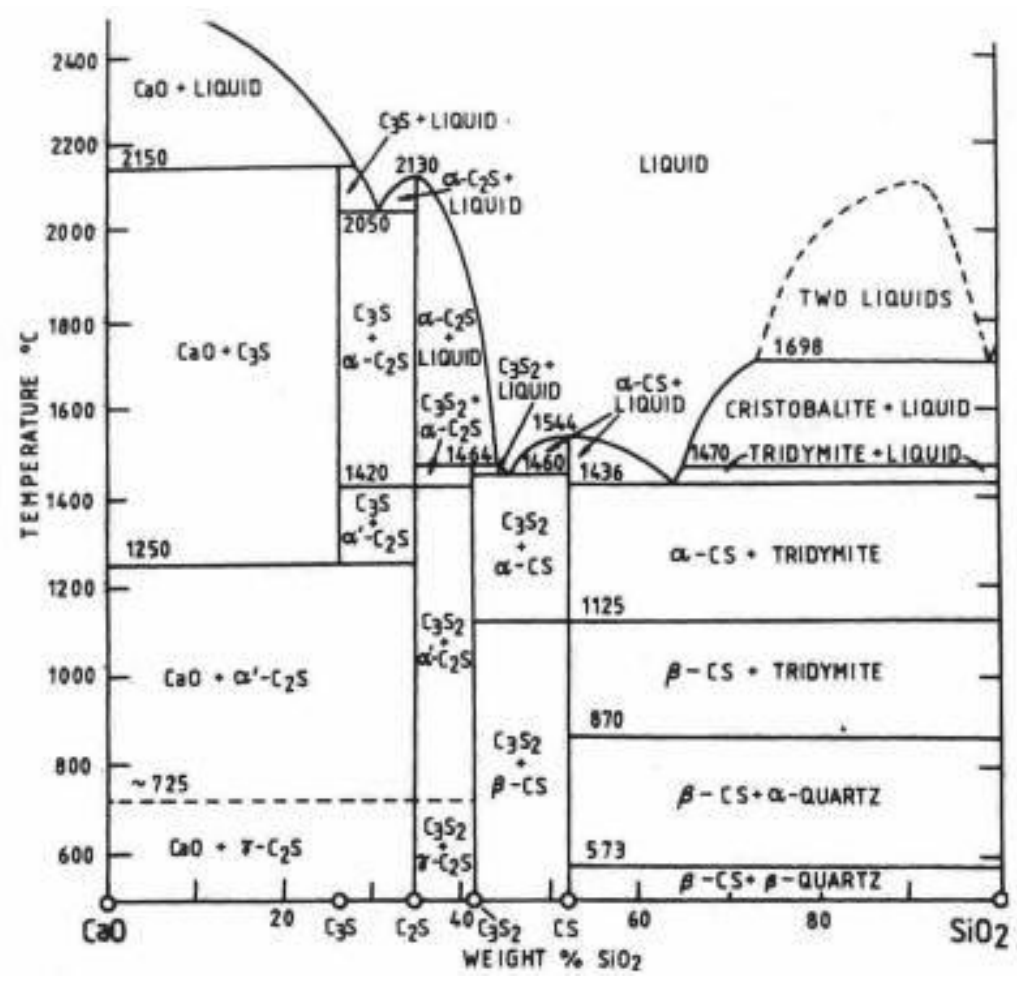

Figura 14 - Diagrama do sistema CaO-SiO ${ }_{2}$ - Welch e Gutt (1959, in Taylor, 1997) 
O diagrama de fases da Figura 14, corresponde ao lado $\mathrm{CaO}$ e $\mathrm{SiO}_{2}$ do diagrama triangular da Figura 12. É possível verificar, novamente, que a formação dos silicatos cálcicos $C_{3} S$ e $C_{2} S$ se dá em uma estreita faixa de teores de $\mathrm{SiO}_{2}$ entre 25 e 35\% (descontando-se os demais elementos). Notase que a partir do ponto eutético a $2050^{\circ} \mathrm{C}$ o resfriamento lento, em equilíbrio, gera uma mistura de $\mathrm{C}_{3} \mathrm{~S}$ e $\alpha \mathrm{C}_{2} \mathrm{~S}$ esse último, a $1420^{\circ} \mathrm{C}$, passa a outra forma polimórfica, o $\alpha^{\prime} \mathrm{C}_{2} \mathrm{~S}$. Abaixo de $1250^{\circ} \mathrm{C}$ o $\mathrm{C}_{3} \mathrm{~S}$ se decompõe em $\mathrm{CaO}+\alpha^{\prime} \mathrm{C}_{2} \mathrm{~S}$ e esse último finalmente se transforma em $\gamma \mathrm{C}_{2} \mathrm{~S}$ abaixo de $725^{\circ} \mathrm{C}$. $\mathrm{O} \mathrm{CaO}$ e o $\mathrm{\gamma C}_{2} \mathrm{~S}$ exibem baixa ou nenhuma reatividade com a água, o que justifica o esforço em estabilizar uma mineralogia de mais alta temperatura por meio de um resfriamento rápido.

\subsection{Alita ou silicato tri cálcico $\left(C_{3} S\right)$}

A alita ou $\mathrm{C}_{3} \mathrm{~S}$ ocorre no clínquer na forma de cristais idiomórficos tabulares e compactos que em seções transversais são pseudo hexagonais (Kihara et al., 1990). Esses cristais possuem bordas externas sub-retilíneas a pouco corroídas com dimensões médias que variam normalmente de 20 a mais de $100 \mu \mathrm{m}$ (Figura 15). Os cristais possuem densidade de aproximadamente $3,20 \mathrm{~g} / \mathrm{cm}^{3}$.

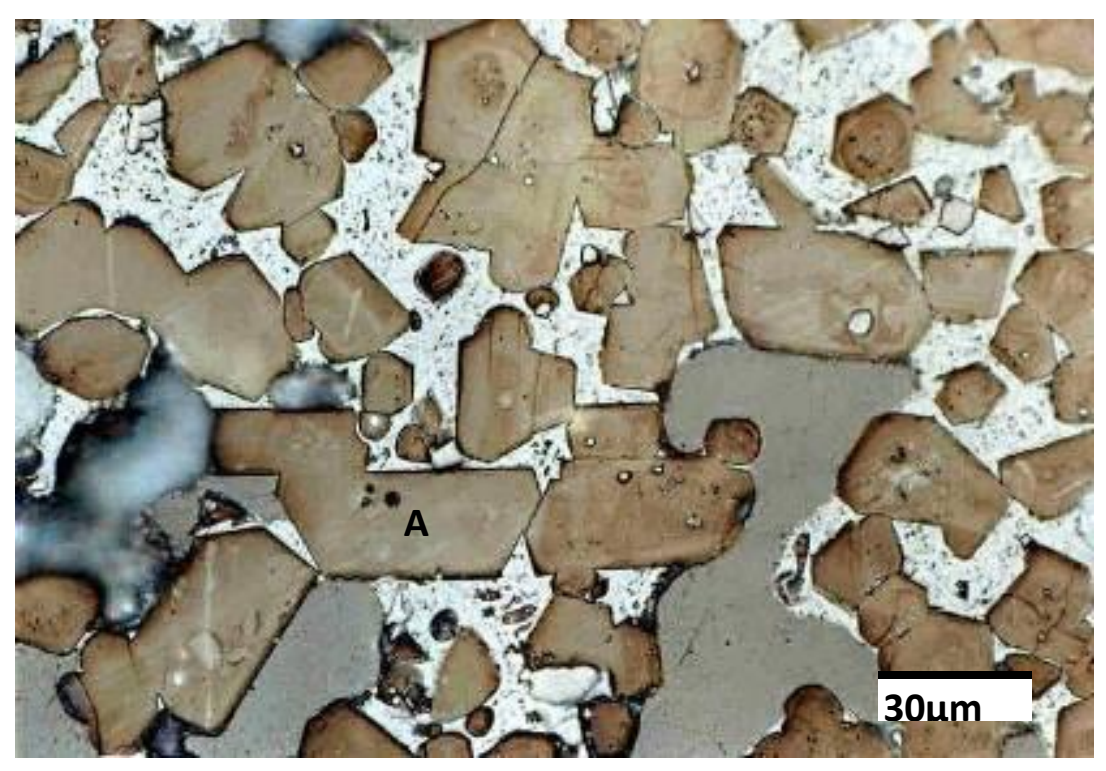

Figura 15-Aspecto do clínquer ao microscópio destacando-se os cristais idiomórficos de alita (A)

Alguns aspectos morfológicos e texturais relacionados aos cristais de alita podem ser correlacionados ao processo de fabricação do clínquer e podem ser utilizados como ferramentas para seu aprimoramento. A dimensão média dos cristais é um aspecto relacionado à queima da farinha ou à energia de calcinação; desse modo, quando o clínquer exibir cristais de alita com dimensões médias entre 30 e $40 \mu \mathrm{m}$, pode-se considerar as condições de queima normais, ou seja, o sistema recebeu um volume de energia suficiente para promover as reações de clinquerização. Por outro lado, quando a dimensão média dos cristais de alita for inferior a $20 \mu \mathrm{m}$, considera-se a 
queima branda insuficiente para seu desenvolvimento e, portanto, as reações de clinquerização estão incompletas. Já quando as dimensões médias dos cristais de alita superam a 60 $\mu m$, considera-se que o clínquer foi super queimado. Outro aspecto importante é quanto à estabilidade dos cristais, que reflete a eficiência do resfriamento. Quando o resfriamento do clínquer não é adequando, a alita passa a exibir corrosão em suas bordas com deposição, nos casos mais graves, de belita secundária originária da perda de cálcio para a massa intersticial (Campbell, 1999), como mostrado na Figura 16.

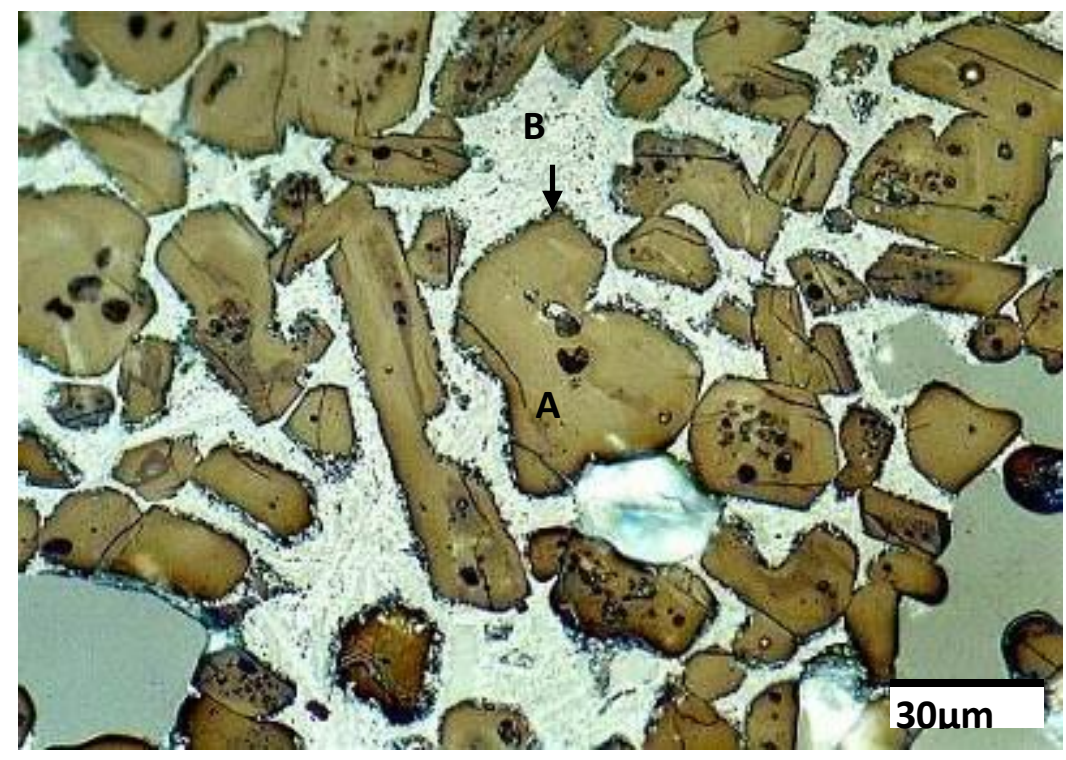

Figura 16 - Cristais idiomórficos de alita (A) exibindo bordas corroídas e formação de belita secundária (B)

As primeiras determinações das estruturas dos cristais de alita foram feitas por Jeffery (1952 in Taylor 1997) que propôs uma estrutura média (pseudoestrutura) para as fases hoje conhecidas como R (romboédrica), T1 (triclínica) e M3 (monoclínica), consideradas similares (Tabela 5). Essa estrutura é construída a partir de cátions de $\mathrm{Ca}^{2+}$, tetraedros isolados de $\mathrm{SiO}_{4}{ }^{-4}$ e íons de $\mathrm{O}^{-2}$, que se ligam aos íons $\mathrm{Ca}^{2+}$ como no $\mathrm{CaO}$.

Mais tarde, outros autores (Bigare et al., 1967, Guinier e Regourd, 1969) estabeleceram que o silicato tricálcico puro poderia assumir a seguinte sequência de transformações polimórficas (Figura 17) quando aquecido a partir da temperatura ambiente até sua fusão.

\begin{tabular}{|llllllllllllll}
\hline & $620^{\circ} \mathrm{C}$ & & $920^{\circ} \mathrm{C}$ & & $980^{\circ} \mathrm{C}$ & & $990^{\circ} \mathrm{C}$ & & $1060^{\circ} \mathrm{C}$ & & $1070^{\circ} \mathrm{C}$ & \\
& & & & & & & & & & & & & \\
$\mathrm{T} 1$ & $\leftrightarrow$ & $\mathrm{T} 2$ & $\leftrightarrow$ & $\mathrm{T} 3$ & $\leftrightarrow$ & $\mathrm{M} 1$ & $\leftrightarrow$ & $\mathrm{M} 2$ & $\leftrightarrow$ & $\mathrm{M} 3$ & $\leftrightarrow$ & $\mathrm{R}$ \\
\hline
\end{tabular}

Figura 17 - Temperaturas das transições polimórficas do silicato tricálcico puro. T=triclínico, M=monoclínico e R=romboédrico.

De acordo com a Figura 14, nenhum polimorfo do $\mathrm{C}_{3} \mathrm{~S}$ é estável à temperatura ambiente. No entanto, as formas polimórficas triclínicas não são facilmente observadas nos clínqueres industriais, que quando resfriados a temperatura ambiente, apresentam mais comumente as 
formas monoclínicas M1 ou M3 ou uma mistura de ambas.

A difração de raios $X$ permitiu a determinação da simetria e das dimensões dos diferentes polimorfos, e Golovasticov et al. (1985) estabeleceram os primeiros resultados para a estrutura do polimorfo T1. Mais tarde o polimorfo R foi resolvido por Nishi e Takeuchi (1984) e por Il'inets e Malinovski (1985). Nishi et al. (1985) propuseram uma superestrutura com uma cela unitária média monoclínica para o polimorfo M3. Mais tarde, Mumme (1995) determinou a estrutura de um cristal de alita extraído de um clínquer industrial, similar àquela determinada por Nishi et al. (1985), porém sem as características de uma superestrutura. As superestruturas correspondem a grandes celas unitárias, com centenas de átomos, e que permitem uma maior flexibilidade na alocação de defeitos cristalinos e soluções sólidas. Recentemente, de La Torre et al (2002), com base em análises de difração de luz síncrotron de alta resolução, propuseram uma nova superestrutura simplificando o modelo de Nishi et al (1985). Já Noirfontaine et al. (1999, 2003 in Dunstetter et al., 2004) e (Noirfointaine et al., 2006) propuseram uma relação entre as superestruturas dos polimorfos T1, M1 e M3 com um modelo estrutural para o polimorfo M1.

A diferença estrutural entre os polimorfos afeta a coordenação dos íons de $\mathrm{Ca}^{2+}$ e dos átomos de oxigênio nos tetraedros de $\mathrm{SiO}_{4}{ }^{-4}$. Para cada polimorfo há uma série de distintas posições atômicas para o cálcio, com diferentes coordenações, e para uma dada posição a coordenação poderá variar entre átomos individuais devido à desordem na orientação dos tetraedros circundantes. De qualquer modo, a definição do número de coordenação do Ca é arbitrária podendo variar em função do comprimento das ligações, por exemplo: em polimorfos R a $1200^{\circ} \mathrm{C}$ em uma das posições o Ca pode ter coordenação 7 quando as ligações possuem comprimento de 0,296Å e coordenação 5 se não possuir esse comprimento. O número de coordenação médio para o Ca é de 5,66 no polimorfo R, 6,15 em M3 e 6,21 em T1 (Taylor, 1997).

Tabela 5 - Polimorfos de $C_{3} S$-Informações cristalográficas (modificada de Taylor 1997)

\begin{tabular}{|c|c|c|c|c|c|c|c|c|c|}
\hline \multirow{2}{*}{ Polimorfos } & \multirow{2}{*}{$\begin{array}{c}\text { Grupo } \\
\text { Espacial }\end{array}$} & \multicolumn{6}{|c|}{ Parâmetros de Cela Unitária } & \multirow{2}{*}{ Z } & \multirow{2}{*}{ Referência } \\
\hline & & $a(\AA ̊)$ & $b(\AA ̊)$ & $c(\AA)$ & $\alpha\left(^{\circ}\right)$ & $\beta\left(^{\circ}\right)$ & $\gamma\left({ }^{\circ}\right)$ & & \\
\hline Pseudo es trutura & R3m & 7,0 & 7,0 & 25,0 & 90 & 90 & 120 & 9 & Jeffery (1952) \\
\hline $\mathrm{R}\left(\mathrm{a} 1200^{\circ} \mathrm{C}\right)$ & R3m & 7,135 & 7,135 & 25,586 & 90 & 90 & 120 & 9 & Nishi et al. (1984) \\
\hline $\begin{array}{c}\text { R (estabilizado } \\
\mathrm{c} / \mathrm{Sr} \text { ) }\end{array}$ & R3m & 7,056 & 7,056 & 24,974 & 90 & 90 & 120 & 9 & Il'inets et al. (1982) \\
\hline $\begin{array}{l}\text { M3 (estabilizado } \\
\text { c/Mg) }\end{array}$ & $\mathrm{Cm}$ & 33,083 & 7,027 & 18,499 & 90 & 94,12 & 90 & 36 & Nishi et al. (1985) \\
\hline M3 (clinker) & $\mathrm{Cm}$ & 12,235 & 7,073 & 9,298 & 90 & 116,31 & 90 & 6 & Mumme (1995) \\
\hline M1 & $3(\mathrm{M}) \mathrm{Pc}$ & 27,873 & 7,059 & 12,257 & 90 & 116,03 & 90 & 18 & $\begin{array}{c}\text { Noirfontaine et al. } \\
(2004)\end{array}$ \\
\hline $\mathrm{T} 1$ & P1 & 11,67 & 14,24 & 13,72 & 105,5 & 94,3 & 90 & 18 & $\begin{array}{c}\text { Govalastikov et al. } \\
(1975)\end{array}$ \\
\hline
\end{tabular}


A Tabela 5 fornece os dados cristalográficos dos diferentes polimorfos obtidos a partir de métodos do cristal único (modificada de Taylor 1997).

Maki et al. (2004) estudaram a cristalização da alita utilizando seções delgadas em microscópio óptico de alta temperatura com análises térmicas e difração de raios X. A alita se cristaliza a partir de um líquido a cerca de $1450^{\circ} \mathrm{C}$ na forma $\mathrm{R}$, transformando-se em formas de mais baixa temperatura com o resfriamento.

Em altas temperaturas de formação ou recristalização, pequenos cristais de alita se formam com relativamente alto conteúdo de íons substituintes podendo se transformar no polimorfo M3 durante o resfriamento até a temperatura ambiente. Os cristais formados em temperaturas mais baixas são grandes e pobres em íons substituintes e podem transformar-se parcial ou completamente no polimorfo $\mathrm{M} 1$, ou mais raramente em $\mathrm{T} 2$. Os conteúdos de $\mathrm{MgO}$ e $\mathrm{SO}_{3}$ são importantes controladores da transformação para M1 (Maki et al. 2004). O Mg substitui exclusivamente o Ca em suas posições cristalográficas na estrutura da alita (Maki et a l., 1992).

Elevadas concentrações de $\mathrm{MgO}$ e $\mathrm{SO}_{3}$ (Figura 18) favorecem a formação de pequenos cristais euhedrais de M3. Em contraste, baixas concentrações desses elementos, favorecem o rápido e instável crescimento, produzindo cristais grandes e de formas irregulares do polimorfo M1. Esses podem ser esqueletais ou dendríticos com alto conteúdo de inclusões de fase e pequenos cristais de belita e cal livre. Cristais contendo as duas formas polimórficas, M1 e M3, podem ocorrer e são normalmente zonados com núcleos de $\mathrm{M} 1$ e as regiões periféricas de $\mathrm{M} 3$. O zoneamento ocorre porque o líquido do clínquer vai progressivamente se enriquecendo em $\mathrm{MgO}$ com o decorrer da cristalização fazendo com que o material que se deposita tardiamente seja M3. A transformação M3 para M1 é também afetada pelas taxas de resfriamento, de modo que resfriamentos lentos favorecem o aparecimento de M1 (Taylor, 1997).

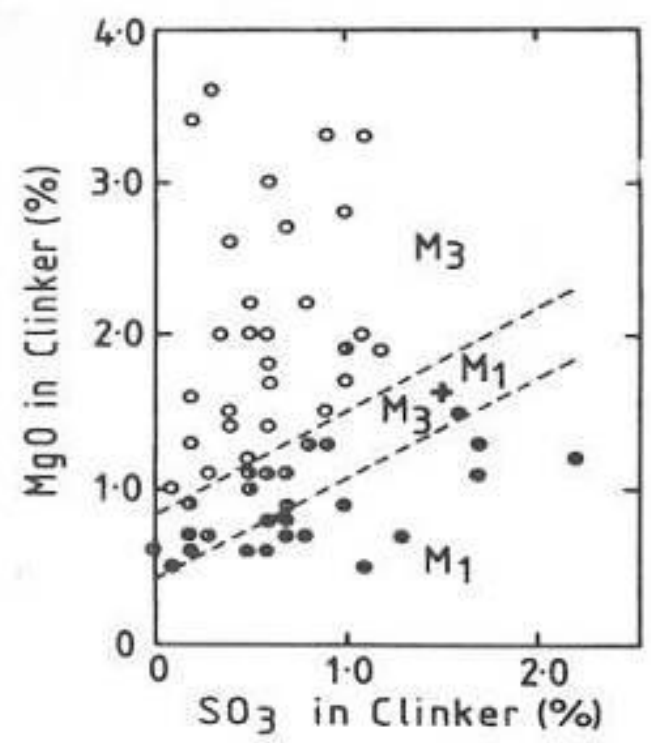

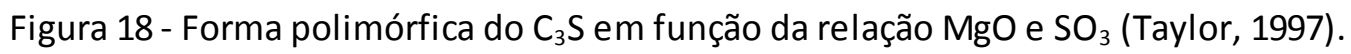


Em queimas prolongadas a altas temperaturas, os grandes cristais de alita crescem a expensas dos menores e nesse processo o conteúdo de íons substituintes decresce, favorecendo a inversão M3 para M1 ou T2. Clínqueres industriais são suficientemente ricos em MgO para evitar essas transformações, apesar de poderem ocorrer recristalizações. As recristalizações podem afetar substancialmente a relação entre temperatura de formação e tamanho de cristal.

Sendo a alita o principal responsável pelo desenvolvimento de resistências mecânicas no cimento, produzir um clínquer com elevado conteúdo desse mineral é um objetivo sempre a ser perseguido. De fato, Taylor (1997) comenta que estudos de difratometria de raios $\mathrm{X}$ aliados a outros métodos mostram que $70 \%$ dos cristais de alita reagem com a água até os 28 dias e com praticamente todos os cristais em até um ano. Esse processo produz hidróxido de cálcio $\left(\mathrm{Ca}(\mathrm{OH})_{2}\right)$ e um silicato hidratado amorfo, chamado de $\mathrm{C}-\mathrm{S}-\mathrm{H}$, que possui propriedades similares a de um gel rígido.

Com relação à interferência da forma polimórfica da alita no desempenho do cimento espera-se que as formas polimórficas de mais alta temperatura, resfriadas à temperatura ambiente (metaestáveis), sejam as mais reativas com a água. Neste sentido, um grande esforço tem sido feito na tentativa de estabilizar a forma romboédrica (R), conseguida por meio da introdução de quantidades específicas dos chamados íons mineralizadores, $\mathrm{F}^{-}$e $\mathrm{SO}_{3}$, na matéria-prima. $\mathrm{O}$ processo de mineralização da alita se dá pela substituição da sílica por enxofre e alumínio nas posições tetraédricas seguindo aproximadamente a proporção: $3 \mathrm{Si}^{4+} \leftrightarrow \mathrm{S}^{6+}+2 \mathrm{Al}^{3+}$. Centurione (1999), Emanuelson et al. (2003), entre outros pesquisadores apontam um aumento de mais de $10 \%$ nas resistências mecânicas do cimento com benefícios adicionais relacionados à diminuição de cerca de 5 a $6 \%$ do consumo energético por tonelada de cimento produzido.

Por outro lado, os experimentos desenvolvidos por Stanĕk e Sulovsky (2002) atribuem à forma polimórfica $\mathrm{M} 1$, estabilizada pela adição de $\mathrm{SO}_{3}$, o desenvolvimento de resistências mecânicas $10 \%$ superiores àquelas obtidas em cimentos com o predomínio da forma M3.

Outro aspecto a ser observado é quanto a correta identificação dos polimorfos presentes no clínquer nesse aspecto Cortial et al. (2004) propõe que essa distinção seja feita por meio da análise de cinco janelas distintas janelas no padrão de difração apresentados na Figura 19. Todavia, devido à possibilidade da mistura de polimorfos, de variações na preparação das amostras ou mesmo razões intrínsecas a análise por difração de raios $X$, a identificação dos polimorfos tem sido feita por meio do método de Rietveld. 

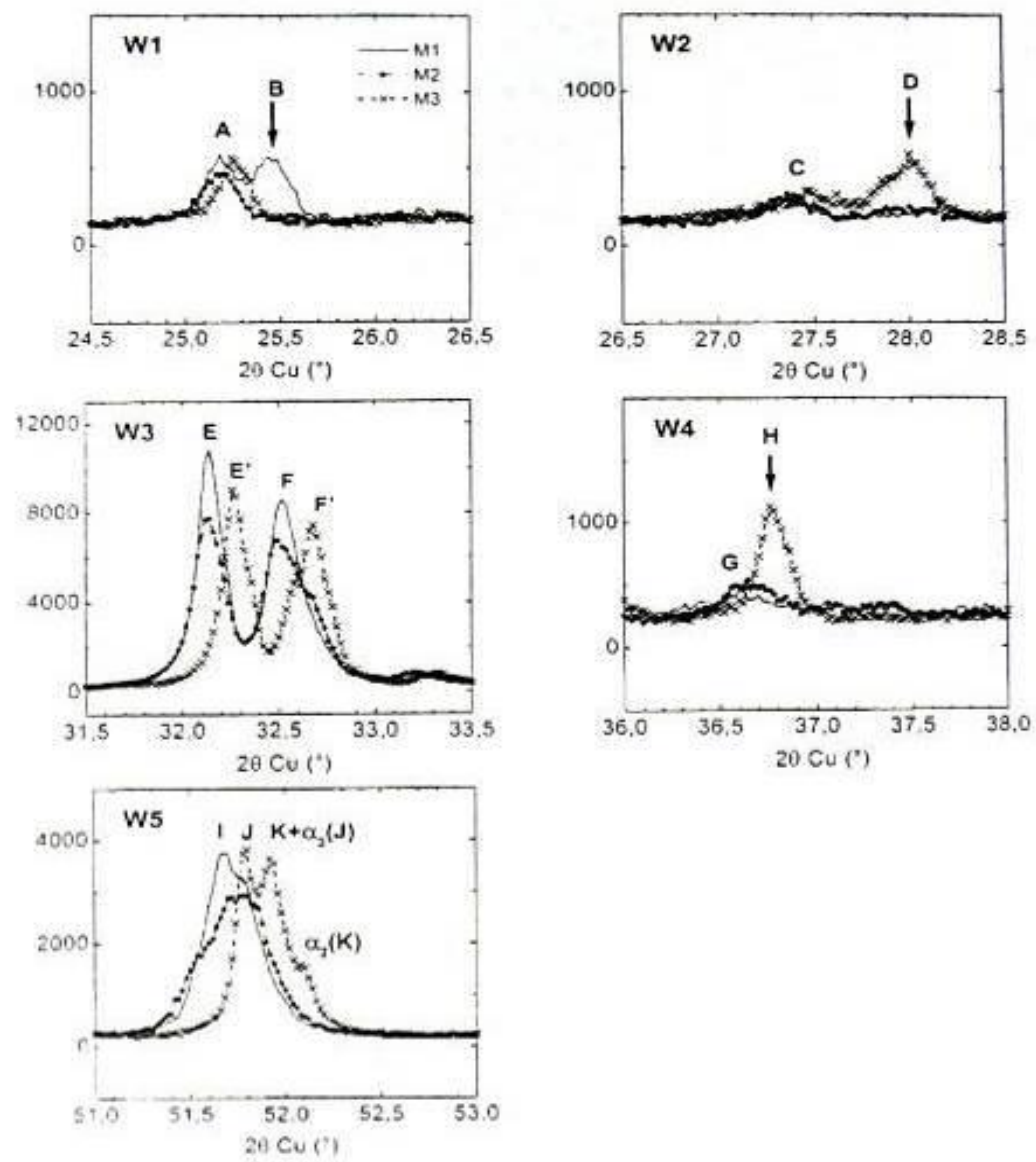

Figura 19 - Intervalos angulares de difração de raios X (tubo Cu K alfa) propostas por Courtial el al . (2004) para identificação dos polimorfos as alita:M1, M2 e M3

\subsection{Belita ou Silicato bicálcico}

A belita ou $\mathrm{C}_{2} \mathrm{~S}$ (silicato bicálcico) é o segundo mais importante mineral do clínquer, ocorrendo em teores inferiores a $20 \%$ em peso. A belita é o mineral responsável pelo desenvolvimento das resistências mecânicas a médias e elevadas idades, já que possui uma taxa de hidratação mais lenta. Taylor (1997) aponta que 30\% dos cristais de belita reagiriam até os 28 dias de cura e $90 \%$ com um ano, além de liberar uma menor quantidade de hidróxido de cálcio em relação ao $\mathrm{C}_{3} \mathrm{~S}$.

Os cristais que possuem densidade de aproximadamente $3,28 \mathrm{~g} / \mathrm{cm}^{3}$ apresentam formas predominantemente arredondadas (Figura 20). No entanto, sua morfologia depende das condições de resfriamento do clínquer (Kihara et al. 1990), podendo passar de cristais arredondados a digitados quando o resfriamento que ocorre entre a máxima temperatura do forno e sua saída for lento. 


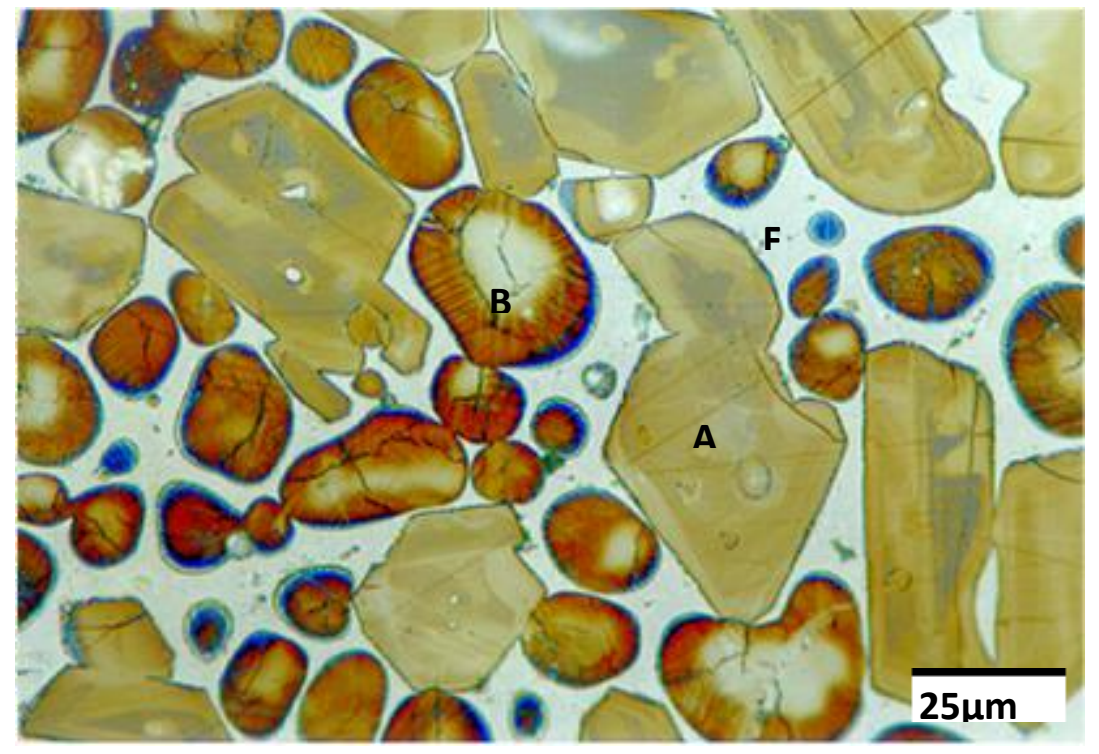

Figura 20 - Cristais arredondados de belita ou $C_{2} S$ (B). $A=A$ lita $F=$ fase intersticial

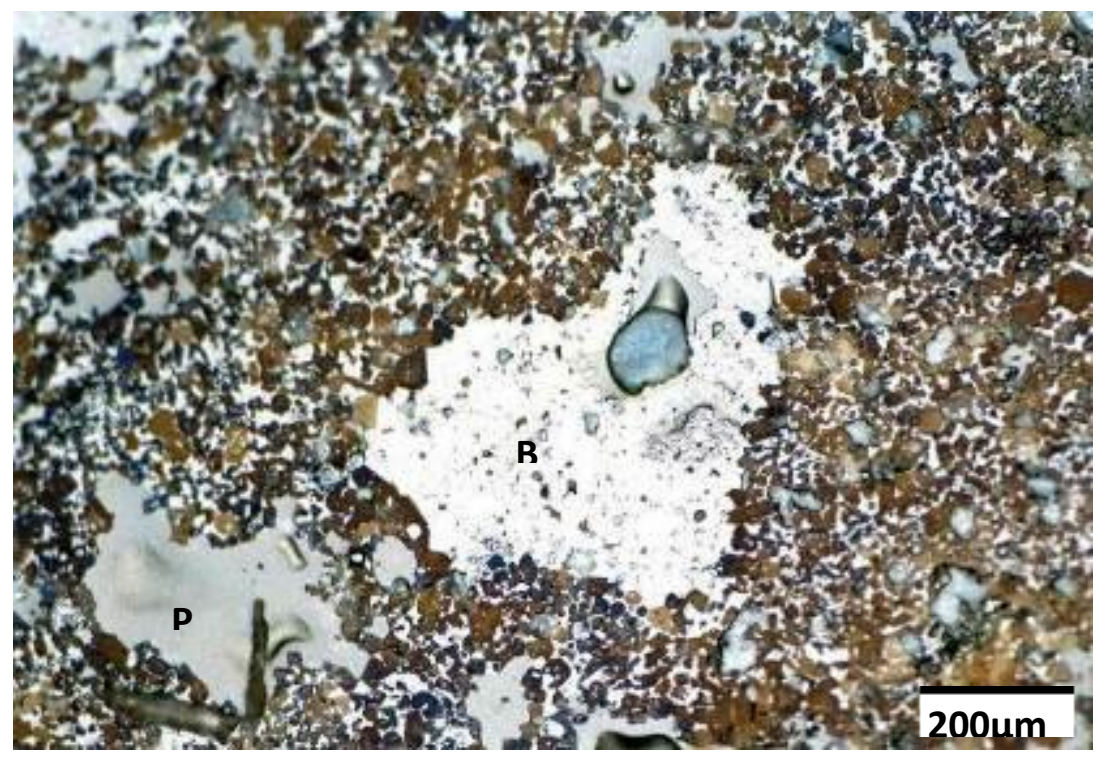

Figura 21 - Cristais de belita agrupados em uma zona regular ou $\mathrm{C}_{2} \mathrm{~S}(\mathrm{~B}) . \mathrm{P}=$ poro

Os cristais de belita ocorrem distribuídos na massa do clínquer ou formando agrupamentos, denominados zonas belíticas (Figura 21). As zonas belíticas, que constituem irregularidades texturais, podem possuir formas regulares com dimensões de $300 \mu \mathrm{m}$, ou formas ameboides de grandes dimensões (maiores que $800 \mu \mathrm{m}$ ).

A ocorrência de heterogeneidades texturais está frequentemente relacionada a problemas de preparação das matérias-primas. Quando as zonas de belita são regulares, com dimensões de 200 a $500 \mu \mathrm{m}$, são correlacionadas a problemas de moagem com presença de grão silicosos grossos na matéria-prima (maiores que $45 \mu \mathrm{m}$ ). Problemas nos equipamentos de homogeneização do cru, por sua vez, podem ser responsáveis pelo aparecimento de zonas irregulares de grandes dimensões no clínquer, associadas a zonas de cal livre (Kihara et al., 1990). 
As belitas em clínqueres apresentam um complexo padrão de estrias que foi estudado por diversos autores. Yamaguchi e Takagui (1969) e Ono et al. (1969) (in Taylor, 1997), utilizando difratometria de raios $X$ e outras técnicas, foram os primeiros a fornecer as mais completas explicações sobre essas feições, bem como correlacioná-las com a forma polimórfica da belita. 0 tipo I, mais comum, é redondo, possui uma série de conjuntos de estrias paralelas e dimensões de 20 a $40 \mu \mathrm{m}$. Esses cristais se formam a partir do polimorfo $\alpha$, e as estrias aparecem quando ocorrem as transformações $\alpha$ para $\alpha_{H}{ }^{\prime}$ e $\alpha_{L}$ para $\beta$ durante o resfriamento (Figura 22).

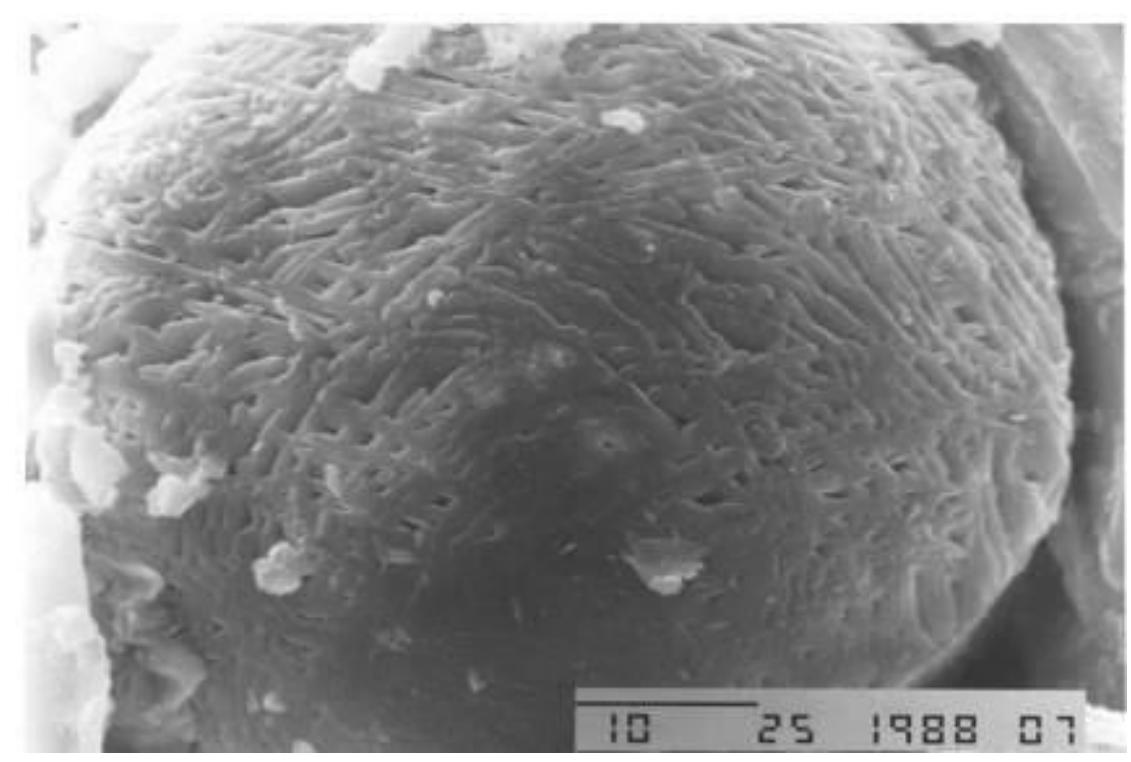

Figura 22- Cristal de belita ao microscópio el etrônico de varredura exibindo variados conjuntos de estrias paralelas (Tipo I)

O tipo II é tipicamente irregular e apresenta apenas um conjunto de estrias que se formam pela transformação $\alpha_{\llcorner}^{\prime}$ para $\beta$. Esse tipo é relativamente raro nos clínqueres modernos. Esses cristais se formam ou a temperaturas inferiores a da transição $\alpha$ para $\alpha^{\prime}{ }_{H}$ ou quando um dos componentes geminados da modificação $\alpha$ 'se desenvolve às expensas do outro. A belita possui outros mecanismos de formação a temperaturas menores e podem não exibir qualquer geminação (Taylor, 1997).

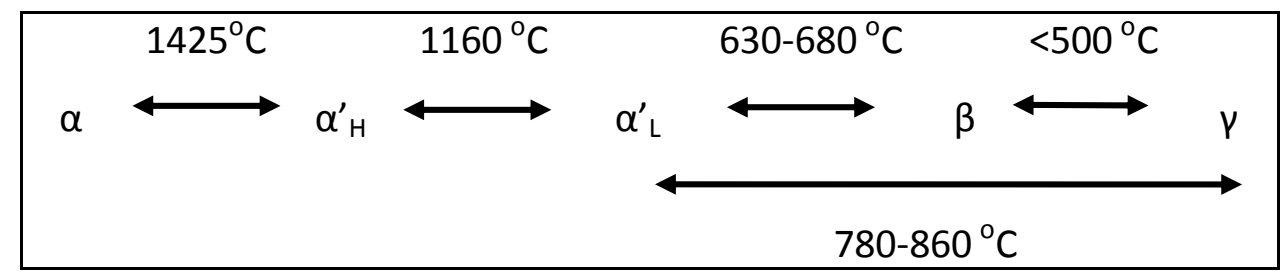

Figura 23 - Temperaturas das transições polimórficas do silicato bicálcico puro, onde: $\alpha=$ hexagonal, $\alpha^{\prime}{ }_{H}, \alpha^{\prime}{ }_{L}$ e $\gamma=$ ortorrômbico e $\beta=$ monoclínico.

Evidências térmicas e difratométricas mostram que existem 5 diferentes polimorfos de belita $\left(\mathrm{C}_{2} \mathrm{~S}\right)$. A estrutura desses cristais é definida pelo arranjo dos íons $\mathrm{Ca}^{2+}$ e $\mathrm{SiO}_{4}{ }^{4-}$ e são bastante similares para $\alpha, \alpha^{\prime} H, \alpha^{\prime} L$ e $\beta$. No entanto, diferem de $\gamma C_{2} S$. Nos clínqueres industriais a belita contem suficientes íons estabilizadores para evitar essa transformação (Figura 23). 
Muitas informações a respeito dos diferentes polimorfos de belita estão baseadas em difratometria de raios $X$ de pó a altas temperaturas, a partir de preparações estabilizadas à temperatura ambiente; a Tabela 6 apresenta dados mais confiáveis obtidos a partir de monocristais (modificado de Taylor, 1997 e Taylor, 1999).

Tabela 6 - Polimorfos de $C_{2} S$ - Informações cristalográficas (modificado de Taylor 1997 e Taylor 1999)

\begin{tabular}{|c|c|c|c|c|c|c|c|}
\hline \multirow[t]{2}{*}{ Polimorfos } & \multirow[t]{2}{*}{ Grupo Espacial } & \multirow[t]{2}{*}{ Sistema cristalino } & \multicolumn{4}{|c|}{ Parâmetros de Cela Unitária } & \multirow[t]{2}{*}{$Z$} \\
\hline & & & a & b & c & & \\
\hline$\alpha$ & $\mathrm{P}_{3} / \mathrm{mmc}$ & Hexagonal & 0,5579 & & 0,7150 & $\gamma=120$ & 2 \\
\hline$\alpha_{H}^{\prime}$ & Pcmm & Ortorrômbico & 0,949 & 0,559 & 0,685 & & 4 \\
\hline$\alpha_{L}^{\prime}$ & $\mathrm{Pna}_{1}$ & Ortorrômbico & 2,0871 & 0,9496 & 0,5600 & & 12 \\
\hline$\beta$ & $\mathrm{P} 2_{1} / \mathrm{n}$ & Monoclínico & 0,5502 & 0,6745 & 0,9297 & $\beta=94,59$ & 4 \\
\hline$\gamma$ & Pbnm & Ortorrômbico & 0,5081 & 1,1224 & 0,6778 & & 4 \\
\hline
\end{tabular}

As estruturas de $\alpha^{\prime} H$, $\alpha^{\prime} \mathrm{L}$ e $\beta$ derivam do $\alpha \mathrm{C}_{2} \mathrm{~S}$ pela perda progressiva de simetria caracterizada pelas mudanças na orientação dos tetraedros de $\mathrm{SiO}_{4}{ }^{4+}$ e por pequenos deslocamentos dos íons substituintes. Similarmente ao que ocorre com $\circ \mathrm{C}_{3} \mathrm{~S}$, observa-se uma mudança no número de coordenação do íon $\mathrm{Ca}^{2+}$ em cada polimorfo. No $\beta \mathrm{C}_{2} \mathrm{~S}$, por exemplo, alguns íons Ca estão ligados a sete ou oito oxigênios.

A estrutura da belita foi melhor estudada por Mumme et al. (1995 in Taylor et al., 1999), utilizando técnicas de refinamento estrutural pelo método de Rietveld.

Os estudos que relacionam o comportamento dos diferentes polimorfos em relação ao desenvolvimento de resistências mecânicas apresentam resultados contraditórios. A reatividade da belita está mais relacionada à presença de exsoluções das impurezas a partir das quais a reação com a água começaria, do que relacionada às diferentes formas polimórficas.

No entanto, muitos estudos foram desenvolvidos no sentido de se produzir o clínquer belítico, que é composto apenas por cristais de belita das formas $\alpha C_{2} S$ e $\alpha^{\prime} C_{2} S$. Essas formas, mais reativas, poderiam ser estabilizadas por resfriamentos rápidos e pela introdução de álcalis; assim o $\mathrm{Na}_{2} \mathrm{O}$ fixaria a forma $\alpha C_{2} S$, o $K_{2} \mathrm{O}$ estabilizaria a forma $\alpha^{\prime} C_{2} S$ (Kihara et al., 1990).

\subsection{Aluminato tricálcico $\left(C_{3} A\right)$}

$\mathrm{O}$ aluminato cálcico compõe, junto com o $\mathrm{C}_{4} \mathrm{AF}$, a chamada fase intersticial, que ocorre em proporção bem inferior aos silicatos cálcicos, com teores da ordem de 15 a $20 \%$ em peso. Sua presença é fundamental, uma vez que os óxidos de ferro e alumínio se comportam como fundentes, facilitando as reações de clinquerização e diminuindo a temperatura de formação do clínquer. Dependendo da taxa de resfriamento do clínquer, a fase intersticial dá origem a dois compostos distintos: o ferroaluminato tetracálcico $\left(C_{4} A F\right)$ e o aluminato tricálcico. $O C_{3} A$ é de 
grande importância, pois está intimamente relacionado à definição do tempo de pega dos cimentos.

O $C_{3} A$ puro não apresenta polimorfos, sendo cúbico ( $a=1,5263 \AA$ ) e pertencente ao grupo espacial Pa3. Sua estrutura é formada por ions $\mathrm{Ca}^{+}$e anéis de tetraedros de $\mathrm{AlO}_{4}$, cuja fórmula pode ser expressa $\mathrm{Al}_{6} \mathrm{O}_{18}{ }^{18-}$ (Mondal e Jeferry, 1975 in Taylor, 1997). A cela unitária é composta por 64 sub células. Nesses anéis os átomos de Al ocupam posições próximas aos vértices de um cubo conforme a Figura 24.

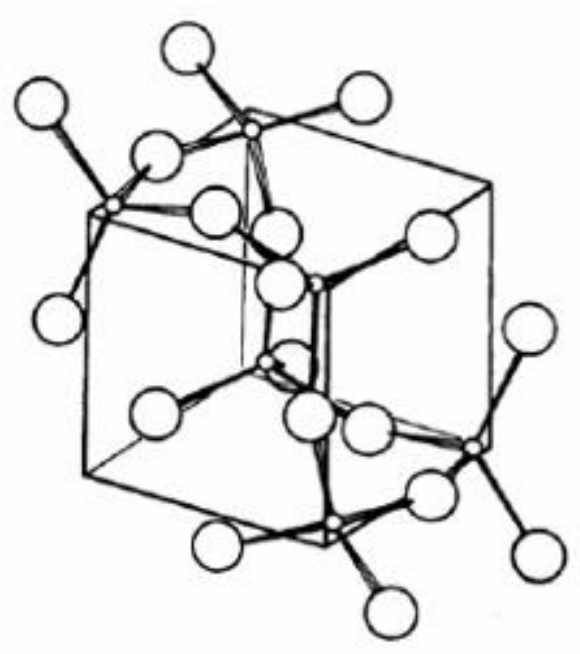

Figura 24 - Cela unitária da fase cúbica segundo Mondal e Jeferry, 1975 (in Taylor, 1997).

$\mathrm{O}_{3} \mathrm{~A}$ pode incorporar um íon de $\mathrm{Na}^{+}$por meio da substituição do íon $\mathrm{Ca}^{2+}$, com inclusão de um segundo íon $\mathrm{Na}^{+}$em outra posição para compensar a valência. Então, a solução sólida obtida tem uma fórmula genérica de $\mathrm{Na}_{2 \times} \mathrm{Ca}_{3-\mathrm{x}} \mathrm{Al}_{2} \mathrm{O}_{6}$. $\mathrm{O}$ sódio pode ser incorporado até o limite de $1 \%$ sem causar mudanças na estrutura, para maiores níveis de incorporação a estrutura se modifica segundo a Tabela 7, até o limite máximo de 5,7\% na ausência de outros elementos substituintes.

Tabela 7-Modificações da estrutura do $\mathrm{C}_{3} \mathrm{~A}$ para a fórmula geral de $\mathrm{Na}_{2 x} \mathrm{Ca}_{3-x} \mathrm{Al}_{2} \mathrm{O}_{6}$ (modificada Taylor, 1997)

\begin{tabular}{|c|c|c|c|c|c|c|c|}
\hline \multirow[t]{2}{*}{ Polimorfos } & \multirow{2}{*}{$\begin{array}{c}\text { Grupo } \\
\text { Espacial }\end{array}$} & \multirow{2}{*}{$\begin{array}{c}\text { Sistema } \\
\text { cristalino }\end{array}$} & \multicolumn{4}{|c|}{ Parâmetros de Cela Unitária } & \multirow[t]{2}{*}{ Teor de $\mathrm{Na}_{2} \mathrm{O}(\%$} \\
\hline & & & $a(\AA)$ & $b(\AA)$ & $c(\AA)$ & $\left({ }^{\circ}\right)$ & \\
\hline$C_{1}$ & Pa3 & Cúbico & 1,524 & - & - & - & $0-1,0$ \\
\hline $\mathrm{C}_{\|}$ & $\mathrm{P} 2{ }_{1} 3$ & Cúbico & 1,5248 & - & - & - & $1,0-2,4$ \\
\hline $\mathrm{C}_{11}+\mathrm{O}$ & - & - & - & - & - & - & $2,4-3,7$ \\
\hline $\mathrm{O}$ & Pbca & Ortorrômbico & 1,0879 & 1,0845 & 1,5106 & & $3,7-4,6$ \\
\hline $\mathrm{M}$ & $\mathrm{P} 2_{1 / \mathrm{a}}$ & Monoclínico & 1,0877 & 1,0854 & 1,5135 & $B=90,1$ & $4,6-5,7$ \\
\hline
\end{tabular}


Uma proporção considerável de íons Al pode ser substituída principalmente por $\mathrm{Fe}^{3+}$ e $\mathrm{Si}^{4+}$ nessas estruturas (Taylor, 1997), atingindo limites de $2 \%$ em peso para a $\mathrm{SiO}_{2}$ e $3-4 \%$ em peso para o $\mathrm{Fe}_{2} \mathrm{O}_{3}$ em condições de equilíbrio (Lee at al., 1982 in Taylor, 1997). Maiores teores podem ser atingidos em condições metaestáveis. A literatura contém muitas referências sobre a fórmula $\mathrm{NC}_{8} \mathrm{~A}_{3}\left(\mathrm{~N}=\mathrm{Na}_{2} \mathrm{O}\right)$ supondo níveis de substituição de $7,6 \%$ de $\mathrm{Na}_{2} \mathrm{O}$, o que não poderá ser atingido apenas substituindo-se o $\mathrm{Na}^{2+}$. Contudo, na presença de Si o limite para a incorporação do sódio é próximo desse valor (Takeuchi et al., 1980 in Taylor, 1997).

Além do sódio, o aluminato pode incorporar íons potássio, porém apenas em condições de resfriamento rápido e, portanto, fora das condições de equilíbrio. Maki (1973) considera que a presença de Si na fase líquida do clínquer favorece as condições de super resfriamento e a formação de $C_{3} A$ nas formas ortorrômbica e monoclínica em condições de não equilíbrio.

No clínquer portland industrial podem ser encontradas as formas cúbica e ortorrômbica do aluminato cálcico ou a mistura de ambas. A forma monoclínica não foi observada. A forma ortorrômbica, também designada de prismática, só aparece quando os teores expressivos de álcalis estão disponíveis. Na presença de enxofre, os álcalis, ao invés de serem incorporados pelos aluminatos dão origem aos sulfatos alcalinos. No entanto, sua formação parece ser favorecida pelo resfriamento rápido e por uma composição rica em aluminatos.

Quando observados ao microscópio óptico, os cristais de $C_{3} A$ só podem ser identificados em clínqueres resfriados de modo mais lento, de modo que esses cristais possam se desenvolver e diferenciar-se da ferrita ( $C_{4} A F$ ) (Figura 25). Nos clínqueres modernos com frequência 0 resfriamento é mais eficiente, realizado por um resfriador de grelhas. Portanto, o $C_{3} A$ encontra-se normalmente mal formado e inter crescido com o $\mathrm{C}_{4} \mathrm{AF}$ (Figura 26).

Os cristais de $\mathrm{C}_{3} \mathrm{~A}$ ortorrômbicos bem cristalizados exibem forma de ripas normalmente geminadas (Figura 25); já quando o $C_{3} A$ está sob a forma cúbica os cristais tendem a ser equidimensionais. Kihara et al. (1990) comenta que a observação ao microscópio do grau de cristalização do $\mathrm{C}_{3} \mathrm{~A}$ e de sua forma pode fornecer informações acerca da eficiência do segundo resfriamento do clínquer, realizado no resfriador industrial $\left(1250^{\circ} \mathrm{C}\right.$ a $\left.200^{\circ} \mathrm{C}\right)$.

No entanto, quando o clínquer é resfriado muito rapidamente, os cristais de $C_{3} A$ são tão pequenos e mal formados que não podem ser observados ao microscópio ótico. Gobbo et al. (2003) utilizam a difratometria de raios $X$ com método de Rietveld para fazer a distinção e identificação dos "poliformos" de aluminatos cálcicos em amostras de cimentos industriais cinzas e brancos.

O aluminato cálcico é a fase mais reativa do clínquer e, em conjunto com o gesso, determina o tempo de pega do cimento, parâmetro essencial para que se possa dar forma e a aplicação adequada dos concretos e argamassas. Nesse sentido, deve-se considerar que a reatividade do $\mathrm{C}_{3} \mathrm{~A}$ é influenciada pelo seu grau de cristalização e pela incorporação de álcalis, conforme discutido por Kihara et al. (1990), e desse modo o $\mathrm{C}_{3} \mathrm{~A}$ bem formado seria mais reativo que o $\mathrm{C}_{3} \mathrm{~A}$ microcristalino obtido no resfriamento muito rápido, do mesmo modo, a forma cúbica seria mais reativa que as formas ortorrômbicas e monoclínicas. 


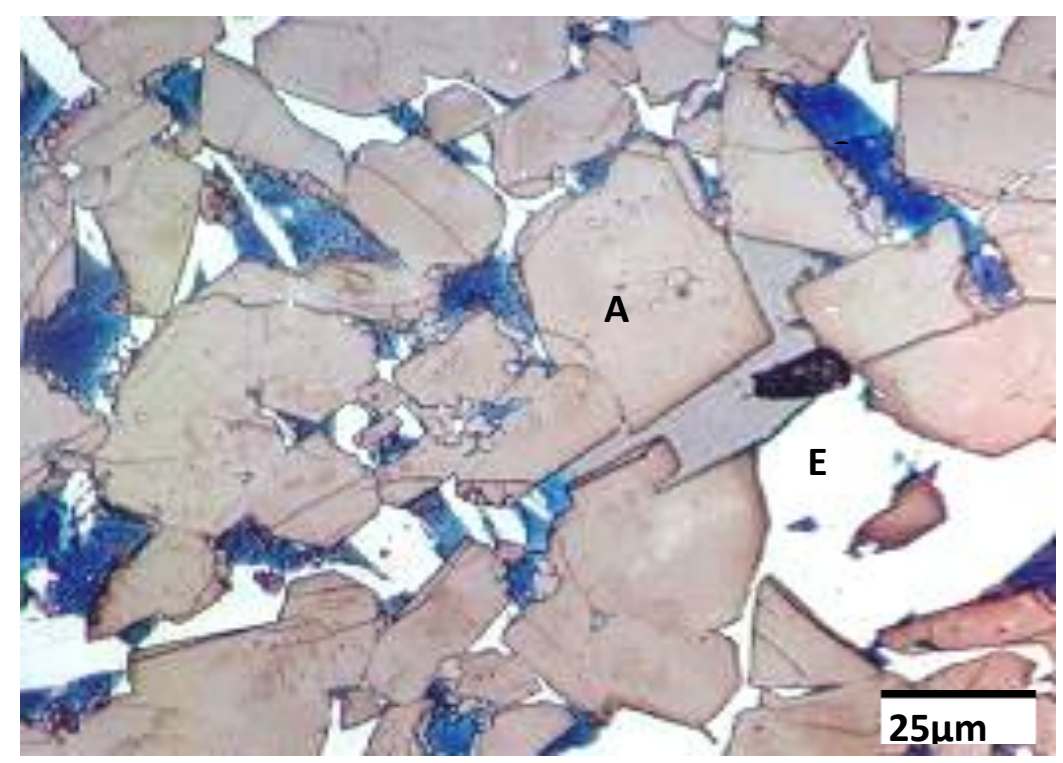

Figura 25 - Detalhe da fase intersticial do clínquer mostrando cristais ortorrômbicos de $C_{3} A$ (C) bem formados. $\mathrm{E}=\mathrm{C}_{4} \mathrm{AF}$ e $\mathrm{A}=\mathrm{alita}$

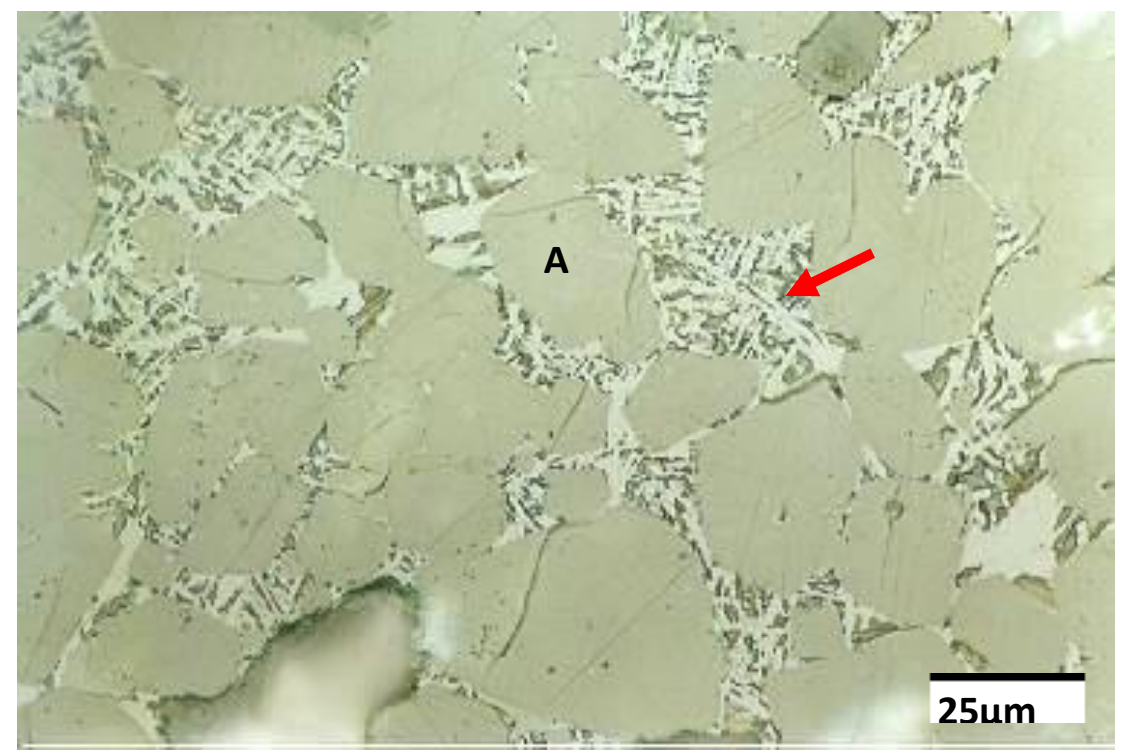

Figura 26 - Detalhe da fase intersticial do clínquer mostrando cristais mal desenvolvidos de $C_{3} A$ (seta) resultantes de um resfriamento classificado como normal. $A=$ alita

Na Figura 27 se observa a cinética de hidratação do $C_{3} A$ com e sem gesso. No primeiro caso, sem gesso, a velocidade de hidratação é alta. No entanto, com a adição de gesso, chamado de regulador de tempo de pega, essa diminui consideravelmente. 


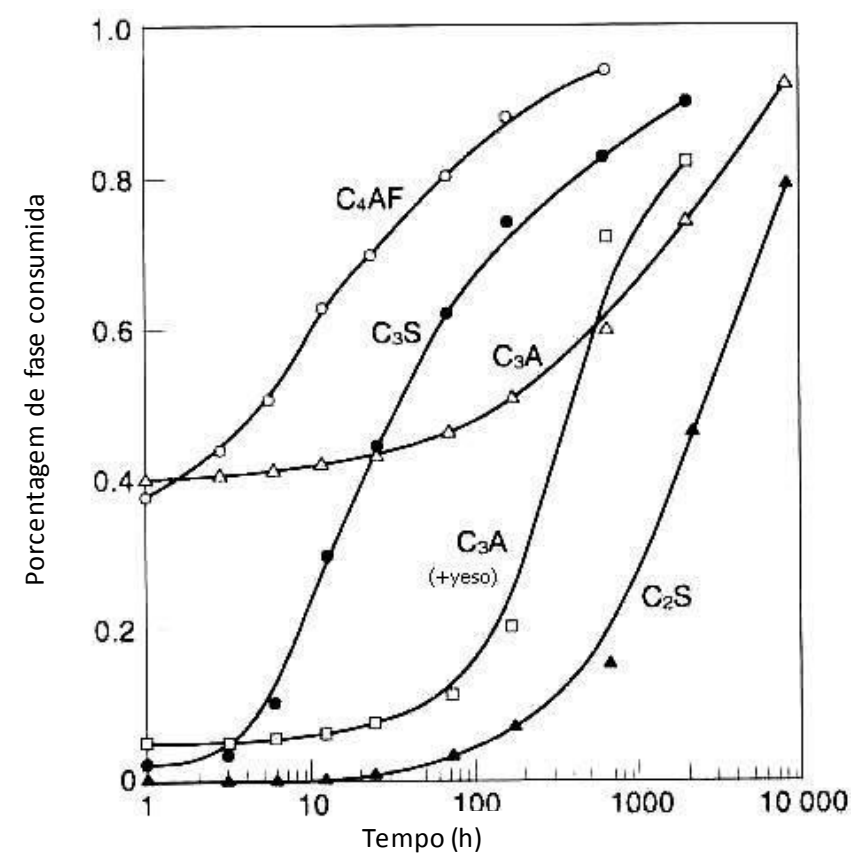

Figura 27 - Cinética de hidratação típica de pastas de fases puras do clínquer a temperatura ambiente. 0 $C_{3} A$ é representado com e sem gesso. (Odler, 1998 in Lea, 1998).

\subsection{Ferrita ( $\left.C_{4} A F\right)$}

Colville et al. (1972) descrevem como uma das principais fases da ferrita encontrada no clínquer portland, a brownmellerita. Mineral de composição similar ao $C_{4} A F$, mas que pode ser encontrado na natureza de forma rara.

$O C_{4} A F$ é um membro intermediário da série $\mathrm{Ca}_{2}\left(\mathrm{Al}_{\mathrm{x}} \mathrm{Fe}_{\mathrm{x}-1}\right)_{2} \mathrm{O}_{5}$, na qual $\mathrm{x}$ pode variar de 0 a $0,7.0$ $\mathrm{C}_{2} \mathrm{~A}$ é um membro extremo para $\mathrm{x}=1$, enquanto o outro extremo seria representado por $\mathrm{Ca}_{2} \mathrm{Fe}_{2} \mathrm{O}_{5}$. Essa série não é isoestrutural e uma mudança de grupo espacial é encontrada para $x=0,33$. A Tabela 8 (modificada de Taylor, 1997) apresenta os dados cristalográficos para várias composições.

Tabela 8 - Modificações da estrutura da ferrita $\left(C_{4} A F\right)$ - fórmula geral de $\mathrm{Ca}_{2}\left(\mathrm{Al}_{\mathrm{x}} \mathrm{Fe}_{1-\mathrm{x}}\right)_{2} \mathrm{O}_{5}$

\begin{tabular}{|c|c|c|c|c|c|c|}
\hline \multirow{2}{*}{$\begin{array}{c}\text { Valores de } \\
\qquad x\end{array}$} & \multirow{2}{*}{$\begin{array}{c}\text { Grupo } \\
\text { Espacial }\end{array}$} & \multirow{2}{*}{$\begin{array}{l}\text { Sistema } \\
\text { cristalino }\end{array}$} & \multicolumn{3}{|c|}{ Parâmetros de Cela Unitária } & \multirow[t]{2}{*}{ Referência } \\
\hline & & & $\mathrm{a}(\AA \AA)$ & $b(\AA)$ & $c(\AA)$ & \\
\hline 0 & Pcmn & Ortorrômbico & 0,5598 & 1,4769 & 0,5453 & Beggren, 1971(*) \\
\hline 0,28 & $\mathrm{Ibm} 2$ & Ortorrômbico & 0,5588 & 1,461 & 0,538 & Colville et al., 1971 \\
\hline 0,36 & $\mathrm{lbm} 2$ & Ortorrômbico & 0,5583 & 1,458 & 0,5374 & Colville et al., 1971 \\
\hline 0,5 & $\mathrm{Ibm} 2$ & Ortorrômbico & 0,5567 & 1,4521 & 0,5349 & Colville et al., 1972 \\
\hline 1 & Ibm2(?) & Ortorrômbico & 0,5410 & 1,445 & 0,523 & Aggarwal et al., $1971\left(^{*}\right)$ \\
\hline
\end{tabular}

$(*)$ in Taylor 1997

A estrutura do $\mathrm{C}_{4} \mathrm{AF}$ é similar à da perovsquita, com substituição do Ti por $\mathrm{Al}$ e $\mathrm{Fe}$, com omissão de átomos de oxigênio, o que faz com que metade dos octaedros na perovsquita seja trocada por 
uma cadeia de tetraedros. Dessa maneira, a composição empírica poderia ser escrita $\mathrm{Ca}_{2} \mathrm{M}_{2} \mathrm{~T}_{2} \mathrm{O}_{5}$, na qual M e T representariam os cátions octaédricos e tetraédricos.

Em muitos clínqueres, o $\mathrm{C}_{4} \mathrm{AF}$ está misturado com o $\mathrm{C}_{3} \mathrm{~A}$ devido à similaridade dos parâmetros de cela e possível intercrescimento. Este fato dificulta a realização de microanálises por microssonda ou por microscopia eletrônica, de maneira que as composições químicas apresentadas na literatura diferem significativamente (Taylor, 1997). A composição típica da ferrita difere bastante do $\mathrm{C}_{4} \mathrm{AF}$ possuindo até $10 \%$ de íons substituintes e muito menos íons Fe, podendo ser escrita como $\mathrm{Ca}_{2} \mathrm{AlFe}_{0,6} \mathrm{Mg}_{0,2} \mathrm{Si}_{0,15} \mathrm{Ti}_{0,05} \mathrm{O}_{5}$.

\subsection{Outros constituintes - cal livre, periclásio e sulfatos alcalinos.}

A cal livre, o periclásio e os sulfatos alcalinos são considerados constituintes secundários do clínquer portland, porém, sua presença pode apresentar reflexos no comportamento reológico e desempenho do cimento e, por conta disso serão discutidos nesse trabalho.

A cal livre é um elemento residual do processo de fabricação, que se cristaliza a partir do CaO que não reagiu com a sílica ou alumínio para a formação dos componentes principais. A cal livre é normalmente encontrada em teores que variam de 0,5 a 2,0\% em peso, podendo atingir em alguns clínqueres industriais teores de até $6 \%$. Nesses casos, costuma-se atribuir seu conteúdo elevado a algum problema de fabricação. De fato, o teor de cal livre no clínquer tem sido utilizado como um importante parâmetro de avaliação da eficiência do processo de clinquerização (Kihara, 1990).

No clínquer portland, a cal livre pode ocorrer na forma de cristais arredondados isolados ou agrupados em zonas regulares ou irregulares (Figura 28). O CaO normalmente se cristaliza no sistema cúbico e os cristais apresentam densidade de $3,30 \mathrm{~g} / \mathrm{cm}^{3}$. O aparecimento de cristais em zonas normalmente não é um aspecto benéfico. Zonas de cal livre que possuam formas regulares bem delimitadas podem ser advindas da presença de grãos grossos de carbonato na matériaprima (Campell, 1999) (grãos de dimensões superiores a $125 \mu \mathrm{m}$ ) que não reagiram por completo durante o processo de calcinação. Já quando as zonas não têm formas definidas e estão associadas a cristais dispersos, ou não possuem uma densidade homogênea de cristais de cal livre seu aparecimento poderá ser decorrente de um excesso de cálcio na composição da farinha crua (Fator de Saturação em Cal elevado).

Em teores elevados (acima de $3 \%$ em peso) a cal livre afeta negativamente a evolução de resistência mecânica, aumenta o calor de hidratação e pode causar sérios problemas de expansibilidade, já que sua transformação em $\mathrm{Ca}(\mathrm{OH})_{2}$ é acompanhada por um aumento de volume de mais de $95 \%$. 


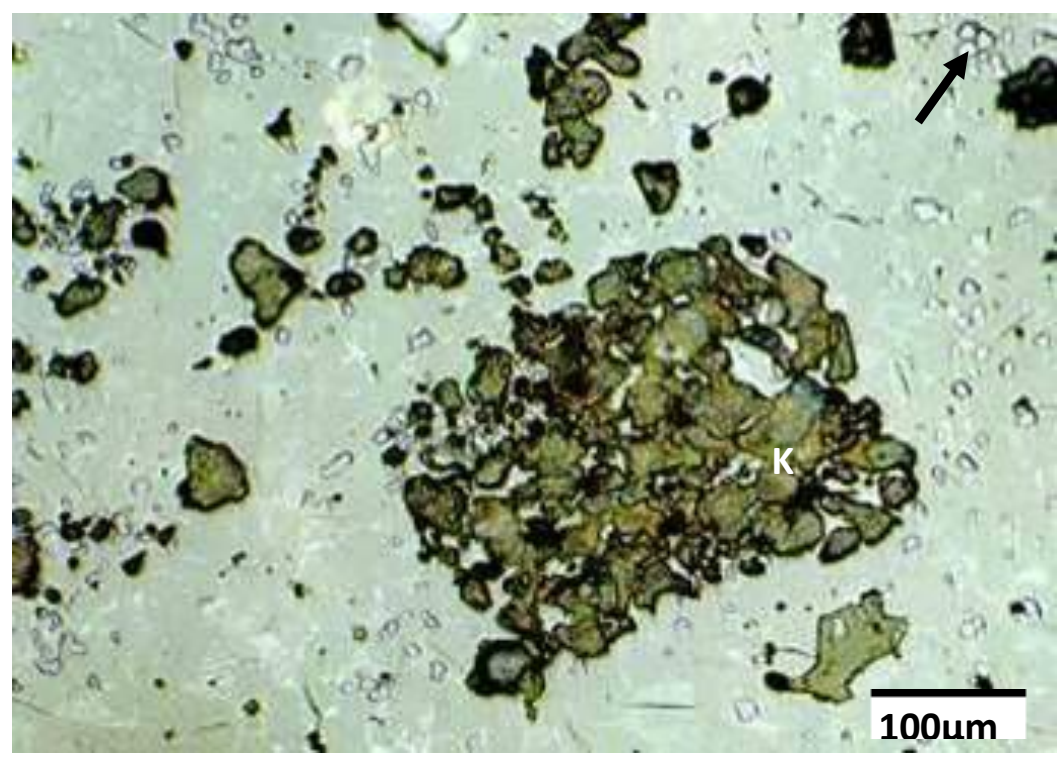

Figura 28 - Zona de cristais de cal livre (K) indicativa da presença de um grão grosso de calcário não absorvido. $\mathrm{P}=$ Cristais de periclásio

O periclásio ou $\mathrm{MgO}$ livre ocorre no clínquer quando o teor de $\mathrm{MgO}$ é superior a 1,5 ou 2\% em peso. Para conteúdos inferiores, o magnésio pode ser absorvido na forma de solução sólida pelos silicatos cálcicos. O MgO frequentemente está associado ao uso de calcários dolomíticos na composição das matérias-primas e, desse modo, não é raro encontramos o $\mathrm{MgO}$ associado à cal livre, principalmente na formas de zonas. O periclásio cristaliza-se no sistema cúbico (Fm3m) com uma densidade de $3,58 \mathrm{~g} / \mathrm{cm}^{3}$ (Kihara, 1990) e ocorre no clínquer na forma de cristais idiomórficos (cúbicos e hexagonais) ou xenomórficos (irregulares ou dendríticos) conforme as condições de resfriamento. Ao microscópio observa-se que os cristais, de dimensões de 5 a $10 \mu \mathrm{m}$, possuem coloração rósea e relevo alto (Figura 29). Esses cristais ocorrem normalmente dispersos no clínquer ou formando pequenas zonas.

Atribui-se à presença do periclásio no cimento problemas de expansão e fissuramento do concreto e argamassas. De fato, em condições de temperatura elevada (aproximadamente $80^{\circ} \mathrm{C}$ ) $\mathrm{O}$ periclásio pode reagir com a água dando origem à brucita, reação que provoca uma variação volumétrica de 2,2 vezes. Na Europa no fim do século XIX, quando se utilizavam cimentos com elevados teores de $\mathrm{MgO}$ (15 a 30\% em peso), foram registrado danos aos concretos. No entanto, Kihara (1990) mostra que os valores de correlação entre os teores de $\mathrm{MgO}$ e os valores de expansão em cura normal (10 anos) ou em autoclave são baixos e que a expansão é fortemente influenciada pelo teor de cal livre. No Brasil, o teor de MgO no cimento é limitado em 6,5\% e no resto do mundo os valores são similares. 


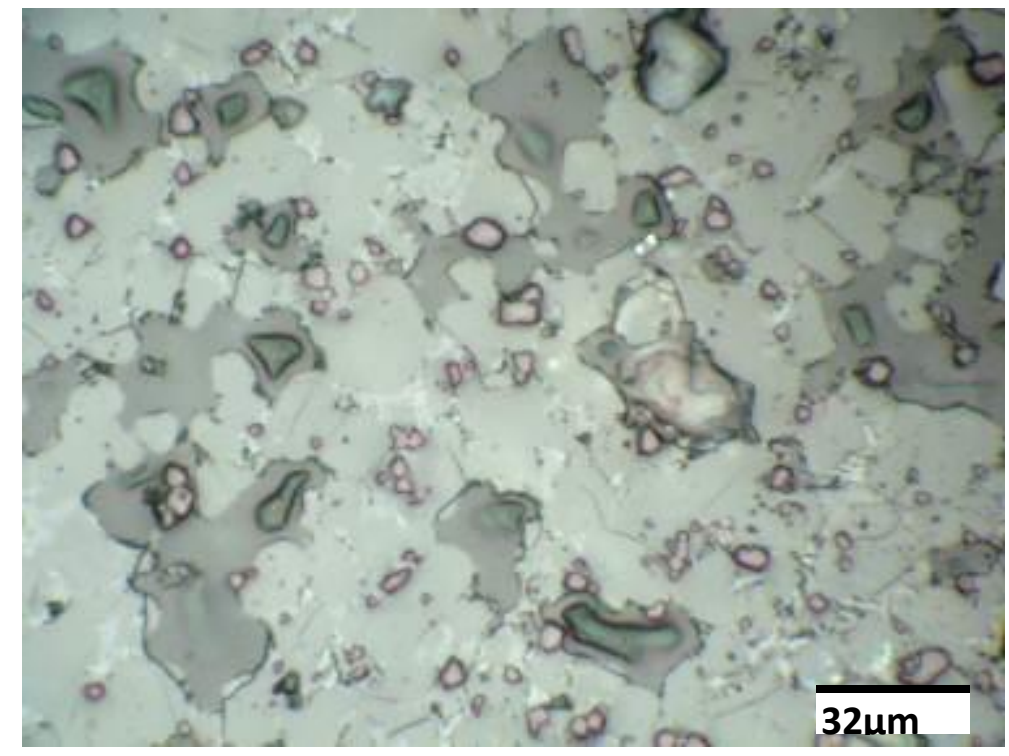

Figura 29-Cristais de periclásio (tons róseos) dispersos no clínquer

Os sulfatos alcalinos ocorrem no clínquer portland como resultado da incorporação do enxofre aportado ao clínquer por meio do combustível ou por meio das matérias-primas. $\mathrm{O}$ uso recente de coque de petróleo com teores de enxofre, expresso na forma de $\mathrm{SO}_{3}$, da ordem de 4 a $6 \%$ em peso, tem sido uma das principais fontes de enxofre nos clínqueres nacionais (Balanço Energético Nacional-BEN 2010) (Figura 10). O uso de coque de petróleo é reportado como uma importante fonte de enxofre também por outros autores (Horkoss et al., 2011; Wang, 2011).

Miller e Tang, (1996) e Horkoss et al. (2011) descrevem as formas de distribuição do enxofre em clínqueres americanos modernos e verificam a presença de sulfatos alcalinos nas seguintes formas mineralógicas:

- Arcanita - $\mathrm{K}_{2} \mathrm{SO}_{4}$

- Thenardita $-\mathrm{Na}_{2} \mathrm{SO}_{4}$

- Aphthitalita - série de soluções solidas $(\mathrm{K}, \mathrm{Na})_{3} \mathrm{Na}\left(\mathrm{SO}_{4}\right)_{2}$

- Calcio Langbeinita $-\mathrm{K}_{2} \mathrm{Ca}_{2}\left(\mathrm{SO}_{4}\right)_{3}$

- Anidrita $-\mathrm{CaSO}_{4}$

A presença de anidrita $\left(\mathrm{CaSO}_{4}\right)$, embora controversa, é descrita na literatura e considerada rara na composição dos clínqueres (Horkoss et al., 2011). A anidrita se forma quando o conteúdo de enxofre é maior do que poderia ser combinado na forma de sulfatos alcalinos ou ser incorporado pelas fases silicáticas.

Os sulfatos alcalinos são normalmente detectados por difratometria de raios $\mathrm{X}$ a partir do resíduo insolúvel do ataque de soluções de ácido salicílico em metanol, que provoca a dissolução dos silicatos cálcicos e a concentração das fases minoritárias. 


\section{ELEMENTOS MENORES NO CLÍNQUER PORTLAND}

\subsection{Conceitos gerais}

Bhatty (1995) define como elementos menores aqueles presentes no clínquer em teores $<1 \%$ em peso, enquanto os elementos traços ocorrem em teores $<0,02 \%$ em peso. $O$ autor classifica como elementos secundários, com base no Rompps Chemie-Lexicon (1987 in Bhatty, 1995), aqueles presentes em teores de 0,15 a 5\% em peso, incluindo nessa categoria: sódio, potássio, enxofre e magnésio.

Herfort et al. (2010) consideram como elementos menores aqueles que ocorrem em teores insuficientes para formar fases cristalinas individuais e estão presentes na forma de soluções sólidas nos componentes principais. Sorrentino (2011) concorda com essa definição e comenta que as duas principais técnicas de avaliação dos efeitos dos elementos menores no clínquer são o estudo de clínqueres industriais até o limite imposto pelas técnicas analíticas e a síntese laboratorial de clínqueres contendo quantidades controladas do elemento em estudo.

A Tabela 9 apresenta as concentrações médias dos elementos menores presentes no clínquer portland apresentadas por Moir e Glasser (1992).

Tabela 9- Concentração média dos elementos menores e traços típicos encontrados no clínquer (Moir e Glasser, 1992)

\begin{tabular}{l|c}
\hline Elementos Menores & Concentração (ppm) \\
\hline $\mathrm{Mg}$ & 8900 \\
$\mathrm{~K}$ & 6100 \\
$\mathrm{~S}$ & 3200 \\
$\mathrm{Na}$ & 1200 \\
$\mathrm{Ti}$ & 1600 \\
$\mathrm{Mn}$ & 420 \\
$\mathrm{P}$ & 440 \\
$\mathrm{Sr}$ & 590 \\
$\mathrm{Zn}$ & 96 \\
$\mathrm{Cr}$ & 70 \\
$\mathrm{~V}$ & 56 \\
$\mathrm{Cl}$ & 90 \\
$\mathrm{As}$ & 42 \\
$\mathrm{Cu}$ & 44 \\
$\mathrm{~Pb}$ & 15 \\
$\mathrm{Cd}$ & 0,5 \\
$\mathrm{Tl}$ & 0,3 \\
\hline
\end{tabular}


As principais fontes de elementos menores no clínquer são as matérias-primas além de eventuais corretivos utilizados no processo de fabricação do clínquer portland. A Tabela 10 apresenta os teores médios de alguns elementos menores presentes em calcários e argilas utilizados como matéria-prima [Sprung (1985); Weisweiler e Krcmar (1989) in Bhatty (1995)].

\begin{tabular}{c|cc}
\hline \multicolumn{3}{c}{$\begin{array}{c}\text { Tabela } 10 \text { - Concentração média de elementos menores em calcários e argilas } \\
\text { (Sprung, 1598 in Bhatty, 1995) }\end{array}$} \\
\hline Elementos menores & Calcário (ppm) & Argila (ppm) \\
\hline As & $0,2-12$ & $13-23$ \\
$\mathrm{Be}$ & 0,5 & 3 \\
$\mathrm{Cd}$ & $0,035-0.1$ & $0,016-0,3$ \\
$\mathrm{Cr}$ & $1,2-16$ & $90-109$ \\
$\mathrm{~Pb}$ & $0,4-13$ & $13-22$ \\
$\mathrm{Hg}$ & 0,03 & 0,45 \\
$\mathrm{Ni}$ & $1,5-7,5$ & $67-71$ \\
$\mathrm{Se}$ & 0,19 & 0,5 \\
$\mathrm{Ag}$ & $\mathrm{n} \cdot \mathrm{a} \cdot{ }^{*}$ & 0,07 \\
$\mathrm{Tl}$ & $0,05-0,5$ & $0,7-1,6$ \\
$\mathrm{~V}$ & $10-80$ & $98-170$ \\
$\mathrm{Zn}$ & $22-24$ & $59-115$ \\
$\mathrm{Cl}$ & $50-240$ & $15-450$ \\
$\mathrm{~F}$ & $100-940$ & $300-990$ \\
$\mathrm{Br}$ & 5,9 & $1-58$ \\
$\mathrm{I}$ & $0,25-0,75$ & $0,2-2,2$ \\
\hline
\end{tabular}

Os combustíveis, tradicionais e alternativos, também constituem uma fonte importante de elementos menores. Tradicionalmente, a indústria de cimento faz uso do carvão mineral como combustível principal.

No entanto, no Brasil a matriz energética das plantas de cimento é constituída principalmente por coque de petróleo, com participação inferior de moinha de carvão e óleo combustível, conforme discutido no item 3.3 Combustíveis. O coque de petróleo, que representa aproximadamente 75\% em peso do combustível utilizado pela indústria, aporta ao clínquer quantidades significativas de enxofre, vanádio e níquel (Tabela 11).

Os elementos menores podem atuar na formação das fases do clínquer de três diferentes formas (Moir e Glasser 1992):

- como fundentes - diminuem as temperaturas de formação da fase líquida, modificam a viscosidade do líquido, modificam a tensão superficial e, consequentemente, a morfologia dos cristais;

- modificando a relação entre as fases - as soluções sólidas podem modificar a estabilidade termodinâmica entre os minerais de clínquer;

- alterando a atividade hidráulica - a reatividade dos minerais de clínquer pode ser alterada pela presença das soluções sólidas e/ou pelos efeitos na simetria dos cristais (polimorfismo). 
Tabela 11 - Concentração média de elementos menores e traços em combustíveis (modificada de (Sprung, 1985; Weisweiler e Krcmar, 1989 in Bhatty, 1995)

\begin{tabular}{c|ccc}
\hline Elementos menores & Carvão (ppm) & Óleos Usados (ppm) & $\begin{array}{c}\text { Coque de Petróleo } \\
(\mathrm{ppm})\end{array}$ \\
\hline $\mathrm{Sb}$ & 1,19 & n.d. & 0,043 \\
$\mathrm{As}$ & $9-50$ & $<0,01-100$ & 0,6 \\
$\mathrm{Ba}$ & 24,5 & $0-3906$ & 8,4 \\
$\mathrm{Be}$ & 2,27 & n.d. & n.d. \\
$\mathrm{Cd}$ & $0,1-10$ & 4 & n.d. \\
$\mathrm{Cr}$ & $5-80$ & $<5-50$ & 11,0 \\
$\mathrm{~Pb}$ & $11-270$ & $10-21700$ & 8,7 \\
$\mathrm{Hg}$ & 0,27 & n.d. & n.d. \\
$\mathrm{Ni}$ & $20-80$ & $3-30$ & 208,0 \\
$\mathrm{Se}$ & 3,56 & n.d. & 0,1 \\
$\mathrm{Ag}$ & 0,06 & n.d. & n.d. \\
$\mathrm{Tl}$ & $0,2-4$ & $<0,02$ & 0,1 \\
$\mathrm{~V}$ & $30-50$ & $240-3000$ & 778,0 \\
$\mathrm{Zn}$ & $16-220$ & n.d. & n.d. \\
$\mathrm{Sr}$ & n.d. & n.d. & 4,34 \\
$\mathrm{Cl}$ & $100-2800$ & $10-2200$ & n.d. \\
$\mathrm{F}$ & $50-370$ & n.d. & n.d. \\
$\mathrm{Br}$ & $7-11$ & n.d. & n.d. \\
$\mathrm{I}$ & $0,8-11,2$ & n.d. & n.d. \\
\hline & & &
\end{tabular}

Apesar da tendência geral de diminuição da temperatura de formação da fase líquida com a introdução de elementos menores, as modificações na viscosidade e na tensão superficial são aspectos mais complexos, que foram estudados por Timashev (1980). Íons fortemente eletropositivos, como $\circ \mathrm{K}^{+}$e $\circ \mathrm{Na}^{+}$, aumentam a viscosidade, enquanto aqueles fortemente eletronegativos, como $\mathrm{Cl}^{-}$e $\mathrm{F}^{-}$, a diminuem. A tensão superficial tende a aumentar com o aumento da eletronegatividade dos elementos do chamado bloco $S$ (alcalinos e alcalinos terrosos exemplo: $\mathrm{Na}, \mathrm{K}, \mathrm{Mg}, \mathrm{Ca}, \mathrm{Sr}, \mathrm{Ba}$ ) e diminuir com o aumento da eletronegatividade dos elementos do chamado bloco $\mathrm{P}$ (os mais importantes: flúor, alumínio, silício, fósforo, enxofre, cloro, entre outros). A viscosidade do líquido é muito importante e influencia fortemente a taxa de dissolução do $\mathrm{CaO}$ e $\mathrm{C}_{2} \mathrm{~S}$ na fase liquida do clínquer e a taxa de difusão do $\mathrm{Ca}^{2+}, \mathrm{O}^{2-}$ e $\mathrm{SiO}_{4}{ }^{4-}$, fatores que favorecem a formação do $\mathrm{C}_{3} \mathrm{~S}$. A tensão superficial é importante por controlar a "molhagem" da superfície dos sólidos que estão reagindo e, em particular, para controlar a penetração do líquido nos poros das partículas de CaO criadas pela descarbonatação (Moir \& Glasser, 1992).

A atividade hidráulica é afetada pelos elementos menores pela introdução de defeitos nos cristais (causados pelas soluções sólidas), estabilização de polimorfos de mais alta temperatura e pela formação de recobrimentos por sais insolúveis nas partículas de cimento durante a hidratação.

Por sua vez, a incorporação de elementos menores nas fases silicáticas, que condiciona o conteúdo de alita e belita, está relacionada à carga e tamanho do cátion, que controla qual o sítio 
(tetraédrico ou octaédrico) a ser ocupado na estrutura cristalina (Sorrentino, 2011). Nesse sentido, Herfort et al. (2010) comentam que o conteúdo real de alita e belita em clínqueres é governado pela razão de sítios tetraédricos e octaédricos, 3:1 e 2:1 respectivamente, ao invés da simples relação $\mathrm{CaO}$ e $\mathrm{SiO}_{2}$ dada por Bogue. Enxofre $\left(\mathrm{S}^{6+}\right)$ e fósforo $\left(\mathrm{P}^{5+}\right)$ substituem o silício favorecendo a cristalização da belita em detrimento da alita, podendo aumentar o conteúdo de belita em 10 a $15 \%$ em peso.

\subsection{Elementos menores selecionados}

\subsubsection{Fósforo}

O fósforo é um elemento químico não metal que possui massa atômica 30,97u e número atômico 15. Sendo um elemento do chamado bloco $\mathrm{P}$ da tabela periódica, seu cátion poss ui valência 5 .

A entrada de fosfato no forno de clínquer se dá pela presença de apatita $\left[\mathrm{Ca}_{5}\left(\mathrm{PO}_{4}\right)_{3}(\mathrm{~F}, \mathrm{Cl}, \mathrm{OH})\right]$ nas matérias-primas, tais como calcários associados a fosforitos (Kihara, 1987), folhelhos negros (Halicz et al., 1983) ou carbonatos do rejeito do beneficiamento de minério de apatita em carbonatitos. Outra possível fonte de fosfato é o coprocessamento de farinha animal, resíduos de esgoto e de abatedouros em fornos de clínquer (Mueller et al., 2003). Os exemplos recentes de destruição em fornos de clínquer de carcaças de animais contaminados, como na "febre da vaca louca" na Europa e na gripe aviária na Ásia, também representam um aporte de fosfato, pois os ossos são compostos por fosfato hidratado de cálcio, que é incorporado à fração inorgânica das matérias-primas do clínquer, substituindo em parte o calcário.

Diversos autores já abordaram o tema do fosfato no cimento (Nurse, 1952; Butt et al.,1968; Akatsu et al., 1970; Halicz et al., 1983; Kihara, 1987; Mueller et al., 2003), mas não há um consenso a respeito dos níveis máximos de fosfato que podem ser incorporados ao clínquer sem comprometimento de sua qualidade final; aparentemente os valores mais usuais de $\mathrm{P}_{2} \mathrm{O}_{5}$ estão abaixo de $1 \%$ em peso. Kihara (1986) apresenta um levantamento do teor de fosfato em clínqueres brasileiros, com dados de 53 indústrias cimenteiras, indicando que mais de $95 \%$ dos clínqueres nacionais apresentam teores de $\mathrm{P}_{2} \mathrm{O}_{5}$ inferiores a $0,2 \%$ em peso.

Halicz et al. (1983) sintetizaram clínqueres com teores entre 1,9 e 5\% de fosfato, nos quais houve redução na proporção relativa de $\mathrm{C}_{3} \mathrm{~S}$ e aumento em $\mathrm{C}_{2} \mathrm{~S}$, com teores crescentes de fosfato. Dados de microssonda eletrônica indicam que os teores de fosfato em $\mathrm{C}_{2} \mathrm{~S}$ são até dez vezes mais elevados que em $\mathrm{C}_{3} \mathrm{~S}$. Esta diferença deve-se em parte ao não equilíbrio entre as fases cristalinas, conforme observado em experimentos complementares de aquecimento continuado das amostras. Halicz et al. (1983) consideram que o efeito do $\mathrm{P}_{2} \mathrm{O}_{5}$ é notado apenas a partir de teores acima de $1,0 \%$.

Nastac et al. (2007), em suas experiências de queima experimental de uma farinha industrial contendo teores crescentes de cinzas de farinha animal, concluem que até o teor de $0,4 \%$ em peso de $\mathrm{P}_{2} \mathrm{O}_{5}$ não ocorre alteração no teor de cal livre dos clínqueres experimentais produzidos. Já 
Staněk e Sulovský (2009) defendem que a partir de $0,7 \%$ em peso de $\mathrm{P}_{2} \mathrm{O}_{5}$ os teores de alita diminuem, com aumento dos teores de belita, e que quando o teor de $\mathrm{P}_{2} \mathrm{O}_{5}$ atinge $4,5 \%$ em peso, a formação de alita fica completamente inibida.

A partir de análises microscópicas dos clínqueres experimentais com teores de $\mathrm{P}_{2} \mathrm{O}_{5}$ de 0,25 e 3,0\% em peso, Staněk e Sulovský (2009), Figura 30 e Figura 31 respectivamente, demonstram a diminuição de núcleos de formação de alita ao redor das zonas de cal livre e o aumento da dimensão dos cristais, que passam de um máximo de $75-85 \mu \mathrm{m}$ a mais de $140 \mu \mathrm{m}$.

Segundo Diouri et al. [(1997) in Nastac et al. 2007), a substituição do $\mathrm{Si}^{4+}$ por $\mathrm{P}^{5+}$ nos sítios tetraédricos provoca a criação de uma vacância de cálcio para atingir o balanço de cargas. Nastac et al. (2007) apontam que a máxima substituição do fósforo seria de 2,3\% e 3,3\% em número de moles na alita e na belita, respectivamente. Os autores sugerem, com base na razão cátion/oxigênio dos cristais de belita, que as diferentes substituições poderiam criar vacâncias na posição do oxigênio, uma vez que a belita possui uma estrutura muito compacta para acomodar íons intersticiais, de modo que a introdução do fósforo provocaria uma contração da cela unitária.

Mueller et al. (2003) estudam o comportamento e formação dos polimorfos da belita $\left(C_{2} S\right)$ com a introdução de íons $\mathrm{P}_{2} \mathrm{O}_{5}$, utilizando fases puras. Por meio do diagrama da Figura 32 de Fix et al. (1969 in Mueller et al., 2003), é possível verificar que com relativamente baixos teores de $\mathrm{P}_{2} \mathrm{O}_{5}$ é possível estabilizar fases belíticas de alta temperatura $\left(\alpha-C_{2} S\right.$ e $\alpha^{\prime}-C_{2} S$ ) sendo que, provavelmente, o polimorfo $\alpha^{\prime}-C_{2} S$ seja o mais comumente observado. Em seus experimentos de refinamento das estruturas dos diferentes polimorfos por Rietveld, o $\alpha-C_{2} S$ mostrou pior ajuste em relação aos demais polimorfos, em função das distorções do retículo provocadas pela vacância do $\mathrm{Ca}^{2+}$ e por serem as ligações $\mathrm{P}$ - O menores que $\mathrm{Si}-\mathrm{O}$ (maior número atômico e menor raio do cátion). 


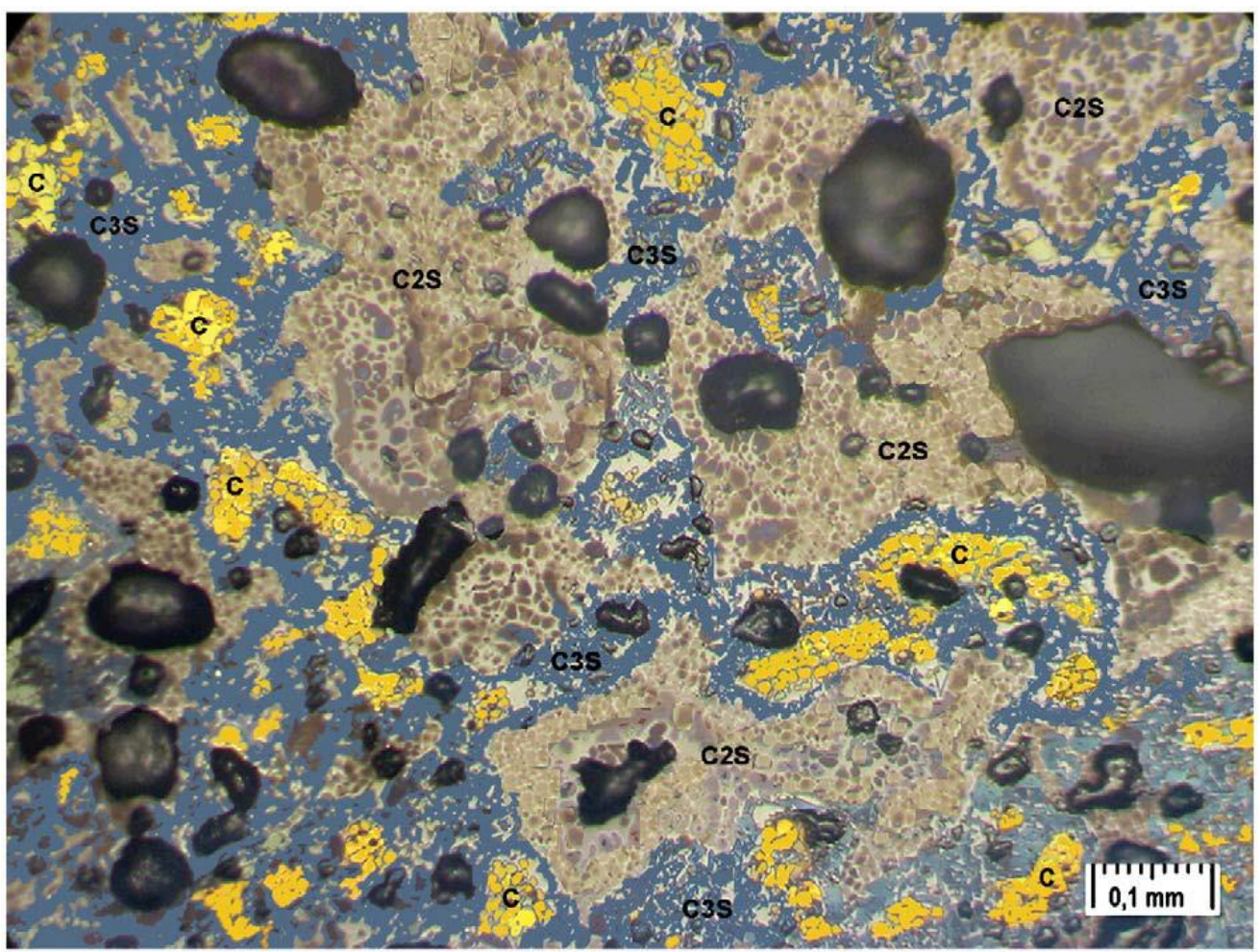

Figura 30 - Fotomicrografia do clínquer contendo 0,25\% $\mathrm{P}_{2} \mathrm{O}_{5}$ (Staněk e Sulovský 2009).Na imagem as fases indicadas são C3S -alita,C2S-belita e C-cal livre

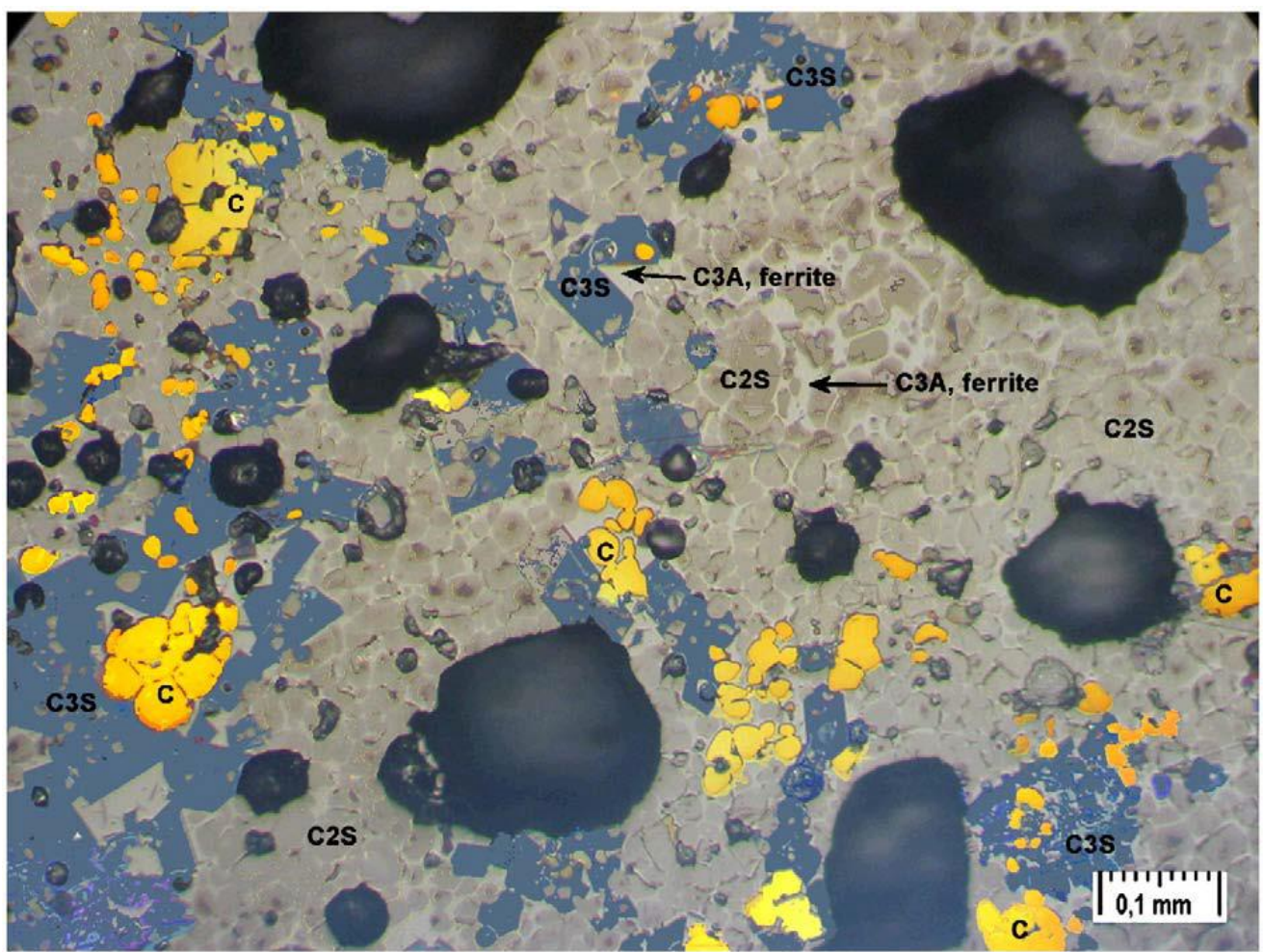

Figura 31 - Fotomicrografia do clínquer contendo $3 \% \mathrm{P}_{2} \mathrm{O}_{5}$ (Staněk e Sulovský 2009). Na imagem as fases indicadas são C3S -alita, C2S-belita, C3A, ferrita - aluminato e ferro aluminato associados e C-cal livre 


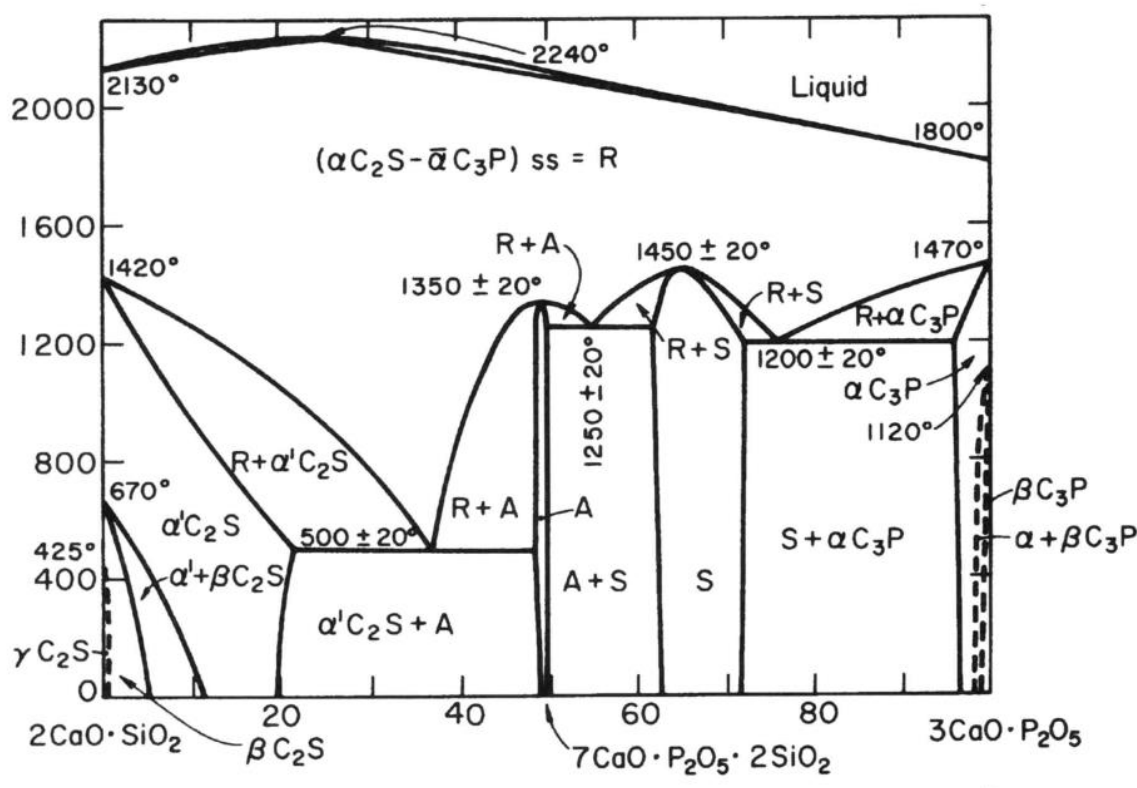

Wt $\%$

Figura 32 - Diagrama do sistema $2 \mathrm{CaO} \mathrm{SiO}_{2}-3 \mathrm{CaO} \mathrm{P}_{2} \mathrm{O}_{5}$ de FIX et al. (1969 in Mueller et al., 2003)

Kolovos et al. $(2001,2004)$ estudaram o efeito de diferentes formas de sulfato e fosfatos na aptidão à clinquerização de farinhas elaboradas a partir de compostos puros calcinados a $1450^{\circ} \mathrm{C}$. $\mathrm{O}$ fósforo, quando adicionado na forma de $\mathrm{CaHPO}_{4}$, tem um efeito positivo, diminuindo os teores de cal livre dos clínqueres obtidos; já quando presente nas formas de $\mathrm{Ca}\left(\mathrm{H}_{2} \mathrm{PO}_{4}\right)_{2}$ e $\mathrm{Ca}_{3}\left(\mathrm{PO}_{4}\right)_{2}, \mathrm{O}$ efeito negativo é bastante pronunciado, conforme mostrado na Figura 33. Esse fato pode ser atribuído às diferentes transformações dos compostos de fósforo durante o aquecimento. $O$ $\mathrm{CaHPO}_{4}$, quando aquecido, se transforma em $\mathrm{Ca}_{2} \mathrm{P}_{2} \mathrm{O}_{7}$, que se funde $1280^{\circ} \mathrm{C}$, misturando-se à fase intersticial do clínquer também fundida.

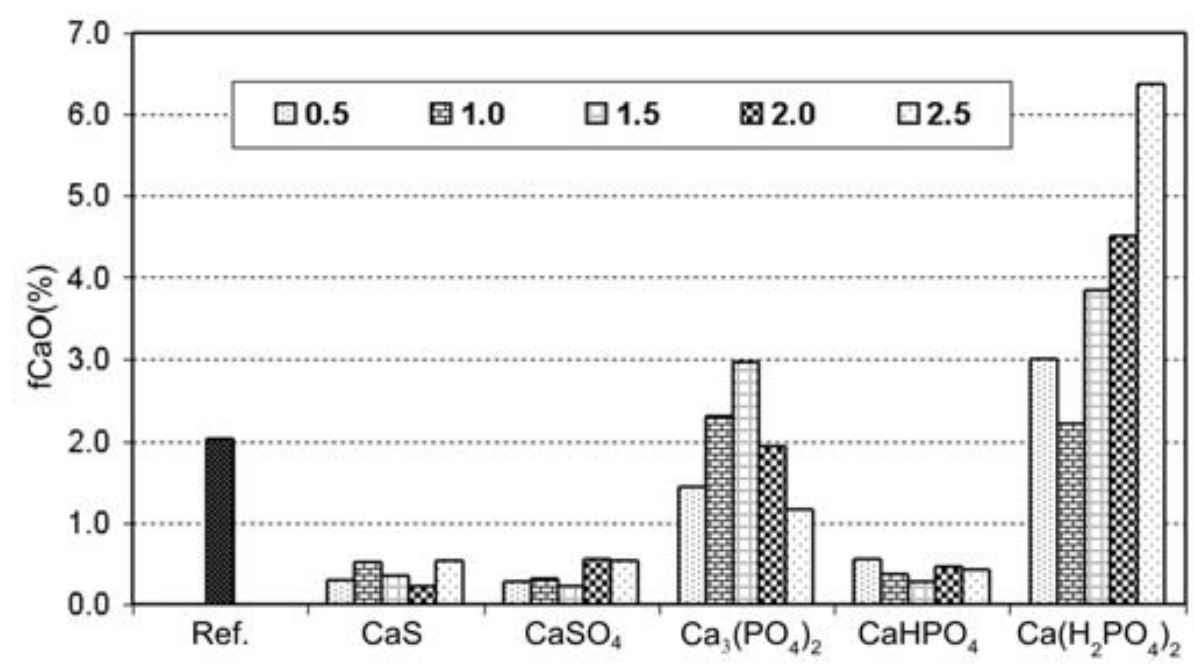

Figura 33 - Teores de cal livre em farinhas calcinadas a 1450ㄷ C dopadas com diversas formas iônicas de enxofre e fósforo Kolovos et al. (2004). 
Com o aumento dos teores de belita, em detrimento dos cristais de alita nos clínqueres, e o aumento da dimensão média desses últimos, o efeito mais comentado na literatura refere-se à diminuição das resistências mecânicas a baixas idades. Coleman ${ }^{1}$ (in Moir e Glasser, 1992) demonstra adequadamente esse efeito por meio de ensaios de resistência mecânica com conteúdos crescentes de fósforo e álcalis (Figura 34). Nota-se a tendência geral de diminuição das resistências a partir de teores de $1 \%$ em peso. Esses efeitos podem ser compensados, em parte, pela presença de álcalis para idades de cura de 28 dias. 0 pequeno aumento das resistências aos 28 dias de cura para teores de $\mathrm{P}_{2} \mathrm{O}_{5}$, variando de 0,05 a $1 \%$ em peso, pode ser atribuído à estabilização do polimorfo $\alpha^{\prime}-C_{2} S$. Esse comportamento também foi registrado por Nastac et al. (2007) em seus experimentos.

A diminuição das resistências mecânicas pode ser também atribuída, em parte, à influência negativa dos fosfatos na taxa de dissolução da alita (silicato tricálcico), conforme defendido por Bénard et al. (2008).

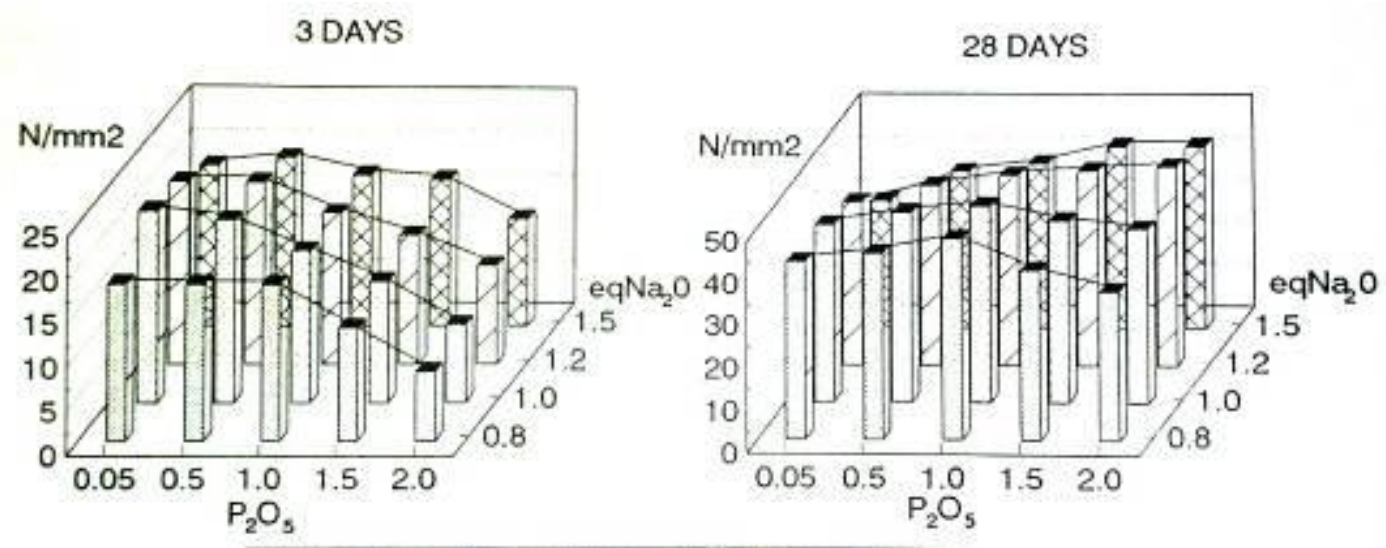

Figura 34 - Influência do $\mathrm{P}_{2} \mathrm{O}_{5}$ e álcalis no desenvolvimento de resistências Coleman ${ }^{1}$ (in Moir e Glasser, 1992)

\subsubsection{Enxofre}

O enxofre, à semelhança do fósforo, é um elemento químico classificado como não metal; possui massa atômica 32,0u e número atômico 16, sendo um elemento do bloco $\mathrm{P}$ da tabela periódica, o cátion mais oxidado possui valência 6 . A diferença entre os raios iônicos do enxofre $S^{+6}(0,26 \AA ̊)$ e do silício $\mathrm{Si}^{+4}(0.40 \AA ̊)$, para coordenações tetraédricas, determina a probabilidade de ocorrer a solução sólida do tipo substitucional nos minerais de clínquer, em particular na belita $\left(\mathrm{Ca}_{2}\left(\mathrm{Si}_{,} \mathrm{S} \mathrm{O}_{4}\right)\right.$. O enxofre pode ser inserido no processo de fabricação do clínquer por meio das matérias-primas

\footnotetext{
${ }^{1}$ Não publicado - relatório interno Bluecircle
} 
ou dos combustíveis (Goldmann et al.,1981). Quando introduzido como matéria-prima, o enxofre pode estar presente de modo "acidental", normalmente associado às rochas carbonáticas. Nessas rochas, o enxofre pode ocorrer na forma de sulfetos de ferro (pirita, marcassita etc.), chumbo (galena) ou zinco, ou mesmo na forma de sulfatos de cálcio (gipsita é o mais comum deles). Em algumas plantas de cimento, o enxofre é adicionado na matéria-prima como sulfatos de cálcio, em conjunto com compostos de flúor, como parte de uma estratégia de mineralização do clínquer.

Quando introduzido na forma de sulfetos, a temperatura elevada e a atmosfera oxidante do forno provocam a decomposição dos sulfetos em óxidos metálicos ( $\mathrm{Fe}_{2} \mathrm{O}_{3}$, por exemplo) e a formação de $\mathrm{SO}_{2}$ gasoso em temperaturas de 600 a $700^{\circ} \mathrm{C}$. O enxofre volatilizado na forma de $\mathrm{SO}_{2}$ pode ser eliminado nas emissões gasosas junto com o $\mathrm{CO}_{2}$, ou ainda pode formar ciclos de volatilização e se condensar nas partes frias do forno, formando "colagens" de composição sulfoalcalina que, em casos mais críticos, podem levar à obstrução do forno (Moir e Glasser, 1992).

A presença de enxofre no clínquer está relacionada ao uso de combustíveis fósseis nos processos de calcinação da farinha, principalmente o coque de petróleo, óleo combustível e carvão mineral (Goldmann et al., 1981). Nesses, o enxofre ocorre sob a forma de diversos compostos orgânicos e inorgânicos. O coque de petróleo, principal combustível da indústria brasileira de cimento, possui teores de enxofre expressos na forma de $\mathrm{SO}_{3}$ de 1 a 6\% em peso. Wang et al. (2011) comentam o uso intensivo de coque de petróleo como combustível e avaliam o efeito do aporte de $\mathrm{SO}_{3}$ na mineralogia de clínqueres industriais e em suas proprieda des físico mecânicas.

A disponibilidade de álcalis ( $\mathrm{Na}$ e K) na formulação da farinha ou do clínquer pode condicionar o aparecimento de sulfatos alcalinos. De acordo com Miller et al. (1996), as principais fases formadas no clínquer pela presença de enxofre e álcalis são: arcanita $\left(\mathrm{K}_{2} \mathrm{SO}_{4}\right)$, aphtitalita $\left[\mathrm{K}_{3} \mathrm{Na}\left(\mathrm{SO}_{4}\right)_{2}\right]$, cálcio-langbeinita $\left(2 \mathrm{CaSO}_{4} \cdot \mathrm{K}_{2} \mathrm{SO}_{4}\right)$, sulfoaluminato de cálcio $\left(4 \mathrm{CaO} \cdot 3 \mathrm{Al}_{2} \mathrm{O}_{3} \cdot \mathrm{SO}_{3}\right)$, sulfospurrita $\left[\mathrm{Ca}_{5}\left(\mathrm{SiO}_{4}\right)_{2} \cdot \mathrm{SO}_{4}\right]$. Não há um consenso entre os autores sobre a formação de compostos sulfatados no processo de clinquerização, em particular quanto à formação de anidrita em clínqueres com alto teor de enxofre. Diversos autores (Goldmann et al., 1981; Richartz, 1987; Strunge et al., 1985; Strunge, 1990) supõem que, com a deficiência em álcalis, o $\mathrm{SO}_{3}$ poderia reagir com $\mathrm{CaO}$, formando sulfatos alcalinos-cálcicos (como a cálcio-langbeinita) e, em casos extremos de ausência de álcalis, formar anidrita $\left(\mathrm{CaSO}_{4}\right)$. No entanto, Sprung (1985) acredita que o $\mathrm{SO}_{3}$ reagiria com $\mathrm{CaCO}_{3}$, proveniente do calcário da farinha, originando anidrita $+\mathrm{CO}_{2}$. Pliego-Cuervo et al. (1979b) apontam a imiscibilidade de dois líquidos à temperatura de clínquerização, um rico em sílica e outro constituído por sulfatos e $\mathrm{K}_{2} \mathrm{O}$, a partir do qual se cristalizariam os sulfatos alcalinos a temperatura inferiores a $850^{\circ} \mathrm{C}$. Dessa forma os sulfatos alcalinos estão dispostos no clínquer depositados nas paredes dos poros, ou depositados nas superfícies dos minerais de clínquer.

O enxofre pode ainda entrar em solução sólida nos silicatos (Goldmann et al., 1981; Richartz, 1987; Pliego-Cuervo et al., 1979a; Skalny et al., 1997, Miller et al., 1996). O aumento na dimensão dos cristais de alita devido à presença de enxofre no clínquer foi documentado por Timashev (1980), Sprung (1985), Strunge et al. (1985), Strunge et al. (1990), Tagnit-Hamou et al. (1990), 
Sprung (1993), Fortsch (2004) e Kolovos et al. (2004), que associaram este aumento a um decréscimo na proporção de belita. O crescimento da alita decorre da diminuição da sua taxa de nucleação, ou seja, menos núcleos cristalinos seriam formados e estes teriam um melhor desenvolvimento, gerando cristais maiores (Tagnit-Hamou et al., 1990). Strunge et al. (1985) observam uma variação dos cristais de alita de 0,05 para $0,150 \mathrm{~nm}$ quando o teor de $\mathrm{SO}_{3}$ passa de 0 para $2,6 \%$. A literatura aponta que essas mudanças texturais podem estar ligadas a alterações na viscosidade da fase líquida. Zhang \& Odler (1992) registram variações texturais em clínqueres com elevado conteúdo de $\mathrm{SO}_{3}$ (máximo de 3,93\%) sintetizados a partir de farinhas experimentais a $1300^{\circ} \mathrm{C}$, com o auxílio da adição de $0,5 \%$ de $\mathrm{CaF}_{2}$. Horkoss et al. (2011) apontam uma dificuldade de observar por microscopia cristais de $\mathrm{C}_{3} \mathrm{~A}$ em clínqueres contendo menos que $3,3 \%$ de $\mathrm{SO}_{3}$ e atribuem esse fato à presença de cristais muito pequenos e mal desenvolvidos (Strunge et al., 1985).

Horkoss et al. (2011) provam que o aumento do teor de $\mathrm{SO}_{3}$ provoca uma diminuição do conteúdo de $\mathrm{C}_{3} \mathrm{~A}$ em clínqueres comerciais, uma vez que parte do alumínio seria incorporado pelos silicatos cálcicos para balanceamento de cargas devido à substituição da sílica.

Herfort et al. (1997) investigam a distribuição do enxofre nos minerais de clínquer, em especial o nível de substituição do enxofre na forma de solução sólida na alita e na belita. Os autores mostram que a incorporação do enxofre se dá nos sítios tetraédricos em substituição ao silício e o balanceamento de cargas se faz pela incorporação concomitante de alumínio nos mesmos sítios, seguindo aproximadamente a equação: $3 \mathrm{Si}^{4+} \leftrightarrow \mathrm{s}^{6+}+2 \mathrm{Al}^{3+}$.

A estabilidade dos polimorfos das fases cristalinas do clínquer depende, em parte, de sua composição química (Tagnit-Hamou et al., 1990; Chaterjee, 1979; Maki et al., 1992). A alita possui seis polimorfos, sendo três triclínicos (TI, TII e TIII), dois monoclínicos (MI e MII) e um trigonalromboédrico $(R)$, dispostos nessa sequência do polimorfo de menor para o de maior temperatura (R). O polimorfo monoclínico M1 da alita seria estabilizado pela presença de $\mathrm{SO}_{3}$ (Maki et al., 1992). A forma romboédrica seria conseguida pela introdução de quantidades específicas dos chamados íons mineralizadores, $\mathrm{F}^{-}$e $\mathrm{SO}_{3}$, na matéria-prima. O processo de mineralização da alita se dá pela substituição da sílica por enxofre e alumínio nas posições tetraédricas, conforme exposto, facilitada pela ação do flúor. A mineralização do clínquer provocaria um aumento de mais de $10 \%$ nas resistências mecânicas do cimento, com benefícios adicionais relacionados à diminuição do consumo energético por tonelada de cimento produzido (Emanuelson et al., 2003; Herfor et al., 2010).

De maneira similar, o incremento do conteúdo de álcalis e $\mathrm{SO}_{3}$ estabilizariam a $\beta$-belita a baixa temperatura por meio da redução da temperatura da fase líquida (Tagnit-Hamou et al., 1990). Gobbo (2003), analisando a composição das diferentes fases cristalinas de clínquer industrial, encontrou os maiores teores em $\mathrm{SO}_{3}$ concentrados no $\mathrm{C}_{2} \mathrm{~S}$. O estudo foi realizado com clínqueres provenientes de fábricas de cimento que utilizaram coque de petróleo (petcoke) como combustível principal. 
A tendência de incorporação do enxofre nos cristais de belita, somada à introdução de álcalis, seriam as bases de obtenção do chamado clínquer belítico, que se vale da estabilização de polimorfos de belita de mais alta temperatura, $\alpha$-belita e $\alpha$-belita. A presença desses poliformos é confirmada por Morsli et al. (2007) por meio de seus estudos, utilizando análises quantitativas pelo método de Rietveld.

Com relação aos efeitos do enxofre no desempenho do cimento e concreto, é importante lembrar que os compostos de enxofre, principalmente a gipsita, são utilizados na composição do cimento como controladores da pega (resistência inicial da pasta) e ao mesmo tempo atuam como um catalizador da hidratação das fases silicáticas, em especial da alita. A presença de sulfatos alcalinos também pode cumprir esse papel, aumentando o tempo de pega do cimento. Regourd e Boikova (1992) afirmam que o enxofre presente nas fases do clínquer reduz o tempo de pega, enquanto o enxofre presente na forma de sulfatos alcalinos retardaria a pega do cimento.

De outro ponto de vista, seus efeitos na mineralogia do clínquer vão se refletir no comportamento do cimento; assim, na ausência de álcalis, o enxofre favorece a formação de belita em detrimento da alita, o que poderá reduzir a resistência às primeiras idades do cimento.

Horkoss et al. (2011) mostram que o aumento do $\mathrm{SO}_{3}$ em clínqueres com baixo conteúdo de álcalis reduz a quantidade de alita, a relação alita/belita e o teor de $\mathrm{C}_{3} \mathrm{~A}$, o que acarreta a diminuição das resistências mecânicas, mas melhora a resistência ao ataque por sulfatos dos cimentos.

A formação de etringita secundária (tardia), advinda do aporte externo de íons sulfatos ou de remobilizações internas de $\mathrm{SO}_{3}$, seria responsável por provocar o aparecimento de trincas e desagregação do concreto. Herford et al. (1997) concluem que as fases silicáticas ao se hidratarem liberariam enxofre e alumínio, mas que a razão $\mathrm{SO}_{3} / \mathrm{Al}_{2} \mathrm{O}_{3}$ não seria alta o suficiente para provocar a formação de etringita.

\subsubsection{Estrôncio}

O estrôncio é um elemento químico alcalino terroso, grupo IIA, possui massa atômica 87,6u e número atômico 38, sendo um elemento do chamado bloco $\mathrm{S}$ da tabela periódica e forma um cátion de valência 2 .

$\mathrm{O} \mathrm{Sr}^{2+}$ tem grande similaridade com o $\mathrm{Ca}^{2+}$, sendo preferencialmente incorporado na belita e inibindo a formação da alita, quando presente em excesso (superior a 4\%), favorecendo também a formação de cal livre (Batty, 1995).

Juel e Jøns (2001) corroboram as observações de Batty (1995) estudando clínqueres experimentais dopados com $\mathrm{MgO}$, SrO e $\mathrm{BaO}$. Eles concluem que a belita apresenta os maiores teores de SrO, enquanto a alita os mais baixos. Por meio de análises pelo método de Rietveld, observam mudanças nos parâmetros de cela unitária dos cristais de belita a partir de teores de incorporação de $4 \%$, apontando para uma alteração polimórfica de monclínico $\beta$ para $\alpha$.

Kolovos et al. (2005) examinaram clínqueres experimentais dopados com 2,5\% em peso de SrO ao 
microscópio eletrônico de varredura e identificaram alterações significativas na microtextura

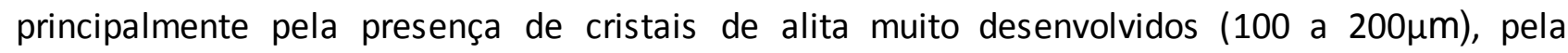
formação de grande quantidade de belitas em zonas, e pela coexistência de belita e cal livre.

Juel e Jøns (2001) e Bhatty et al. (2004) apontam a falta de trabalhos publicados sobre a influência do estrôncio no cimento. Provavelmente isto se deve ao fato deste elemento químico ocorrer tipicamente em teores $<100 \mathrm{ppm}$ nas matérias-primas tradicionais. No Brasil há apenas uma fábrica de cimento que apresenta clínqueres com teores de estrôncio da ordem de 0,8 a 1,0\% em peso. Nessa unidade, a presença de estrôncio no forno de clínquer se deve ao uso de carbonatitos como matéria-prima.

\section{MATERIAIS E MÉTODOS}

\subsection{Amostras}

As amostras de clínquer analisadas nesta pesquisa foram produzidas de modo experimental no Laboratório da Associação Brasileira de Cimento Portland. Os clínqueres experimentais foram produzidos em laboratório por meio da queima (calcinação a $1450^{\circ} \mathrm{C}$ ) em muflas de farinhas elaboradas a partir de substâncias cristalinas puras e de reagentes químicos, nível pureza analítica (PA), adquiridos no mercado nacional, conforme procedimento descrito em 6.2- Reagentes e Matérias-primas. Neste trabalho foram analisadas três séries de clínqueres experimentais confeccionados com teores variáveis e crescentes de estrôncio ( $\mathrm{Sr}$ ), fósforo $(\mathrm{P})$ e enxofre $(\mathrm{S})$. $\mathrm{Na}$ série de clínqueres produzidos com o fósforo buscou-se esse elemento em três diferentes fontes: (a) fosfato de cálcio sintético comercial, (b) apatita natural e (c) osso bovino.

A nomenclatura utilizada para a designação dos diversos materiais utilizados nessa pesquisa é constituída por duas partes: a primeira parte contem as iniciais do autor (Marcelo Pecchio) seguidas da designação genérica do material de tal modo que: RM=matéria-prima (raw material), $F A=f a r i n h a, C L=c l i ́ n q u e r$ experimental. A segunda parte do nome, precedida pelo hífen, se refere ao conteúdo específico, que no caso das matérias primas está relacionado ao tipo de matériaprima (carbonato, quartzo, etc.) e no caso das farinhas e dos clínqueres experimentais se refere ao teor e tipo de contaminante adicionado (FO-Fosfato sintético, AP-apatita, OS-osso, SR-carbonato de estrôncio e SX- gipsita). Exemplo MPCL-FO150 = clínquer dopado com 1,5\% em peso de fosfato sintético.

\subsection{Reagentes e Matérias-primas}

Os clínqueres experimentais foram elaborados a partir de reagentes puros parte deles adquiridos no mercado nacional e alguns elaborados a partir de substâncias cristalinas puras e individualizadas. Assim sendo, foram utilizados:

- Carbonatos de cálcio precipitado1 - marca Merck - lote 1.02066.1000 de 17/02/2005

- Carbonatos de cálcio precipitado2 - marca F. Maia - lote 38471 de 16/09/2009 
- Carbonato de estrôncio - marca Cinética - lote 14864 - 18/12/2008

- Hidróxido de alumínio - marca Dinâmica Química Contemporânea - lote 35044 de 08/2009

- Fosfato de cálcio Di básico anidro - marca Casa Americana - lote 15320 20/06/2009

- Minério de ferro

- Quartzo hialino moído

- Apatita moída

- Osso bovino

Os reagentes puros sintéticos, por serem muito finos, foram utilizados na granulometria na qual foram adquiridos. Os compostos naturais (minério de ferro, quartzo, apatita e osso) foram cominuídos em um moinho vibratório panelas marca Herzog, dotado de panela de carbeto de tungstênio. Depois, esses materiais foram moídos em almofariz de ágata até serem passantes na peneira de malha $45 \mu \mathrm{m}$ (peneira de 325 mesh).

Todos os materiais envolvidos na confecção das farinhas experimentais, reagentes ou substâncias puras, tiveram seus elementos maiores verificados e/ou determinados por análises químicas nos laboratórios da $A B C P$, utilizando as seguintes técnicas:

- Complexometria - $\mathrm{CaO}, \mathrm{MgO}, \mathrm{Al}_{2} \mathrm{O}_{3}$ e $\mathrm{Fe}_{2} \mathrm{O}_{3}$

- Gravimetria - $\mathrm{SiO}_{2}$

- Fotometria de chama - $\mathrm{Na}_{2} \mathrm{O}$ e $\mathrm{K}_{2} \mathrm{O}$

- Analisador LECO SC - $\mathrm{SO}_{3}$

- ICP - SrO

A avaliação da possível presença de elementos menores foi realizada por análises semiquantitativas por espectrometria de raios X. A Tabela 12 apresenta a composição química de todos os reagentes e a Anexo $A$ os elementos menores identificados por análises semiquantitativas por espectrometria de raios $X$.

\begin{tabular}{lccccccccccc}
\hline \multicolumn{10}{c}{ Tabela 12-Composição química das matérias-primas } \\
\hline $\begin{array}{l}\text { Óxidos } \\
\text { (\% em } \\
\text { peso) }\end{array}$ & $\begin{array}{c}\text { MPRM- } \\
\text { carbon1 }\end{array}$ & $\begin{array}{c}\text { MPRM- } \\
\text { carbon2 }\end{array}$ & $\begin{array}{l}\text { MPRM } \\
\text { carbon. } \\
\text { estrôncio }\end{array}$ & $\begin{array}{c}\text { MPRM- } \\
\text { quartzo }\end{array}$ & $\begin{array}{c}\text { MPRM- } \\
\mathrm{Al}(\mathrm{OH})_{3}\end{array}$ & $\begin{array}{c}\text { MPRM- } \\
\text { ferro }\end{array}$ & $\begin{array}{c}\text { MPRM- } \\
\text { fosfato }\end{array}$ & $\begin{array}{c}\text { MPRM- } \\
\text { apatita }\end{array}$ & $\begin{array}{c}\text { MPRM- } \\
\text { osso }\end{array}$ & $\begin{array}{c}\text { MPRM } \\
\text {-gesso }\end{array}$ \\
\hline $\mathrm{CaO}$ & 55,6 & 54,9 & 0,08 & 0,43 & 0,35 & 1,11 & 36,1 & 52,6 & 38,2 & 35,8 \\
$\mathrm{SiO}_{2}$ & 0,25 & 1,91 & 0,43 & 99,5 & 63,8 & 0,42 & 1,04 & 2,38 & 0,80 & - \\
$\mathrm{Al}_{2} \mathrm{O}_{3}$ & 0,00 & 0,33 & 0,07 & 0,15 & 26,8 & 1,22 & 0,20 & 0,74 & 0,00 & - \\
$\mathrm{Fe}_{2} \mathrm{O}_{3}$ & 0,00 & 0,00 & 0,02 & 0,35 & 1,45 & 96,2 & 0,00 & 0,00 & 0,00 & - \\
$\mathrm{MgO}$ & 1,18 & 2,12 & - & 0,00 & 0,00 & 0,16 & 0,57 & 1,13 & 1,02 & - \\
$\mathrm{SO}_{3}$ & - & - & - & 0,00 & 0,00 & 0,00 & - & - & 0,05 & 51,3 \\
$\mathrm{Na}_{2} \mathrm{O}$ & 0,01 & 0,01 & 0,03 & 0,0 & 0,21 & 0,03 & 0,05 & - & 0,67 & - \\
$\mathrm{K}_{2} \mathrm{O}$ & 0,18 & 0,18 & 0,04 & 0,01 & 2,10 & 0,04 & 0,04 & - & 0,01 & - \\
$\mathrm{P}_{2} \mathrm{O}_{5}$ & - & - & - & - & - & - & 44,7 & 38,8 & 23,7 & - \\
$\mathrm{SrO}$ & - & - & 70,0 & - & - & - & - & - & - & - \\
$\mathrm{PF}$ & 42,8 & 40,1 & 23,9 & 0,15 & 4,55 & - & 16,6 & 0,38 & 36,1 & 12,4 \\
Total & 99,9 & $99,5 \%$ & 94,5 & 100,4 & 99,2 & 99,16 & 99,3 & 96,0 & 100,6 & 99,5 \\
\hline
\end{tabular}


A composição mineralógica de todos os materiais envolvidos nos ensaios de queima foi determinada por difratometria de raios $X$, cujos gráficos são mostrados no Anexo B. Os minerais identificados são apresentados na Tabela 13.

\begin{tabular}{|c|c|c|c|c|c|c|c|c|c|c|}
\hline \multirow{2}{*}{ Minerais } & \multicolumn{10}{|c|}{ Matérias-primas } \\
\hline & $\begin{array}{l}\text { MPRM- } \\
\text { carbon1 }\end{array}$ & $\begin{array}{l}\text { MPRM- } \\
\text { carbon2 }\end{array}$ & $\begin{array}{l}\text { MPRM- } \\
\text { Quartzo }\end{array}$ & $\begin{array}{c}\text { MPRM- } \\
\mathrm{Sr}\end{array}$ & $\begin{array}{l}\text { MPRM- } \\
\mathrm{Al}(\mathrm{OH})_{3} \\
\end{array}$ & $\begin{array}{c}\text { MPRM- } \\
\text { Ferro } \\
\end{array}$ & $\begin{array}{l}\text { MPRM- } \\
\text { Fosfato }\end{array}$ & $\begin{array}{l}\text { MPRM- } \\
\text { Apatita }\end{array}$ & $\begin{array}{l}\text { MPRM- } \\
\text { Osso }\end{array}$ & $\begin{array}{l}\text { MPRM- } \\
\text { Gesso }\end{array}$ \\
\hline Muscovita & - & - & - & - & $* * *$ & - & - & - & - & - \\
\hline Estroncianita & - & - & - & $* * * *$ & - & - & - & - & - & - \\
\hline Pirofilita & - & - & - & - & $* *$ & - & - & - & - & - \\
\hline Gipsita & - & - & - & - & - & - & - & - & - & $* * * *$ \\
\hline Quartzo & - & - & $* * * *$ & - & $* *$ & - & - & - & - & - \\
\hline Calcita & $* * * *$ & $* * * *$ & - & - & - & - & - & - & - & - \\
\hline Monetita & - & - & - & - & - & - & $* * * *$ & - & - & \\
\hline Apatita & - & - & - & - & - & - & - & $* * * *$ & $* *$ & - \\
\hline Hematita & - & - & - & - & - & $* * * *$ & - & - & - & - \\
\hline \multicolumn{11}{|c|}{$\begin{array}{l}\text { Composição química aproximada dos compostos identificados: } \\
\text { Muscovite }-\left(\mathrm{K}_{0.727} \mathrm{Na}_{0.170} \mathrm{Ca}_{0.011}\right)\left(\mathrm{Al}_{0.933} \mathrm{Fe}_{0.016} \mathrm{Mg}_{0.011}\right)_{2}\left(\mathrm{Si}_{0.782} \mathrm{Al}_{0.221} \mathrm{Ti}_{0.005}\right)_{4} \mathrm{O}_{10}(\mathrm{OH})_{2} \\
\text { Pyrophyllite }-\left(\mathrm{Al}_{4} \mathrm{~S}_{8} \mathrm{O}_{20}(\mathrm{OH})_{4}\right)_{.3333} \\
\text { Gipsita - } \mathrm{CaSO}_{4.2 \mathrm{H}_{2} \mathrm{O}} \\
\text { Quartzo - } \mathrm{SiO}_{2}\end{array}$} \\
\hline
\end{tabular}

\subsection{Clínqueres e Farinhas Experimentais}

A partir da composição de cada um dos reagentes e compostos puros foram projetadas as dosagens das farinhas para a produção dos clínqueres experimentais. A mistura dos carbonatos de cálcio 1 e 2, do hidróxido de alumínio, do quartzo e do minério de ferro perfaz a composição das farinhas referência (MPFA-REF1 e MPFA-REF2). As demais farinhas foram elaboradas por meio do acréscimo do carbonato de estrôncio nos teores de $0,20,0,50,1,00,1,50$ e 2,00\% em peso ou a partir do acréscimo progressivo das diversas fontes de fosfato nos teores $0,25,0,5,1,0,1,5$ e $2,0 \%$ em peso.

As misturas foram balanceadas de modo a manter estáveis os módulos químicos: Fator de

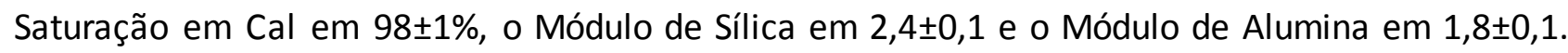
Isso se faz necessário para tentar eliminar a influencia da variação dos compostos principais do clínquer e permitir verificar a influência isolada de cada um dos elementos menores investigados. As Tabelas I, II e II constantes do Anexo C trazem as dosagens projetadas das farinhas dopadas com estrôncio, enxofre e com as diversas formas de fosfato, respectivamente. As Tabelas 16 e 18 apresentam a composição química das farinhas com estrôncio e com fosfato, respectivamente, obtidas após dosagem e determinadas por espectrometria de fluorescência de raios $\mathrm{X}$. 


\subsubsection{Queima laboratorial (Queimabilidade)}

A facilidade de com a qual os componentes de uma determinada farinha de clínquer portland reagem entre si é designada como queimabilidade ou aptidão à clinquerização. Essa pode ser determinada em laboratório medindo-se a cal livre residual após a farinha ter sofrido um tratamento térmico adequado (Christensen et al., 1978). Com base nesse método desenvolvido por Christensen et al. (1978) e que vem ainda sendo utilizado por diversos pesquisadores para simular em laboratório modificações introduzidas à farinha, é que se pode avaliar a influência das adições dos elementos dopantes nas características da farinha e dos clínqueres experimentais.

A produção dos clínqueres experimentais foi realizada por meio da queima das farinhas em forno mufla de alta temperatura marca Nezsch.

As farinhas foram previamente moldadas manualmente na forma de pellets de diâmetro aproximado de $15 \mathrm{~mm}$, adicionando-se cerca de $20 \%$ em peso de água destilada.

Os pellets foram secos, no mínimo por 12 horas em estufa a $100^{\circ} \mathrm{C}$, para eliminação da água livre. Posteriormente, esses foram acondicionados em cápsula de porcelana e calcinados a $600^{\circ} \mathrm{C}$, por $30 \mathrm{~min}$, com o objetivo de promover grande parte da descarbonatação da farinha. Dessa maneira, ao serem queimados na mufla evita-se a fragmentação do clínquer por processos de crepitação ou saída abrupta de água.

Os pellets secos e parcialmente calcinados foram acondicionados em cadinhos de platina- ródioouro, em quantidades aproximadas de 8 a 10 pellets, para queima a temperatura de $1450^{\circ} \mathrm{C}$ por 30min. Transcorrido esse tempo, os cadinhos são retirados do forno e imediatamente resfriados sob o jato de ar.

Uma vez resfriados, cerca de dez pellets foram levados à caracterização mineralógica por difratometria de raios $X$ e microscopia ótica de luz refletida e outros cinco ou seis foram moídos para a realização das análises químicas e dos ensaios de cal livre residual.

\subsubsection{Determinação do teor de cal livre residual}

Os ensaios de cal livre residual foram executados conforme a norma NBR NM 13:2012 - Cimento Portland - Análise química - Determinação de óxido de cálcio livre pelo etileno glicol. O método estabelece que $1 \mathrm{~g}$ de amostra de clínquer moído ou cimento seja mantido em solução de etilenoglicol previamente neutralizado ( $\mathrm{pH}-7$ a 8), durante $30 \mathrm{~min}$ a $65^{\circ} \mathrm{C}$ em banho-maria. Após essa etapa a solução é filtrada e o passante é titulado com ácido clorídrico. $O$ cal livre presente no clínquer eleva o pH da solução, de modo que o conteúdo de ácido necessário para neutralizar novamente a solução é proporcional ao teor de cal livre presente.

\subsubsection{Análise química por fluorescência de raios X (FRX)}

As amostras de farinha e clínquer experimental foram submetidas a análises químicas por espectrometria de fluorescência de raios X (FRX). No caso das farinhas, essa determinação teve 
como objetivo verificar se as condições de dosagem e preparação foram efetivas e identificar possíveis desvios. No caso dos clínqueres, as análises químicas tiveram como meta verificar possíveis alterações na composição química provocadas pelo processo de calcinação e, em particular nas farinhas dopadas com enxofre (MPCL - SX), avaliar se o elemento enxofre sofreu volatilização durante as etapas de queima.

As análises químicas foram realizadas no espectrômetro de fluorescência de raios X Rigaku modelo RIX 2000 da ABCP (Associação Brasileira de Cimento Portland) pelo método das pastilhas fundidas (pérolas de vidro), obtidas pela fusão da amostra em conjunto com uma mistura de tetraborato $(33,3 \%$ em peso) e metaborato de lítio $(66,6 \%$ em peso) na proporção de $1: 5$. As análises utilizaram como referência uma curva de calibração elaborada com 7 padrões primários de cimento NIST (National Institute of Standards and Technology) e dois padrões elaborados pelo IPT (Instituto de Pesquisas Tecnológicas - SP). As condições do equipamento foram:

- atmosfera vácuo (aproximadamente 3,7Pa),

- tensão e corrente do tubo de Rh 50kV e 50mA, respectivamente.

\subsubsection{Microscopia ótica}

Para a realização dos ensaios de microscopia ótica de luz refletida foram elaboradas seções polidas das amostras de clínquer experimental. Para tanto, os pellets foram primeiramente lixados de modo que o núcleo do nódulo ficasse exposto. Na sequência, os pellets lixados foram embutidos em resina epóxi à vácuo de modo que grande parte dos poros fosse preenchida pela resina, o que facilita sua observação.

As seções polidas foram observadas ao fotomicroscópio ótico Zeiss Modelo II, com sistema ótico triplo que possibilita ampliações de 62,5 a 1000 vezes. As diferentes feições do clínquer e sua textura foram reveladas por meio do uso de reagentes químicos que reagem de modo diferente com cada uma das fases, conforme a Tabela 14.

\begin{tabular}{|c|c|c|c|c|c|c|c|}
\hline \multirow{2}{*}{ Reagente } & \multirow{2}{*}{ Concentração } & \multirow{2}{*}{$\begin{array}{l}\text { Tempo de } \\
\text { ataque (s) }\end{array}$} & \multirow{2}{*}{ Tipo } & \multicolumn{4}{|c|}{ Resposta } \\
\hline & & & & Alita & Belita & $\mathrm{C} 3 \mathrm{~A}$ & Ferrita \\
\hline $\mathrm{KOH}+$ sacarose & $\begin{array}{l}\text { Solução de } \mathrm{KOH} \mathrm{(10 \% )} \mathrm{+} \\
\text { sacarose em água }\end{array}$ & $3-4$ & Coloração & - & - & $* * *$ & - \\
\hline Ácido nítrico & $\begin{array}{c}\text { Solução de } \mathrm{HNO}_{3}(0,1 \%) \text { em } \\
\text { álcool etílico }\end{array}$ & $8-10$ & Estrutural & $* *$ & $* * *$ & - & - \\
\hline $\begin{array}{l}\text { Sulfato de } \\
\text { magnésio }\end{array}$ & $\begin{array}{l}\text { Solução de } \mathrm{MgSO}_{4} \quad(5 \%) \text { em } \\
\text { agua destilada }\end{array}$ & 5 & Coloração & $* * *$ & $*$ & - & - \\
\hline Ácido nítrico & $\begin{array}{l}\text { Solução de } \mathrm{HNO}_{3} \text { (1\%) em } \\
\text { álcool etílico }+1 / 3 \text { água }\end{array}$ & 10 & $\begin{array}{l}\text { Coloração e } \\
\text { estrutural }\end{array}$ & $* *$ & $* * *$ & - & - \\
\hline
\end{tabular}


A quantificação das fases minerais principais foi realizada através da contagem de pontos na seção polida de maneira similar ao descrito por Marciano Jr. et al.(1987). Os teores de $C_{3} A$ e $C_{4} A F$ foram obtidos a partir de sua proporção determinada pelo cálculo de Bogue.

\subsubsection{Difratometria de raios $X$ e Método de Rietveld}

A difratometria de raios $X$ sempre é utilizada como uma técnica de identificação e análise de substâncias cristalinas. Seu potencial de uso no estudo do clínquer inclui análises qualitativas e quantitativas. A análise qualitativa do clínquer tem sido largamente explorada pelos pesquisadores para identificação das fases do clínquer e seus polimorfos, análises de matérias-primas e colagens do forno, buscando elucidar problemas de fabricação e aprimorar o processo produtivo.

Nesse sentido, as análises quantitativas de fases cumprem um papel fundamental e têm sido um anseio dos técnicos de fabricação desenvolver uma metodologia segura de quantificação das fases cristalinas do clínquer e do cimento. No final da década de 1990 muitos pesquisadores desenvolveram rotinas experimentais para determinar os teores das fases do clínquer por difratometria de raios $X$, uma vez que as técnicas disponíveis por microscopia ótica e dissolução seletiva eram muito trabalhosas e imprecisas. No entanto, essas metodologias tinham como base a avaliação da altura de picos ou a integração de suas áreas para a montagem de curvas de calibração. Os problemas analíticos relacionados à intensa sobreposição de raias das principais fases do clínquer, concentradas em um intervalo angular de $2 \theta 25^{\circ}$ a $50^{\circ}(\mathrm{Cu} \mathrm{K \alpha})$, somadas à presença de diversos polimorfos e aos problemas de cristalinidade tornam as quantificações utilizando esses parâmetros impossíveis (Taylor et al., 1999).

Com base nos desenvolvimentos do método de Rietveld no final da década de 1960 a partir da difração de nêutrons (Rietveld, 1969), sua posterior adaptação para a difratometria de raios X por Malmros e Thomas (1977) e Young et al. (1977) (in Walenta e Fullman, 2004), passou-se a utilizar cada ponto do padrão de difração ao invés da área integrada de linhas individuais, o que reduziu os problemas de sobreposição das raias. Assim, depois de diversos estudos na quantificação de fases cristalinas Taylor e Aldridge (1993, in De la Torre, 2003) foram os pioneiros a utilizar o método para a quantificação das fases do clínquer fazendo seus experimentos em padrões NIST. Mais tarde, Taylor et al. (1999) fizeram um estudo comparativo entre os resultados pelo método do Rietveld e a contagem microscópica de pontos ressaltando sua aplicabilidade e rapidez.

O método de Rietveld se baseia no ajuste de um difratograma calculado ao experimental a partir das estruturas cristalinas de cada fase presente e dos parâmetros instrumentais de coleta de dados. Durante o refinamento, que utiliza o método dos mínimos quadrados, se ajustam diversos parâmetros da estrutura cristalina, do perfil dos picos de difração, parâmetros relacionados à preparação da amostra e entre eles os teores de cada fase presente na mistura, buscando a melhor aproximação ou convergência entre o difratograma calculado e o observado.

De La Torre (2003) desenvolveu um protocolo de análises quantitativas pelo método de Rietveld 
em materiais de construção, especialmente cimentos cinza e branco, assim como revisou a estrutura da alita por difração de raios-X luz sincrotron, difração de nêutrons e método de Rietveld, obtendo uma nova superestrutura mais simples que a do polimorfo monoclínico. Do mesmo modo, Noirfontaine et al. (2004) procuraram estabelecer uma metodologia de quantificação sugerindo que antes de aplicar o refinamento se faça uma seleção do polimorfo da alita (M1 ou M3) com base nos cinco intervalos angulares descritos por Courtial et al. (2003) e defendem que se utilize o modelo de estrutura (M)Pc seja qual for o polimorfo presente.

Gobbo et al. (2004) investigam as formas polimórficas do $\mathrm{C}_{3} \mathrm{~A}$ em oito clínqueres industriais, cinzas e brancos, contendo diferentes conteúdos de sódio, potássio e enxofre utilizando o método de Rietveld. A precisão do método na determinação do teor dessas fases foi avaliada por meio de dissolução seletiva em clínqueres brancos.

Gomes (2007) utiliza o método de Rietvelt para investigar as variações polimórficas e determinar as alterações dos parâmetros de cela de cristais de sulfo belita produzida em laboratório a partir de compostos puros.

De la Torre et al. (2011) apresentam sua experiência no controle de implementação do método de Rietveld "off-line" e "on-line" utilizando o programa HighScore da PANalytical em diversas fábricas de cimento, para o controle de processo e controle de qualidade do produto final. Para tanto se desenvolvem várias rotinas analíticas ajustadas a cada tipo de material e conjunto de fases.

Nesse trabalho, as análises de difratometria de raios $\mathrm{X}$ foram realizadas com $\mathrm{o}$ material policristalino (método do pó). Os dados foram coletados na Associação Brasileira de Cimento Portland (ABCP) em um equipamento de marca Rigaku ${ }^{\circledR}$, modelo DMAX 1100, dotado de tubo de $\mathrm{Cu}$ de potência $2 \mathrm{~kW}$, geometria Bragg-Brentano com configuração horizontal $\theta: 2 \theta$ e varredura por passo angular goniômetro horizontal, detector de cintilação e monocromador de grafite.

Os dados qualitativos de caracterização das matérias-primas foram obtidos de acordo com a seguinte configuração:

\begin{tabular}{|l|l|}
\hline \multicolumn{1}{|c|}{ Análise Qualitativa } & \multicolumn{1}{c|}{ Análise Qualitativa } \\
\hline $\begin{array}{l}\text { Tensão e corrente do tubo }-40 \mathrm{kV} \text { e } 20 \mathrm{~mA} \\
\text { Intervalo analítico } 2 \theta-3-60^{\circ}\end{array}$ & Tensão e corrente do tubo $-40 \mathrm{kV}$ e $40 \mathrm{~mA}$ \\
Contínuo $-2^{\circ} / \mathrm{min}$ & Intervalo analítico $2 \theta-10-70^{\circ}$ \\
Monocromador no feixe difratado & Passo angular $-0,02^{\circ}$ \\
Radiação de cobre $(\lambda K \alpha 1=1,54056 \AA)$ & Tempo $-4 \mathrm{~s}$ \\
Fenda de divergência $-1 \mathrm{deg}$ & Monocromador no feixe difratado \\
Fenda de espalhamento $-1 \mathrm{deg}$ & Radiação de cobre $(\lambda \mathrm{K} \alpha 1=1,54056 \AA)$ \\
Fenda de recebimento $-0,6 \mathrm{~mm}$ & Fenda de divergência $-0,5 \mathrm{deg}$ \\
Fenda do monocromador $-0,6 \mathrm{~mm}$ & Fenda de espalhamento $-1 \mathrm{deg}$ \\
& Fenda de recebimento $-0,3 \mathrm{~mm}$ \\
& Fenda do monocromador $-0,6 \mathrm{~mm}$ \\
\hline
\end{tabular}




\subsubsection{Estratégia de refinamento de clínqueres MPCL}

Para os refinamentos pelo método de Rietveld utilizou-se o software High Score Plus 3.0 (PANalytical). A estratégia de refinamento incluiu: (1) determinação automática do background granulação=20, bending fator=0; (2) procura automática de picos; (3) inserção individual das fases e refinamento do fator de escala; (4) correção da posição da amostra - corrige o deslocamento perpendicular à superfície da amostra que provoca o deslocamento dos picos de difração ("peak shift"); (5) refinamento dos parâmetros de cela unitária e fator de escala para todas as fases conjuntamente; (6) Ajuste do perfil de pico utilizando a função pseudo-Voigt, em particular do parâmetro W; (7) refinamento da orientação preferencial da alita $\left(C_{3} S\right)$ segundo a face hkl (-101). Os refinamentos foram precedidos de testes do polimorfismo do $C_{3} S, C_{2} S$ e de ocupação Al-Fe no $\mathrm{C}_{4} \mathrm{AF}$. Os primeiros tiveram como objetivo determinar qual a estrutura melhor se ajustaria aos clínqueres experimentais obtidos. Para o teste de polimorfos de $\mathrm{C}_{3} \mathrm{~S}$ foram selecionadas as estruturas descritas por entre De La Torre et al (2002), Mumme (1995) e Nishi et al (1985). O teste revelou que a estrutura do $\mathrm{C}_{3} \mathrm{~S}$ monoclínico descrita por Mumme (1995) foi a mais adequada.

Os testes de polimorfismo do $\mathrm{C}_{2} \mathrm{~S}$ realizados entre as estruturas monoclínicas descrita por Mumme et al (1995) e ortorrômbica de Mumme et al (1992) indicam que a primeira é que prevalece.

$O$ fator de ocupação de alumínio e ferro na estrutura do $C_{4} A F$ também foi objeto de avalição e não resultou em melhoria do refinamento. Dada à complexidade mineralógica das amostras, o parâmetro térmico não foi levado em consideração.

Foram utilizadas para o refinamento as informações cristalográficas das fases identificadas constantes dos arquivos (CIFs) listados a seguir:

- $\quad C_{3} S$ monoclínico Mumme (1995)

- $\mathrm{C}_{2} \mathrm{~S}$ monoclínico Mumme et. al., (1995)

- $\mathrm{C}_{3} \mathrm{~A}$ isométrico Mondal \& Jeffery (1929)

- $C_{4} A F$ ortorrômbico Colville Geller (1971)

- $\mathrm{CaO}$ isométrico Natta e Passerini (1929)

- $\mathrm{Ca}(\mathrm{OH})_{2}$ hexagonal Desgranges et. al., (1993)

- Quartzo hexagonal Norby (1997)

\section{RESULTADOS}

\subsection{Teor de Cal livre e a Queimabilidade das Farinhas Experimentais}

Os resultados das determinações do teor de cal livre nas farinhas experimentais após calcinação a $1450^{\circ} \mathrm{C}$ são apresentados na Tabela 15.

Dentre os elementos estudados, o estrôncio é o elemento que provoca os maiores aumentos de cal livre residual, chegando a atingir aproximadamente $400 \%$ de aumento para teores de adição de 2,0\% (Figura 35). Por outro lado, a incorporação do $\mathrm{SO}_{3}$ tende a reduzir o teor de cal livre nos clínqueres experimentais e mesmo para teores e adição elevados ( $>1,5 \%$ em peso) os teores de 
cal livre tendem a ser menores que a referência (Figura 35).

\begin{tabular}{ccccccc}
\hline \multicolumn{7}{c}{ Tabela 15- Teor de cal livre após queima 1450 ${ }^{\circ}$ (\% em peso) * } \\
\hline \multirow{7}{*}{$\begin{array}{c}\text { Carbonato de } \\
\text { Estrôncio }\end{array}$} & MPCL-REF1 & MPCL-SR20 & MPCL-SR50 & MPCL-SR100 & MPCL-SR150 & MPCL-SR200 \\
\hline \multirow{2}{*}{ Gesso } & 2,57 & 4,16 & 3,76 & 4,61 & 5,59 & 10,40 \\
\hline \multirow{2}{*}{ Fosfato sintético } & MPCL-REF2 & MPCL-SX25 & MPCL-SX50 & MPCL-SX100 & MPCL-SX150 & MPCL-SX200 \\
& 2,66 & 1,86 & 1,59 & 1,19 & 1,09 & 2,94 \\
\hline \multirow{2}{*}{ Apatita natural } & MPCL-REF2 & MPCL-FO25 & MPCL-FO50 & MPCL-FO100 & MPCL-FO150 & MPCL-FO200 \\
& 2,66 & 2,70 & 2,59 & 2,89 & 5,06 & 6,32 \\
\hline \multirow{2}{*}{ Osso } & MPCL-REF2 & MPCL-AP25 & MPCL-AP50 & MPCL-AP100 & MPCL-AP150 & MPCL-AP200 \\
& MPCL-REF2 & MPCL-OS25 & MPCL-OS50 & MPCL-OS100 & MPCL-OS150 & MPCL-OS200 \\
\hline & 2,66 & 2,59 & 2,83 & 2,87 & 7,80 & 4,87 \\
\hline
\end{tabular}

$\left({ }^{*}\right)$ Determinado pelo método do etileno glicol segundo método (NBR NM 13:2012)

A adição de fósforo a partir das diferentes fontes (fosfato sintético, apatita natural e osso) causou efeitos similares para baixos teores e não provocou alterações significativas no teor de cal livre. A partir da adição de $1 \%$ em peso, nota-se um aumento do teor de cal livre, ressaltando-se que dentre as três fontes de fósforo ensaiadas, a adição do fosfato sintético é a que parece causar maior efeito na reatividade da farinha, com um aumento de mais de $200 \%$ no teor de cal livre.

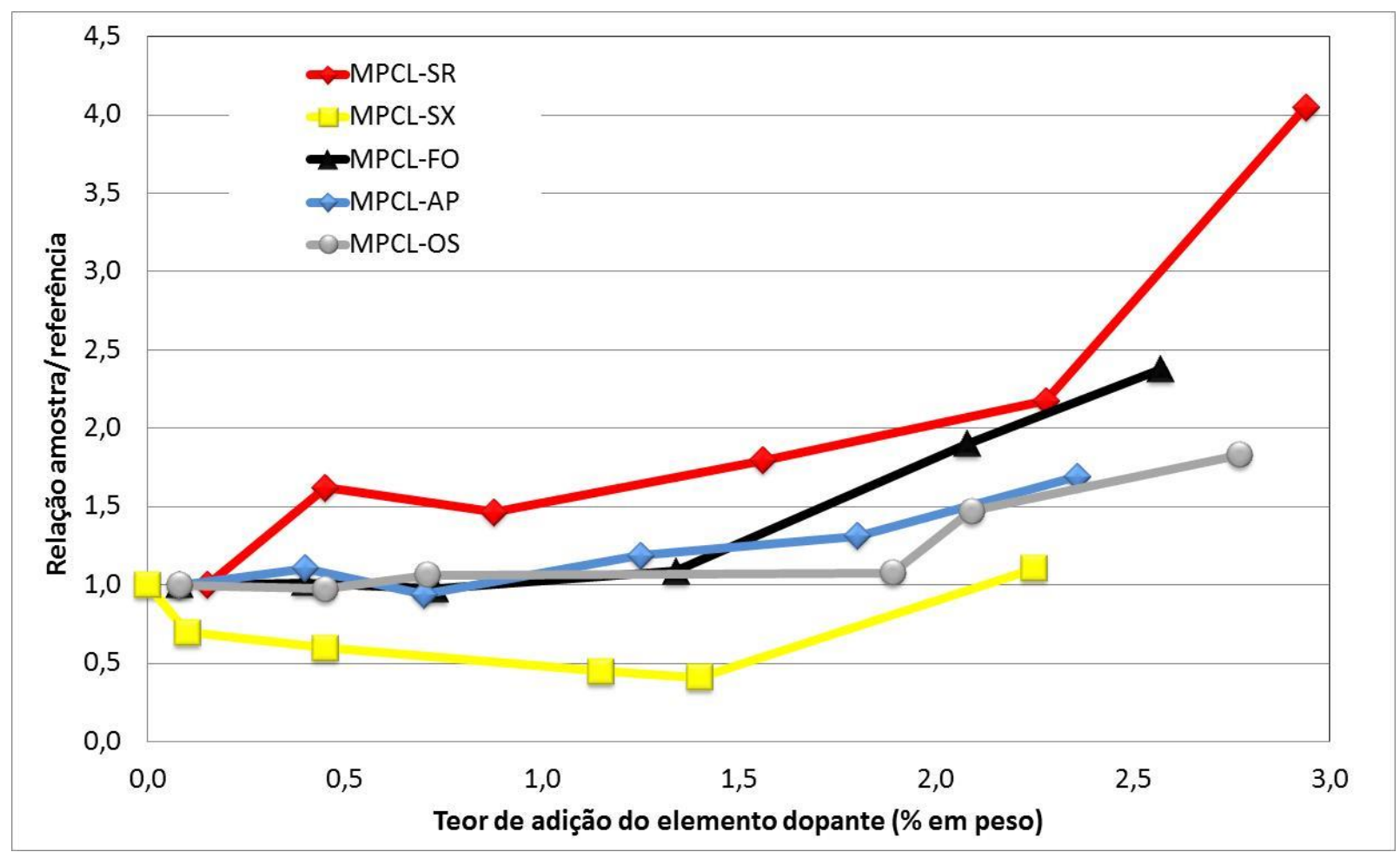

Figura 35 - Evolução do teor de cal livre dos clínqueres experimentais em função do teor dos elementos dopantes 


\subsection{Composição química dos clínqueres experimentais}

As Tabelas 16, 17 e 18 mostram a composição química das farinhas experimentais e as Tabelas 19, 20 e 21, dos clínqueres obtidos após calcinação. As análises químicas foram realizadas por espectrometria de fluorescência de raios $X$ descritas no item 6.3.3 Análise química por fluorescência de raios $X(F R X)$.

Ao serem dosadas procurou-se fixar os módulos químicos Fator de Saturação em Cal (FSC), Módulo de Sílica (MS) e o Módulo de Alumina (MA) de todas as farinhas ensaiadas de modo que as alterações na sua composição química não se tornassem mais um fator de variabilidade dos clínqueres obtidos e apenas a incorporação dos elementos estudados fosse avaliada. Desse modo, normalizando os valores de FSC, MS e MA das farinhas e dos clínqueres pelos módulos das amostras de referência (MPFA-Ref1 e 2 e MPCL-Ref1 e 2) foi possível calcular o desvio relativo para cada amostra (Figuras 36 e 37).

É possível verificar que as variações obtidas são pequenas e normalmente inferiores a $5 \%$. Esse limite só é ultrapassado para os valores de MA das amostras da série MPCL- SX, dopada com enxofre. Todavia, deve-se considerar que o MA não é um fator preponderante e a variação encontrada é sistemática e semelhante para todas as amostras da série, podendo ser utilizada para estudos comparativos propostos nesse estudo. 
Tabela 16 - Análise química por espectrometria de raios $X$ das farinhas dopadas com estrôncio

\begin{tabular}{lcccccc}
\hline \multirow{2}{*}{$\begin{array}{l}\text { Óxidos }(\% \\
\text { em peso) }\end{array}$} & \multicolumn{5}{c}{ Farinhas } \\
\cline { 2 - 6 } & MPFA-REF1 & MPFA-SR20 & MPFA-SR50 & MPFA-SR100 & MPFA-SR150 & MPFA-SR200 \\
\hline $\mathrm{CaO}$ & 43,5 & 43,7 & 43,2 & 42,6 & 42,2 & 41,7 \\
$\mathrm{SiO}_{2}$ & 13,7 & 13,4 & 13,4 & 13,3 & 13,3 & 13,2 \\
$\mathrm{Al}_{2} \mathrm{O}_{3}$ & 3,84 & 3,82 & 3,74 & 3,85 & 3,76 & 3,72 \\
$\mathrm{Fe}_{2} \mathrm{O}_{3}$ & 2,34 & 2,33 & 2,31 & 2,28 & 2,30 & 2,26 \\
$\mathrm{SO}_{3}$ & 0,0 & 0,0 & 0,0 & 0,01 & 0,01 & 0,02 \\
$\mathrm{MgO}$ & 0,21 & 0,21 & 0,21 & 0,21 & 0,21 & 0,21 \\
$\mathrm{~K}_{2} \mathrm{O}$ & 0,54 & 0,52 & 0,52 & 0,49 & 0,50 & 0,48 \\
$\mathrm{TiO}_{2}$ & 0,05 & 0,05 & 0,06 & 0,06 & 0,06 & 0,07 \\
$\mathrm{Na}_{2} \mathrm{O}$ & 0,0 & 0,0 & 0,0 & 0,0 & 0,0 & 0,0 \\
$\mathrm{SrO}$ & 0,10 & 0,29 & 0,56 & 0,99 & 1,44 & 1,88 \\
$\mathrm{P}_{2} \mathrm{O}_{5}$ & 0,05 & 0,05 & 0,05 & 0,05 & 0,05 & 0,05 \\
$\mathrm{MnO}$ & 0,01 & 0,01 & 0,01 & 0,01 & 0,01 & 0,01 \\
$\mathrm{PF}_{\mathrm{Total}}$ & 35,0 & 35,1 & 35,3 & 35,1 & 34,9 & 34,9 \\
\hline $\mathrm{FSC}$ & 99,3 & 99,5 & 99,3 & 98,9 & 98,8 & 98,6 \\
$\mathrm{MS}$ & 98,1 & 100 & 99,3 & 98,2 & 97,8 & 96,9 \\
$\mathrm{MA}$ & 2,21 & 2,18 & 2,21 & 2,17 & 2,19 & 2,21 \\
\hline
\end{tabular}

Tabela 17 - Análise química por espectrometria de raios $X$ das farinhas dopadas com enxofre

\begin{tabular}{lcccccc}
\hline \multirow{2}{*}{$\begin{array}{l}\text { Óxidos }(\% \\
\text { em peso) }\end{array}$} & \multicolumn{5}{c}{ Farinhas } \\
\cline { 2 - 7 } & MPFA-REF2 & MPFA-SX25 & MPFA-SX50 & MPFA-SX100 & MPFA-SX150 & MPFA-SX200 \\
\hline $\mathrm{CaO}$ & 43,4 & 44,1 & 43,7 & 43,4 & 43,2 & 43,5 \\
$\mathrm{SiO}_{2}$ & 13,8 & 13,7 & 13,7 & 13,8 & 13,8 & 13,8 \\
$\mathrm{Al}_{2} \mathrm{O}_{3}$ & 3,75 & 3,46 & 3,44 & 3,42 & 3,40 & 3,44 \\
$\mathrm{Fe}_{2} \mathrm{O}_{3}$ & 2,29 & 2,31 & 2,30 & 2,28 & 2,28 & 2,29 \\
$\mathrm{SO}_{3}$ & 0,00 & 0,30 & 0,52 & 0,97 & 1,42 & 2,03 \\
$\mathrm{MgO}$ & 0,18 & 0,19 & 0,19 & 0,19 & 0,18 & 0,19 \\
$\mathrm{~K}_{2} \mathrm{O}$ & 0,54 & 0,53 & 0,54 & 0,53 & 0,53 & 0,53 \\
$\mathrm{TiO}_{2}$ & 0,06 & 0,06 & 0,06 & 0,06 & 0,06 & 0,06 \\
$\mathrm{Na}_{2} \mathrm{O}$ & 0,00 & 0,02 & 0,02 & 0,03 & 0,03 & 0,03 \\
$\mathrm{SrO}$ & 0,00 & 0,11 & 0,11 & 0,11 & 0,11 & 0,11 \\
$\mathrm{P}_{2} \mathrm{O}_{5}$ & 0,11 & 0,08 & 0,09 & 0,08 & 0,08 & 0,08 \\
$\mathrm{MnO}$ & 0,06 & 0,01 & 0,01 & 0,01 & 0,01 & 0,01 \\
$\mathrm{PF}$ & 35,1 & 34,7 & 35,2 & 35,1 & 35,2 & 34,6 \\
$\mathrm{Total}$ & 99,4 & 99,6 & 99,9 & 100 & 99,9 & 100 \\
\hline FSC & 97,0 & 100 & 99,6 & 98,3 & 98,1 & 98,3 \\
$\mathrm{MS}$ & 2,29 & 2,38 & 2,38 & 2,42 & 2,42 & 2,41 \\
$\mathrm{MA}$ & 1,64 & 1,50 & 1,50 & 1,50 & 1,49 & 1,50 \\
\hline
\end{tabular}




\begin{tabular}{|c|c|c|c|c|c|c|c|c|c|c|c|c|c|c|c|c|}
\hline \multirow[t]{2}{*}{ Óxidos (\% em peso) } & \multicolumn{16}{|c|}{ Farinhas } \\
\hline & $\begin{array}{l}\text { MPFA- } \\
\text { REF2 }\end{array}$ & $\begin{array}{c}\text { MPFA- } \\
\text { FO25 }\end{array}$ & $\begin{array}{c}\text { MPFA- } \\
\text { FO50 }\end{array}$ & $\begin{array}{l}\text { MPFA- } \\
\text { FO100 }\end{array}$ & $\begin{array}{l}\text { MPFA- } \\
\text { F0150 }\end{array}$ & $\begin{array}{l}\text { MPFA- } \\
\text { FO200 }\end{array}$ & $\begin{array}{l}\text { MPFA- } \\
\text { AP25 }\end{array}$ & $\begin{array}{c}\text { MPFA- } \\
\text { AP50 }\end{array}$ & $\begin{array}{l}\text { MPFA- } \\
\text { AP100 }\end{array}$ & $\begin{array}{l}\text { MPFA- } \\
\text { AP150 }\end{array}$ & $\begin{array}{l}\text { MPFA- } \\
\text { AP200 }\end{array}$ & $\begin{array}{c}\text { MPFA- } \\
\text { OS25 }\end{array}$ & $\begin{array}{c}\text { MPFA- } \\
\text { OS50 }\end{array}$ & $\begin{array}{l}\text { MPFA- } \\
\text { OS100 }\end{array}$ & $\begin{array}{l}\text { MPFA- } \\
\text { OS150 }\end{array}$ & $\begin{array}{l}\text { MPFA- } \\
\text { OS200 }\end{array}$ \\
\hline $\mathrm{CaO}$ & 43,4 & 43,5 & 43,26 & 43,9 & 43,3 & 43,1 & 43,9 & 43,9 & 43,9 & 43,8 & 41,3 & 43,9 & 43,5 & 43,0 & 43,1 & 42,7 \\
\hline $\mathrm{SiO}_{2}$ & 13,9 & 13,7 & 13,7 & 13,6 & 13,4 & 13,3 & 13,6 & 14,0 & 13,3 & 13,6 & 12,8 & 13,9 & 13,4 & 13,4 & 13,4 & 13,3 \\
\hline $\mathrm{Al}_{2} \mathrm{O}_{3}$ & 3,75 & 3,83 & 3,82 & 3,40 & 3,71 & 3,84 & 3,88 & 3,45 & 4,11 & 3,83 & 3,82 & 3,85 & 3,82 & 3,8 & 3,77 & 3,76 \\
\hline $\mathrm{Fe}_{2} \mathrm{O}_{3}$ & 2,29 & 2,29 & 2,27 & 2,30 & 2,25 & 2,29 & 2,27 & 2,28 & 2,31 & 2,26 & 2,19 & 2,33 & 2,27 & 2,28 & 2,28 & 2,27 \\
\hline $\mathrm{SO}_{3}$ & 0,00 & 0,00 & 0,00 & 0,00 & 0,00 & 0,00 & 0,00 & 0,01 & 0,03 & 0,06 & 0,07 & 0,0 & 0,00 & 0,00 & 0,00 & 0,00 \\
\hline $\mathrm{MgO}$ & 0,18 & 0,21 & 0,20 & 0,21 & 0,20 & 0,21 & 0,21 & 0,20 & 0,19 & 0,20 & 0,17 & 0,20 & 0,20 & 0,22 & 0,22 & 0,22 \\
\hline $\mathrm{K}_{2} \mathrm{O}$ & 0,54 & 0,53 & 0,53 & 0,54 & 0,52 & 0,53 & 0,54 & 0,54 & 0,52 & 0,52 & 0,49 & 0,55 & 0,55 & 0,54 & 0,54 & 0,53 \\
\hline $\mathrm{TiO}_{2}$ & 0,06 & 0,05 & 0,05 & 0,05 & 0,05 & 0,05 & 0,05 & 0,06 & 0,07 & 0,05 & 0,06 & 0,06 & 0,07 & 0,06 & 0,06 & 0,05 \\
\hline $\mathrm{Na}_{2} \mathrm{O}$ & 0,00 & 0,00 & 0,00 & 0,00 & 0,00 & 0,00 & 0,00 & 0,00 & 0,02 & 0,00 & 0,03 & 0,0 & 0,04 & 0,01 & 0,0 & 0,02 \\
\hline $\mathrm{SrO}$ & 0,0 & 0,11 & 0,11 & 0,11 & 0,11 & 0,11 & 0,11 & 0,11 & 0,11 & 0,11 & 0,10 & 0,11 & 0,11 & 0,11 & 0,11 & 0,11 \\
\hline $\mathrm{P}_{2} \mathrm{O}_{5}$ & 0,11 & 0,25 & 0,46 & 0,89 & 1,37 & 1,78 & 0,27 & 0,45 & 1,03 & 1,20 & 1,85 & 0,30 & 0,59 & 1,04 & 1,25 & 1,74 \\
\hline $\mathrm{MnO}$ & 0,06 & 0,01 & 0,01 & 0,21 & 0,01 & 0,01 & 0,01 & 0,01 & 0,01 & 0,01 & 0,01 & 0,01 & 0,01 & 0,01 & 0,01 & 0,01 \\
\hline PF & 35,1 & 35,3 & 35,4 & 34,5 & 34,5 & 34,1 & 34,7 & 34,6 & 34,0 & 33,7 & 36,8 & 32,9 & 33,6 & 33,7 & 33,4 & 33,5 \\
\hline Total & 99,4 & 99,7 & 99,6 & 99,5 & 99,4 & 99,3 & 99,5 & 99,6 & 99,6 & 99,4 & 99,6 & 98,1 & 99,1 & 98,2 & 98,1 & 98,2 \\
\hline FSC & 97,0 & 97,9 & 97,4 & 100 & 99,7 & 99,6 & 99,1 & 98,0 & 100 & 99,2 & 99,0 & 97,2 & 99,8 & 98,7 & 99,4 & 98,6 \\
\hline MS & 2,29 & 2,24 & 2,24 & 2,38 & 2,25 & 2,17 & 2,21 & 2,44 & 2,08 & 2,24 & 2,12 & 2,25 & 2,20 & 2,20 & 2,21 & 2,21 \\
\hline MA & 1,64 & 1,67 & 1,68 & 1,45 & 1,65 & 1,68 & 1,71 & 1,51 & 1,78 & 1,70 & 1,74 & 1,65 & 1,68 & 1,67 & 1,65 & 1,66 \\
\hline
\end{tabular}




\begin{tabular}{|c|c|c|c|c|c|c|}
\hline \multirow[t]{2}{*}{ Óxidos (\% em peso) } & \multicolumn{6}{|c|}{ Clínqueres } \\
\hline & MPCL-REF1 & MPCL-SR20 & MPCL-SR50 & MPCL-SR100 & MPCL-SR150 & MPCL-SR200 \\
\hline $\mathrm{CaO}$ & 68,3 & 68,1 & 67,2 & 66,1 & 66,0 & 64,9 \\
\hline $\mathrm{SiO}_{2}$ & 21,0 & 20,9 & 21,2 & 20,7 & 20,5 & 20,4 \\
\hline $\mathrm{Al}_{2} \mathrm{O}_{3}$ & 5,88 & 5,66 & 5,59 & 5,70 & 5,62 & 5,47 \\
\hline $\mathrm{Fe}_{2} \mathrm{O}_{3}$ & 3,62 & 3,54 & 3,55 & 3,52 & 3,22 & 3,53 \\
\hline $\mathrm{SO}_{3}$ & 0,0 & 0,0 & 0,0 & 0,0 & 0,0 & 0,0 \\
\hline $\mathrm{MgO}$ & 0,35 & 0,34 & 0,34 & 0,34 & 0,33 & 0,32 \\
\hline $\mathrm{K}_{2} \mathrm{O}$ & 0,25 & 0,22 & 0,33 & 0,35 & 0,26 & 0,34 \\
\hline $\mathrm{TiO}_{2}$ & 0,08 & 0,08 & 0,08 & 0,08 & 0,09 & 0,09 \\
\hline $\mathrm{Na}_{2} \mathrm{O}$ & 0,0 & 0,0 & 0,0 & 0,0 & 0,0 & 0,0 \\
\hline $\mathrm{SrO}$ & 0,15 & 0,45 & 0,88 & 1,56 & 2,28 & 2,94 \\
\hline $\mathrm{P}_{2} \mathrm{O}_{5}$ & 0,08 & 0,08 & 0,08 & 0,08 & 0,08 & 0,08 \\
\hline $\mathrm{MnO}$ & 0,02 & 0,01 & 0,02 & 0,02 & 0,02 & 0,02 \\
\hline PF & 0,30 & 0,58 & 0,44 & 0,58 & 0,38 & 0,51 \\
\hline Total & 99,9 & 100 & 99,6 & 99,0 & 98,9 & 98,5 \\
\hline Cal livre (a $\left.1450^{\circ} \mathrm{C}\right)$ & 2,57 & 4,16 & 3,76 & 4,61 & 5,59 & 10,40 \\
\hline FSC & 100 & 101 & 98,4 & 98,8 & 99,5 & 98,5 \\
\hline MS & 2,21 & 2,28 & 2,31 & 2,24 & 2,32 & 2,26 \\
\hline MA & 1,62 & 1,60 & 1,58 & 1,62 & 1,74 & 1,55 \\
\hline
\end{tabular}

$\left({ }^{*}\right)$ A determinação dos teores de cal livre foi realizada pelo método do etileno glicol segundo método NBR NM 13:2012

\begin{tabular}{|c|c|c|c|c|c|c|}
\hline \multirow[t]{2}{*}{ Óxidos (\% em peso) } & \multicolumn{6}{|c|}{ Clínqueres } \\
\hline & MPCL-REF2 & MPCL-SX25 & MPCL-SX50 & MPCL-SX100 & MPCL-SX150 & MPCL-SX200 \\
\hline $\mathrm{CaO}$ & 68,3 & 68,6 & 68,00 & 67,5 & 67,2 & 66,4 \\
\hline $\mathrm{SiO}_{2}$ & 21,0 & 21,3 & 21,1 & 21,1 & 21,0 & 21,7 \\
\hline $\mathrm{Al}_{2} \mathrm{O}_{3}$ & 5,88 & 5,66 & 5,54 & 5,71 & 5,71 & 5,68 \\
\hline $\mathrm{Fe}_{2} \mathrm{O}_{3}$ & 3,62 & 3,59 & 3,56 & 3,56 & 3,62 & 3,51 \\
\hline $\mathrm{SO}_{3}$ & 0,00 & 0,10 & 0,45 & 1,15 & 1,40 & 2,25 \\
\hline $\mathrm{MgO}$ & 0,35 & 0,30 & 0,31 & 0,28 & 0,27 & 0,29 \\
\hline $\mathrm{K}_{2} \mathrm{O}$ & 0,25 & 0,23 & 0,52 & 0,59 & 0,58 & 0,66 \\
\hline $\mathrm{TiO}_{2}$ & 0,08 & 0,09 & 0,10 & 0,09 & 0,09 & 0,09 \\
\hline $\mathrm{Na}_{2} \mathrm{O}$ & 0,00 & 0,00 & 0,00 & 0,00 & 0,00 & 0,00 \\
\hline $\mathrm{SrO}$ & 0,15 & 0,17 & 0,17 & 0,17 & 0,17 & 0,16 \\
\hline $\mathrm{P}_{2} \mathrm{O}_{5}$ & 0,08 & 0,13 & 0,14 & 0,13 & 0,13 & 0,13 \\
\hline $\mathrm{MnO}$ & 0,02 & 0,01 & 0,01 & 0,01 & 0,01 & 0,01 \\
\hline PF & 0,30 & 0,14 & 0,18 & 0,12 & 0,12 & 0,18 \\
\hline Total & 99,9 & 100 & 100 & 100 & 100 & 100 \\
\hline Cal livre $\left(\right.$ a $\left.1450^{\circ} \mathrm{C}\right)$ & 2,66 & 1,86 & 1,59 & 1,19 & 1,09 & 2,94 \\
\hline FSC & 100,1 & 99,6 & 99,7 & 99,9 & 99,8 & 99,7 \\
\hline MS & 2,21 & 2,31 & 2,32 & 2,25 & 2,25 & 2,32 \\
\hline MA & 1,62 & 1,58 & 1,56 & 1,60 & 1,58 & 1,56 \\
\hline
\end{tabular}

$\left({ }^{*}\right)$ A determinação dos teores de cal livre foi realizada pelo método do etileno glicol segundo método NBR NM 13:2012 
Tabela 21 - Análise química por espectrometria de raios $X$ dos clínqueres dopados com fósforo

\begin{tabular}{|c|c|c|c|c|c|c|c|c|c|c|c|c|c|c|c|c|}
\hline \multirow[t]{2}{*}{ Óxidos (\% em peso) } & \multicolumn{16}{|c|}{ Clínqueres } \\
\hline & $\begin{array}{c}\text { MPCL- } \\
\text { REF2 }\end{array}$ & $\begin{array}{c}\text { MPCL- } \\
\text { FO25 }\end{array}$ & $\begin{array}{l}\text { MPCL- } \\
\text { FO50 }\end{array}$ & $\begin{array}{l}\text { MPCL- } \\
\text { F0100 }\end{array}$ & $\begin{array}{l}\text { MPCL- } \\
\text { F0150 }\end{array}$ & $\begin{array}{l}\text { MPCL- } \\
\text { FO200 }\end{array}$ & $\begin{array}{c}\text { MPCL- } \\
\text { AP25 }\end{array}$ & $\begin{array}{c}\text { MPCL- } \\
\text { AP50 }\end{array}$ & $\begin{array}{l}\text { MPCL- } \\
\text { AP100 }\end{array}$ & $\begin{array}{l}\text { MPCL- } \\
\text { AP150 }\end{array}$ & $\begin{array}{l}\text { MPCL- } \\
\text { AP200 }\end{array}$ & $\begin{array}{l}\text { MPCL- } \\
\text { OS25 }\end{array}$ & $\begin{array}{l}\text { MPCL- } \\
\text { OS50 }\end{array}$ & $\begin{array}{l}\text { MPCL- } \\
\text { OS100 }\end{array}$ & $\begin{array}{l}\text { MPCL- } \\
\text { OS150 }\end{array}$ & $\begin{array}{l}\text { MPCL- } \\
\text { OS200 }\end{array}$ \\
\hline $\mathrm{CaO}$ & 68,3 & 67,9 & 67,2 & 66,6 & 66,4 & 65,4 & 67,8 & 67,7 & 67,0 & 66,4 & 65,8 & 67,6 & 67,0 & 65,7 & 65,7 & 65,0 \\
\hline $\mathrm{SiO}_{2}$ & 21,0 & 21,1 & 21,3 & 21,0 & 20,3 & 20,7 & 21,4 & 21,1 & 21,0 & 20,9 & 20,8 & 21,0 & 21,3 & 20,9 & 20,7 & 20,5 \\
\hline $\mathrm{Al}_{2} \mathrm{O}_{3}$ & 5,88 & 5,91 & 5,89 & 5,96 & 5,70 & 5,70 & 5,99 & 5,97 & 5,81 & 5,83 & 5,66 & 6,11 & 5,94 & 5,70 & 5,94 & 5,85 \\
\hline $\mathrm{Fe}_{2} \mathrm{O}_{3}$ & 3,62 & 3,54 & 3,54 & 3,52 & 3,41 & 3,42 & 3,54 & 3,53 & 2,52 & 3,49 & 3,47 & 3,51 & 3,49 & 3,44 & 3,50 & 3,48 \\
\hline $\mathrm{SO}_{3}$ & 0,00 & 0,00 & 0,00 & 0,00 & 0,00 & 0,00 & 0,00 & 0,00 & 0,01 & 0,04 & 0,06 & 0,00 & 0,00 & 0,00 & 0,00 & 0,00 \\
\hline $\mathrm{MgO}$ & 0,35 & 0,33 & 0,33 & 0,32 & 0,31 & 0,31 & 0,33 & 0,33 & 0,30 & 0,31 & 0,28 & 0,32 & 0,34 & 0,34 & 0,37 & 0,39 \\
\hline $\mathrm{K}_{2} \mathrm{O}$ & 0,25 & 0,50 & 0,53 & 0,56 & 0,58 & 0,73 & 0,51 & 0,50 & 0,53 & 0,49 & 0,49 & 0,48 & 0,59 & 0,60 & 0,56 & 0,64 \\
\hline $\mathrm{TiO}_{2}$ & 0,08 & 0,08 & 0,09 & 0,09 & 0,08 & 0,09 & 0,09 & 0,09 & 0,09 & 0,08 & 0,08 & 0,08 & 0,08 & 0,11 & 0,09 & 0,08 \\
\hline $\mathrm{Na}_{2} \mathrm{O}$ & 0,00 & 0,00 & 0,00 & 0,00 & 0,00 & 0,00 & 0,00 & 0,00 & 0,00 & 0,00 & 0,00 & 0,00 & 0,00 & 0,09 & 0,02 & 0,05 \\
\hline $\mathrm{SrO}$ & 0,15 & 0,17 & 0,17 & 0,17 & 0,17 & 0,17 & 0,17 & 0,16 & 0,16 & 0,16 & 0,16 & 0,17 & 0,17 & 0,16 & 0,16 & 0,16 \\
\hline $\mathrm{P}_{2} \mathrm{O}_{5}$ & 0,08 & 0,40 & 0,73 & 1,34 & 2,08 & 2,57 & 0,40 & 0,70 & 1,25 & 1,80 & 2,36 & 0,45 & 0,71 & 1,72 & 2,09 & 2,77 \\
\hline $\mathrm{MnO}$ & 0,02 & 0,01 & 0,01 & 0,01 & 0,01 & 0,01 & 0,01 & 0,01 & 0,01 & 0,02 & 0,02 & 0,01 & 0,01 & 0,01 & 0,01 & 0,01 \\
\hline PF & 0,30 & 0,34 & 0,36 & 0,35 & 0,62 & 0,41 & 0,10 & 0,08 & 0,08 & 0,10 & 0,16 & 0,24 & 0,24 & 0,24 & 0,21 & 0,24 \\
\hline Total & 99,9 & 100 & 100 & 99,9 & 99,6 & 99,5 & 100 & 100 & 99,8 & 99,6 & 99,4 & 99,9 & 99,9 & 99,0 & 99,3 & 99,2 \\
\hline Cal livre (a $\left.1450^{\circ} \mathrm{C}\right)(*)$ & 2,66 & 2,70 & 2,59 & 2,89 & 5,06 & 6,32 & 2,94 & 2,50 & 3,16 & 3,49 & 4,50 & 2,59 & 2,83 & 2,87 & 7,80 & 4,87 \\
\hline FSC & 100 & 99,0 & 97,5 & 97,4 & 100 & 97,5 & 97,6 & 98,8 & 98,4 & 98,1 & 97,7 & 98,7 & 97,2 & 97,2 & 97,7 & 97,4 \\
\hline MS & 2,21 & 2,24 & 2,26 & 2,22 & 2,23 & 2,27 & 2,25 & 2,22 & 2,25 & 2,24 & 2,28 & 2,18 & 2,26 & 2,29 & 2,19 & 2,20 \\
\hline MA & 1,62 & 1,67 & 1,66 & 1,69 & 1,67 & 1,67 & 1,69 & 1,69 & 1,65 & 1,67 & 1,63 & 1,70 & 1,70 & 1,66 & 1,70 & 1,68 \\
\hline
\end{tabular}

(*)A determinação dos teores de cal livre foi realizada pelo método do etileno glicol segundo método NBR NM 13:2012 


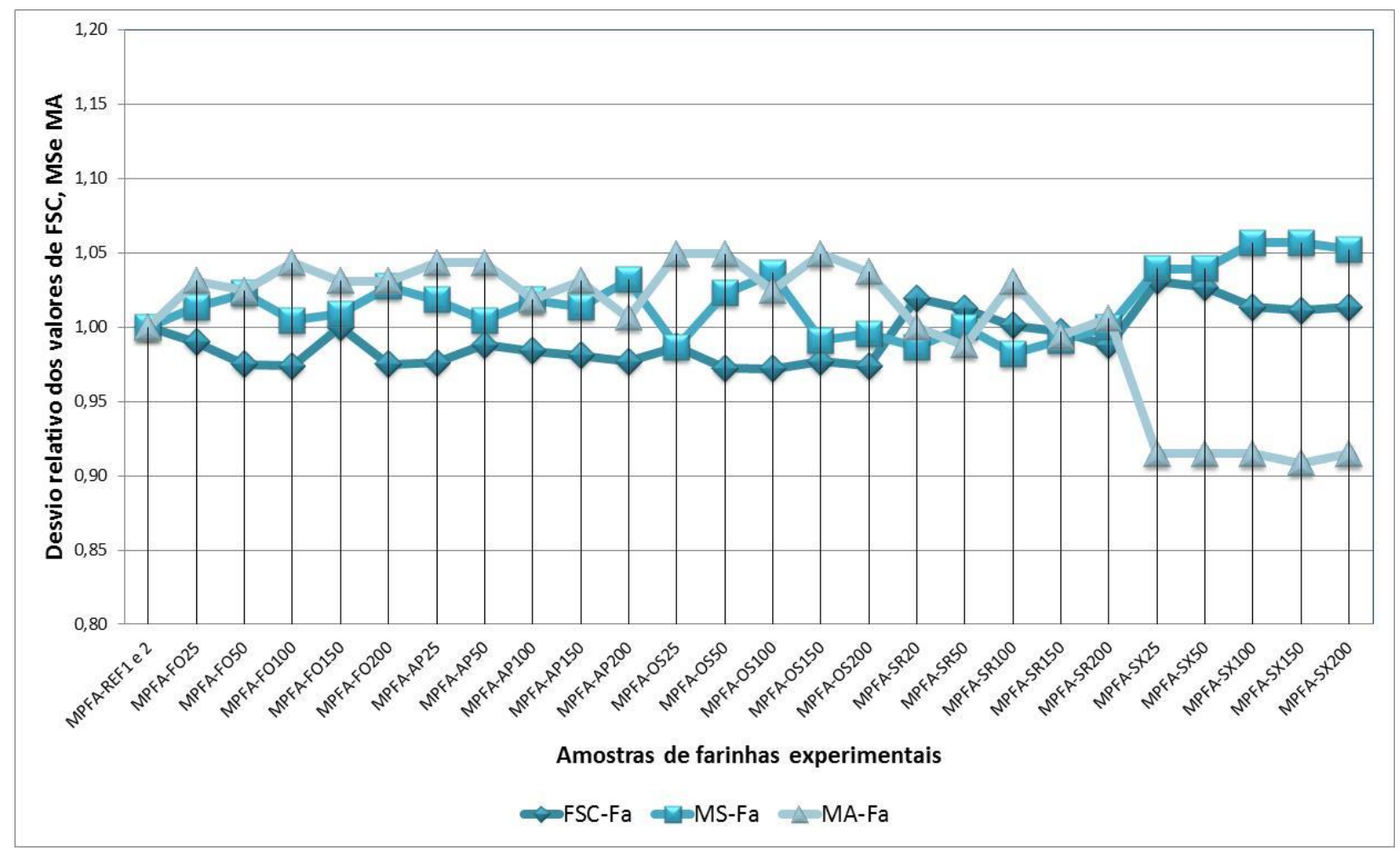

Figura 36 - Desvios relativos dos módulos químicos (FSC, MS e MA) das amostras de farinha elaboradas.

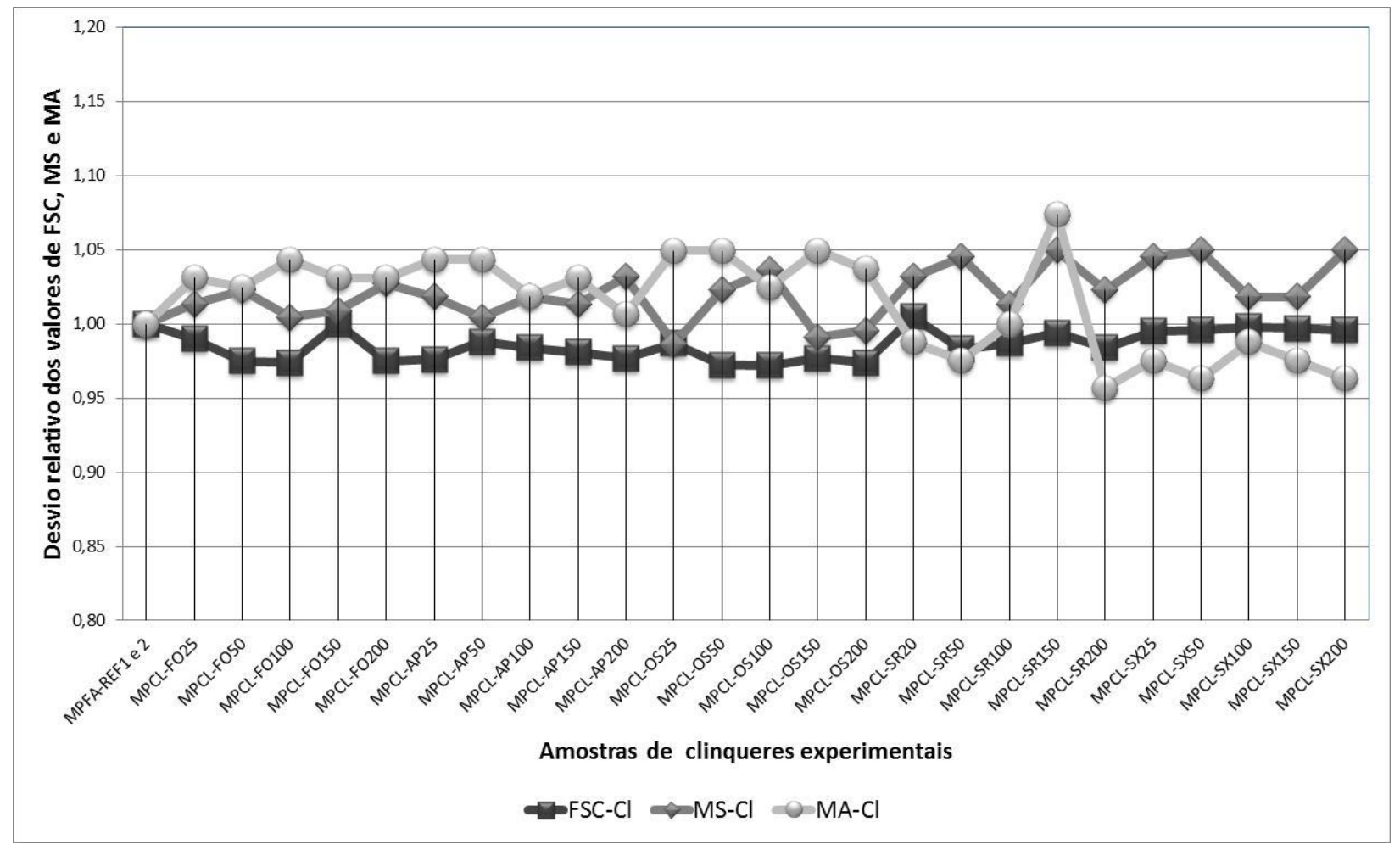

Figura 37 - Desvios relativos dos módulos químicos (FSC, MS e MA) das amostras de clínquer experimentais.

A volatilização dos elementos dopantes no processo de calcinação é outro aspecto a ser analisado. 
A Tabela 22 apresenta o teor dos elementos dopantes nos clínqueres experimentais e nas farinhas, sendo que esse último foi recalculado subtraindo-se os valores da perda ao fogo (PF) determinados a temperatura de $1000^{\circ} \mathrm{C}$. Desse modo, é possível identificar as diferenças entre o teor do elemento efetivamente assimilado pelo clínquer e o adicionado à farinha.

Deve-se considerar que, pelo menos em parte, esses erros também estejam relacionados a erros das análises químicas.

Tabela 22 - Avaliação da variação dos teores de elementos dopantes por volatilização

\begin{tabular}{l|llllll}
\hline \multicolumn{1}{c|}{ Séries estudadas } & \multicolumn{5}{c}{ Teor de elemento dopante (\% em peso) } \\
\hline SrO clínquer MPCL-SR & 0,15 & 0,45 & 0,88 & 1,56 & 2,28 & 2,94 \\
SrO farinha MPFA-SR (PF=0) & 0,15 & 0,45 & 0,87 & 1,53 & 2,21 & 2,89 \\
\hline $\mathrm{SO}_{3}$ clínquer MPCL-SX & 0,00 & 0,10 & 0,45 & 1,15 & 1,40 & 2,25 \\
$\mathrm{SO}_{3}$ farinha MPFA-SX (PF=0) & 0,00 & 0,46 & 0,80 & 1,49 & 2,19 & 3,10 \\
\hline $\mathrm{P}_{2} \mathrm{O}_{5}$ clínquer MPCL-FO & 0,08 & 0,40 & 0,73 & 1,34 & 2,08 & 2,57 \\
$\mathrm{P}_{2} \mathrm{O}_{5}$ farinha MPFA-FO (PF=0) & 0,17 & 0,39 & 0,71 & 1,36 & 2,09 & 2,70 \\
\hline $\mathrm{P}_{2} \mathrm{O}_{5}$ clínquer MPCL-OS & 0,08 & 0,45 & 0,71 & 1,72 & 2,09 & 2,77 \\
$\mathrm{P}_{2} \mathrm{O}_{5}$ farinha MPFA-OS (PF=0) & 0,17 & 0,45 & 0,89 & 1,57 & 1,88 & 2,62 \\
\hline $\mathrm{P}_{2} \mathrm{O}_{5}$ clínquer MPCL-AP & 0,08 & 0,40 & 0,70 & 1,25 & 1,80 & 2,36 \\
$\mathrm{P}_{2} \mathrm{O}_{5}$ farinha MPFA-AP (PF=0) & 0,17 & 0,41 & 0,69 & 1,56 & 1,81 & 2,93 \\
\hline
\end{tabular}

Obs - A expressão $P F=0$ significa que os te ores do elemento dopante das farinhas foram corrigidos para valores de perda ao fogo igual a zero comparável à queles obtidos nos clínqueres após ca lcin ação, segundo a expressão Y=X/((100-PF)/100)

A análise da Tabela 22 e da Figura 38 permite verificar que a série de clínqueres dopada com estrôncio (MPCL-SR) exibe uma boa correspondência entre o conteúdo de SrO das farinhas (recalculado para $\mathrm{PF}=0$ ) nos clínqueres permitindo afirmar que não houve perda no processo de calcinação.

De modo análogo, as três séries dopadas com $\mathrm{P}_{2} \mathrm{O}_{5}$ apresentam em $80 \%$ dos casos uma boa correspondência entre o conteúdo de $\mathrm{P}_{2} \mathrm{O}_{5}$ nas farinhas (recalculado para $\mathrm{PF}=0$ ) e dos clínqueres. Todavia, para as amostras MPCL-AP100 e MPCL-AP200 da série da apatita e a amostra MPCL-OS50 da série com adição de osso observa-se um discrepância entre esses valores da ordem de $20 \%$. 0 caráter aleatório dessa variação sugere que ela seja decorrente de erros da análise química e não deve estar relacionada a fenômenos de volatilização desses elementos.

No caso da série de clínqueres dopados com enxofre (MPCL-SX), a comparação dos teores desse elemento nas farinhas e nos respectivos clínqueres mostra que houve perda por volatilização no processo de calcinação. O gráfico da Figura 39 mostra uma comparação entre os teores de enxofre obtidos nas análises químicas dos clínqueres experimentais e aqueles calculados com base na adição de gipsita e na perda ao fogo das farinhas. A diferença observada refere-se ao conteúdo de enxofre volatilizado. 


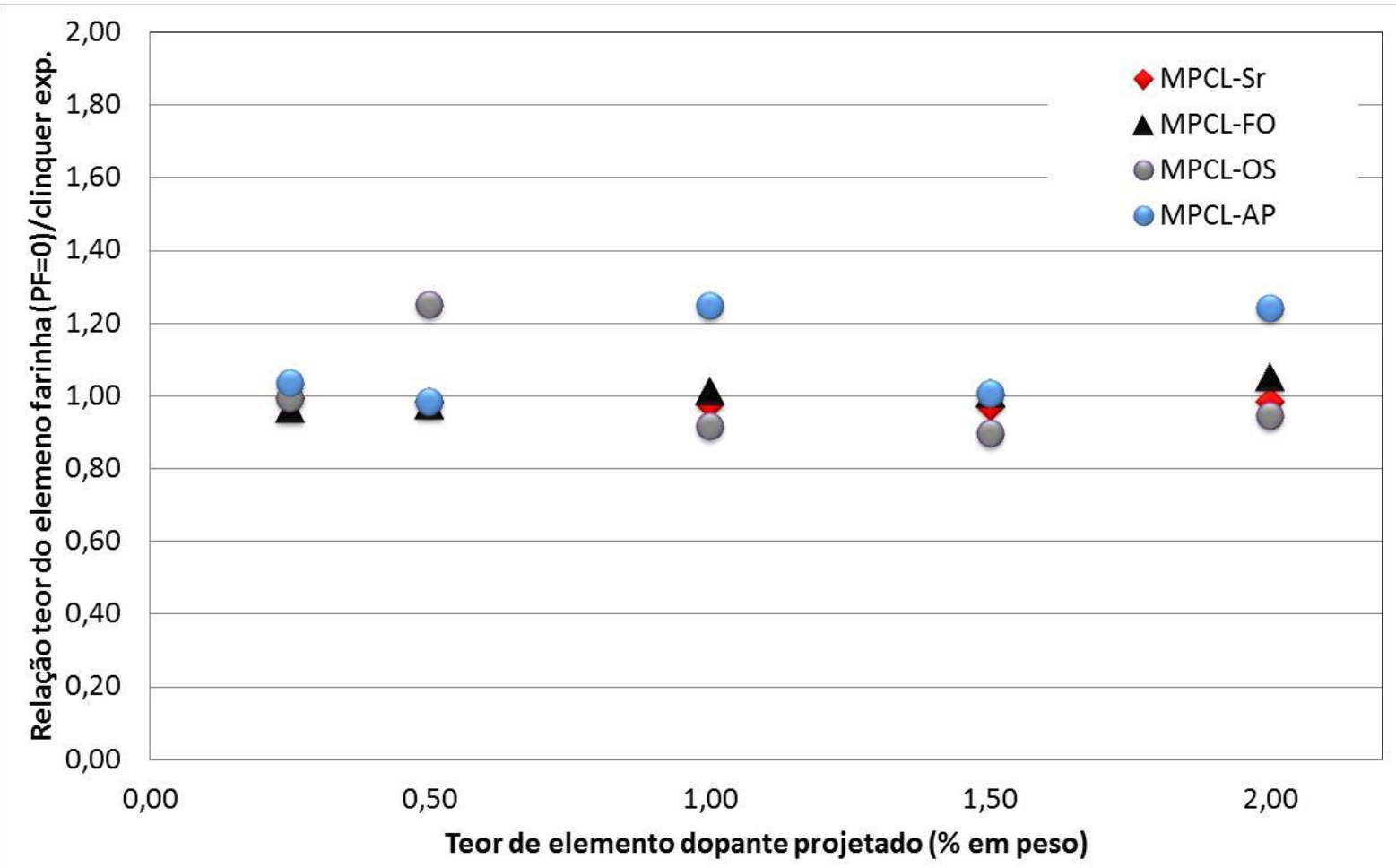

Figura 38 - Comparação entre os teores de elementos dopantes $\left(\mathrm{P}_{2} \mathrm{O}_{5}\right.$ e $\left.\mathrm{SrO}\right)$ das farinhas e dos clínqueres experimentais.

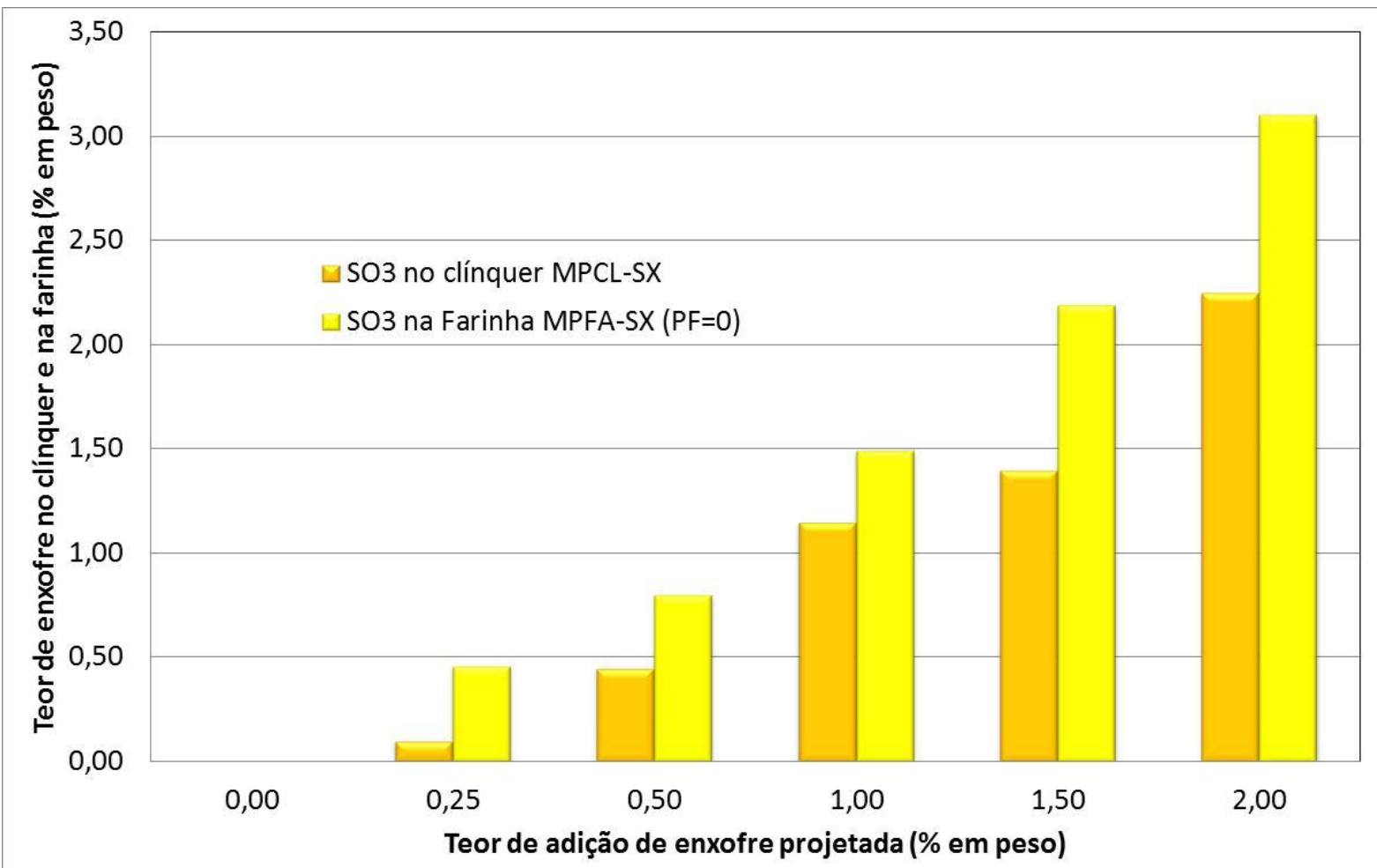

Figura 39- Comparação entre os teores de enxofre das farinhas dos clínqueres experimentais. 


\subsection{Composição Mineralógica}

A composição mineralógica dos clínqueres experimentais foi determinada por microscopia ótica e por difratometria de raios $X$ pelo método de Rietveld. Os resultados são apresentados nas Tabelas $23,24,25$ e 26.

\begin{tabular}{|c|c|c|c|c|c|c|c|c|c|c|c|c|}
\hline \multirow{3}{*}{$\begin{array}{l}\text { Minerais } \\
\text { (\% em } \\
\text { peso) }\end{array}$} & \multicolumn{12}{|c|}{ Clínqueres } \\
\hline & \multicolumn{2}{|c|}{ MPCL-REF1 } & \multicolumn{2}{|c|}{ MPCL-SR2O } & \multicolumn{2}{|c|}{ MPCL-SR50 } & \multicolumn{2}{|c|}{ MPCL-SR100 } & \multicolumn{2}{|c|}{ MPCL-SR150 } & \multicolumn{2}{|c|}{ MPCL-SR200 } \\
\hline & Rietveld & Microsc. & Rietveld & Microsc. & Rietveld & Microsc. & Rietveld & Microsc. & Rietveld & Microsc. & Rietveld & Microsc. \\
\hline Alita & 74,8 & 71,7 & 69,5 & 70,2 & 67,6 & 67,1 & 65,8 & 59,8 & 60,6 & 56,5 & 46,1 & 37,2 \\
\hline Belita & 3,9 & 9,5 & 7,4 & 10,3 & 8,4 & 11,7 & 9 & 18,1 & 11,1 & 18,0 & 25,3 & 32,9 \\
\hline $\mathrm{C}_{3} \mathrm{~A}$ & 11,8 & 7,1 & 11,8 & 6,9 & 12,9 & 6,9 & 13,9 & 6,5 & 15 & 6,6 & 13,7 & 6,6 \\
\hline $\mathrm{C}_{4} \mathrm{AF}$ & 7,0 & 10,2 & 7,1 & 10,3 & 7,3 & 10,5 & 6,1 & 9,5 & 6,3 & 8,4 & 4,1 & 10,3 \\
\hline Cal livre & 1,9 & 1,5 & 4,1 & 2,3 & 3,9 & 3,9 & 5,1 & 6,1 & 7,0 & 10,6 & 10,7 & 12,9 \\
\hline $\mathrm{R}_{\mathrm{wp}}$ & 13,1 & - & 13,6 & - & 13,1 & - & 13,4 & - & 13,8 & - & 17,6 & - \\
\hline GOF & 11,2 & - & 11,5 & - & 11,1 & - & 12 & - & 12,3 & - & 20,4 & - \\
\hline$C_{3} S+C_{2} S$ & 78,7 & 81,1 & 76,9 & 80,5 & 76,0 & 78,8 & 74,8 & 77,9 & 71,7 & 74,4 & 71,4 & 70,2 \\
\hline $\mathrm{C}_{3} \mathrm{~A}+\mathrm{C}_{4} \mathrm{AF}$ & 18,8 & 17,3 & 18,9 & 17,2 & 20,2 & 17,4 & 20,0 & 16,0 & 21,3 & 15,0 & 17,8 & 17,0 \\
\hline $\mathrm{C}_{3} \mathrm{~S} / \mathrm{C}_{2} \mathrm{~S}$ & 19,2 & 7,55 & 9,4 & 6,82 & 8,0 & 5,74 & 7,3 & 3,31 & 5,5 & 3,15 & 1,8 & 1,13 \\
\hline $\mathrm{C}_{3} \mathrm{~A} / \mathrm{C}_{4} \mathrm{AF}$ & 1,7 & 0,69 & 1,7 & 0,67 & 1,8 & 0,66 & 2,3 & 0,69 & 2,4 & 0,78 & 3,3 & 0,64 \\
\hline \multicolumn{13}{|c|}{ Tabela 24 - Análise mineralógica dos clínqueres experimentais do pados com enxofre } \\
\hline \multirow{3}{*}{$\begin{array}{c}\text { Minerais (\% } \\
\text { em peso) }\end{array}$} & \multicolumn{12}{|c|}{ Clínqueres } \\
\hline & \multicolumn{2}{|c|}{ MPCL-REF2 } & \multicolumn{2}{|c|}{ MPCL-SX25 } & \multicolumn{2}{|c|}{ MPCL-SX50 } & \multicolumn{2}{|c|}{ MPCL-SX100 } & \multicolumn{2}{|c|}{ MPCL-SX150 } & \multicolumn{2}{|c|}{ MPCL-SX200 } \\
\hline & Rietveld & Microsc. & Rietveld & Microsc. & Rietveld & Microsc. & Rietveld & Microsc. & Rietveld & Microsc. & Rietveld & Microsc. \\
\hline Alita & 69,8 & 68,2 & 72,2 & 66,9 & 72,3 & 65,8 & 70,6 & 61,0 & 65,1 & 55,7 & 52,6 & 44,3 \\
\hline Belita & 6,2 & 13,7 & 8,0 & 13,5 & 9,6 & 14,8 & 13,2 & 22,8 & 18,7 & 28,0 & 28 & 38,4 \\
\hline $\mathrm{C}_{3} \mathrm{~A}$ & 13,6 & 7,1 & 12,8 & 7,0 & 10,4 & 6,8 & 9,3 & 5,2 & 8,5 & 5,0 & 8,1 & 5,8 \\
\hline $\mathrm{C}_{4} \mathrm{AF}$ & 6,8 & 10,3 & 5,7 & 10,4 & 6,7 & 10,5 & 5,4 & 7,8 & 6 & 7,6 & 8,4 & 8,5 \\
\hline Cal livre & 3,5 & 0,6 & 0,9 & 2,2 & 0,5 & 2,1 & 1,0 & 3,2 & 1,4 & 3,7 & 2,4 & 3,1 \\
\hline $\mathrm{R}_{\mathrm{wp}}$ & 14,2 & - & 15,5 & - & 16,5 & - & 19,5 & - & 20,9 & - & 17,6 & - \\
\hline GOF & 5,1 & - & 6,2 & - & 7,0 & - & 9,6 & - & 11,1 & - & 7,8 & - \\
\hline $\mathrm{C}_{3} \mathrm{~S}+\mathrm{C}_{2} \mathrm{~S}$ & 76,0 & 82,0 & 80,2 & 80,4 & 81,9 & 80,7 & 83,8 & 83,8 & 83,8 & 83,7 & 80,6 & 82,7 \\
\hline$C_{3} A+C_{4} A F$ & 20,4 & 17,4 & 18,5 & 17,4 & 17,1 & 17,3 & 14,7 & 13,0 & 14,5 & 12,5 & 16,5 & 14,2 \\
\hline $\mathrm{C}_{3} \mathrm{~S} / \mathrm{C}_{2} \mathrm{~S}$ & 11,3 & 4,98 & 9,0 & 4,97 & 7,5 & 4,44 & 5,3 & 2,68 & 3,5 & 1,98 & 1,9 & 1,15 \\
\hline $\mathrm{C}_{3} \mathrm{~A} / \mathrm{C}_{4} \mathrm{AF}$ & 2,0 & 0,7 & 2,2 & 0,7 & 1,6 & 0,6 & 1,7 & 0,7 & 1,4 & 0,7 & 1,0 & 0,7 \\
\hline
\end{tabular}


Tabela 25 - Análise mineralógica dos clínqueres experimentais dopados com fósforo

\begin{tabular}{|c|c|c|c|c|c|c|c|c|c|c|c|c|c|c|c|c|}
\hline \multirow{3}{*}{$\begin{array}{l}\text { Minerais } \\
\text { (\% em peso) }\end{array}$} & \multicolumn{16}{|c|}{ Clínqueres } \\
\hline & \multicolumn{2}{|c|}{ MPCL-REF2 } & \multicolumn{2}{|c|}{ MPCL-FO25 } & \multicolumn{2}{|c|}{ MPCL-FO50 } & \multicolumn{2}{|c|}{ MPCL-F0100 } & \multicolumn{2}{|c|}{ MPCL-FO150 } & \multicolumn{2}{|c|}{ MPCL-FO200 } & \multicolumn{2}{|c|}{ MPCL-AP25 } & \multicolumn{2}{|c|}{ MPCL-AP50 } \\
\hline & Rietveld & Microsc. & Rietveld & Microsc. & Rietveld & Microsc. & Rietveld & Microsc. & Rietveld & Microsc. & Rietveld & Microsc. & Rietveld & Microsc. & Rietveld & Microsc \\
\hline Alita & 69,8 & 68,2 & 68,5 & 62,0 & 63,8 & 56,9 & 55,6 & 48,7 & 42,3 & 43,3 & 28,1 & 32,6 & 67,2 & 63,1 & 62,4 & 62,0 \\
\hline Belita & 6,2 & 13,7 & 8,7 & 16,5 & 13,5 & 23,0 & 21,8 & 31,6 & 31,1 & 37,0 & 42,5 & 47,6 & 9,5 & 16,8 & 15,3 & 23,0 \\
\hline $\mathrm{C}_{3} \mathrm{~A}$ & 13,6 & 7,1 & 12,5 & 7,6 & 14,4 & 7,3 & 13,2 & 6,6 & 15,5 & 5,0 & 18,1 & 5,9 & 14,1 & 7,6 & 13,6 & 5,4 \\
\hline $\mathrm{C}_{4} \mathrm{AF}$ & 6,8 & 10,3 & 7,4 & 10,5 & 5,8 & 10,1 & 6,3 & 8,9 & 4,8 & 6,9 & 9,2 & 8,1 & 7,8 & 10,2 & 6,9 & 7,4 \\
\hline Cal livre & 3,5 & 0,6 & 2,9 & 3,4 & 2,3 & 2,8 & 3,0 & 4,2 & 6,1 & 7,7 & 1,8 & 5,8 & 1,3 & 2,3 & 1,7 & 2,2 \\
\hline $\mathrm{R}_{\mathrm{wp}}$ & 14,2 & - & 15,5 & - & 15,5 & - & 18,6 & - & 20,7 & - & 21,9 & - & 16,1 & - & 15,2 & - \\
\hline GOF & 5,1 & - & 5,8 & - & 5,9 & - & 8,7 & - & 10,6 & - & 12,2 & - & 6,6 & - & 5,9 & - \\
\hline $\mathrm{C}_{3} \mathrm{~S}+\mathrm{C}_{2} \mathrm{~S}$ & 76,0 & 82,0 & 77,2 & 78,5 & 77,3 & 79,9 & 77,4 & 80,3 & 73,4 & 80,3 & 70,6 & 80,2 & 76,7 & 79,8 & 77,7 & 85,0 \\
\hline$C_{3} A+C_{4} A F$ & 20,4 & 17,4 & 19,9 & 18,1 & 20,2 & 17,3 & 19,5 & 15,5 & 20,3 & 12,0 & 27,3 & 14,0 & 21,9 & 17,8 & 20,5 & 12,8 \\
\hline $\mathrm{C}_{3} \mathrm{~S} / \mathrm{C}_{2} \mathrm{~S}$ & 11,3 & 4,98 & 7,9 & 3,77 & 4,7 & 2,47 & 2,6 & 1,54 & 1,4 & 1,17 & 0,7 & 0,68 & 7,1 & 3,76 & 4,1 & 2,69 \\
\hline $\mathrm{C}_{3} \mathrm{~A} / \mathrm{C}_{4} \mathrm{AF}$ & 2,0 & 0,69 & 1,7 & 0,73 & 2,5 & 0,72 & 2,1 & 0,74 & 3,2 & 0,73 & 2,0 & 0,72 & 1,8 & 0,74 & 2,0 & 0,74 \\
\hline
\end{tabular}

Tabela 26 - Análise mineralógica dos clínqueres experimentais dopados com fósforo

\begin{tabular}{|c|c|c|c|c|c|c|c|c|c|c|c|c|c|c|c|c|}
\hline \multirow{3}{*}{$\begin{array}{l}\text { Minerais } \\
\text { (\% em peso) }\end{array}$} & \multicolumn{16}{|c|}{ Clínqueres } \\
\hline & \multicolumn{2}{|c|}{ MPCL-AP100 } & \multicolumn{2}{|c|}{ MPCL-AP150 } & \multicolumn{2}{|c|}{ MPCL-AP200 } & \multicolumn{2}{|c|}{ MPCL-OS25 } & \multicolumn{2}{|c|}{ MPCL-OS50 } & \multicolumn{2}{|c|}{ MPCL-OS100 } & \multicolumn{2}{|c|}{ MPCL-OS150 } & \multicolumn{2}{|c|}{ MPCL-OS200 } \\
\hline & Rietveld & Microsc. & Rietveld & Microsc. & Rietveld & Microsc. & Rietveld & Microsc. & Rietveld & Microsc. & Rietveld & Microsc. & Rietveld & Microsc. & Rietveld & Microsc. \\
\hline Alita & 51,8 & 56,5 & 40,3 & 49,6 & 32,0 & 47,9 & 65 & 64,8 & 64,4 & 61,4 & 48,0 & 43,2 & 41,1 & 37,4 & 27,1 & 35,3 \\
\hline Belita & 24,9 & 28,3 & 34,8 & 33,7 & 45,2 & 34,3 & 10,2 & 16,0 & 12 & 19,9 & 27,3 & 36,0 & 31 & 40,1 & 45,8 & 44,8 \\
\hline $\mathrm{C}_{3} \mathrm{~A}$ & 14,1 & 5,2 & 13,7 & 6,1 & 12,3 & 5,9 & 14,1 & 7,3 & 15,2 & 6,5 & 16,9 & 6,2 & 16,2 & 6,5 & 15,6 & 5,7 \\
\hline $\mathrm{C}_{4} \mathrm{AF}$ & 6,2 & 7,3 & 7,2 & 8,4 & 6,5 & 8,5 & 6,2 & 9,4 & 5,4 & 8,7 & 6,5 & 8,8 & 5,9 & 8,7 & 6,8 & 7,8 \\
\hline Cal livre & 3,0 & 2,7 & 3,9 & 2,1 & 3,9 & 3,4 & 2,7 & 2,5 & 0,8 & 3,6 & 0,8 & 5,7 & 3,9 & 7,4 & 1,0 & 6,4 \\
\hline $\mathrm{R}_{\mathrm{wp}}$ & 18,2 & - & 20,8 & - & 22 & - & 14,9 & - & 15,4 & - & 19,6 & - & 19,7 & - & 20,9 & - \\
\hline GOF & 8,2 & - & 10,6 & - & 12,3 & - & 5,5 & - & 5,9 & - & 9,6 & - & 9,2 & - & 11,5 & - \\
\hline $\mathrm{C}_{3} \mathrm{~S}+\mathrm{C}_{2} \mathrm{~S}$ & 76,7 & 84,9 & 75,1 & 83,3 & 77,2 & 82,2 & 75,2 & 80,8 & 76,4 & 81,3 & 75,3 & 79,2 & 72,1 & 77,5 & 72,9 & 80,2 \\
\hline$C_{3} A+C_{4} A F$ & 20,3 & 12,4 & 20,9 & 14,6 & 18,8 & 14,4 & 20,3 & 16,7 & 20,6 & 15,1 & 23,4 & 15,0 & 22,1 & 15,1 & 22,4 & 13,4 \\
\hline $\mathrm{C}_{3} \mathrm{~S} / \mathrm{C}_{2} \mathrm{~S}$ & 2,1 & 2,00 & 1,2 & 1,47 & 0,7 & 1,39 & 6,4 & 4,06 & 5,4 & 3,09 & 1,8 & 1,20 & 1,3 & 0,93 & 0,6 & 0,79 \\
\hline $\mathrm{C}_{3} \mathrm{~A} / \mathrm{C}_{4} \mathrm{AF}$ & 2,3 & 0,71 & 1,9 & 0,73 & 1,9 & 0,70 & 2,3 & 0,78 & 2,8 & 0,75 & 2,6 & 0,71 & 2,7 & 0,75 & 2,3 & 0,73 \\
\hline
\end{tabular}




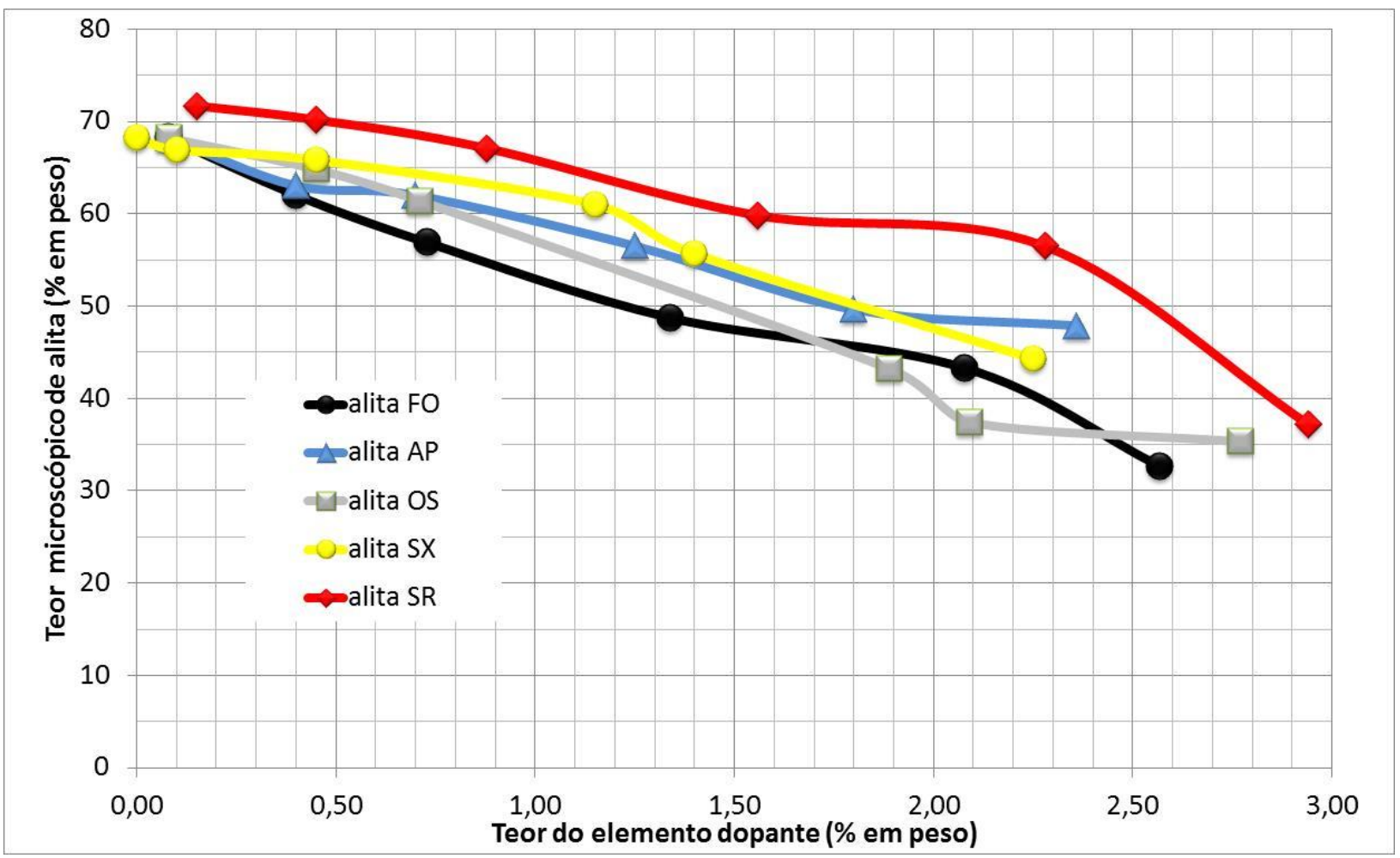

Figura 40 - Variação dos teores de alita com o incremento dos elementos dopantes

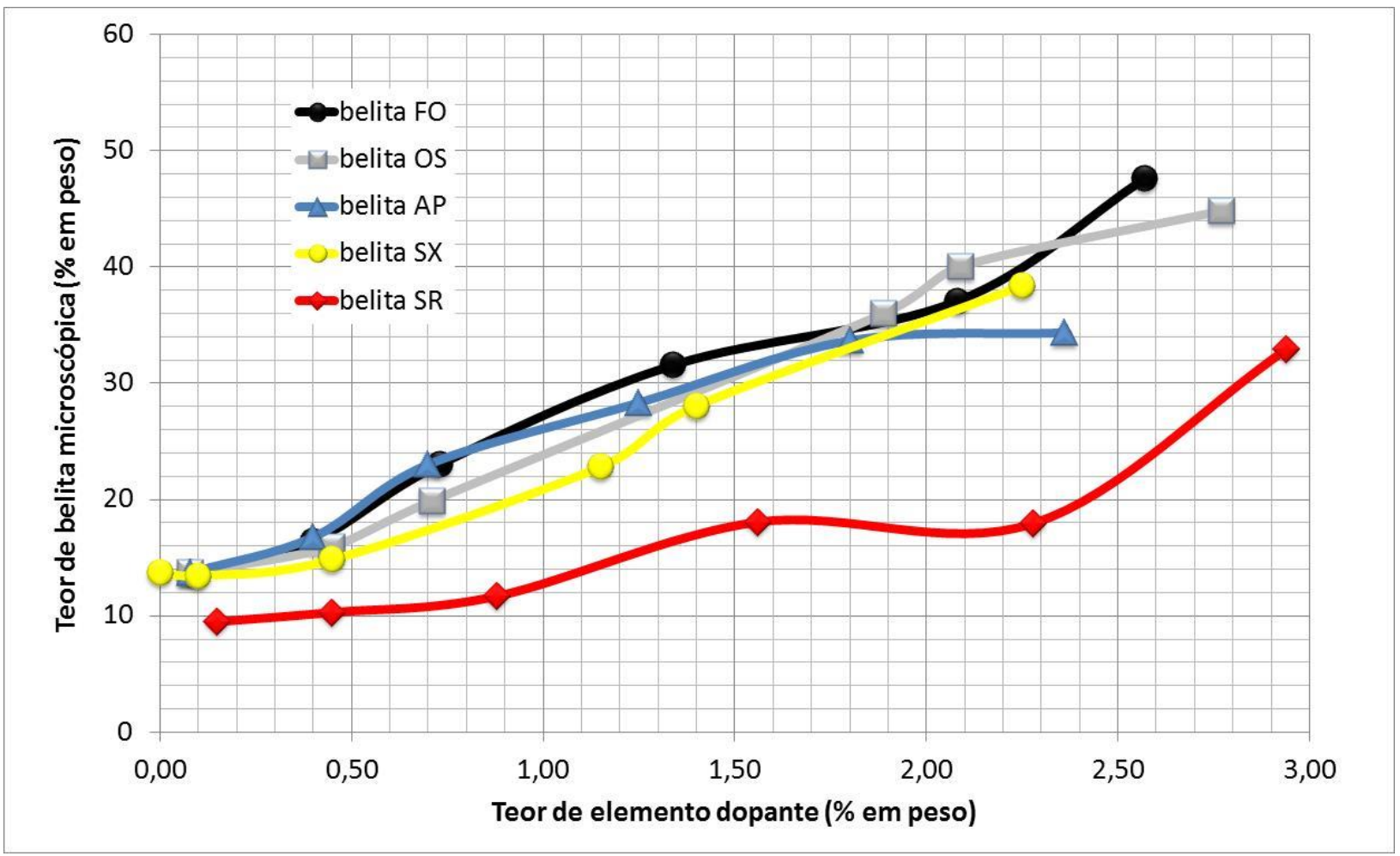

Figura 41 - Variação dos teores de belita com o incremento dos elementos dopantes

Nota-se uma tendência geral nos clínqueres experimentais de diminuição do teor de alita e aumento do teor de belita com o aumento da adição dos elementos dopantes. 
Dentre os clínqueres obtidos pela adição de fósforo proveniente de diferentes fontes, nota-se uma tendência da adição de apatita (série MPCL- AP), de apresentar clínqueres com maior conteúdo de alita em relação ao fosfato puro (MPCL-FO) e a adição de osso (MPCL-OS).

A Tabela 27 apresenta os coeficientes das retas obtidas na tentativa de se aproximar os dados de variação dos teores de alita e belita pelo conteúdo de elementos dopantes (Figuras 40 e 41) por uma regressão linear. Verifica-se que os coeficientes angulares das retas que descrevem os dados da série MPCL-AP são menores que aqueles observados nas séries MPCL-FO e MPCL-OS, tanto para alita como para belita, comprovando essa tendência. Analogamente, os valores apresentados pela série do enxofre (MPCL-SX) assemelham-se mais aos obtidos na série MPCL AP que aos demais.

A série que possui adição de estrôncio (MPCL- SR), dentre os clínqueres obtidos, é a que apresenta os maiores teores de alita e menores conteúdos de belita, situando-se nas porções superiores e inferiores respectivamente dos gráficos das Figuras 40 e 41 . Os parâmetros das retas obtidos da Tabela 27 mostram baixos coeficientes angulares e os termos independentes posicionam as curvas da alita e belita, respectivamente, nos pontos superior e inferior dos gráficos.

Apesar de não se possuir na literatura informações quanto às equações que melhor descrevem a variação do teor do mineral com a adição do elemento dopante, as aproximações obtidas apresentaram um $\mathrm{R}^{2}$ sistematicamente superior a 0,90 sugerindo boa aderência dos dados.

\begin{tabular}{lccc}
\hline \multicolumn{3}{c}{ Tabela 27 - Regressão linear dos teores de alita e belita com a adição de elementos } \\
dopantes \\
\hline Séries & \multicolumn{3}{c}{ Parâmetros das curvas (y=aX+b) } \\
\cline { 2 - 4 } & \multicolumn{4}{c}{ Coeficiente angular } & Termo independente & $\mathrm{R}^{2}$ \\
\hline Alita MPCL-FO & $-13,21$ & 67,82 & 0,981 \\
Alita MPCL-AP & $-9,078$ & 67,86 & 0,974 \\
Alita MPCL-OS & $-13,62$ & 69,88 & 0,973 \\
Alita MPCL-SX & $-10,22$ & 69,43 & 0,950 \\
Alita MPCL-SR & $-11,21$ & 75,86 & 0,902 \\
\hline Belita MPCL-FO & 13,15 & 12,46 & 0,983 \\
Belita MPCL-AP & 9,604 & 14,43 & 0,939 \\
Belita MPCL-OS & 12,55 & 11,70 & 0,988 \\
Belita MPCL-SX & 11,31 & 11,79 & 0,973 \\
Belita MPCL-SR & 7,457 & 6,479 & 0,853 \\
\hline
\end{tabular}

O gráfico da Figura 42 apresenta a variação da soma dos silicatos (alita + belita) e dos aluminatos $\left(C_{3} A+C_{4} A F\right)$ em relação ao teor de elemento dopante. Pode-se verificar que o conteúdo de aluminatos $\left(\mathrm{C}_{3} \mathrm{~A}+\mathrm{C}_{4} \mathrm{AF}\right)$ que constituem a fase intersticial dos clínqueres é constante, não apresentando variações com o incremento de teor dos elementos dopantes.

O conteúdo total de silicatos (alita+belita) nos clínqueres experimentais também mostra em sua 
maioria boa estabilidade de valores com o aumento do teor de elemento dopante. Todavia, a série com adição de estrôncio mostra tendência de diminuição desse parâmetro para adições superiores a $2 \%$ em peso. De um modo geral, a constância desses parâmetros pode ser atribuída à estabilidade e manutenção dos módulos químicos (FSC, MS e MA) dentro de um pequeno intervalo de valores.

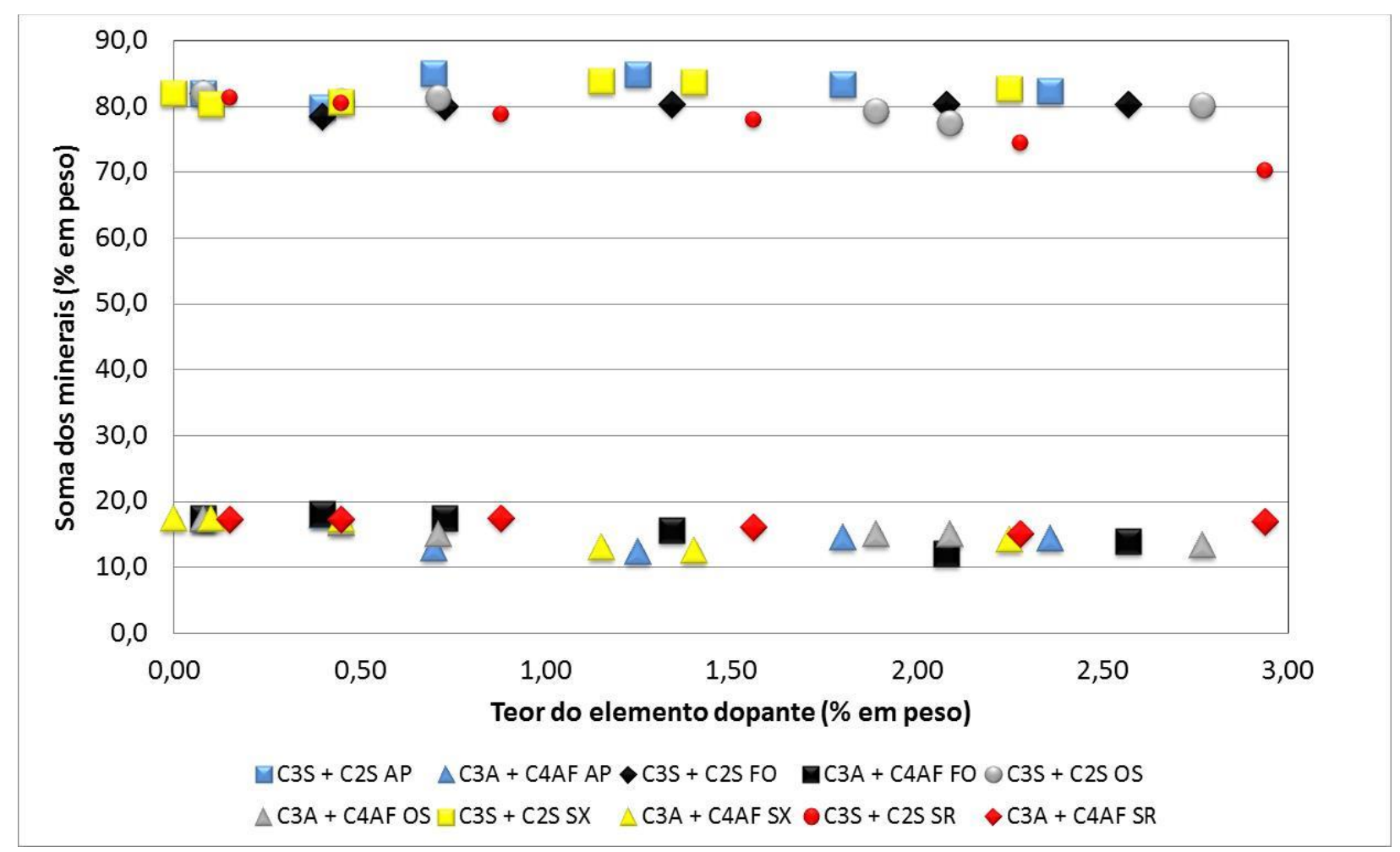

Figura 42 - Variação do conteúdo de silicatos $\left(C_{3} S+C_{2} S\right)$ e fase intersticial $\left(C_{3} A+C_{4} A F\right)$ presentes nos clínqueres experimentais.

\subsubsection{Composição mineralógica Microscopia ótica X Método de Rietveld}

Neste item procura-se comparar os dados de composição mineralógica obtidos por microscopia ótica e pelo Método de Rietveld, apresentados nas Tabelas 23, 24, 25 e 26.

As duas técnicas de determinação do teor de fases minerais apresentaram pequenas diferenças e se observam as mesmas tendências gerais registradas pela microscópia ótica e discutidas anteriormente.

Tendo em vista, a perspectiva de utilização dos parâmetros do refinamento para análise das variações polimórficas ou dos parâmetros de cela unitária dos clínqueres experimentais, julga-se oportuno comparar as duas técnicas, procurando-se definir limites e tendências.

Os gráficos das Figuras 43 e 44 apresentam a relação entre os dados obtidos pelo Método de Rietveld e aqueles obtidos por microscopia ótica para todas as séries elaboradas. Nota-se, como tendência geral, que os conteúdos de alita determinados por Rietveld tendem a ser pouco 
superiores que os obtidos por microscopia, apresentando um pequeno aumento dessa diferença com o aumento do teor de elemento dopante.

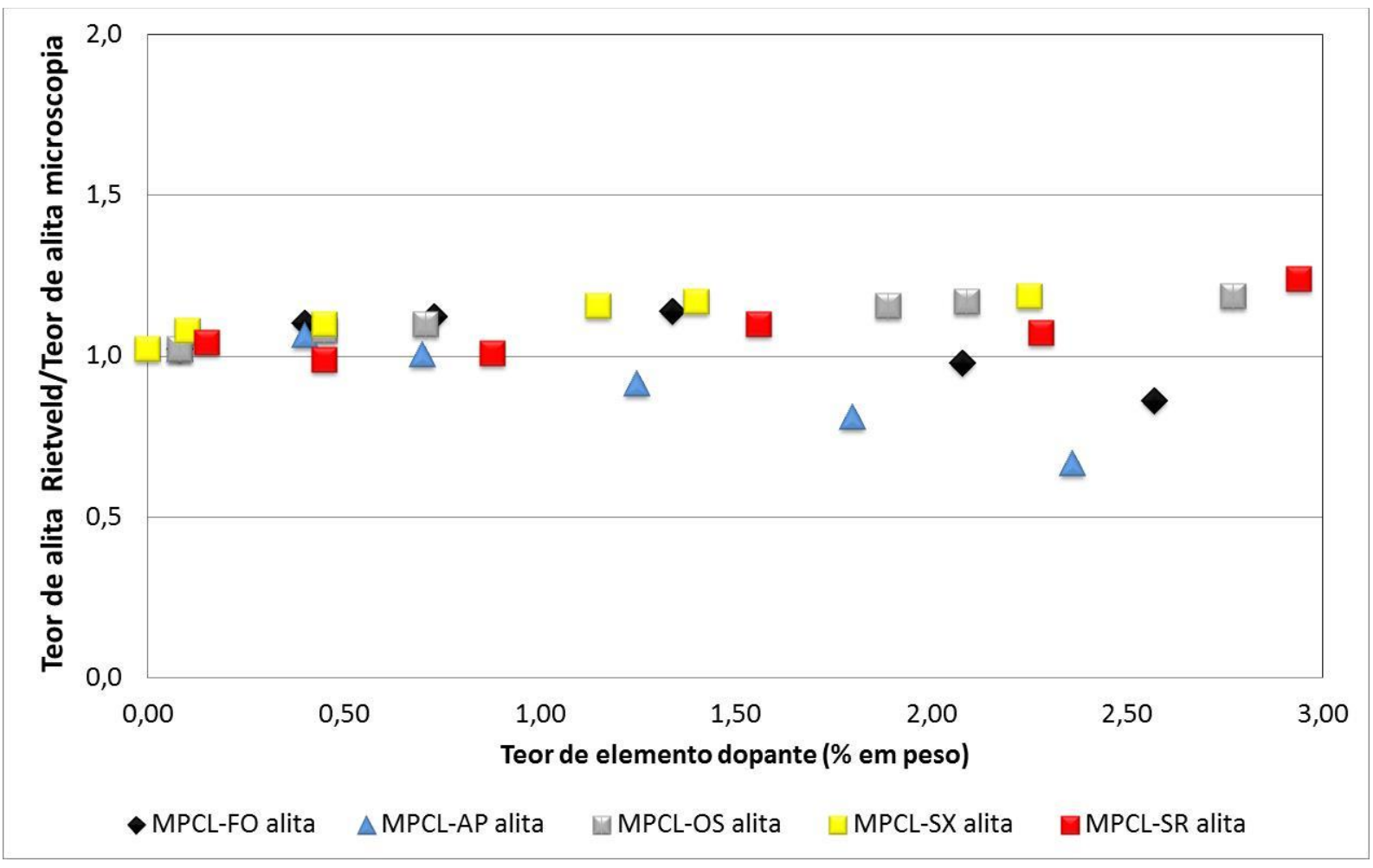

Figura 43- Relação entre os teores de alita determinados por microscopia e Método de Rietveld.

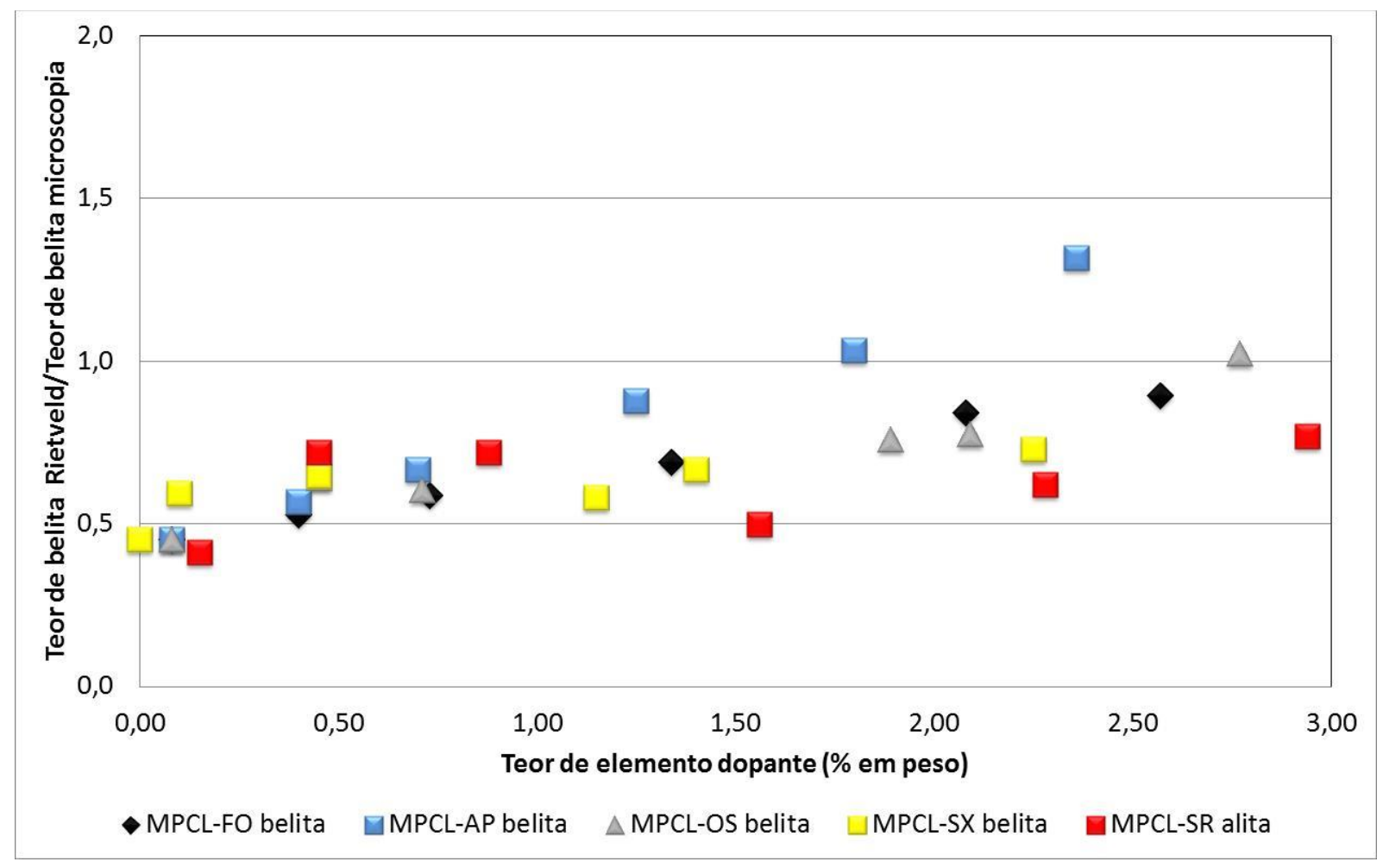

Figura 44 - Relação entre os teores de belita determinados por microscopia e Método de Rietveld. 
Para as séries MPCL-SR, MPCL-SX e MPCL-FO os teores de alita determinados pelo Método de Rietveld podem ser até $20 \%$ superiores aos determinados por microscopia. As séries MPCL-AP e MPCL-OS exibem uma tendência distinta das demais; nessas, a partir de teores de adição superiores a $1,5 \%$ em peso, são os teores microscópicos que tendem a serem maiores. A diferença também aumenta com o aumento do teor de elemento dopante, porém, de modo mais intenso.

No caso da amostra MPCL-AP200 o teor de alita determinado por microscopia é superior ao obtido por Rietveld em relativamente $30 \%$.

Com relação à belita, o Método de Rietveld tende a apresentar resultados subestimados em sua maioria, com uma concentração de valores da diferença ao redor de $50 \%$ em relação à microscopia ótica. Porém, observa-se uma tendência de diminuição da diferença entre os dois métodos com o aumento do teor de elemento dopante. A série MPCL-AP possui um comportamento distinto das demais, se aproximando dos valores apresentados pela microscopia ótica a partir de teores de adição de $\mathrm{P}_{2} \mathrm{O}_{5}$ de $1,0 \%$ em peso.

A qualidade dos dados obtidos pelo método de Rietveld pode ser inferida pela qualidade do ajuste entre o difratograma experimental e o calculado e para tanto se utilizam dois fatores: o Rwp (Residue weight profile), também conhecido como R ponderado, e o GOF (goodness of fit) ou X2 (Toby, 2006). O Rwp determina quanto os valores dos parâmetros em refinamento (intensidade calculada) convergiram para o valor real (intensidade observada) para todos e cada ponto do difratograma.

Já o GOF é definido pela razão entre o Rwp e o Rexp (Rexp=valor estatisticamente esperado para o Rwp) e idealmente deve estar próximo de 1, indicando que nada mais pode ser melhorado para aproximar os valores observados dos calculados. Todavia, deve-se considerar que Rexp é função da qualidade dos difratogramas e das estatísticas de contagem. Desse modo, altos valores de Rexp, ou difratogramas de baixa qualidade, podem originar baixos valores de GOF sem que se obtenha um bom ajuste do modelo. De modo inverso, um bom ajuste do refinamento para um difratograma de alta qualidade, com baixo valor de Rexp, pode resultar elevados valores de GOF. Sendo assim, neste trabalho optou-se pela análise apenas de Rwp.

A Figura 45 correlaciona o Rwp, apresentado nas Tabelas 23, 24, 25 e 26, com o teor de elementos dopantes para as séries de clínqueres experimentais. As séries dopadas com fósforo (MPCL-AP, MPCL-OS e MPCL-FO) apresentam comportamento muito similar e praticamente estão sobrepostas, o Rwp chega a ser superior a 20 para os teores próximos a $2 \%$ em peso.

A introdução de estrôncio, série MPCL-SR, não provoca alterações significativas no Rwp até o teor de aproximadamente $2 \%$ em peso, nas quais este se mantem ao redor de 13 , a partir daí nota-se um aumento (amostra MPCL-SR200) e o Rwp atinge o valor de 17,6. 


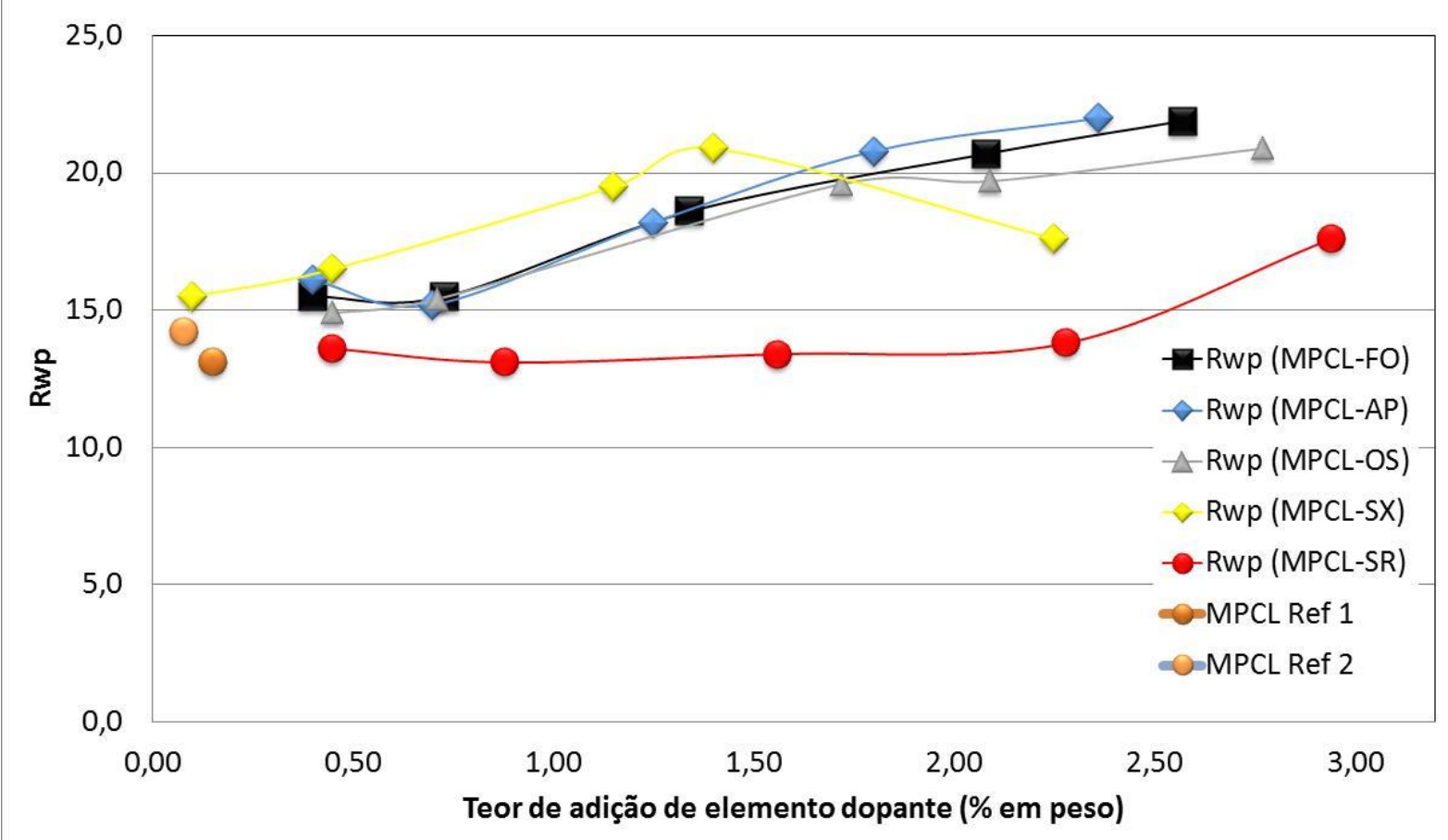

Figura 45 - Variação do Rwp dos refinamentos pelo teor de elementos dopantes - Método de Rietveld.

A incorporação do enxofre, série MPCL-SX, parece provocar um comportamento diferenciado dos demais. O Rwp aumenta progressivamente de 14 a 20 até o teor de 1,5\% (MPCL-SX150), para depois cair para 17 na amostra MPCL-SX200.

Deve-se considerar que a análise pelo Método de Rietveld, assim como a análise modal por microscopia, totaliza todos os minerais em 100\%, o que significa que os possíveis erros de quantificação de uma fase mineral são propagados ou compensados pelas demais.

\subsection{Parâmetros de Cela Unitária}

As variações dos parâmetros da cela unitária das fases alita $\left(C_{3} S\right)$ e belita $\left(C_{2} S\right)$ em função das adições e seus distintos teores são apresentadas respectivamente nas Tabelas 28 e 29 e nas Figuras 46 e 47.

Observa-se que os volumes das celas unitárias dos cristais de $\mathrm{C}_{3} \mathrm{~S}$ determinados pelo refinamento de Rietveld possuem tendências distintas de acordo com o tipo de elemento dopante, porém não se notam variações em função do aumento do teor de elemento dopante. O que sugere que mesmo em baixos teores esses efeitos já se processam. 


\begin{tabular}{|c|c|c|c|c|c|c|c|}
\hline Amostras & $\begin{array}{l}\text { Teor de adição } \\
\text { (\% peso) }\end{array}$ & a $(\AA ̊)$ & $b(\AA ̊)$ & c ( $(\AA)$ & $\beta\left(^{\circ}\right)$ & $\mathrm{R}_{\mathrm{B}}(*)$ & $\begin{array}{c}\text { Volume da } \\
\text { cela }\left(\AA^{3}\right)\end{array}$ \\
\hline Ref1 & 0,00 & 12,23334 & 7,07899 & 9,30233 & 116,07390 & 10,69 & 723,59344 \\
\hline Ref2 & 0,00 & 12,23747 & 7,08077 & 9,30350 & 116,08000 & 11,33 & 724,07276 \\
\hline MPCLSR20 & 0,20 & 12,23559 & 7,08261 & 9,30319 & 116,08700 & 11,53 & 724,08170 \\
\hline MPCLSR50 & 0,50 & 12,23657 & 7,08160 & 9,30477 & 116,10940 & 11,23 & 724,02171 \\
\hline MPCLSR100 & 1,00 & 12,23736 & 7,08193 & 9,30619 & 116,11740 & 12,93 & 724,16302 \\
\hline MPCLSR150 & 1,50 & 12,23540 & 7,08593 & 9,30478 & 116,12490 & 12,56 & 724,29933 \\
\hline MPCLSR200 & 2,00 & 12,24513 & 7,08249 & 9,30430 & 116,16450 & 19,25 & 724,24080 \\
\hline MPCL AP 25 & 0,25 & 12,24636 & 7,08150 & 9,30840 & 116,07560 & 14,07 & 725,08271 \\
\hline MPCL AP 50 & 0,50 & 12,24822 & 7,08230 & 9,30612 & 116,07670 & 14,30 & 725,09030 \\
\hline MPCL AP100 & 1,00 & 12,25262 & 7,07959 & 9,30838 & 116,08840 & 15,17 & 725,17676 \\
\hline MPCL AP 150 & 1,50 & 12,24831 & 7,08247 & 9,30753 & 116,06630 & 18,07 & 725,28772 \\
\hline MPCL AP200 & 2,00 & 12,24914 & 7,08066 & 9,30913 & 116,09590 & 20,39 & 725,09257 \\
\hline MPCLFO25 & 0,25 & 12,24373 & 7,08251 & 9,30596 & 116,06550 & 13,07 & 724,90295 \\
\hline MPCLFO50 & 0,50 & 12,24936 & 7,08127 & 9,30704 & 116,10630 & 18,96 & 724,94083 \\
\hline MPCLFO100 & 1,00 & 12,24970 & 7,08183 & 9,30778 & 116,09920 & 18,98 & 725,12032 \\
\hline MPCLFO150 & 1,50 & 12,24980 & 7,08067 & 9,30733 & 116,06260 & 16,71 & 725,19809 \\
\hline MPCLFO200 & 2,00 & 12,25418 & 7,07928 & 9,30669 & 116,09300 & 21,58 & 725,07649 \\
\hline MPCLOS25 & 0,25 & 12,24364 & 7,08335 & 9,30580 & 116,05430 & 11,94 & 725,03977 \\
\hline MPCLOS50 & 0,50 & 12,24599 & 7,08155 & 9,30715 & 116,08200 & 12,97 & 724,92915 \\
\hline MPCLOS100 & 1,00 & 12,24537 & 7,08094 & 9,30647 & 116,05280 & 17,42 & 724,95674 \\
\hline MPCLOS150 & 1,50 & 12,24608 & 7,08149 & 9,30613 & 116,05980 & 16,74 & 724,98603 \\
\hline MPCLOS200 & 2,00 & 12,24608 & 7,08149 & 9,30613 & 116,05980 & 14,33 & 724,98603 \\
\hline MPCL SX25 & 0,25 & 12,22962 & 7,07474 & 9,29619 & 116,08220 & 11,55 & 722,41072 \\
\hline MPCL SX50 & 0,50 & 12,23115 & 7,07479 & 9,29565 & 116,10540 & 11,67 & 722,32098 \\
\hline MPCL SX100 & 1,00 & 12,23481 & 7,07320 & 9,29533 & 116,07830 & 16,83 & 722,51721 \\
\hline MPCL SX150 & 1,50 & 12,23439 & 7,07192 & 9,29542 & 116,05930 & 17,25 & 722,48585 \\
\hline MPCL SX200 & 2,00 & 12,23435 & 7,07165 & 9,29427 & 116,17130 & 15,73 & 721,67463 \\
\hline
\end{tabular}

$(*) \mathrm{R}_{\mathrm{B}}$ indica o erro estatís tico referente ao $\mathrm{C}_{3} \mathrm{~S}$ no refinamento pelo método de Rietveld 
Tabela 29 - Parâmetros de cela de $\mathrm{C}_{2} \mathrm{~S}$ de amostras de clínquer sintetizadas em laboratório

\begin{tabular}{|c|c|c|c|c|c|c|c|}
\hline Amostras & $\begin{array}{l}\text { Teor de a dição } \\
\text { (\% peso) }\end{array}$ & $a(\AA)$ & $b(\AA)$ & $c(\AA)$ & $\beta\left(^{o}\right)$ & $R_{B}\left({ }^{*}\right)$ & $\begin{array}{c}\text { Volume da } \\
\text { cela }\left(\AA^{3}\right)\end{array}$ \\
\hline Ref1 & 0,00 & 5,48808 & 6,77057 & 10,45613 & 117,44750 & 23,68 & 344,78827 \\
\hline Ref2 & 0,00 & 5,50247 & 6,77609 & 10,53103 & 117,60690 & 20,98 & 347,94775 \\
\hline MPCLSR20 & 0,20 & 5,48917 & 6,78476 & 10,47703 & 117,21010 & 25,07 & 347,01291 \\
\hline MPCLSR50 & 0,50 & 5,48817 & 6,76986 & 10,48600 & 117,19610 & 20,56 & 346,52740 \\
\hline MPCLSR100 & 1,00 & 5,49750 & 6,78620 & 10,49689 & 117,62880 & 21,91 & 346,95398 \\
\hline MPCLSR150 & 1,50 & 5,50065 & 6,78795 & 10,50785 & 117,60450 & 20,53 & 347,68185 \\
\hline MPCLSR200 & 2,00 & 5,43795 & 6,79901 & 10,71332 & 118,93910 & 26,61 & 346,64077 \\
\hline MPCL AP 25 & 0,25 & 5,48438 & 6,78303 & 10,52092 & 117,86020 & 25,36 & 346,02040 \\
\hline MPCL AP 50 & 0,50 & 5,49634 & 6,77729 & 10,51823 & 117,55280 & 19,86 & 347,37029 \\
\hline MPCL AP100 & 1,00 & 5,49456 & 6,77532 & 10,51827 & 117,59290 & 20,91 & 347,03103 \\
\hline MPCL AP 150 & 1,50 & 5,50400 & 6,77494 & 10,51520 & 117,66040 & 20,93 & 347,29240 \\
\hline MPCL AP200 & 2,00 & 5,50940 & 6,77094 & 10,51235 & 117,52530 & 22,08 & 347,76215 \\
\hline MPCLFO25 & 0,25 & 5,48129 & 6,77766 & 10,48775 & 117,40880 & 23,09 & 345,88623 \\
\hline MPCLFO50 & 0,50 & 5,48910 & 6,77995 & 10,50076 & 117,41530 & 22,09 & 346,90527 \\
\hline MPCLFO100 & 1,00 & 5,48501 & 6,78094 & 10,49613 & 117,39410 & 22,43 & 346,61097 \\
\hline MPCLFO150 & 1,50 & 5,47573 & 6,78234 & 10,54151 & 117,68210 & 24,54 & 346,68235 \\
\hline MPCLFO200 & 2,00 & 5,50634 & 6,77354 & 10,52894 & 117,61850 & 24,87 & 347,95506 \\
\hline MPCLOS25 & 0,25 & 5,49780 & 6,77254 & 10,49118 & 117,33800 & 18,84 & 347,00126 \\
\hline MPCLOS50 & 0,50 & 5,47850 & 6,77791 & 10,50157 & 117,43330 & 23,20 & 346,10187 \\
\hline MPCLOS100 & 1,00 & 5,49446 & 6,77327 & 10,52005 & 117,55750 & 26,22 & 347,09071 \\
\hline MPCLOS150 & 1,50 & 5,48294 & 6,78294 & 10,52552 & 117,65430 & 20,00 & 346,73162 \\
\hline MPCLOS200 & 2,00 & 5,48294 & 6,78294 & 10,52552 & 117,65430 & 17,00 & 346,73162 \\
\hline MPCL SX25 & 0,25 & 5,49944 & 6,76440 & 10,51926 & 117,75060 & 22,19 & 346,31217 \\
\hline MPCL SX50 & 0,50 & 5,50469 & 6,76159 & 10,50829 & 117,63870 & 23,72 & 346,49244 \\
\hline MPCL SX100 & 1,00 & 5,50511 & 6,75700 & 10,51842 & 117,72810 & 24,22 & 346,33384 \\
\hline MPCL SX150 & 1,50 & 5,50456 & 6,75868 & 10,52195 & 117,74000 & 18,69 & 346,46375 \\
\hline MPCL SX200 & 2,00 & 5,50778 & 6,76360 & 10,48279 & 117,33460 & 16,87 & 346,90507 \\
\hline
\end{tabular}

$(*) \mathrm{R}_{\mathrm{B}}$ indica o erro estatístico referente ao $\mathrm{C}_{2} \mathrm{~S}$ no refinamento pelo método de Rietveld. 


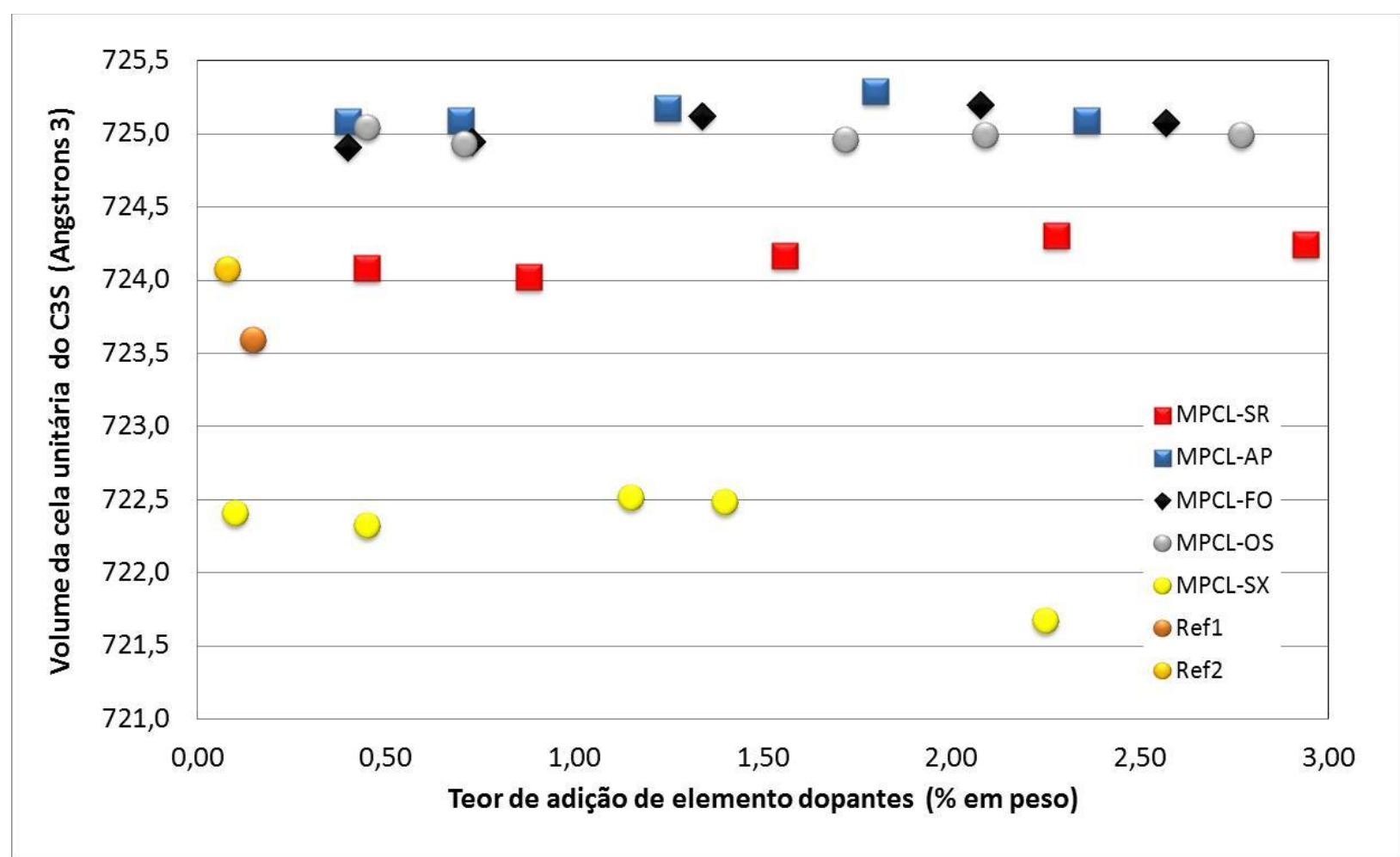

Figura 46 - Variação do volume de cela unitária do $C_{3}$ S em função do teor de adição de elementos dopantes

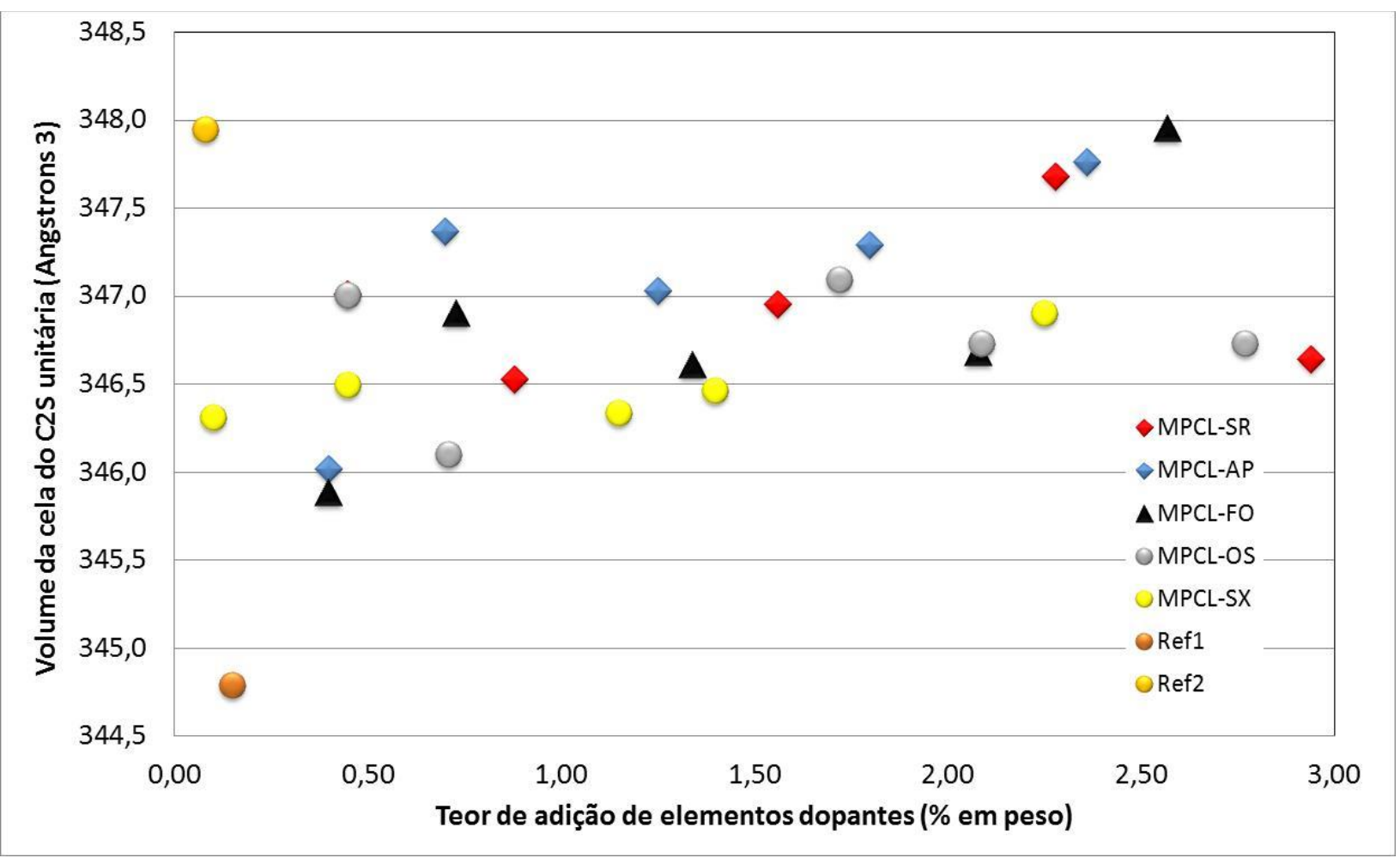

Figura 47 - Variação do volume de cela unitária do $C_{2} S$ em função do teor de adição de elementos dopantes

Para os clínqueres dopados com fósforo (MPCL-AP, MPCL-FO e MPCL-OS) as celas unitárias dos cristais de alita são muito similares, pouco superiores à referência e situam-se ao redor do valor de $725 \AA^{3}$. 
Para a série MPCL-SR, o volume da cela unitária do $C_{3} S$ não se altera em relação à referência e apresenta valores em torno de $724 \AA^{3}$. A série que recebeu a adição de enxofre (MPCL-SX) apresenta valores sistematicamente menores que o observado na referência, com valores ao redor de $722,5 \AA^{3}$. Para a amostra MPCL-SX200, o valor determinado do volume da cela unitária do alita foi de aproximadamente $721,5 \AA^{3}$.

Os valores de volume da cela unitária dos cristais de belita apresentam comportamento mais disperso com tendências menos nítidas e consistentes. De maneira similar aos cristais de alita, não se observam variações do volume da cela unitária em função do aumento do teor de elemento dopante. A série MPCL-SR apresenta volumes de cela unitária superiores à referência, amostra Ref1, com uma tendência de aumento até teores de $2 \%$ em peso. Do modo similar, a série MPCLSX apresenta volumes de cela unitária sempre inferiores aos apres entados pela referência.

As séries dopadas com fósforo (MPCL-AP, MPCL-FO e MPCL-OS) exibem valores de volume da cela unitária inferiores ao observado na referência Ref2. Apenas as amostras MPCL-AP200 e MPCLFO200 possuem valores de cela unitária similar ao da referência. A série MPCL-SX mostra valores de volume de cela unitária, inferiores ao da referência (Ref2), porém mais constantes, ao redor do valor de $346,5 \AA^{3}$.

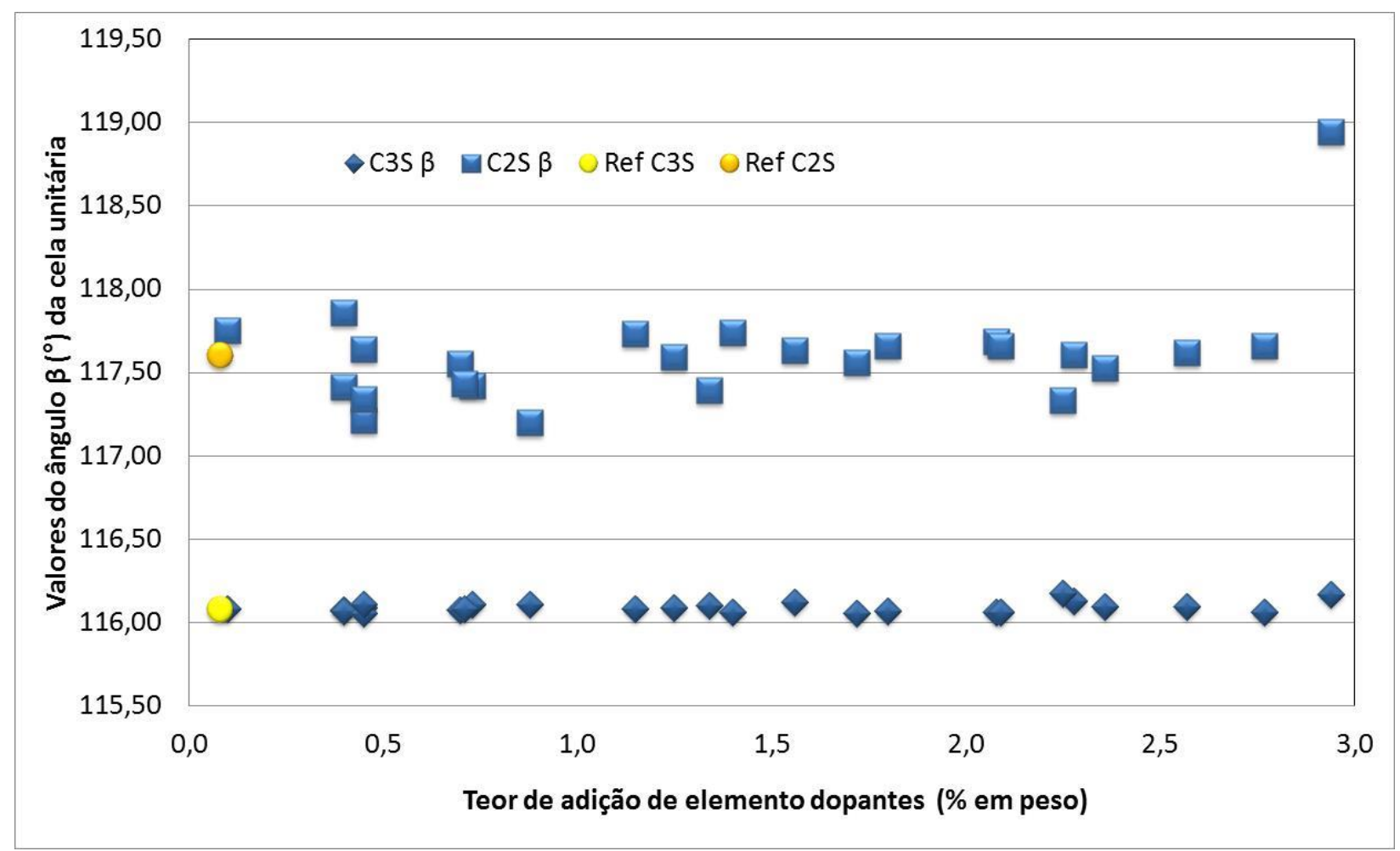

Figura 48 - Valores do ângulo $\beta$ da cela unitária monoclínica dos cristais de $C_{3} S$ e $C_{2} S$ em função do teor de adição de elementos dopantes

$A$ variação dos ângulos $\beta$ das celas unitárias monoclínicas para os cristais de $C_{3} S_{\text {e }} C_{2} S$ de todas as séries analisadas são apresentadas nas Tabelas 28 e 29 e na Figura 48. Nota-se que os valores do ângulo $\beta$ para os cristais de $\mathrm{C}_{3} \mathrm{~S}$ são muito estáveis e apresentam uma pequena oscilação ao redor 
do valor médio de $116,1^{\circ}$, com desvio padrão da média de 0,03 . Para os cristais de belita, o ângulo $\beta$ da cela monoclínica exibe uma dispersão maior dos valores com uma média de $117,6^{\circ}$ e desvio padrão igual 0,31 . Não se observam nas amostras variações em função do aumento do teor de elemento dopante.

Ao analisar as tendências de variação dos parâmetros de cela unitária descritas devem-se considerar os erros intrínsecos ao refinamento da análise pelo Método de Rietveld. Um dos indicadores estatísticos de qualidade do refinamento de difratogramas calculados pelo método de Rietveld é $R_{B}$, que indica a qualidade do ajuste de cada fase individual presente na mistura. Este indicador é útil, pois depende apenas do ajuste dos parâmetros estruturais de cada fase (IUCR, 2012). O valor de $R_{B}$ considera, portanto, o difratograma calculado de cada fase e é dado pela formula:

$$
\mathrm{R}_{\mathrm{B}}=\frac{\sum\left|\mathrm{I}_{\mathrm{obs}}-\mathrm{I}_{\text {calc }}\right|}{\sum\left|\mathrm{I}_{\mathrm{obs}}\right|}
$$

$\mathrm{Na}$ qual $\mathrm{I}_{\mathrm{obs}}$ corresponde às intensidades observadas e $\mathrm{I}_{\text {calc }}$ às intensidades calculadas em cada ponto do difratograma. Assim como os demais indicadores estatísticos de erro, um pequeno valor de $R_{B}$ representa um bom ajuste entre os dados observados e o modelo calculado, e vice-versa. Um elevado valor de $R_{B}$ indica que o modelo estrutural adotado não está sendo eficiente na simulação do difratograma observado (Toby, 2006). Isto ocorre porque as complexidades estruturais das amostras não são adequadamente descritas pelo modelo teórico adotado a priori.

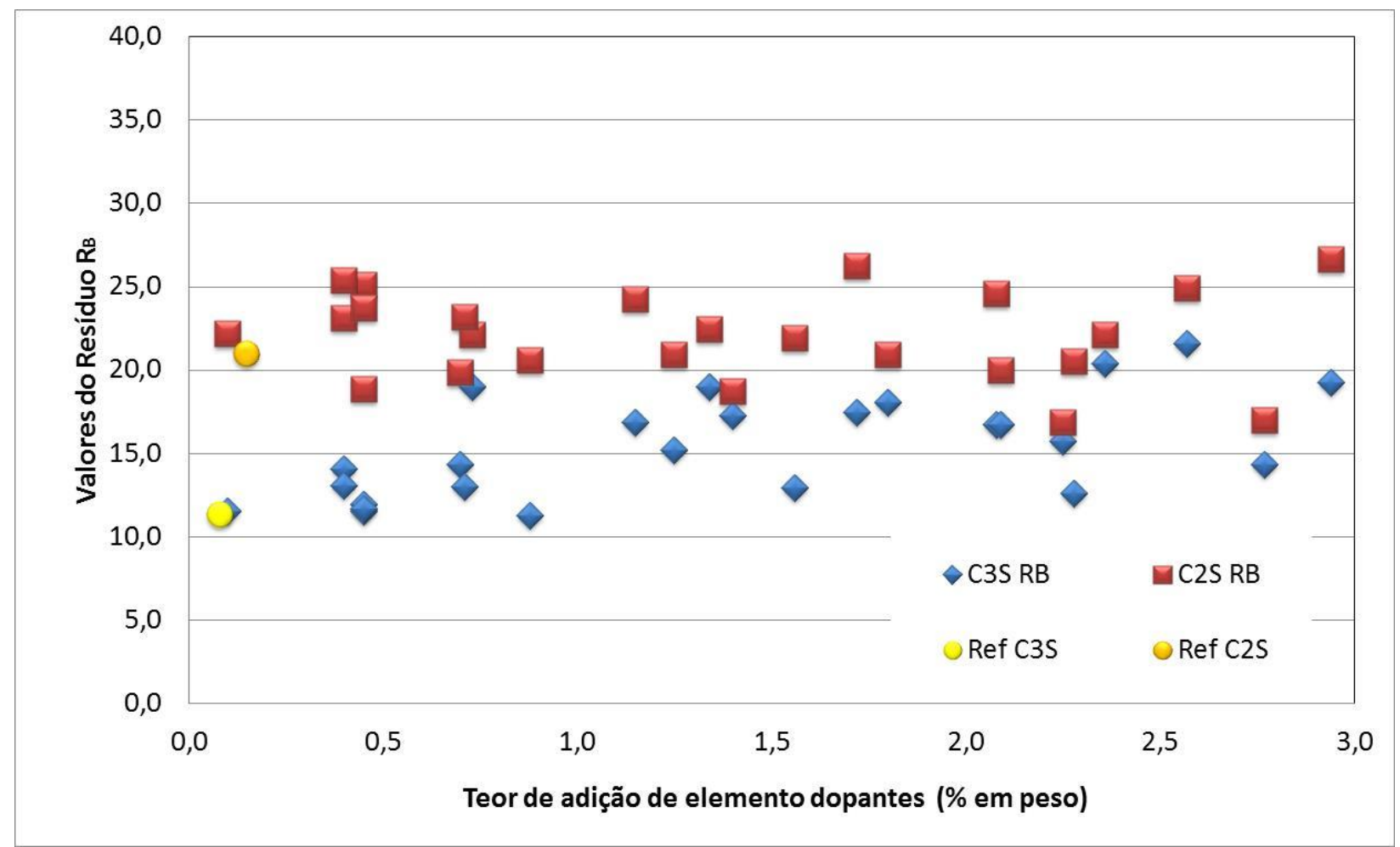

Figura 49 - Valores de $R_{B}$ das fases cristalinas $C_{3} S$ e $C_{2} S$ das séries anualidades função do teor de adição de elementos dopantes 
Os valores de $R_{B}$ dos cristais de alita $\left(C_{3} S\right)$ e belita $\left(C_{2} S\right)$ em função das adições e dos teores de elementos dopantes são apresentados respectivamente nas Tabelas 28 e 29.

A Figura 49 apresenta os valores de $R_{B}$ dos $C_{3} S$ e $C_{2} S$ das amostras, plotados em função do teor de elementos dopantes. Há uma pequena tendência de aumento de $R_{B}$ de $C_{3} S$ com o aumento no teor das adições, em comparação com as amostras de referência (Ref). Por outro lado, os valores de $R_{B}$ de $C_{2} S$ apresentam uma grande dispersão sem qualquer tendência em relação à adição de elementos dopantes.

Adicionalmente, é importante ressaltar que os valores de $\mathrm{Rb}$ para o $\mathrm{C}_{2} \mathrm{~S}$ são sistematicamente superiores àqueles encontrados para $\circ \mathrm{C}_{3} \mathrm{~S}$. Isto sugere que a estrutura do $\mathrm{C}_{3} \mathrm{~S}$ monoclínico apresenta um melhor ajuste e que o modelo cristalográfico adotado Mumme (1995) é mais susceptível a variações estruturais do que a estrutura do $C_{2} S$ (Mumme et al.,1995). Como o $C_{3} S$ é a fase mais abundante no clínquer, ela tem peso importante nos resíduos estatísticos globais (Rwp) do refinamento pelo método de Rietveld. Cabe ressaltar que a determinação de parâmetros estruturais de fases individuais é limitada em amostras polifásicas, especialmente em amostras de clínquer, devido à grande sobreposição de picos de praticamente todas as fases, principalmente no intervalo angular $2 \theta$ de $25^{\circ}$ a $35^{\circ}$, onde se situam os principais picos de $\mathrm{C}_{2} \mathrm{~S}$ e $\mathrm{C}_{3} \mathrm{~S}$.
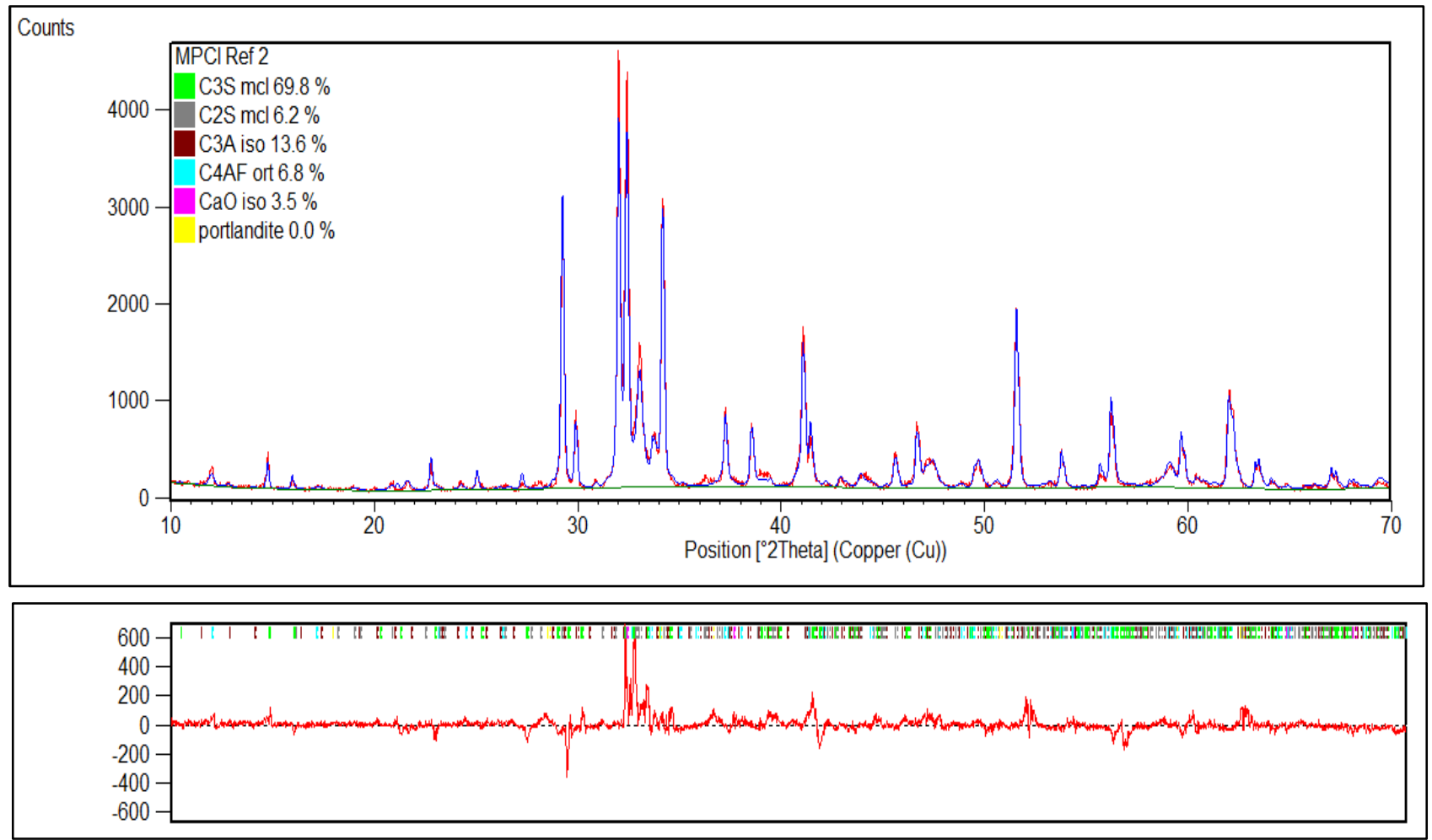

Figura 50 - Diagrama de Rietveld da amostra MPCL-Ref2 (Rwp=14,2) - difratograma experimental é observado em vermelho e o calculado em azul, na parte inferior a linha da diferença em vermelho. 

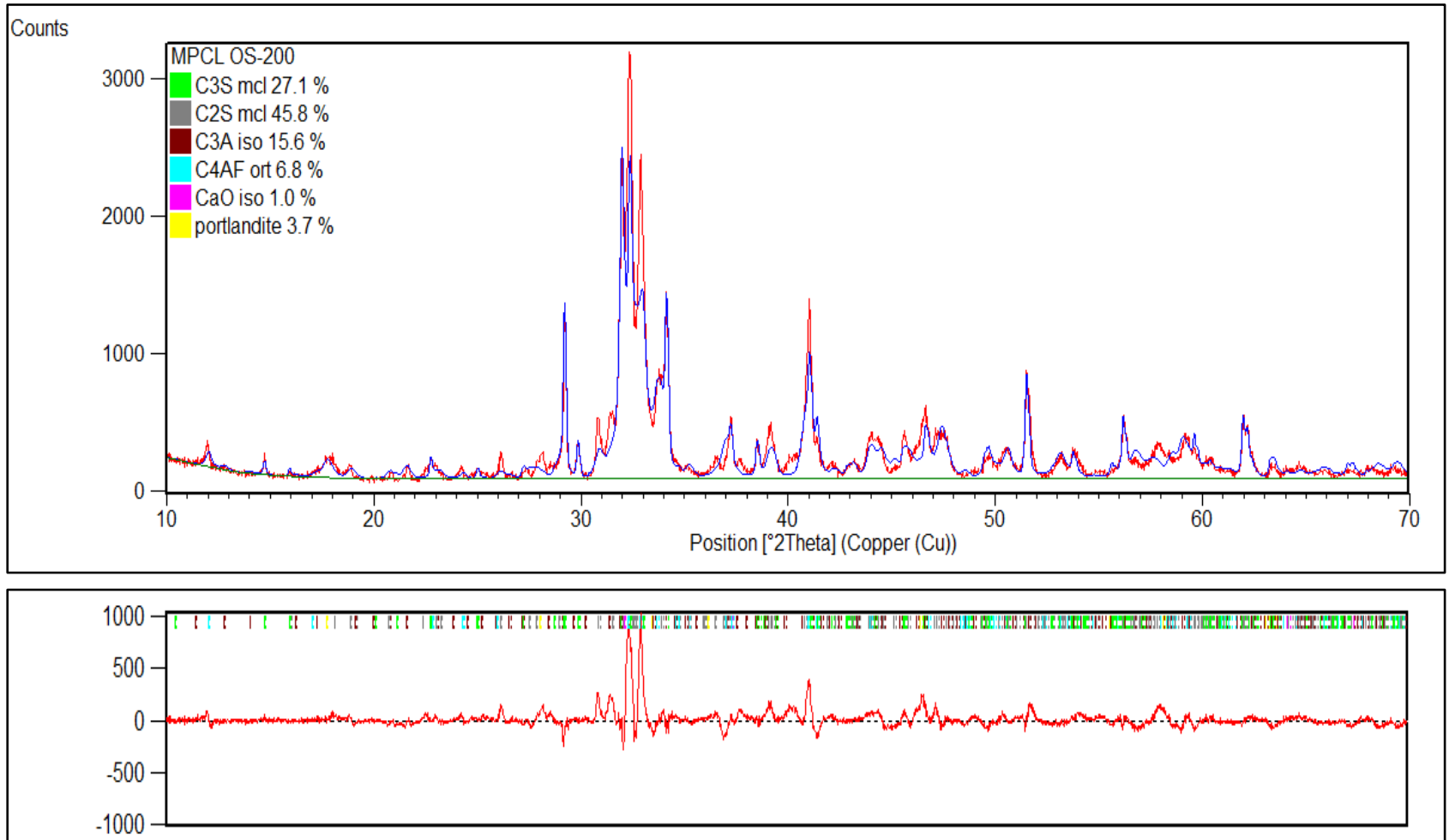

Figura 51 - Diagrama de Rietveld da amostra MPCL-OS200 (Rwp=20,9) - difratograma experimental é observado em vermelho e o calculado em azul, na parte inferior a linha da diferença em vermelho.

As Figuras 50 e 51 apresentam exemplos de refinamento pelo Método de Rietveld dos clínqueres experimentais. Na porção superior do gráfico é possível identificar o difratograma experimental (observado) em vermelho e o calculado em azul. Na porção inferior do gráfico uma linha vermelha mostra o resíduo final do refinamento (intensidade observada $\left(\mathrm{I}_{\text {obs }}\right)$ - intensidade calculada $\left(\mathrm{I}_{\text {calc }}\right)$ ). Notar que nos dois exemplos. MPCL - Ref2 (Rwp=14,2) e MPCO-OS200 (Rwp=20,92), as diferenças se concentram no intervalo angular de $2 \theta$ de $25^{\circ}$ a $35^{\circ}$.

\subsection{Microscopia Ótica de Luz Refletida - Feições e Texturas}

Os clínqueres experimentais obtidos foram observados ao microscópio de luz refletida de acordo com a metodologia descrita no item 6.3.4-Microscopia ótica. Essas observações tiveram como objetivo identificar as possíveis alterações na mineralogia e nos aspectos texturais impostos pela adição dos elementos dopantes.

Deve-se considerar inicialmente que as texturas dos clínqueres tal como descrita por Kihara et al. (1990) e Campbell (1999), entre outros, é determinada pela composição química das farinhas, pelas características granulométricas e mineralógicas do cru, assim como pelas condições de queima e resfriamento no forno rotativo. As condições de preparação das matérias-primas e calcinação em laboratório foram sistematizadas e padronizadas, porém distanciam-se muito das reais condições encontradas na fábrica de cimento, o que torna difícil uma comparação direta com o descrito pelos autores citados. 
Por outro lado, pode-se esperar que os aspectos gerais e texturas dos clínqueres sejam muito semelhantes. De fato, os nódulos apresentam coloração escura, possuem elevada porosidade e, por esse motivo, são friáveis e pouco coerentes.

Quando observados ao microscópio ótico ficam evidentes as variações nos teores de alita e belita em função da adição dos elementos dopantes, conforme mostrado no item 7.3 Composição Mineralógica. Essa variação impõe uma alteração na textura geral dos clínqueres, em especial para aqueles com elevados teores de adição e nos quais os teores de alita e belita são equivalentes.

Os cristais de alita $\left(\mathrm{C}_{3} \mathrm{~S}\right)$ são subhexagonais, subidiomórficos a localmente xenomórficos, em sua maioria apresentam-se alongados ou com forte tendência ao alongamento (Figura 52). Esse comportamento é comumente observado em clínqueres laboratoriais e está relacionado, possivelmente, ao aquecimento abrupto da farinha a $1450^{\circ} \mathrm{C}$. Cristais equidimensionais são menos frequentes e normalmente são mais desenvolvidos.

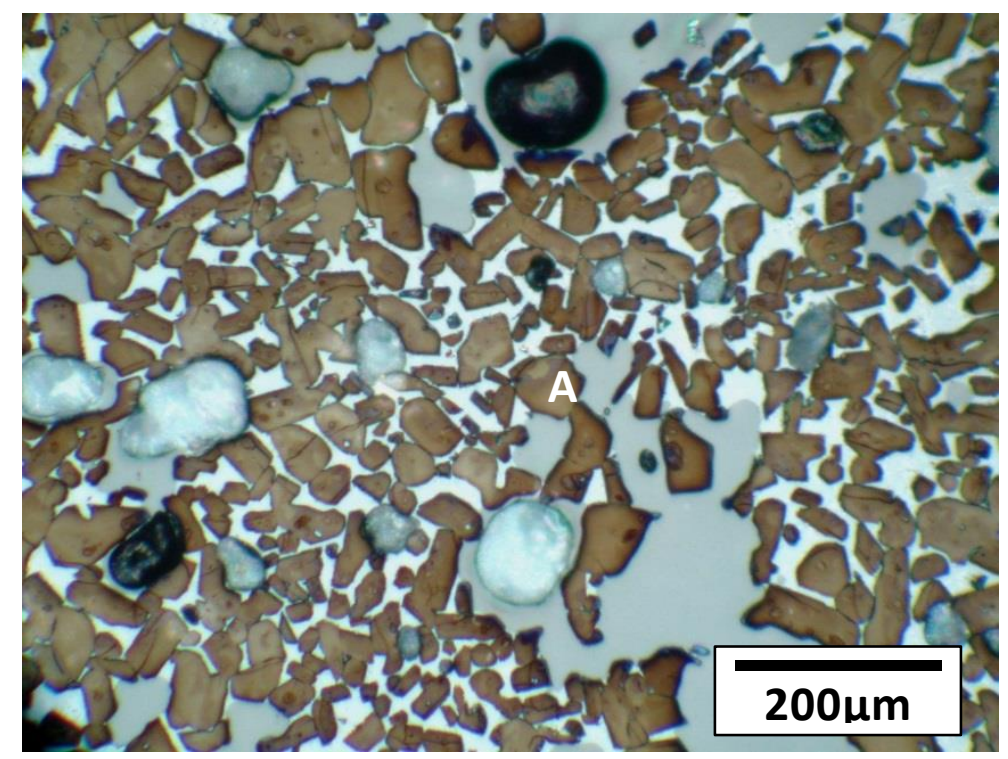

Figura 52 - Aspecto geral da textura do clínquer MPCL-SX25 no qual se observam cristais de alita (A) de formas alongadas dispersos. Ataque de $\mathrm{HNO}_{3} 1 \%$ em álcool $+\mathrm{H}_{2} \mathrm{O}$ - Microscópio ótico de luz refletida - Ampliação 100x

Figura 53 - Aspecto de detalhe dos cristais de alita (A). Notar os cristais alongados pequenos e cristais maiores melhor desenvolvidos. As bordas são retilíneas e não apresentam belita secundária. Clínquer MPCL-AP50 - B=belita Ataque de $\mathrm{HNO}_{3} 1 \%$ em álcool $+\mathrm{H}_{2} \mathrm{O}$ - Microscópio ótico de luz refletida - Ampliação 400x

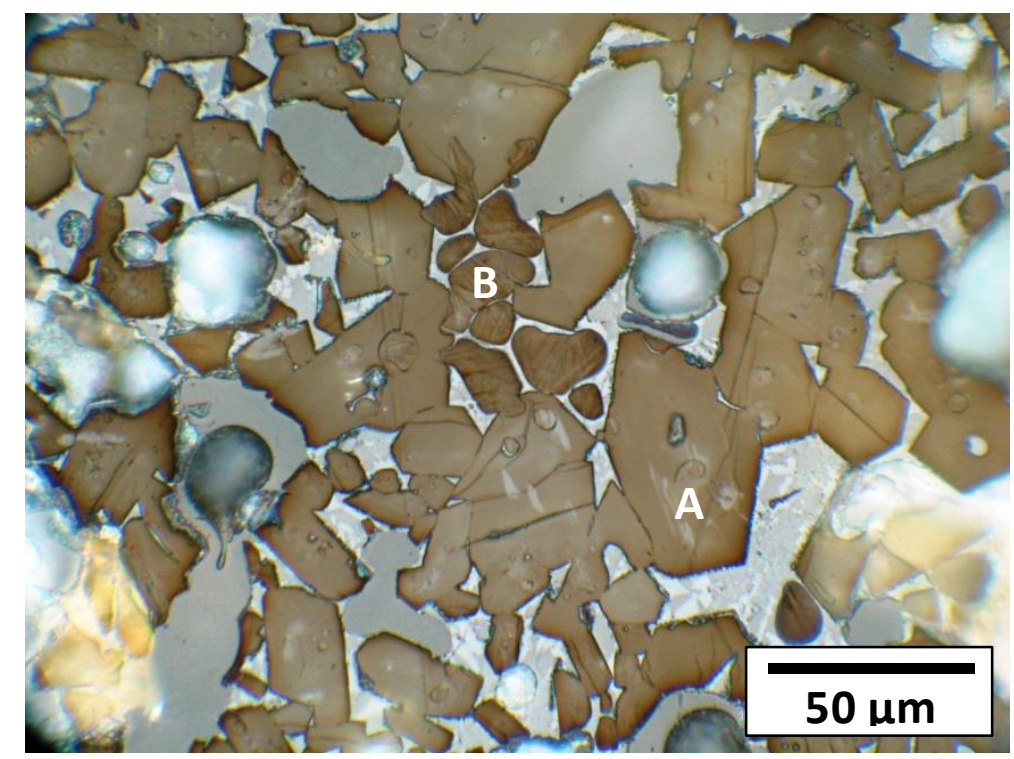




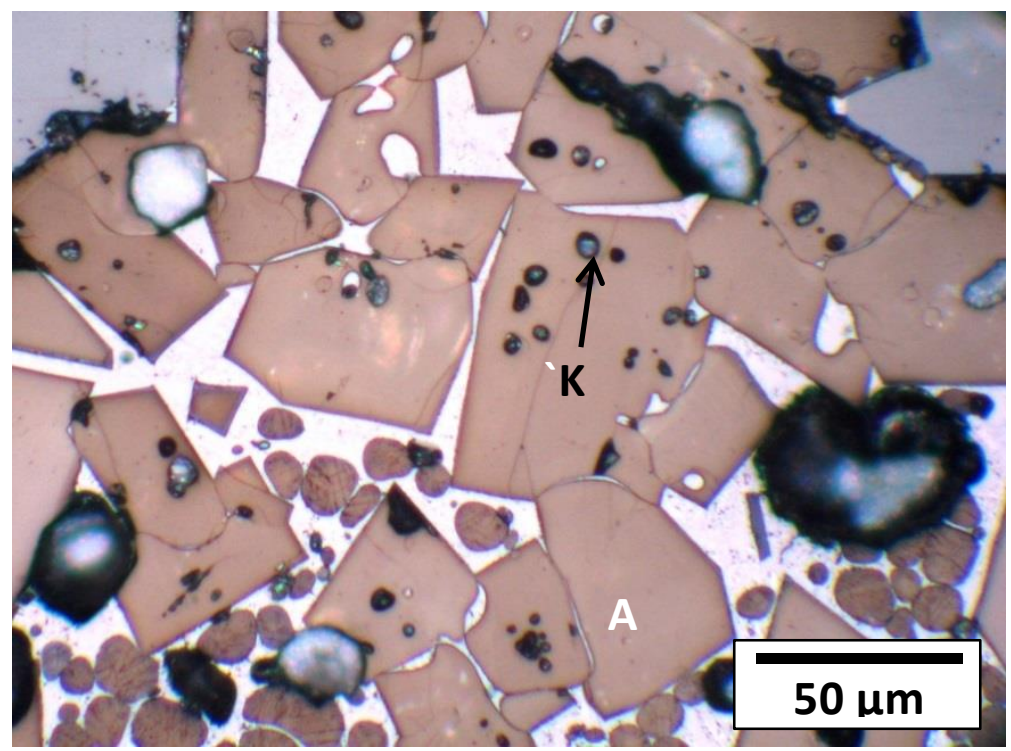

Figura 54 - Cristais desenvolvidos de alita (A) do clínquer MPCL-SX200. Notar as bordas retilínease as inclusões de cal livre (K). Ataque de $\mathrm{HNO}_{3} 1 \%$ em álcool $+\mathrm{H}_{2} \mathrm{O}-$ Microscópio ótico de luz refletida Ampliação 400x

Devido ao resfriamento rápido, os cristais apresentam bordas retilíneas a subretilíneas com corrosão incipiente e, localmente, observa-se a formação de belita secundária. $O$ nível de inclusões é normal e as inclusões são constituídas principalmente por belita, com a ocorrência eventual de cal livre e fase intersticial (Figura 53).

Os cristais normalmente são envolvidos pela fase intersticial, porém heterogeneidades locais permite observar a formação de massas contínuas de cristais justapostos de alita. Campbell (1999) aponta essa feição como indicativa de queima excessiva e alguns autores as chamam de "canibalismo".

Tendo em vista que todos os clínqueres foram elaborados sob as mesmas condições de calcinação $\left(1450^{\circ} \mathrm{C}\right.$ por $30 \mathrm{~min}$ ), os cristais de alita nas séries MPCL-SR, MPCL-FO, MPCL-AP e MPCL-OS se desenvolveram até atingirem uma dimensão média de 35 a $40 \mu \mathrm{m}$. Os cristais que compõe os clínqueres da série MPCL-SX, em especial aqueles com teores de adição superiores a 1\%, apresentam dimensões ao redor de 55 a 60 $\mu \mathrm{m}$ (Figura 54).

Os cristais de belita estão presentes nos clínqueres experimentais em pelo menos três formas distintas: cristais individualizados de formas arredondadas, na forma zonas compactas de cristais poligonizados e na forma de cristais dendríticos mal desenvolvidos. Pelo menos em parte, pode-se atribuir a ocorrência de zonas de belita à presença de grãos grossos de quartzo utilizado como matéria-prima e que não foi perfeitamente assimilado no processo de queima.

Os cristais de belita individualizados de formas arredondadas exibem vários conjuntos de geminações, podendo ser correlacionadas ao tipo I de Yamaguchi e Takagui (1969) e Ono et al. (1969 in Taylor 1997), que por sua vez podem ser relacionados ao polimorfo monoclínico $\beta$. Esses cristais são encontrados dispersos individualizados ou mesmo formando agrupamentos regulares e irregulares. Essa morfologia predomina nos clínqueres experimentais em especial nos clínqueres com elevados teores de elemento dopante, nos quais os teores de alita e belita são equivalentes e os cristais de belita parecem definir a textura geral do clínquer (Figuras 55 e 56). 


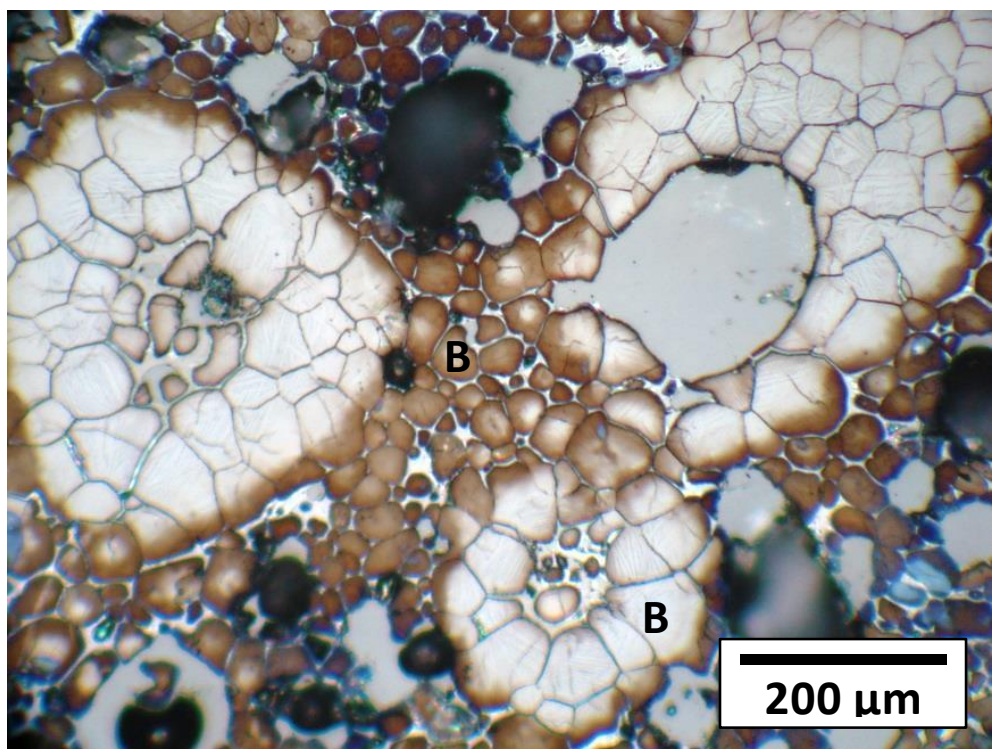

Figura 55 - Cristais de belita em zonas regulares (B) do clínquer MPCL-AP200. Notar as bordas retilíneas e as inclusões de cal livre (K). Ataque de $\mathrm{HNO}_{3} 1 \%$ em álcool $+\mathrm{H}_{2} \mathrm{O}$ - Microscópio ótico de luz refletida Ampliação 100x

Figura 56-Detalhe de uma zona de belita na qual se observam as três formas de belita identificadas. Ao centro cristais dendríticos (B1), na porção externa cristais individualizados (B3) e na porção intermediária massas de cristais indistintas (B2). Clínquer MPCL-SX50 - Ataque de $\mathrm{HNO}_{3} 1 \%$ em álcool $+\mathrm{H}_{2} \mathrm{O}-$ Microscópio ótico de luz refletida - Ampliação 200x
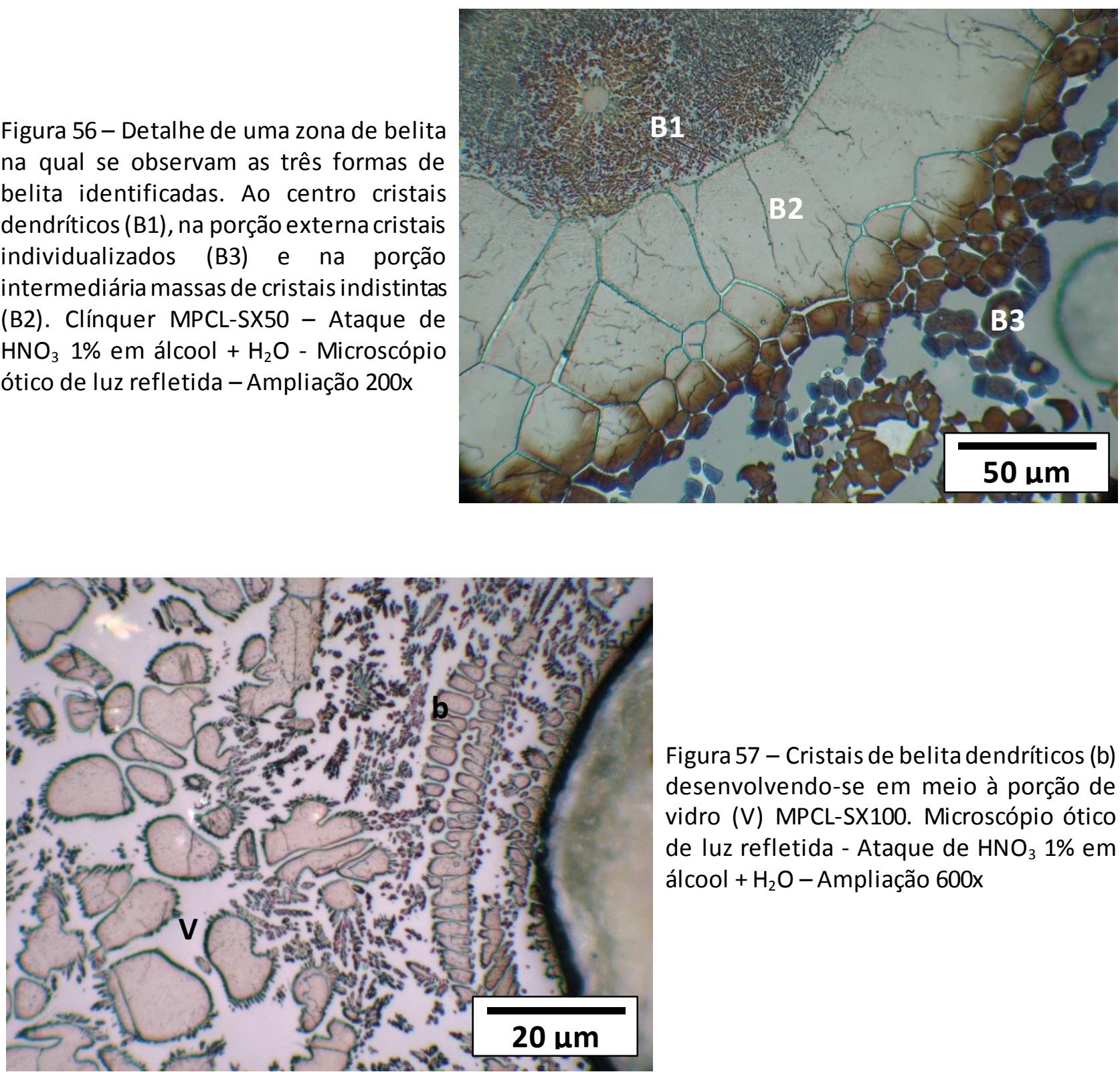

Figura 57 - Cristais de belita dendríticos (b) desenvolvendo-se em meio à porção de vidro (V) MPCL-SX100. Microscópio ótico de luz refletida - Ataque de $\mathrm{HNO}_{3} 1 \%$ em álcool $+\mathrm{H}_{2} \mathrm{O}-$ Ampliação $600 x$ 
A segunda forma de ocorrência dos cristais de belita, ou seja, os cristais de belita que se apresentam na forma de grandes massas indistintas ou na forma de cristais poligonizados, ocorrem na porção interna dos agrupamentos de belitas. Nesses, não se observam quaisquer geminações ou, mais localmente, as geminações são tênues e tendem a ser mais simples. Nas fotos das Figuras 55 e 56 é possível identificar esses cristais pela coloração mais clara que apresentam como resposta ao ataque químico com HNO3 1\% em álcool + água destilada.

A forma dendrítica da belita ocorre de modo menos frequente e está restrita às porções mais internas das zonas. Esses cristais possuem dimensões de poucos micrometros e estão imersos em um material homogêneo de aspecto liso que se acredita tratar-se de vidro (Figura 57).

Localmente, observam-se grandes zonas de belita $(>1000 \mu \mathrm{m})$, que possuem em seu núcleo um material branco de aspecto fundido, que ao microscópio aparece liso e uniforme, interpretado como vidro. O vidro ocorre em teores inferiores a 3\% e seu aparecimento está provavelmente relacionado à presença de grãos muito grossos de quartzo na matéria prima e que não reagiram completamente.

A fase intersticial, que preenche os espaços entre os cristais silicáticos devido ao resfriamento rápido utilizado em todos os clínqueres experimentais, exibe cristais de $C_{3} A$ principalmente submicroscópicos imersos em uma matriz constituída pelo $\mathrm{C}_{4} \mathrm{AF}$. Esses cristais exibem certa orientação que confere a essa textura um aspecto de "renda". Notam-se em algumas porções a associação de cristais melhor desenvolvidos que eventualmente possuem formas alongadas ou prismáticas.

Figura 58 - Aspecto da fase intersticial no qual se notam cristais melhor desenvolvidos de $C_{3} A(D)$ associados a uma textura rendilhada de cristais menores. Ataque com $\mathrm{KOH}+$ sacarose $5 \%$ em $\mathrm{H}_{2} \mathrm{O}$ Microscópio ótico de luz refletida Ampliação 600x

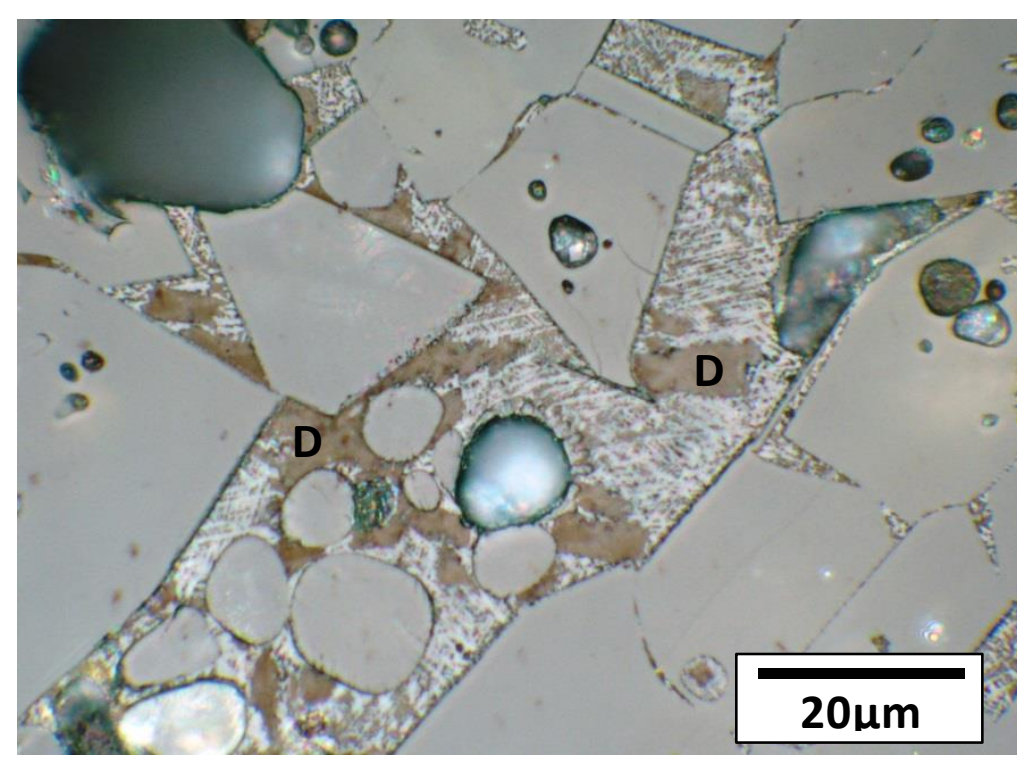


Figura 59 - Pequenos cristais de cal livre (K) individualizados de formas arredondadas. Sem ataque - Microscópio ótico de luz refletida - Ampliação 100x

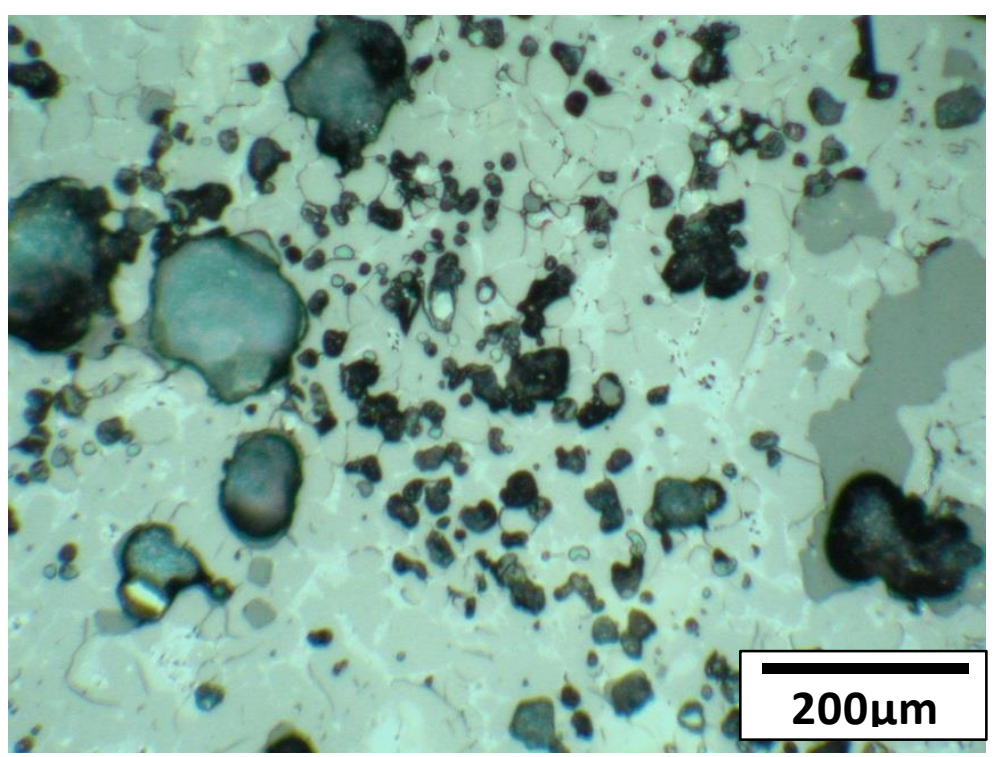

A cal livre ocorre como pequenos cristais (menores que $10 \mu \mathrm{m}$ ) de formas arredondadas e cores escuras. Encontram-se individualizados, inclusos nos cristais de alita, ou mesmo dão origem a concentrações em determinadas regiões do clínquer. Não se observam zonas compactas regulares, que normalmente seriam relacionadas à finura do calcário utilizado como matériaprima.

\section{DISCUSSÃO DOS RESULTADOS}

O efeito dos elementos menores na mineralogia do clínquer portland está relacionado ao tipo e teor das incorporações desses elementos no retículo cristalino de seus minerais constituintes. A incorporação de elementos estranhos como solução sólida em uma fase cristalina é resultado de um complexo equilíbrio entre as valências e os raios iônicos de cada átomo substituinte (Tabela 30).

A Tabela 31 traz aquelas que seriam as principais reações de substituição para os elementos estudados neste trabalho.

\begin{tabular}{c|cccc}
\hline \multicolumn{5}{c}{ Tabela 30 } \\
\hline Elemento & $\begin{array}{c}\text { Nómero de } \\
\text { coordenação }\end{array}$ & $\begin{array}{c}\text { Raio atômico } \\
(\AA)\end{array}$ & $\begin{array}{c}\text { Raio iônico } \\
(\AA)\end{array}$ & Valência \\
\hline Silício & IV & 0,40 & 0,26 & -4 \\
Alumínio & IV & 0,53 & 0,39 & -3 \\
Enxofre & IV & 0,26 & 0,12 & -6 \\
Fósforo & IV & 0,31 & 0,17 & -5 \\
Cálcio & VII & 1,14 & 1,00 & +2 \\
Estrôncio & VII & 1,32 & 1,18 & +2 \\
\hline
\end{tabular}




\begin{tabular}{c|c}
\hline Tabela 31-Reações possíveis de substituição de elementos dopantes no clínquer \\
\hline Elemento dopante & Reação de Substituição \\
\hline Fósforo & $2 \mathrm{Si}^{4+}+\mathrm{Ca}^{2+} \longleftrightarrow 2 \mathrm{P}^{5+}+[]$ \\
\hline Enxofre & $3 \mathrm{Si}^{4+} \longleftrightarrow \mathrm{S}^{6+}+2 \mathrm{Al}^{3+}$ \\
\hline Estrôncio & $\mathrm{Ca}^{2+} \longleftrightarrow \mathrm{Sr}^{2+}$ \\
\hline
\end{tabular}

Da Tabela 31 depreende-se que a simples substituição da sílica por fósforo ou enxofre não é direta, pois o equilíbrio de cargas impõe à estrutura o deslocamento de um íon $\mathrm{Ca}^{2+}$ e a criação de uma vacância ou, como no caso do enxofre, a incorporação de íons de alumínio. Adicionalmente, é possível imaginar que ocorram deformações na estrutura cristalina decorrentes das diferenças entre os raios iônicos dos átomos de silício $(0,26 \AA ̊)$, fósforo $(0,17 \AA ̊)$ ou enxofre $(0,12 \AA)$, que ocupam o sítio tetraédrico (número de coordenação IV) da estrutura dos silicatos. As distâncias interatômicas $\mathrm{Si}-\mathrm{O}$ são maiores que as encontradas entre $\mathrm{P}-\mathrm{O}$ e $\mathrm{S}-\mathrm{O}$, considerando que as diferenças dos raios iônicos observadas são de -34\% para o fósforo e -54\% para o enxofre.

A substituição do cálcio pelo estrôncio não necessita de uma compensação de cargas já que ambos possuem valência +2 , e a diferença entre os raios atômicos é de apenas $18 \%$, o que não implica necessariamente uma deformação significativa no sítio octaédrico (número de coordenação VI).

\subsection{Fósforo}

No presente estudo a adição de fosfato a partir das três diferentes formas, fosfato sintético, apatita natural e osso, apresentaram comportamento geral muito similar, devendo-se considerar na análise dos dados características particulares de cada tipo de fosfato adicionado.

A apatita natural revelou a presença de pequenas quantidades de flúor em sua composição, aproximadamente $0,35 \%$ em peso, determinado por análise semiquantitativa por espectrometria de raios $X$. O flúor é um elemento de caráter fortemente fundente (reduz as temperaturas de reação) e que pode auxiliar no desenvolvimento das reações de clínquerização.

A amostra de osso analisada por difratometria de raios $X$ mostrou uma estrutura similar à apatita, porém mal cristalizada (Figura 60), de modo que os íons fosfato estariam facilmente disponíveis para a reação, sem a necessidade de decomposição inicial pela ação da temperatura.

O fosfato de cálcio sintético possui a mesma estrutura do mineral monetita (CaHPO4), caracterizado por difratometria de raios X. A Figura 60 apresenta uma comparação entre os difratograma dos três tipos de fosfato utilizados nesse trabalho. 


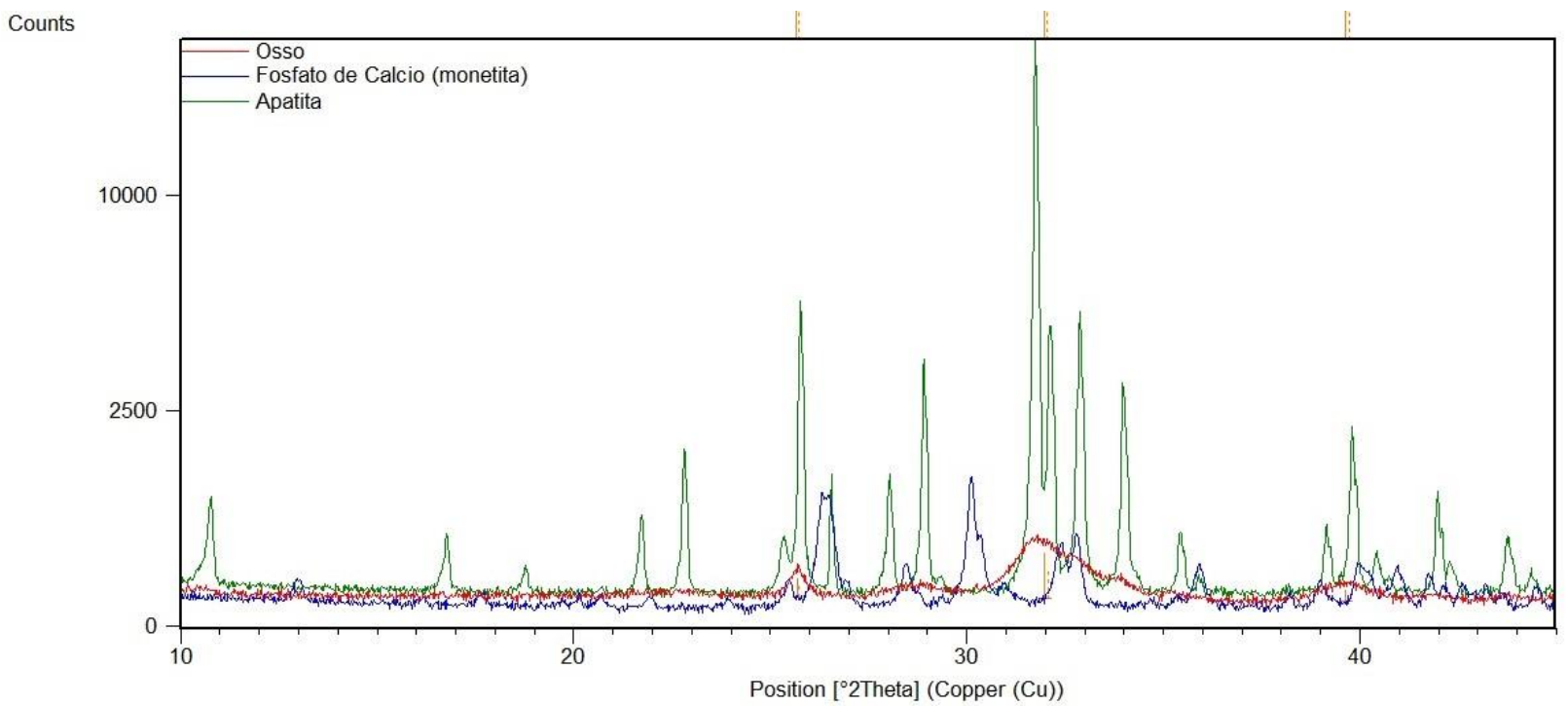

Figura 60 - Gráfico de difratometria de raios X dos três tipos de fosfatos utilizados sobrepostos

Essas características se refletem, pelos menos parcialmente, nos ensaios de queimabilidade que, de um modo geral, mostram que a incorporação do fósforo só afetou a queimabilidade (reatividade) das farinhas, de maneira mais significativa, a partir de teores superiores a $1 \%$, corroborando o observado por Halicz et al. (1983). Kolovos et al. (2004) apontam limites maiores de incorporação do fosfato, porém fazem diferenciações relativas ao tipo de fosfato adicionado (Figura 33).

No presente estudo, as farinhas dopadas com o fosfato sintético apresentaram, após queima, maiores teores de cal livre que aquelas contendo apatita natural e osso, para níveis de adição superiores a $1 \%$ em peso. Este fato sugere que a presença do flúor na apatita e os problemas de cristalinidade do osso afetam a sua incorporação no clínquer. Esse fato discorda do observado por Kolovos et al. (2004), que comentam que a forma correspondente ao fosfato sintético $\left(\mathrm{CaHPO}_{4}\right)$ apresenta um comportamento positivo em relação à queimabilidade, reduzindo os teores de cal livre após queima mesmo para teores de $2,5 \%$ em peso, enquanto o $\mathrm{Ca}\left(\mathrm{H}_{2} \mathrm{PO}_{4}\right)_{2}$, um tipo de fertilizante, apresenta um comportamento negativo, elevando o teor de cal livre em até $6 \%$ em peso para os mesmos teores de adição.

O aumento da cal livre, quando observado sob o aspecto da composição mineralógica dos clínqueres experimentais, pode ser traduzido por meio da diminuição sistemática dos teores de alita com respectivo aumento nos teores de belita. Conforme apontado pela grande maioria dos autores, a presença do íon fosfato tende a estabilizar a belita. Nesse contexto, nota-se novamente que a adição de apatita provocou um menor efeito na diminuição do teor de alita e no aumento do teor de belita, conforme pode ser observado na Tabela 27, sugerindo que o flúor presente, mesmo em baixos teores, tenha facilitado as reações e compensado o efeito negativo da adição de fósforo.

As adições do fosfato sintético e do osso afetaram a mineralogia de modo mais pronunciado, 
diminuindo o teor de alita com acréscimo do teor de belita. Esses clínqueres, quando observados ao microscópio ótico, mostram texturas bastante diferentes dos clínqueres referência e similares às encontradas por Staněk e Sulovský (2009). Porém, não se observa o aumento da dimensão média dos cristais de alita tal qual relatado por esses autores em nenhum dos casos analisados.

As análises mineralógicas realizadas por difratometria de raios $X$ e pelo método de Rietveld mostraram, em relação ao volume da cela unitária dos cristais de alita, um pequeno aumento quando comparado com a referência. No entanto, tendo em vista as diferenças dos raios iônicos de Si e P no sitio tetraédrico, esperava-se uma contração da cela conforme apontado por Nastac et al. (2007). Considerando que o nível de incorporação de fósforo nos cristais de alita são de 2 a 3 vezes menores que na belita (Nastac et al., 2007 e Andrade et al., 2011) era de se supor que nesses cristais esse efeito pudesse ser mais pronunciado e melhor observado. Todavia, os volumes de cela unitária determinados para os cristais de belita possuem comportamento aleatório e não exibem nenhuma tendência clara. Acredita-se que as dificuldade de ajuste do modelo utilizado para os cristais de belita (Mumme et al., 1995), evidenciadas pelos valores elevados de Rwp, que variaram principalmente entre 20 a 25 (Figura 49), tenham mascarado possíveis tendências.

\subsection{Enxofre}

A adição de enxofre na forma gesso $\left(\mathrm{CaSO}_{4} \cdot 2 \mathrm{H}_{2} \mathrm{O}\right)$, conferiu às farinhas um bom desempenho nos ensaios de queimabilidade. Observa-se uma tendência de diminuição do teor de cal livre em relação à referência com o aumento da adição (Figura 33). Essa redução chega a um máximo de $50 \%$ para o teor de adição de 1,5\% em peso; a partir desse teor de adição observa-se a elevação da cal livre. Timashev (1980), Kolovos et al., (2004), entre outros, apontam comportamento similar em seus estudos, comentando que o enxofre se dissolve na fase líquida alterando sua viscosidade e tensão superficial, de modo a melhorar a reatividade da farinha.

A incorporação do enxofre no clínquer se dá preferencialmente nos cristais de belita conforme mostrado por vários pesquisadores. Strunge et al. (1985) e Herfort et al. (1997) entre outros reportam a tendência de estabilização da belita pela adição de enxofre, como observado nas amostras estudadas, enquanto os teores de fase intersticial permanecem inalterados. Horkoss et al. (2011) comentam que para teores superiores a $2 \%$ existe a tendência da relação alita/belita se aproximar de 1. Andrade et al. (2011), estudando a composição de cristais de alita e belita em clínqueres industriais por microssonda eletrônica mostraram que a belita possui maior capacidade de armazenamento do enxofre, cerca de 3 vezes mais que a alita em número de cátions. Nos clínqueres dopados com enxofre nota-se a diminuição progressiva do teor de alita acompanhada pelo aumento no conteúdo de belita, que na amostra MPCL SX200 (teor de $\mathrm{SO}_{3}=2 \%$ ) chega a ser de $180 \%$.

É importante comentar que as análises de Rietveld apontam para uma redução sistemática dos teores de $\mathrm{C}_{3} \mathrm{~A}$ nesses clínqueres, não observada por microscopia, que pode ser justificada com base na incorporação do alumínio no balanço de cargas do sítio tetraédrico. 
A composição mineralógica observada nesses clínqueres contradiz em certo ponto o observado nos ensaios de queimabilidade. A estabilização da belita em detrimento da alita deveria disponibilizar maior quantidade de cal livre para o sistema. Acredita-se, que pelo menos em parte, o CaO esteja sendo incorporado na fase vítrea; a observação de cristais de belita de formas dendríticas se desenvolvendo no interior da fase vítrea corrobora essa conclusão (Figura 57).

Ao microscópio ótico é marcante o aumento da dimensão média dos cristais de alita, que atingem $60 \mu \mathrm{m}$, notadamente para teores de adição superiores a 1\%. Esse efeito já havia sido descrito por vários autores, entre eles Timashev (1980), Strunge et al.(1985) e Maki et al. (1992), que atribuem o crescimento dos cristais à redução de viscosidade da fase líquida durante a queima e ao predomínio do crescimento dos cristais sobre a nucleação. Maki et al.(1992) comentam que esse crescimento é instável e pode dar origem a cristais desenvolvidos sob a forma do polimorfo M1. Strunge et al., (1985) sugerem uma tendência dos cristais serem idiomórficos, o que também foi observado nessas análises.

Uma textura comum observada nos clínqueres com elevado conteúdo de enxofre são as massas de cristais de alita justapostos, atribuída ao excesso de queima (Campbell, 1999) e denominada como "canibalismo". Wang (2011) também descreve esse tipo de textura como resultado da incorporação do enxofre no clínquer.

Outro aspecto discutido na literatura e que pode ser constatado nessas amostras é a perda do enxofre por volatilização. Quando se compara o conteúdo de $\mathrm{SO}_{3}$ nos clínqueres com o $\mathrm{SO}_{3}$ da farinha corrigido pelo valor da perda ao fogo $(P F=0)$, os primeiros são sempre menores. $A$ porcentagem de enxofre volatilizada é menor com o aumento do teor de adição (Figura 39) e, no caso em estudo, varia de 27 a 78\%. Isso pode ser explicado pelo fato do $\mathrm{CaSO}_{4}$ se decompor ao redor de $1200^{\circ} \mathrm{C}$ temperatura inferior ao de formação dos compostos de clínquer, dando origem a uma fase líquida e a uma porção gasosa que se perde sem ser incorporada pelas fases silicáticas (Pliego-Cuervo e Glasser, 1979).

A determinação do volume da cela unitária obtido pelas análises de Rietveld dos cristais de alita e belita demostram que a incorporação do enxofre provocou uma forte contração da cela unitária quando comparadas com a referência. Gomes (2007) comenta que para uma solução sólida S-Si espera-se um decréscimo nos eixos cristalográficos com o aumento de enxofre, pois os comprimentos das ligações S-O no tetraedro $\mathrm{SO}_{4}$ (em média 1,4686 ̊., Cole et.al, 1974 in Gomes 2007) são menores do que das ligações $\mathrm{Si}-\mathrm{O}$ no tetraedro $\mathrm{SiO}_{4}$ (em média 1,6321 Å, Jost et.al, 1977 in Gomes 2007).

\subsection{Estrôncio}

Entre os elementos estudados, a influência mais negativa sobre a queimabilidade das farinhas foi devida à incorporação do estrôncio, tendo em vista que os ensaios de queimabilidade da série MPCL-SR apresentaram os maiores teores de cal livre. Dada a similaridade química entre cálcio e estrôncio, foi cogitada nesse estudo a possibilidade de interferência do SrO nos ensaios de 
determinação química da cal livre. Para testar essa hipótese foram realizadas dissoluções em etileno glicol de uma mistura de SrO:quartzo, em proporções 5:95 e 10:90. A titulação com ácido clorídrico não indicou a presença de SrO no filtrado, eliminando a possibilidade de interferência do estrôncio no ensaio de cal livre.

Do posto de vista mineralógico, nota-se a diminuição dos teores de alita com correspondente aumento dos teores de belita em função da adição de SrO. Todavia, seu efeito sobre a mineralogia é significativamente menor que o dos demais elementos dopantes analisados nesse trabalho. Esse fato já havia sido descrito por Batty (1995) e Kolovos et al. (2005) que apontam o aumento do teor de belita para teores de adição SrO de respectivamente 4 e 2,5\%. Provavelmente, o aumento do teor da belita esteja relacionado à maior capacidade desses cristais em absorver os íons de estrôncio conforme mostrado por Juel e Jøns (2001) e Andrade et al (2011).

Ao microscópio ótico observam-se texturas similares ao demais clínqueres com presença de belita em zonas e cristais de alita subidiomórficos. Kolovos et al. (2005) apontam um crescimento da dimensão média dos cristais de alita que, no entanto, não foi observado nesses clínqueres.

Quando comparamos os dados da composição mineralógica por microscopia ótica e a determinada pelo Método de Rietveld, a série dopada com estrôncio é a que mostra melhor correspondência entre esses dados e os menores erros de refinamento (Rwp), que se deve à grande similaridade química e de raios iônico entre estrôncio e cálcio.

Com relação ao volume da cela unitária dos cristais de alita não se observam alterações significativas quando comparadas à referência. Para os cristais de belita, apesar dos dados não serem tão consistentes devido aos elevados valores de $R_{B}$, pode-se observar uma tendência de aumento do volume da cela unitária em todos os clínqueres analisados. Isto pode estar relacionado à maior tendência de incorporação de estrôncio na belita, à natureza da substituição dos íons Ca pelo Sr e à pequena diferença entre os raios iônicos desses elementos.

\section{CONCLUSÕES}

Nos últimos anos o Brasil tem experimentado um aumento consistente da produção de cimento, que conta inclusive com a instalação de novas e modernas unidades fabris. Esse movimento se dá graças à retomada dos grandes projetos de infraestrutura, aos abundantes créditos destinados às moradias e às perspectivas de manutenção das taxas de aumento do consumo relacionadas ao ritmo de crescimento econômico do país.

Contudo, o crescimento da produção está relacionado a compromissos ambientais e ações em prol da sustentabilidade, dentre os quais se podem destacar o uso de adições ao cimento (escórias e pozolanas), a melhoria da eficiência energética do processo, o uso de matérias-primas e combustíveis alternativos e o coprocessamento de resíduos industriais. 
O uso de adições no Brasil já é adotado há mais de 40 anos e é uma atividade regulamentada pela Associação Brasileira de Normas Técnicas desde a década de 1950. Pode-se atribuir ao uso intensivo de escórias e pozolanas o fato do Brasil apresentar atualmente uma das menores taxas de emissão de $\mathrm{CO}_{2}$ por tonelada de cimento produzido.

Com relação à eficiência energética, o Brasil hoje conta com um parque industrial moderno, com 99\% dos seus fornos via seca equipados com pré-aquecedores e pré-calcinadores, além de maçaricos multicanais que possibilitam a queima de grande variedade de combustíveis. $O$ consumo energético médio do Brasil, 800 a $850 \mathrm{kcal} / \mathrm{kg}$ de clínquer, é similar ao dos países mais desenvolvidos.

Após mais de 10 anos do início de atividade regulamentada, a queima de resíduos em fornos de cimento, também conhecido como coprocessamento, é hoje uma atividade consagrada no Brasil e no mundo. Segundo os dados mais recentes do Balanço Energético Nacional, o coprocessamento já é responsável por aproximadamente $10 \%$ da matriz energética da indústria cimenteira nacional, com tendências de crescimento futuras alavancadas pela maior oferta de resíduos, e pela possibilidade da queima de lixo urbano tratado, como é feito em países como o Japão.

Nesse contexto, o clínquer passou a ser um insumo de maior variabilidade química e mineralógica e o cimento um material de reologia e comportamento hidráulico mais complexo.

Sendo um produto obtido por meio do processamento de recursos naturais, pode-se esperar que no clínquer uma grande variedade de elementos químicos esteja presente. Quando em teores muito baixos, tais elementos são assimilados pelos compostos cristalinos do clínquer na forma de soluções sólidas e não provocam alterações sensíveis no comportamento do produto final. A partir do momento em que os teores dos elementos menores se tornaram mais expressivos, tornou-se premente estudar seus efeitos na mineralogia do clínquer e, consequentemente, nas características do cimento.

Nos últimos anos dez anos, o uso do coque de petróleo como principal combustível da indústria aportou ao clínquer quantidades importantes de enxofre (de 1 a $2 \%$ em peso). Este trabalho, por meio da adição de enxofre na forma de gipsita (sulfato de cálcio di-hidratado), procurou identificar os diversos efeitos desse elemento. Na farinha, observou-se que o enxofre melhora a reatividade quando adicionado em até $1 \%$ em peso, resultando em menor teor de cal livre. No clínquer, o enxofre promoveu um crescimento dos cristais de alita que atingiram dimensões de $60 \mu \mathrm{m}$, o que significa um aumento de $50 \%$ em relação à referência. Por outro lado, os clínqueres dopados com enxofre apresentaram uma diminuição dos teores de alita e um incremento no teor de belita, provavelmente como resultado de sua maior afinidade com essa fase. Nos cristais de belita, o enxofre favorece a cristalização do polimorfo $\beta$, caracterizado pelas observações ao microscópio ótico. A análise microscópica revelou a presença de cristais de belita de morfologias distintas, cuja forma polimórfica não pôde ser perfeitamente caracterizada.

O enxofre, em conjunto com o flúor, é descrito na literatura como um importante mineralizador dos cristais de alita, estabilizando a forma polimórfica romboédrica de mais alta temperatura. 
Nesse trabalho não foi possível identificar essa transformação polimórfica na alita, apesar de haver sido constatada a contração da cela unitária pelo método de Rietveld.

As análises químicas nas farinhas e nos clínqueres confirmaram o caráter volátil do enxofre, cuja perda por volatilização mostrou-se inversamente proporcional ao teor adicionado do elemento. Cabe ressaltar que nos clínqueres experimentais sintetizados para este estudo o enxofre foi adicionado nas matérias-primas, que ao serem aquecidas, perdem voláteis $\left(\mathrm{H}_{2} \mathrm{O}, \mathrm{CO}_{2}\right.$, enxofre). Tal perda não é concomitante com a formação das fases cristalinas, o que não permite que o enxofre seja por elas absorvido. Por outro lado, a adição do enxofre nos fornos industriais por meio do combustível (coque de petróleo) ocorre no pico térmico do sistema, favorecendo sua incorporação nas fases cristalinas ali formadas e minimizando as emissões de SOx.

As possíveis fontes de fósforo na produção do clínquer podem estar ligadas a rochas carbonáticas ricas em apatita (carbonatito, fosforito), ao coprocessamento de farinha animal, a resíduos de esgoto e de abatedouros, e à destruição de carcaças de animais em fornos de cimento. O fósforo, nesse trabalho, foi adicionado às farinhas em três formas distintas: fosfato sintético, apatita natural e osso bovino. Todas as formas de fosfato mostraram um efeito negativo sobre a queimabilidade das farinhas, na medida em que de sua adição resultaram elevados teores de cal livre. Além disso, nota-se que a adição de fósforo é seguida de um aumento do teor de belita e um decréscimo do conteúdo de alita para todos os tipos de fosfato analisados. Dentre eles, a apatita natural apresentou um efeito menos danoso, provavelmente devido à presença de flúor em sua composição. A belita possui maior capacidade de incorporar o fósforo, que substitui os íons de silício no sitio tetraédrico e induz a formação de uma vacância no sítio do cálcio para o balanceamento de cargas da estrutura. De modo análogo aos ensaios realizados com enxofre, não foi possível identificar alterações nas formas polimórficas dos cristais de alita e belita pelo método de Rietveld, prevalecendo as formas monoclínicas de ambos. Todos os clínqueres dopados com fósforo são semelhantes entre si e as alterações texturais, observadas por microscopia, estão relacionadas ao aumento do conteúdo de belita.

O estrôncio possui grande similaridade química com o cálcio e costuma também estar presente em todos os minerais de que esse elemento químico faz parte. Portanto, o estrôncio é um elemento muito comum na composição das farinhas, porém em baixo teor, normalmente inferior a $0,5 \%$ em peso. Todavia, em raros casos como o do carbonatito de Jacupiranga, cujo calcário resultante da extração do minério de apatita é utilizado como matéria-prima para a fabricação de clínquer, pode-se encontrar o estrôncio em teores ao redor de $1 \%$ em peso. Por ser um elemento pouco usual, são poucos os estudos publicados a respeito dos efeitos do estrôncio no clínquer. Neste trabalho, observou-se que a adição do estrôncio atuou negativamente sobre a queimabilidade da farinha e favoreceu a formação da belita em detrimento dos cristais de alita. As análises de Rietveld não apontaram variações da cela unitária dos cristais de alita e apenas um pequeno incremento para os cristais de belita, o que sugere que as pequenas diferenças entre os raios iônicos entre o $\mathrm{Ca}^{2+}$ e o $\mathrm{Sr}^{2+}$ não provocaram deformações significativas na cela unitária desses minerais. 
Finalmente, cumpre comentar que futuras pesquisas sobre esse tema poderiam avaliar a ação conjunta desses elementos, dois a dois ou os três ao mesmo tempo. Investigações sobre o efeito do magnésio em conjunto com os elementos abordados também seriam importantes, uma vez que se atribui a ele a estabilização do polimorfo M3 da alita.

Com relação à investigação do polimorfismo das fases silicáticas alita e belita, a elevada sobreposição entre as raias de difratometria de raios $\mathrm{X}$ desses minerais torna essa tarefa bastante difícil. As investigações feitas utilizando o método de Rietveld mostraram uma grande dificuldade dos modelos em simular as estruturas obtidas nos ensaios de queima, fato sugerido pelo expressivo aumento dos fatores globais que controlam a qualidade do refinamento (Rwp e GOF). Sugere-se que futuras pesquisas possam obter melhor resultado utilizando processos de concentração das fases cristalinas por meio de dissoluções seletivas com ácido salicílico ou KOH +sacarose.

\section{REFERÊNCIAS BIBLIOGRÁFICAS}

ABONYI, J.; TAMÁS, F.; POTGIETER, S.; POTGIETER, H.; Analysis of trace Elements in South African Clinkers using Latent Variable Model and Clustering. South African Journal Chemistry, Cidade do Cabo, v. 56, p. 15-20, 2003.

ANDRADE, F.R.D.; PECCHIO, M.; KIHARA, Y. A mineralogical study of industrial Portland Clinker produced with non-traditional raw materials (carbonatite) and fuels (coal, pet coke, waste tires). In: CONGRESO TÉCNICO FICEM-APCAC, 2011, São Paulo. Disponível em: http://www.ficem.org/multimedia/2011/tecnico11/4_andrade\%20et\%20al\%20FICEM\%202011\%2 OFinal.pdf . Acesso em 01 fev. 2013.

ASSOCIAÇÃO BRASILEIRA DE CIMENTO PORTLAND. O coque de petróleo na indústria de cimento. São Paulo, 2002. 16p.

ASSOCIAÇÃO BRASILEIRA DE NORMAS TÉCNICAS (ABNT). Cimento Portland - Análise química Determinação de óxido de cálcio livre pelo etileno glicol - NM 13. Rio de Janeiro, 2012.

. Cimento Portland comum - ABNT NBR 5732. Rio de Janeiro, 1991. 5p.

. Cimento Portland de alta resistência inicial. Especificação - ABNT NBR 5733. Rio de Janeiro, 1991. $5 p$.

. Cimento Portland de alto-forno. Especificação - ABNT NBR 5735. Rio de Janeiro, 1991.

$5 p$.

. Cimento Portland pozolânico. Especificação - ABNT NBR 5736. Rio de Janeiro, 1991.

$5 p$.

Janeiro, 1992. 4p.

Cimentos Portland resistentes a sulfatos. Especificação - ABNT NBR 5737. Rio de . Cimento Portland composto. Especificação - ABNT NBR 11578. Rio de Janeiro, 1991.

$5 p$.

Cimento Portland branco. Especificação - ABNT NBR 12989. Rio de Janeiro, 1993. 5p.

. Cimento Portland de baixo calor de hidratação. Especificação - ABNT NBR 13116. Rio 
de Janeiro, 1994. 5p.

ARIYARATNE, W.K.H.; MELAAEN M.C.; EINE, K.; TOKHEIM L.A. Meat and Bone Meal as a Renewable Energy Source in Cement Kilns:Investigation of Optimum Feeding Rate. In: INTERNATIONAL CONFERENCE ON RENEWABLE ENERGIES AND POWER QUALITY (ICREPQ'11), 2010, Las Palmas de Gran Canaria. Disponível em: http://www.icrepq.com/icrepq'11/609-ariyaratne.pdf. Acesso em 07 fev. 2013.

BÉNARD, P.; GARRAULT, S.; NONAT, A.; CAU-DIT-COUMES, C. Influence of orthophosphate ion on the dissolution of tricalcium silicate. Cement and Concrete Research. v. 38, p. 1137-1141, 2008.

BHATTY, J. I. Role of Minor Elements in Cement Manufacture and Use. Skokie: Portland Cement Association, 1995. $42 \mathrm{p}$.

BHATTY, J. I. Effect of Minor Elements on Clinker and Cement Performance: A Laboratory Analysis. Skokie:Portland Cement Association, 2006. 99 p.

BIGARE, M.; GUINIER, A.; MAZIERES, C.; REGOURD, M.; YANNAQUIS, N.; EYSEL, W.; HAHN, T.; WOERMANN, E. Polymorphism of tricalcium silicate and its solid solutions. Journal of American Ceramic Society, v. 50, p. 609-619, 1967.

CAMPBELL, D. H. Microscopical Examination and Interpretation of Portland Cement and Clinker. Skokie:Portland Cement Association, 1999. 202p.

COLVILLE, A.A.; GELLERS, S. The crystal structure of brownmillerite, $\mathrm{Ca}_{2} \mathrm{FeAlO}_{5}$. Acta Crystallographica, 1971.

COLVILLE, A.A.; GELLERS, S. Crystal structures of $\mathrm{Ca}_{2} \mathrm{Fe}_{1.43} \mathrm{Al}_{0.57} \mathrm{O}_{5}$ and $\mathrm{Ca}_{2} \mathrm{Fe}_{1.28} \mathrm{Al}_{0.72} \mathrm{O}_{5}$. Acta Crystallographica, 1972.

COURTIAL, M.; NOIRFONTAINE, M.N.; DUNSTETTER, F.; GASECKI, G.; FREHEL, S. Polymorphism of tricalcium silicate in Portland Cement: A fast visual identification of structure and superstructure. Powder Diffraction, v. 18, p. 7-15, 2003.

CENTURIONE, S.L. A mineralização do clínquer portland e seus benefícios tecnológicos. 1999. Tese (Doutorado) - Instituto de Geociências da Universidade de São Paulo, São Paulo.

CHRISTENSEN N.H.; JEPSEN O.L.; JOHANSEN V. Rate of Alite-Formation in Clinker Sandwiches. Cement and Concrete Research, vol. 8, pp. 693-702, 1978.

DE LA TORRE, A.G.; BRUQUE, S.; CAMPO, J.; ARANDA, M.A.G. The superstructure of $\mathrm{C}_{3} \mathrm{~S}$ from synchrotron and neutron powder diffraction and its role in quantitative phase analyses. Cement and Concrete Research, v. 32, p. 1347-1356, 2002.

DE LA TORRE, A.G.; ARANDA, M.A.G. Rietveld Mineralogical analysis of portland Cement. In: INTERNATIONAL CONGRESS ON THE CHEMISTRY OF CEMENT (ICCC), XI, 2003, África do Sul. Anais, Durban:ICCC, 2003, p. 135-144.

DE LA TORRE, M. A. G. Estudio de cementos y materiales relacionados por el método de Rietveld. 2003. Tese (Doutorado) - Universidad de Málaga, Facultad de Ciencias, Departamento de Química Inorgânica, Cristalografía y Mineralogía, Malaga.

DE LA TORRE, A.G.; LLORENTE, H.A.; ARANDA, M.A.G.; LEON REINA, L. Ultimas novidades em la aplication del método de Rietveld em el control de calidade de cementos. Cemento Hormigon, $v$. 44, p. 16-27, 2011.

DESGRANGES, L.; GREBILLE, D.; CALVARIN, G.; CHEVRIER, G.; FLOQUET, N.; NIEPCE, J.C. Hydrogen thermal motion in calcium hydroxide: $\mathrm{Ca}(\mathrm{OH})_{2}$. Acta Crystallographica, 1993. 
DUDA, W.H. Cement Data Book. Berlin:Bauverlag, 1985. v. 1.

DUNSTETTER, F.; NOIRFONTAINE, M,-N.; COURTIAL, M. Polymorphism of tricalcium silicate, the major compound of Portland cement clinker. Cement and Concrete Research, v. 36, 2006, p. 3953.

EMANUELSON, A.; LANDA-CANOVAS, A.R.; HANSEN, S. A comparative study of ordinary and mineralised Portland cement clinker from two different production units Part II: Characteristics of the calcium silicates. Cement and Concrete Research, v. 33, 2003, p. 1623-1630.

FIX, W.; HEYMANN, H.; HEINKE, R. Subsolidus Relations in the System $2 \mathrm{CaO} \mathrm{SiO}_{2}-3 \mathrm{CaO} \mathrm{P}_{2} \mathrm{O}_{5}$. Journal of the American Ceramic Society, v. 52, 1969, p. 346-347.

FUKUDA, K.; MAKI, I.; ITO, S.; MIYAKE, T. Structural Change in Phosphorus-Bearing Dicalcium Silicates. Journal of the Ceramic Society of Japan, v. 105, 1997, p.117-121.

GINEYS, N.; AOUAD, G.; SORRENTINO, F.; DAMIDOT, D. Treshold Limits for trace elements in Portland Cement Clinker. Cement and concrete research, v. 41, 2011, p. 1177-1184.

GOBBO, L.; SANT'AGOSTINO, L.; GARCEZ, L. C 3 A Polymorphs Related to Industrial Clinker Alkalies Content. Cement and Concrete Research, v. 34, 2004, p. 657-664.

GOBBO, L.A. Os compostos do clínquer Portland: sua caracterização por difração de raios $X e$ quantificação por refinamento de Rietveld. 2003. 157 f. Dissertação (Mestrado) - Instituto de Geociências da Universidade de São Paulo, São Paulo.

GOLDMANN, W.; KERFT, W.; SCHÜTTE, R. Cyclic phenomena of sulphur in cement kilns. World cement technology, 1981, p. 424-430.

GOMES, S.D. Incorporação de enxofre no silicato dicálcico do clínquer de cimento Portland: influência na estabilidade de polimorfos e na reatividade hidráulica. 2007. 67 f. Dissertação (Mestrado) - Instituto de Geociências da Universidade de São Paulo, São Paulo.

GUINIER A.; REGOURD, M. Structure of Portland cement minerals. The Cement Association of Japan, v. 1, 1969, p. 1-41.

HALICZ, L.; NATHAN, Y.; BEM-DOR, L. The influence of P2O5 on clinker reactions. Cement and Concrete Research, v. 14, 1983, p. 11-18.

HERFORT, D.; SOERENSEN, J.; COUTHARD, E. Mineralogy of sulfate rich clinker and potential for internal sulfate attack. World Cement Research and development, 1997, p. 77-85.

HERFORT, D.; MOIR, G.K.; JOHANSEN V.; SORRENTINO, F.; BOLIO ARCEO, H. The Chemistry of Portland cement clinker. Advances in Cement Research, v. 22, no 4, 2010, p. 187-194.

HORKOSS, S.; LTEIF, R.; RIZK, T. Influence of the clinker SO3 on cement characteristics. Cement Concrete Research, v. 41, 2011, p. 913-919.

HORKOSS, S.; LTEIF, R.; RIZK, T. The effect of clinker SO3 on the mineralogical composition of the cement and its expected impacto $\mathrm{n}$ sulfate resistance level. Advanced in Cement Research, v. 23, issue 4, 2011, p. 193-201.

ONLINE DICTIONARY OF CRYSTALLOGRAPHY. IUCR (International Union of Crystallography), 2012. Disponível em: http://reference.iucr.org/dictionary/Bragg_R_factor. Acesso em: 27 out. 2012.

JANTZEN, C.; JOHNSOSN, A.; READ, D.; STEGEMANN, J.A. Cements in waste management. Advanced in Cement Research, v. 22, n. 4, 2010, p. 225-231.

JUEL, I.; JøNS E. The influence of earth alkalis on the mineralogy in a mineralized portland cement clinker. Cement and Concrete Research, v. 31, 2001, p. 893-897. 
KIHARA, Y. O periclásio no clínquer portland e sua correlação com as expansões do cimento. In: CONGRESSO BRASILEIRO DE CIMENTO, II, 1990, São Paulo. Anais do II Congresso Brasileiro de Cimento. São Paulo: ABCP, 1990, p. 369-388.

KIHARA, Y. O fósforo nas matérias-primas para a fabricação do cimento e sua influência na clinquerização e qualidade do cimento. 37 $7^{\mathrm{a}}$ RTIC. Associação Brasileira de Cimento Portland (ABCP), inédito, 1987, $22 \mathrm{p}$.

KIHARA, Y.; BATTAGIN, A.F.; CENTURIONE, S.L.; PECCHIO, M. A microscopia do clínquer portland e seus benefícios tecnológicos. In: CONGRESSO BRASILEIRO DE CIMENTO, II, 1990, São Paulo. Anais do Il Congresso Brasileiro de Cimento. São Paulo: ABCP, 1990, p. 241-264.

KOLOVOS, K. G.; LOUTSI, P.; TSIVILIS, S.; KAKALI, G. The effect of foreign ions on the reactivity of the $\mathrm{CaO} \pm \mathrm{SiO}_{2} \pm \mathrm{Al}_{2} \mathrm{O}_{3} \pm \mathrm{Fe}_{2} \mathrm{O}_{3}$ system Part I. Anions. Cement and Concrete Research, v. 31, 2001, p. 425-429.

KOLOVOS, K. G.; TSIVILIS, S.; KAKALI, G. Study of clinker dopped with P and S compounds. Journal of thermal analysis and calorimetry, v. 77, p. 759-766, 2004

KOLOVOS, K.; TSIVILIS, S.; KAKALI, G. SEM examination of clinker containing foreign elements. Cement and Concrete Composites, v. 27, 2005, p. 163-170.

LEA, F.M. The chemistry of Cement and Concrete. 3o ed. London:P. C. Hewlett Arnold Pub Ltda., 1998. 1092 p.

MAKI, I. Formation and Microscopic Textures of Portland Cement Clinker Minerals. Japan, 2004. $115 \mathrm{p}$.

MAKI, I.; FUKUDA, K.; YOSHIDA, H.; KUMAKI, J. Effect of $\mathrm{MgO}$ and $\mathrm{SO}_{3}$ on the impurity concentration in alite in Portland cement clinker. Journal of American Ceramic Society, v. 75, $\mathrm{n}$. 11, 1992, p. 3163-3165.

MARCIANO JR, E.; ZAMPIERI, V.A.; CENTURIONE, S.L. Considerations about the quantitative study of Portland cement clinker through reflected light microscopy. In: INTERNATIONAL CONFERENCE ON CEMENT MICROSCOPY, IX, 1987. Anais. Reno, 1987.

MARINGOLO, V. Clínquer coprocessado: produto de tecnologia integrada para sustentabilidade $e$ competitividade da indústria de cimento. 2001. 1v. Tese (doutorado) - Instituto de Geociências da Universidade de São Paulo, São Paulo.

MILLER, F. M.; TANG, F. J. The distribution of sulfur in present-day clinkers of variable sulfur content. Cement and Concrete Research, v. 26, n. 12, 1996, p. 1821-1829.

MOIR, G.K.; GRASSER, F.P. Mineralisers, modifiers and activators in the clinkering process. In: INTERNATIONAL CONGRESS ON THE CHEMISTRY OF CEMENT, IX, 1992, Índia. Anais, Nova Délhi:ICCC, 1992, p. 125-152.

MONDAL, P.; JEFFERY, J.W. The crystal structure of tricalcium aluminate, $\mathrm{Ca}_{3} \mathrm{Al}_{2} \mathrm{O}_{6}$. Acta Crystallographica B, v. 31, 1975, p. 689-697.

MÜLLER, R.; NEUBAUER, J.; GÖTZ-NEUNHOEFFER, F. Effects of phosphate-rich raw materials on the crystallographic and hydraulic properties of dicalcium silicate. In: INTERNATIONAL CONGRESS ON THE CHEMISTRY OF CEMENT (ICCC), XI, 2003, África do Sul. Anais, Durban:ICCC, 2003, p. 10431049.

MUMME, W.G.;HILL, R.J.; BUSHNELL, G.W.; SEGNIT, E.R. Rietveld crystal structure refinements, crystal chemistry and calculated powder diffraction data for the polymorphs of dicalcium silicate and related phases. Neues Jahrbuch fuer Mineralogie Abhandlungen, v. 169, 1995, p. 35-68. 
MUMME, W.G. Crystal structure of tricalcium silicate from a Portland cement clinker and its application to quantitative XRD analysis. Neues Jahrbuch fuer Mineralogie Monatshefte, v. 4, 1995, p. $145-160$.

MUMME, W.; CRANSWICK, L.; CHAKOUMAKOS, B. Rietveld crystal structure refinement from high temperature neutron powder diffraction data for the polymorphs of dicalcium silicate. Neues Jahrbuch fuer Mineralogie Abhandlungen, v. 170, 1996, p. 171-188.

NASTAC, D.C.; KAANTEE, U.; LIIMATAINEN, J.; HUPA, M.; MUNTEAN, M. Influence of P(V) on the characteristics of calcium silicates and the hydration of clinker. Advances in Cement Research, $\mathrm{v}$. 19, 2007, p. 93-100.

NATTA, G.; PASSERINI, L. Soluzioni solide, isomorfismo e simmorfismo tragliossidi dei metalli bivalenti. - 1. Sistemi: CaO-CdO, CaO-MnO, CaO-CoO, CaO-NiO, CaO-MgO. Gazzetta Chimica Italiana, v. 59, 1929, p. 129-154.

NOIRFONTAINE, M. N.; DUNSTETTER, F.; COURTIAL, M.; GASECKI, G.; SIGNES-FREHEL, M. Polymorphism of tricalcium silicate, the major compound of portland cement clinker 2 . Modelling alite for Rietveld analysis, an industrial challenge. Cement and Concrete Research, v. 36, 2006, p. 54-64.

NORBY, P. Synchrotron powder diffraction using imaging plates: crystal structure determination and Rietveld refinement. Journal of Applied Crystallography, 1997.

NURSE, R.W. The effect of phosphate on the constitution and hardening of Portland cement. Journal of Applied Chemistry, v. 2, 1952, p. 708-716.

OLIVEIRA, C.B. Co processamento de ARF en Cimpor Brasil. Cemento Hormigón, n. 945, 2011, p. 72-80.

PLIEGO-CUERVO, Y. B.; GLASSER, F. P. The role of sulphates in cement clinkering: subsolidus phase relations in the system $\mathrm{CaO}-\mathrm{Al}_{2} \mathrm{O}_{3}-\mathrm{SiO}_{2}-\mathrm{SO}_{3}$. Cement and concrete research, v. 9, 1979, p. 51-56.

PLIEGO-CUERVO, Y. B., GLASSER, F. P. The role of sulphates in cement clinkering: phase formation in the system $\mathrm{CaO}-\mathrm{Al}_{2} \mathrm{O}_{3}-\mathrm{Fe}_{2} \mathrm{O}_{3}-\mathrm{SiO}_{2}-\mathrm{CaSO}_{4}-\mathrm{K}_{2} \mathrm{SO}_{4}$. Cement and concrete research, v. 9, 1979, $\mathrm{p}$. 573-581.

REGOURD, M.M.; BOIKOVA, A. I. Chemistry, Structure, properties and quality of clinker. In: INTERNATIONAL CONGRESS ON THE CHEMISTRY OF CEMENT, IX, 1992, Índia. Anais, Nova Délhi:ICCC, 1992, p. 3-45.

RIETVELD, H. M. A profile refinement method for nuclear and magnetics structures. Journal of Applied Crystallography, v. 2, 1969, p. 65-71.

ROCHA, S. D. F.; LINS, V. F. C.; ESPIRITO SANTO, B. C. Aspectos do coprocessamento de resíduos em fornos de clínquer. Revista de Engenharia Sanitária e Ambiental, v. 16, n. 1, 2011, p. 1-10.

RUBERTI, E.; BARROS, C. G.; MELCHER G. C. Geological and Petrological Aspects of the Jacupiranga Alkaline-Carbonatite Association, Southern Brazil. Field Trip Guide. In: INTERNATIONAL GEOLOGICAL CONGRESS, XXXI, Rio de Janeiro. Anais, Rio de Janeiro:IGC, 2000, v. 1, p. 1-21.

SANTOS, B. L. A Indústria de Cimento No Brasil: Origens, Consolidação e Internacionalização. Sociedade \& Natureza, Uberlândia, v. 23, n. 1, p. 77-94, 2011.

SERCLÉRAT, I.; MOSZKOWICZ, P.; POLLET, B. Retentions mechanisms in mortars of the trace metals contained in Portland cement clinkers. Waste Management, v. 20, p. 259-264, 2000.

SHANNON, R. D. Revised Effective Ionic Radii and Systematic Studies of Interatomie Distances in Halides and Chaleogenides. Acta Crystalografica, v. 32, p. 751-767, 1976. 
SKALNY, J.; JOHANSEN, V.; MILLER, F. M. Sulfates in cement clinker and their effect on concrete durability. In: ADVANCES IN CONCRETE TECHNOLOGY - INTERNATIONAL CONFERENCE, III, Nova Zelândia. Anais, Auckland, 1997, p. 625-631.

RIO DE JANEIRO (Estado). Sindicato Nacional da Indústria do Cimento. A História do cimento no Brasil, Rio de Janeiro:SNIC, 2012.2 Disponível em: http://www.snic.org.br/pdf/Historia_do_Cimento_no_Brasil.pdf. Acesso em: 10 out. 2012.

Relatório Anual 2011, Rio de Janeiro:SNIC, 2011. Disponível em: http://www.snic.org.br/pdf/snic-relatorio2011-12_web.pdf. Acesso em: 10 out. 2012.

SORRENTINO, F. Chemistry and engineering of production process: State of the art. Cement and Concrete Research, v. 41, p. 616-623, 2011.

STANĚK, T.; SULOVSKÝ, P. The influence of phosphorous pentoxide on the phase composition and formation of Portland clinker. Material Characterizations, v. 60, n. 7, p. 749-755; 2009.

STANĔK, T.; SULOVSKY, P. The influence of the alite polymorphism on the strength of the Portland cement. Cement and Concrete Research, v. 32, p. 1169-1175, 2002.

STRUNGE, J.; KNÖFEL, D.; SIEGEN, D.; DREIZLER, I. Influence of alkalis and sulphur on the properties of cement. Part I: Effect of the $\mathrm{SO} 3$ content on the cement properties. Zement-KalkGips, n. 5, p. 130-133, 1985.

TAMÁS, F.; ABONYI, J.; BORSZEKI, J.; HALMOS, P. Trace elements in clinker I. Qualitative identification by fuzzy clustering. Cement Concrete Research, v. 32, p. 1325-1330, 2002.

TAYLOR, H. F. W. Cement chemistry. London: Academic Press, 1997, 475 p.

TAYLOR, J.C.; HINCZAK, I; MATULIS, C.E. Rietveld full-profile quantification of Portland cement clinker: The importance of including a full crystallography of the major phase polymorphs. Powder Diffraction, v. 15, n. 1, 2000.

TIMASHEV, V. V. The kinetics of clinker formation. The structure and composition of clinker and its phases. In: INTERNACIONAL CONGRESS OF THE CHEMISTRY OF CEMENT, VII, Paris, 1980. Anais, Paris, 1980, v. 1, p. I-3/1.

TOBY, B. H. R factors in Rietveld analysis: How good is good enough? Powder Diffraction, v. 21, p. 67-70, 2006.

USA. United States Geological Survey (USGS). Mineral Commodity Summaries, 2012. Disponível em: http://minerals.usgs.gov/minerals/pubs/mcs. Acesso em: 20 nov. 2012.

WALENTA, G.; FULLMANN, T. Advances in quantitative XRD analysis for clinker cement and cementitious additions. Advances in X-ray Analysis, v. 47, p. 287-296, 2004.

WANG, H.; FARZAM, H.; CABALLERO, E. Clinker mineralogy and reactivity with the use of HighSulfur Petcoke Fuel. In: INTERNATIONAL CONGRESS ON CEMENT CHEMISTRY, XIII, 2011, Madri. Anais, 2011.

WOLTER, A. Influence of the kiln system on the clinker properties. Zement Kalks-Gips, v. 37, p. 327 $-329,1985$. 


\section{ANEXO A - ANÁLISE QUÍMICA SEMIQUANTITATIVA DOS REAGENTES}

\begin{tabular}{|c|c|c|c|c|c|c|c|c|c|c|}
\hline \multirow[b]{2}{*}{$\begin{array}{l}\text { Composição } \\
\text { Química (\% em } \\
\text { peso) }\end{array}$} & \multicolumn{10}{|c|}{$\%$ em massa } \\
\hline & $\begin{array}{c}\text { MPRM- } \\
\text { Carbonato } 1\end{array}$ & $\begin{array}{c}\text { MPRM- } \\
\text { Carbonato2 }\end{array}$ & $\begin{array}{l}\text { MPRM- } \\
\text { Quartzo }\end{array}$ & $\begin{array}{l}\mathrm{MPRM}- \\
\mathrm{AlOH}_{3}\end{array}$ & $\begin{array}{l}\text { MPRM- } \\
\text { Ferro }\end{array}$ & $\begin{array}{c}\text { MPRM } \\
\text { carbon. } \\
\text { estrôncio }\end{array}$ & $\begin{array}{l}\text { MPRM- } \\
\text { Fosfato }\end{array}$ & $\begin{array}{l}\text { MPRM- } \\
\text { Apatita }\end{array}$ & $\begin{array}{l}\text { MPRM- } \\
\text { Osso }\end{array}$ & $\begin{array}{l}\text { MPRM- } \\
\text { Gesso }\end{array}$ \\
\hline $\mathrm{SiO}_{2}$ & 0,5 & 0,3 & 99,1 & 65,22 & 3,52 & 0,05 & 0,18 & 2,78 & 0,06 & $\operatorname{Tr}$ \\
\hline $\mathrm{Na}_{2} \mathrm{O}$ & - & - & - & 0,31 & - & - & - & - & 0,87 & 0,1 \\
\hline $\mathrm{MgO}$ & 0,5 & 0,4 & - & - & 0,06 & - & 0,28 & 0,04 & 0,97 & $\operatorname{Tr}$ \\
\hline $\mathrm{Al}_{2} \mathrm{O}_{3}$ & 0,6 & 0,1 & $\operatorname{Tr}$ & 30,5 & 2,58 & 0,04 & 0,07 & 0,04 & 0,05 & $\operatorname{Tr}$ \\
\hline $\mathrm{SO}_{3}$ & $\operatorname{Tr}$ & $\operatorname{Tr}$ & $\operatorname{Tr}$ & 0,01 & 0,04 & 0,31 & 0,04 & 1,50 & 0,26 & 55,0 \\
\hline $\mathrm{K}_{2} \mathrm{O}$ & $\operatorname{Tr}$ & $\operatorname{Tr}$ & - & 3,08 & - & - & - & - & - & - \\
\hline $\mathrm{CaO}$ & 97,4 & 98,4 & $\operatorname{Tr}$ & 0,03 & 1,06 & 0,08 & 44,9 & 52,3 & 55,7 & - \\
\hline $\mathrm{P}_{2} \mathrm{O}_{5}$ & 0,1 & 0,2 & $\operatorname{Tr}$ & 0,05 & 0,63 & - & 54,1 & 39,1 & 41,7 & $\operatorname{Tr}$ \\
\hline $\mathrm{V}_{2} \mathrm{O}_{5}$ & - & - & - & - & - & - & - & - & 0,03 & - \\
\hline $\mathrm{Cr}_{2} \mathrm{O}_{3}$ & - & - & $\operatorname{Tr}$ & 0,01 & - & - & 0,03 & - & - & - \\
\hline $\mathrm{TiO}_{2}$ & - & - & - & 0,35 & 0,08 & - & - & - & - & - \\
\hline $\mathrm{Fe}_{2} \mathrm{O}_{3}$ & 0,1 & $\mathrm{Tr}$ & 0,4 & 0,36 & 92,0 & 0,02 & 0,08 & 0,12 & 0,17 & - \\
\hline $\mathrm{Co}_{2} \mathrm{O}_{3}$ & - & - & $\mathrm{Tr}$ & - & - & - & - & - & - & - \\
\hline $\mathrm{NiO}$ & $\mathrm{Tr}$ & - & $\mathrm{Tr}$ & 0,01 & - & 0,01 & 0,01 & - & 0,01 & - \\
\hline $\mathrm{ZnO}$ & - & - & - & - & - & - & - & - & 0,02 & - \\
\hline $\mathrm{CuO}$ & - & - & - & - & - & 0,03 & - & - & - & - \\
\hline SrO & 0,6 & 0,4 & - & 0,01 & 0,01 & 99,2 & 0,30 & 0,05 & 0,14 & $\mathrm{Tr}$ \\
\hline $\mathrm{Y}_{2} \mathrm{O}_{3}$ & - & - & - & 0,03 & - & - & - & 0,04 & - & - \\
\hline $\mathrm{CeO} 2$ & - & - & - & - & - & - & - & 0,14 & - & - \\
\hline $\mathrm{ZrO}_{2}$ & - & - & - & 0,03 & - & - & - & - & - & - \\
\hline $\mathrm{BaO}$ & - & - & - & - & - & 0,29 & - & - & - & - \\
\hline $\mathrm{WO}_{3}$ & - & - & 0,2 & - & - & - & - & - & - & - \\
\hline $\mathrm{Ga}_{2} \mathrm{O}_{3}$ & - & - & - & 0,01 & - & - & - & - & - & - \\
\hline $\mathrm{ThO}_{2}$ & - & - & - & - & - & - & - & 0,15 & - & - \\
\hline $\mathrm{Cl}$ & - & - & - & - & - & - & 0,02 & 0,09 & 0,03 & - \\
\hline $\mathrm{F}$ & - & - & - & - & - & - & & 3,47 & - & - \\
\hline
\end{tabular}


12. ANEXO B - GRÁFICOS DE DIFRATOMETRIA DE RAIOS X DAS MATÉRIAS-PRIMAS E REAGENTES UTILIZADOS

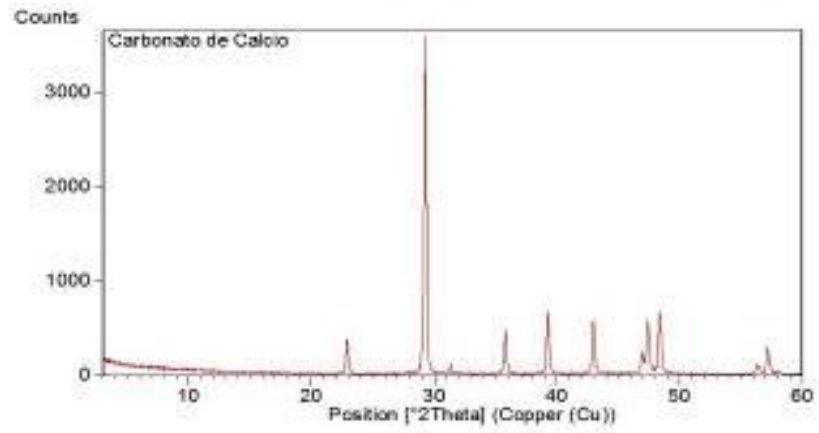

Figura 61 - Difração de raios X - MPRM- Carbonato 1

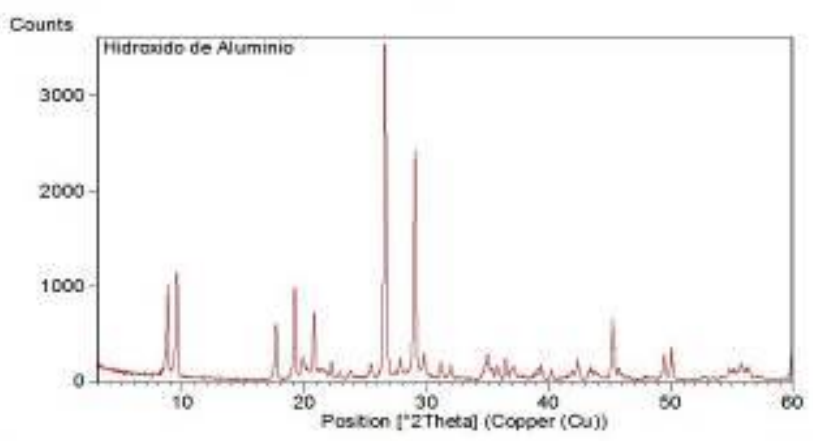

Figura 64-Difração de raios X-MPRM- $\mathrm{AlOH}_{3}$

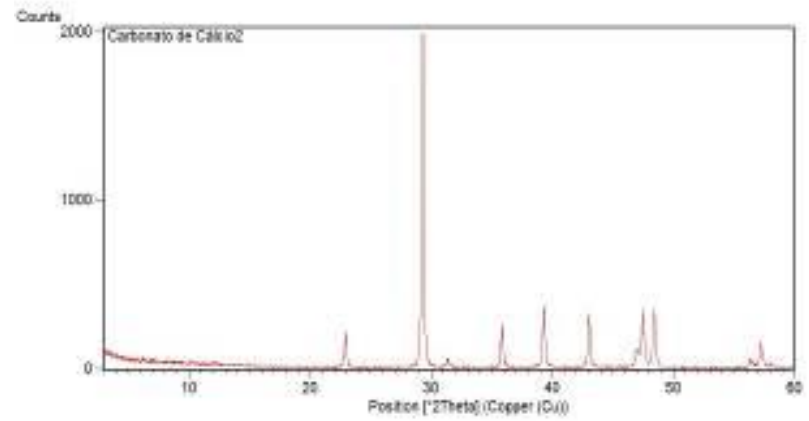

Figura 62 - Difração de raios X - MPRM- Carbonato 2

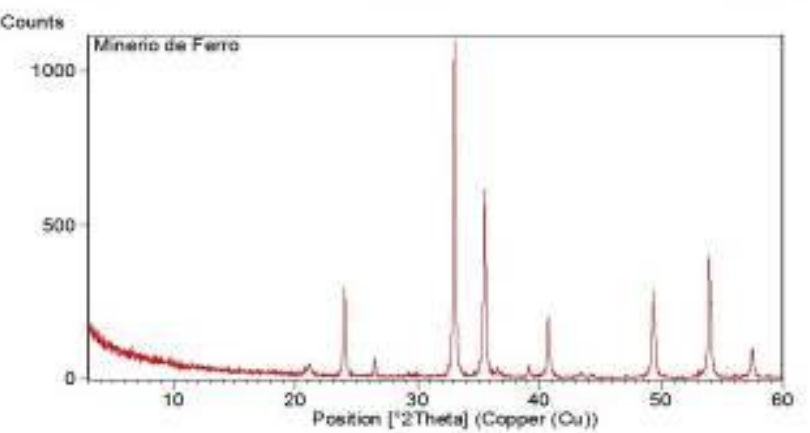

Figura 65-Difração de raios X-MPRM- Ferro

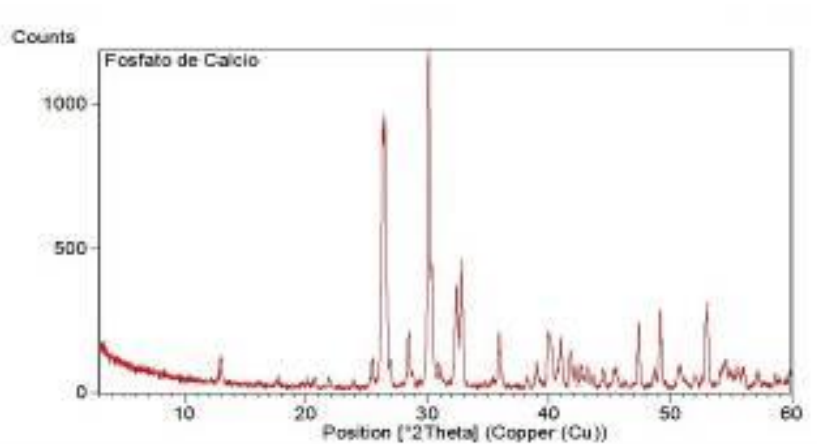

Figura 63-Difração de raios X-MPRM- Fosfato 


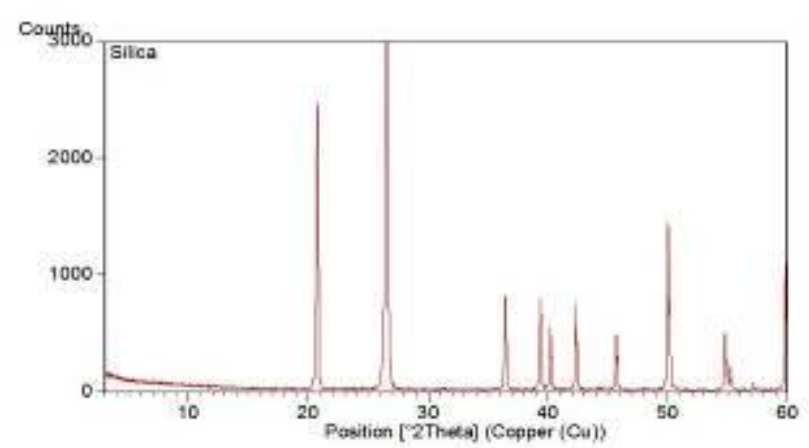

Figura 66 - Difração de raios X - MPRM- Quartzo

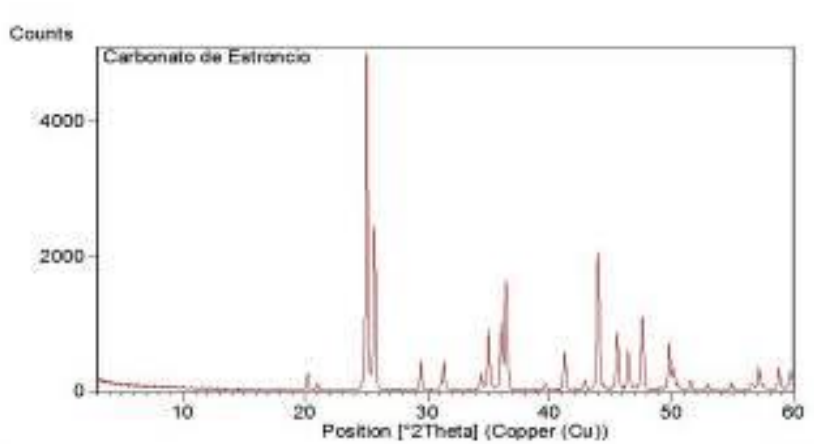

Figura 69-Difração de raios X - MPRM- Carbonato de Sr

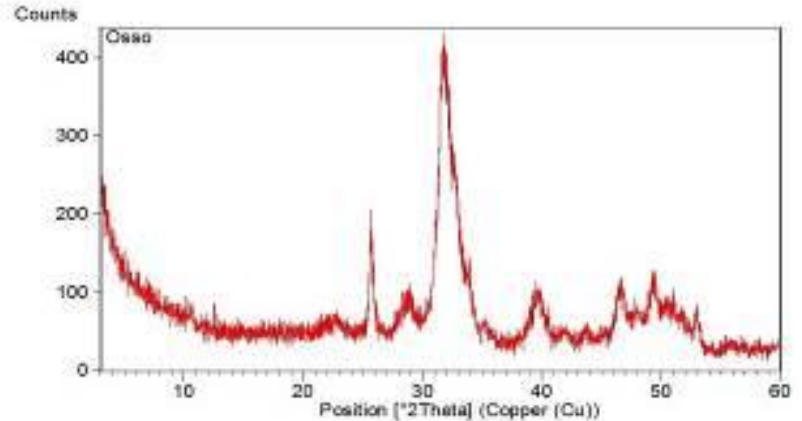

Figura 67-Difração de raios X-MPRM- Osso

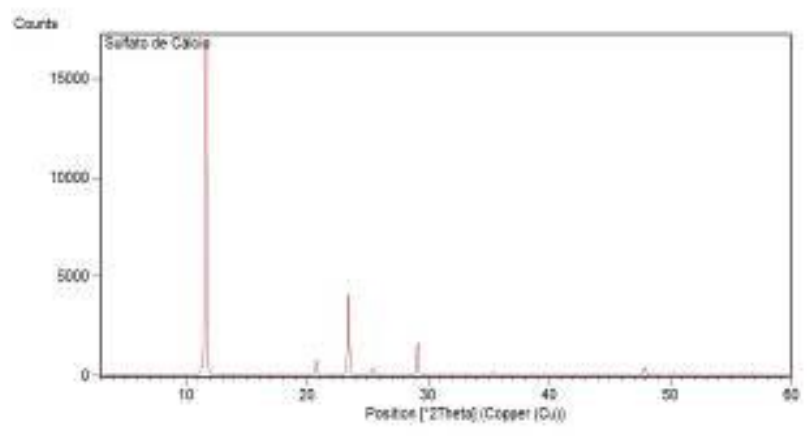

Figura 70-Difração de raios X - MPRM- Gesso

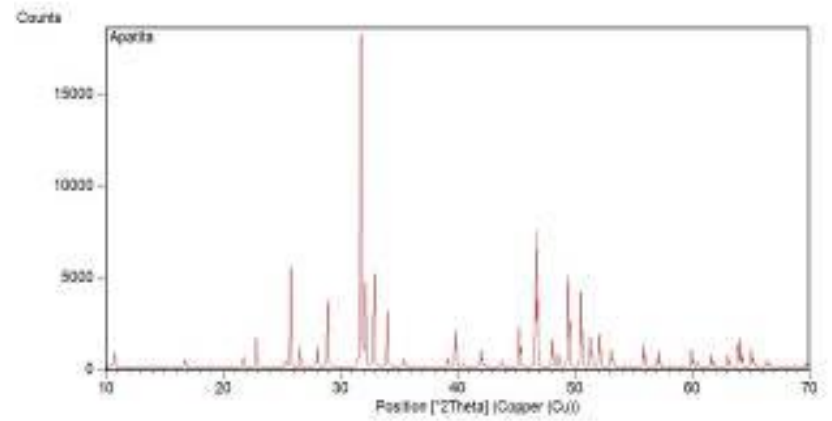

Figura 68-Difração de raios X-MPRM- Apatita 


\section{ANEXO C - DOSAGEM PROJETADA DAS FARINHAS}

\begin{tabular}{|c|c|c|c|c|c|c|}
\hline \multirow[t]{2}{*}{ Matérias-primas } & \multicolumn{6}{|c|}{ Farinhas } \\
\hline & MPFA-REF1 & MPFA-SR20 & MPFA-SR50 & MPFA-SR100 & MPFA-SR150 & MPFA-SR200 \\
\hline MPRM-Carbonato1 & 79,4 & 79,2 & 78,9 & 78,3 & 77,8 & 77,2 \\
\hline MPRM-Quartzo & 5,85 & 5,8 & 5,8 & 5,7 & 5,71 & 5,66 \\
\hline MPRM-AlOH 3 & 12,2 & 12,2 & 12,2 & 12,1 & 12,0 & 11,9 \\
\hline MPRM-Ferro & 2,45 & 2,44 & 2,43 & 2,40 & 2,40 & 2,37 \\
\hline MPRM-Sr & 0,00 & 0,29 & 0,72 & 1,43 & 2,14 & 2,86 \\
\hline Total & 100,0 & 100,0 & 100,0 & 100,0 & 100,0 & 100,0 \\
\hline Fatos de Saturação em Cal & 98,0 & 98,0 & 98,0 & 98,0 & 98,0 & 98,0 \\
\hline Módulo de Silica & 2,40 & 2,40 & 2,40 & 2,40 & 2,40 & 2,40 \\
\hline Módulo de Alumina & 1,59 & 1,60 & 1,60 & 1,60 & 1,59 & 1,60 \\
\hline
\end{tabular}

Tabela II - Dosagem projetada das farinhas dopadas com enxofre

\begin{tabular}{l|cccccc}
\hline \multicolumn{1}{c|}{ Matérias-primas } & \multicolumn{5}{|c}{ Farinhas } \\
\cline { 2 - 6 } & MPFA-REF2 & MPFA-SX25 & MPFA-SX50 & MPFA-SX100 & MPFA-SX150 & MPFA-SX200 \\
\hline MPRM-Carbonato2 & 79,2 & 78,7 & 78,2 & 77,2 & 76,4 & 75,5 \\
MPRM-Quartzo & 5,37 & 5,40 & 5,37 & 5,37 & 5,37 & 5,35 \\
MPRM-AlOH 3 & 13,0 & 13,0 & 13,0 & 12,9 & 12,8 & 12,8 \\
MPRM-Ferro & 2,40 & 2,41 & 2,39 & 2,39 & 2,38 & 2,39 \\
MPRM-Gesso & 0,00 & 0,50 & 1,11 & 2,10 & 3,00 & 4,00 \\
Total & 100,0 & 100,0 & 100,0 & 100,0 & 100,0 & 100,0 \\
\hline Fatos de Saturação em Cal & 98,0 & 98,1 & 98,1 & 98,0 & 98,1 & 98,0 \\
Módulo de Silica & 2,40 & 2,40 & 2,40 & 2,40 & 2,40 & 2,40 \\
Módulo de Alumina & 1,60 & 1,59 & 1,60 & 1,59 & 1,59 & 1,58 \\
\hline
\end{tabular}




\begin{tabular}{|c|c|c|c|c|c|c|c|c|c|c|c|c|c|c|c|c|}
\hline \multirow[t]{2}{*}{ Matérias-primas } & \multicolumn{16}{|c|}{ Farinhas } \\
\hline & $\begin{array}{l}\text { MPFA- } \\
\text { REF2 }\end{array}$ & $\begin{array}{l}\text { MPFA- } \\
\text { FO25 }\end{array}$ & $\begin{array}{l}\text { MPFA- } \\
\text { FO50 }\end{array}$ & $\begin{array}{l}\text { MPFA- } \\
\text { FO100 }\end{array}$ & $\begin{array}{l}\text { MPFA- } \\
\text { FO150 }\end{array}$ & $\begin{array}{l}\text { MPFA- } \\
\text { FO200 }\end{array}$ & $\begin{array}{l}\text { MPFA- } \\
\text { AP25 }\end{array}$ & $\begin{array}{l}\text { MPFA- } \\
\text { AP50 }\end{array}$ & $\begin{array}{l}\text { MPFA- } \\
\text { AP100 }\end{array}$ & $\begin{array}{l}\text { MPFA- } \\
\text { AP150 }\end{array}$ & $\begin{array}{l}\text { MPFA- } \\
\text { AP200 }\end{array}$ & $\begin{array}{l}\text { MPFA- } \\
\text { OS25 }\end{array}$ & $\begin{array}{l}\text { MPFA- } \\
\text { OS50 }\end{array}$ & $\begin{array}{l}\text { MPFA- } \\
\text { OS100 }\end{array}$ & $\begin{array}{l}\text { MPFA- } \\
\text { OS150 }\end{array}$ & $\begin{array}{l}\text { MPFA- } \\
\text { OS200 }\end{array}$ \\
\hline MPRM-Carbonato 2 & 79,2 & 78,7 & 78,2 & 77,1 & 76,1 & 75,1 & 78,6 & 77,9 & 76,7 & 75,5 & 74,2 & 78,2 & 77,2 & 75,3 & 73,3 & 71,3 \\
\hline MPRM-Quartzo & 5,37 & 5,40 & 5,37 & 5,35 & 5,34 & 5,29 & 5,39 & 5,38 & 5,37 & 5,38 & 5,37 & 5,35 & 5,35 & 5,29 & 5,26 & 5,19 \\
\hline $\mathrm{MPRM}-\mathrm{AlOH}_{3}$ & 13,0 & 13,0 & 13,0 & 12,9 & 12,8 & 12,8 & 13,0 & 13,0 & 12,9 & 12,9 & 12,8 & 13,0 & 12,9 & 12,8 & 12,8 & 12,7 \\
\hline MPRM-Ferro & 2,40 & 2,41 & 2,39 & 2,38 & 2,37 & 2,36 & 2,40 & 2,40 & 2,41 & 2,39 & 2,40 & 2,39 & 2,38 & 2,37 & 2,35 & 2,34 \\
\hline MPRM-Fosfato & 0,00 & 0,55 & 1,11 & 2,23 & 3,36 & 4,47 & 0,00 & 0,00 & 0,00 & 0,00 & 0,00 & 0,00 & 0,00 & 0,00 & 0,00 & 0,00 \\
\hline MPRM-Apatita & 0,00 & 0,00 & 0,00 & 0,00 & 0,00 & 0,00 & 0,64 & 1,30 & 2,57 & 3,86 & 5,15 & 0,00 & 0,00 & 0,00 & 0,00 & 0,00 \\
\hline MPRM-Osso & 0,00 & 0,00 & 0,00 & 0,00 & 0,00 & 0,00 & 0,00 & 0,00 & 0,00 & 0,00 & 0,00 & 1,05 & 2,11 & 4,22 & 6,30 & 8,44 \\
\hline Total & 100,0 & 100,0 & 100,0 & 100,0 & 100,0 & 100,0 & 100,0 & 100,0 & 100,0 & 100,0 & 100,0 & 100,0 & 100,0 & 100,0 & 100,0 & 100,0 \\
\hline Fatos de Saturação em Cal & 98,0 & 98,0 & 98,0 & 98,0 & 98,0 & 98,0 & 98,0 & 98,0 & 98,0 & 98,0 & 98,0 & 98,0 & 98,0 & 98,0 & 98,0 & 98,0 \\
\hline Módulo de Silica & 2,40 & 2,40 & 2,40 & 2,40 & 2,40 & 2,40 & 2,40 & 2,40 & 2,40 & 2,40 & 2,40 & 2,40 & 2,40 & 2,40 & 2,40 & 2,40 \\
\hline Módulo de Alumina & 1,60 & 1,59 & 1,60 & 1,60 & 1,60 & 1,60 & 1,60 & 1,60 & 1,60 & 1,60 & 1,60 & 1,60 & 1,60 & 1,60 & 1,60 & 1,60 \\
\hline
\end{tabular}

